\title{
Costing the cold: \\ Connecting fuel poverty \& supplier switching in Wellington, New Zealand
}

\section{Sam Fraser McLean}

\begin{abstract}
A 120 point thesis submitted to Victoria University of Wellington in partial fulfilment of the requirements for the degree of Master of Science
\end{abstract}

School of Geography, Environment and Earth Sciences Victoria University of Wellington 



\section{Abstract}

Fuel poverty describes the inability of households to afford adequate energy services, such as space heating. In New Zealand, where $25 \%$ of households are estimated to be 'fuel poor', high electricity prices in a restructured electricity market have an important influence on fuel poverty. However, the ability of the New Zealand Government to regulate these high electricity prices is constrained. Consequently, there is a strong reliance on consumers to switch energy suppliers, which promotes competitive prices and in turn regulates the price of electricity. In contrast to energy efficiency improvements, switching offers fuel poor households a low-cost opportunity to improve the short-term affordability of energy services. Yet, switching is suggested to not benefit fuel poor households who are in most need of affordable energy.

This thesis explored the relationship between fuel poverty and supplier switching in Wellington, New Zealand through a geographic lens. First, a new approach to identifying fuel poverty in New Zealand was applied. Using geographic information systems (GIS), a fuel poverty index was calculated to identify fuel poverty in Wellington at meshblock level. Spatial analysis of the index revealed the complexity of identifying fuel poverty and the extent to which the spatial distribution of fuel poverty in Wellington is shaped by the city's colonial history. The index was then used to identify survey participants through which a survey was conducted exploring Wellington households' switching behaviours. In a competitive market, consumers are expected to switch according to economically rational behaviours. However, switching behaviours in the survey sample 
were influenced by factors other than these economically rational behaviours. Integrating the findings of this thesis supports suggestions that switching is not benefiting the fuel poor. Finally, this thesis sheds light on the extent to which an understanding of the geography of fuel poverty can be applied towards improving the effectiveness of policy and equitable outcomes for fuel poor households. 


\section{Acknowledgements}

Completing this thesis is the outcome of the contributions and commitments of many. I am truly grateful for their support, patience and dedication along the way. I would like to thank all who have supported this research.

To my research supervisors, Dr Wokje Abrahamse and Dr Mairéad de Róiste. Thank you for your guidance, encouragement and feedback. The skills I have acquired and the opportunities that have become available as a result of your supervision have been rewarding. Wokje, thank you for providing perspective, reminding me of what is important and forgotten connections, your quick response to my questions and willingness to help at the last minute. Mairéad, thank you for your constructive feedback and helpful resources, your support and patience when it came to my inexperience with GIS, and the opportunity to learn more in the geospatial field. I am grateful to have had both of you as supervisors.

Thank you to the Institute for the Study of Competition and Regulation, Wellington City Council and Critchlow. Your support has been essential to this thesis and would not have been possible otherwise.

Thank you to the Australasian Association for Digital Humanities for a scholarship which enabled me to develop the GIS skills necessary to conduct this research. To Andrew Rae, Stella Blake-Kelly and the MGIS students at Victoria University, thank you also for your time and experience. 
To the survey participants, thank you for taking the time to share with me your thoughts, opinions, and experiences. Your responses have been inspirational and have motivated me to pursue more work in this field for a better New Zealand. Thank you also, to the pilot survey participants and team of survey folders for taking the time to help me with these tasks.

To the academic and administrative staff in the School of Geography, Environment and Earth Sciences, thank you for your support and positivity. Also, a huge thank you to Aleksander Beliaev for working a miracle.

To my colleagues and friends in Geography, Development Studies and Environmental Studies at Victoria University it has been an honour to share this journey with you. Your support and encouragement has been remarkable. Thank you to my friends who have supported me over the past two years.

Thank you to my family, who have been a solid source of support during this journey. To my parents especially, thank you for your financial support and enduring the stresses of this research alongside me. I am truly grateful in every single way. Grace, thank you for being an incredible sister and the times we share. To my partner Dayne, you have been my rock from day one. Thank you for your patience, understanding and support. I am eternally grateful.

Sam McLean, March 2016 


\section{Table of Contents}

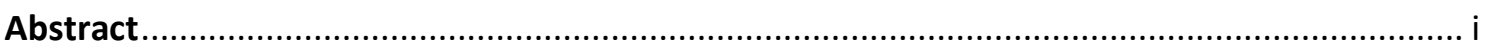

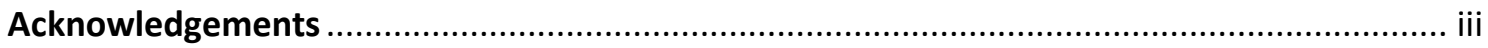

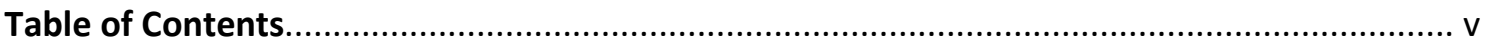

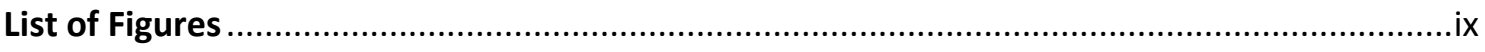

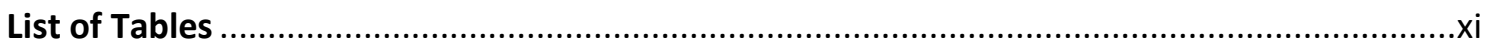

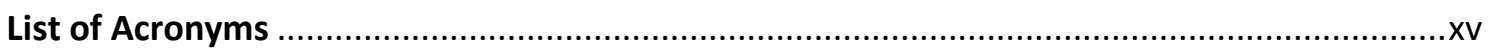

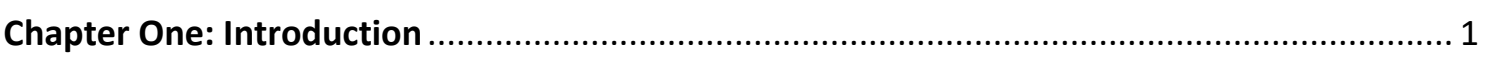

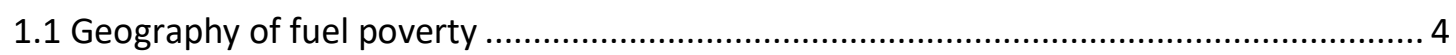

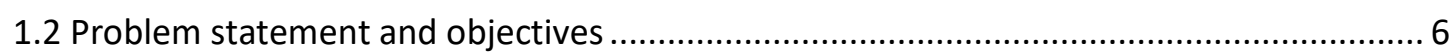

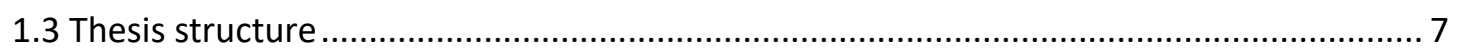

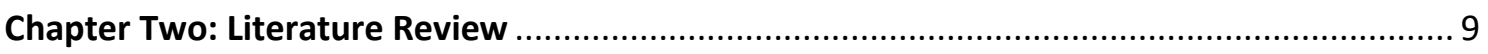

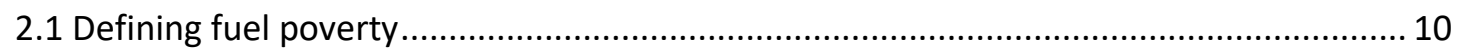

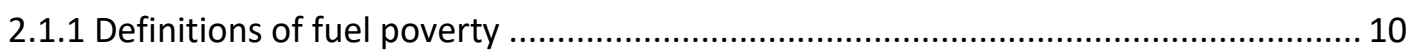

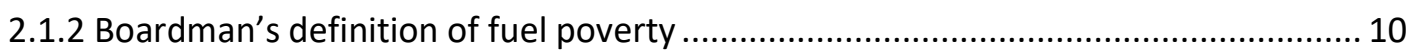

2.1.3 Low Income, High Cost definition of fuel poverty...................................................... 11

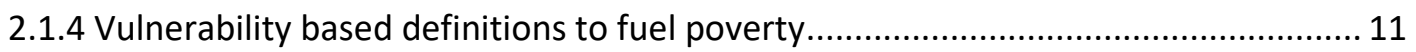

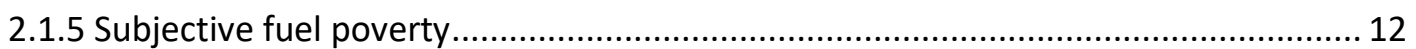

2.2 Defining affordable and adequate energy services ....................................................... 12

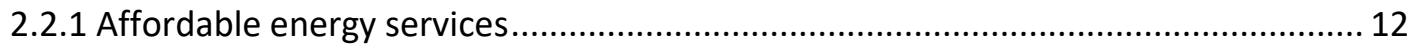

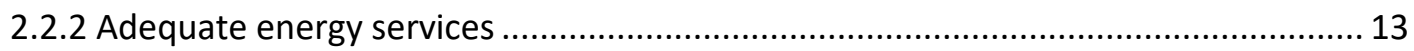

2.3 New Zealand definitions of fuel poverty ..................................................................... 14

2.3.1 The geography of fuel poverty in New Zealand ...................................................... 14

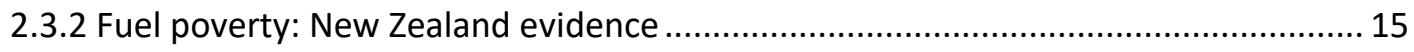

2.4 Fuel poverty in restructured electricity markets ......................................................... 19

2.4.1 Solving fuel poverty: Policy approaches................................................................ 19 


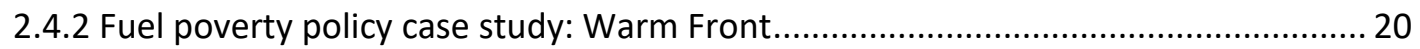

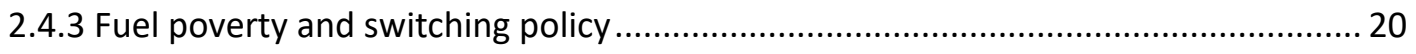

2.4.4 Incompatible? Restructured markets and switching policy.................................... 21

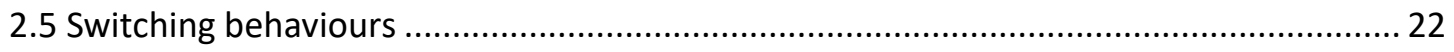

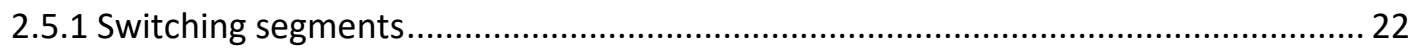

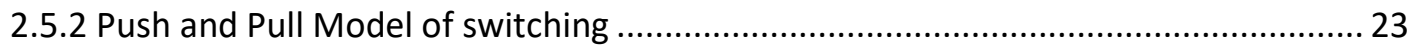

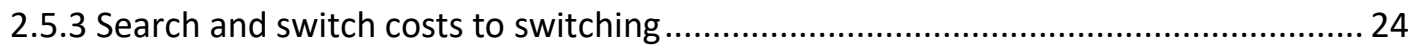

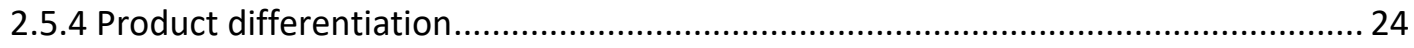

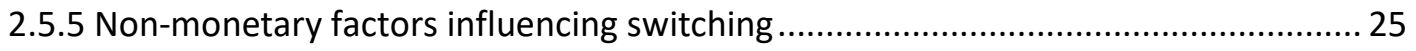

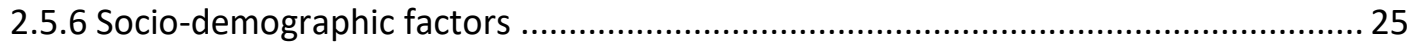

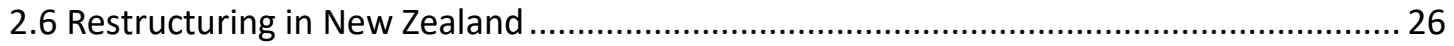

2.6.1 Switching in New Zealand: What's My Number..................................................... 26

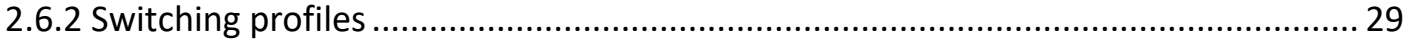

2.7 Connecting fuel poverty and supplier switching: Initial evidence .................................. 31

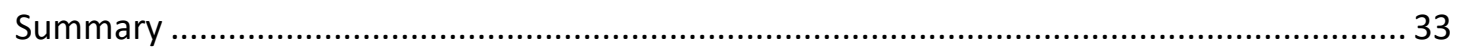

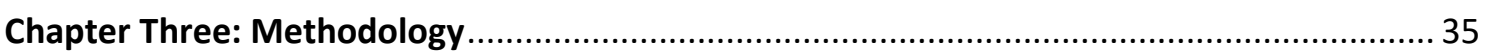

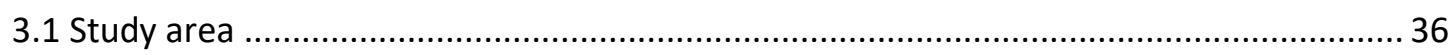

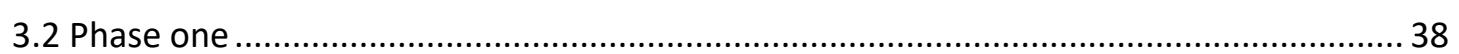

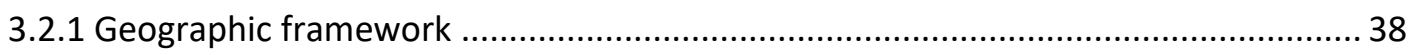

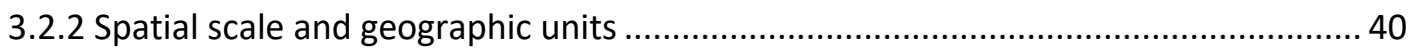

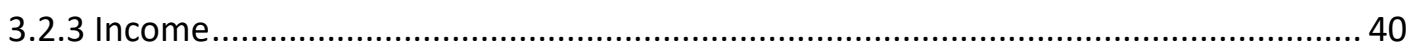

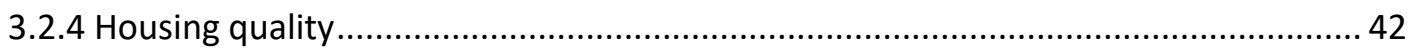

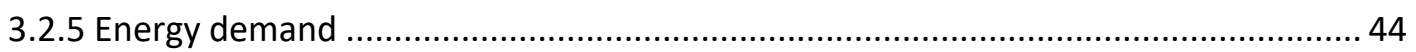

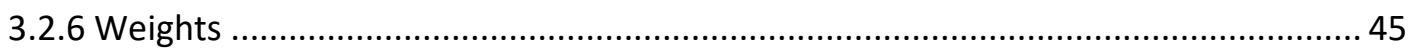

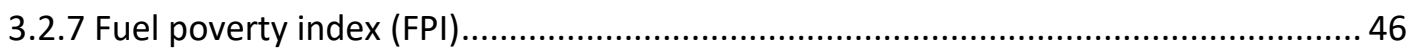

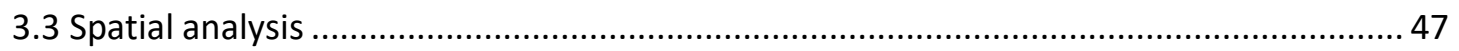

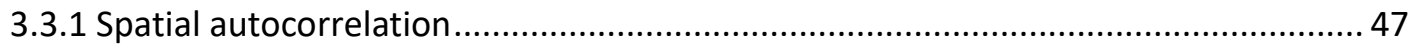

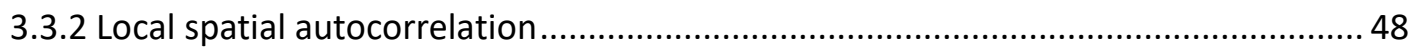

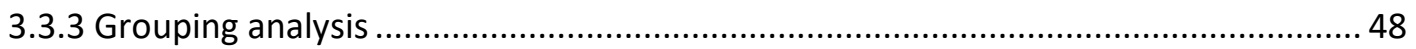

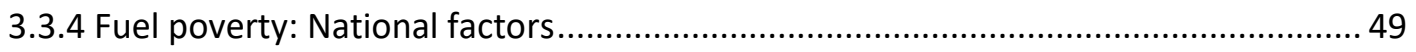

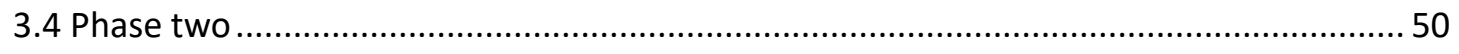

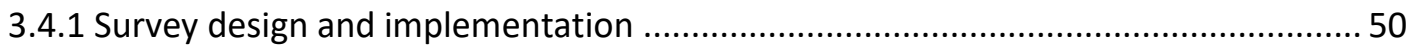

3.4.2 Energy Prices and Warm Homes Survey (EPWHS) .................................................. 54

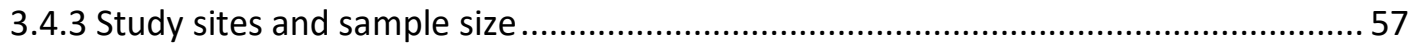

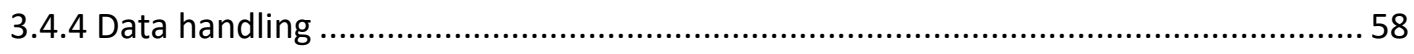

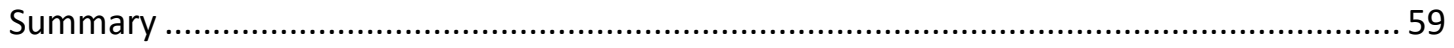




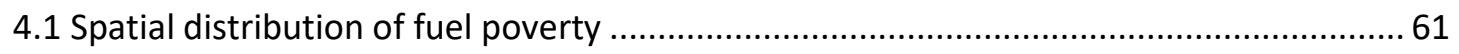

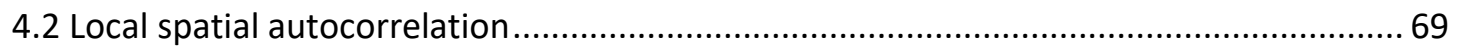

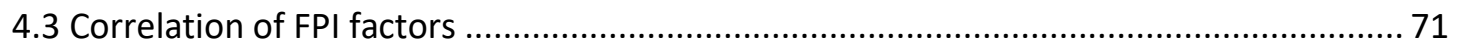

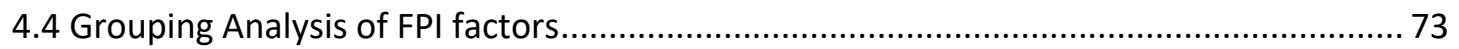

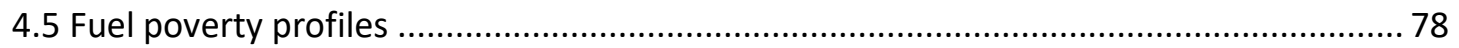

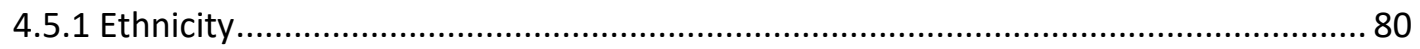

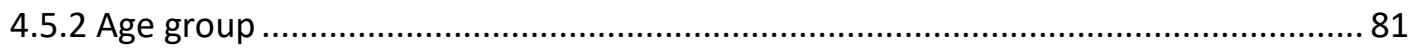

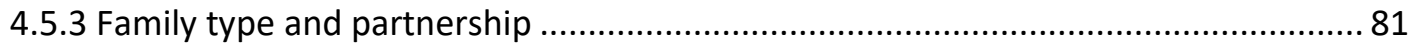

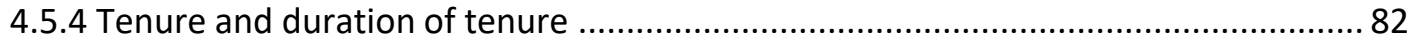

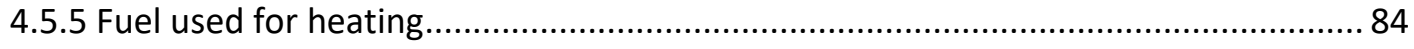

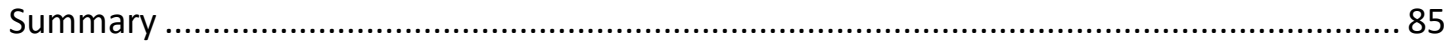

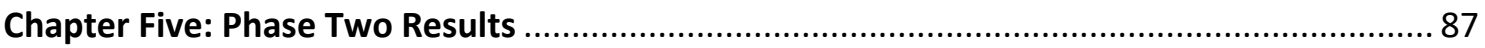

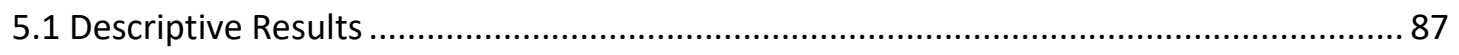

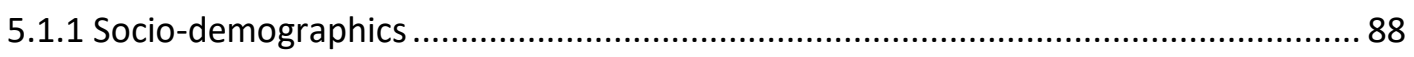

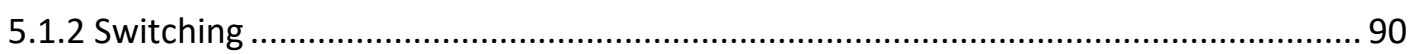

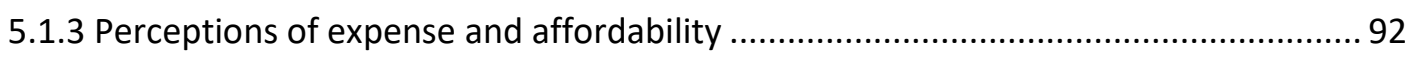

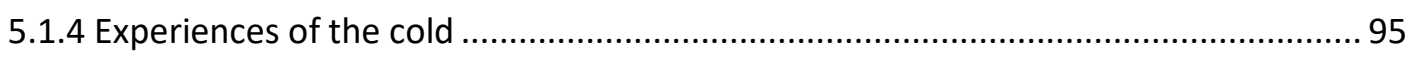

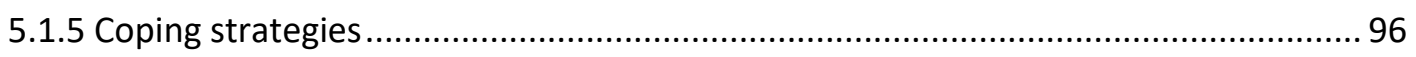

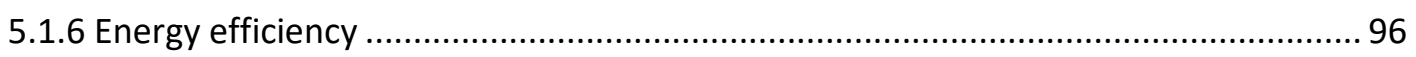

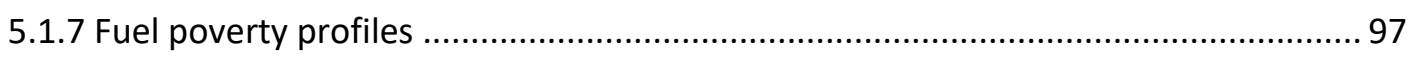

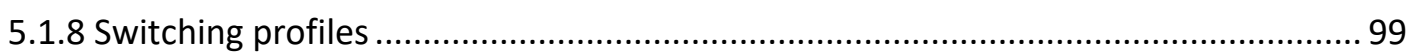

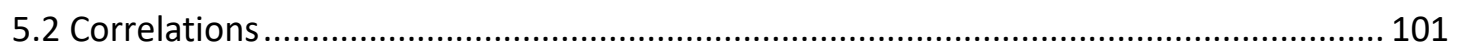

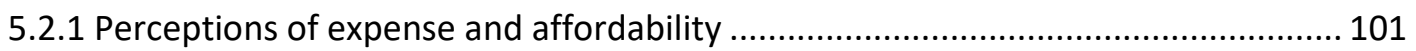

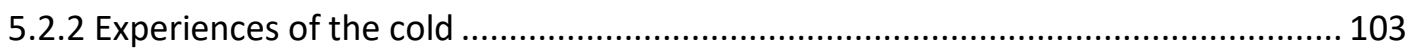

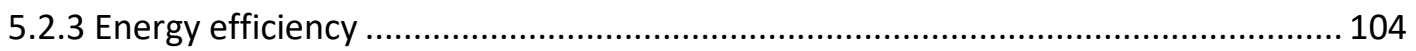

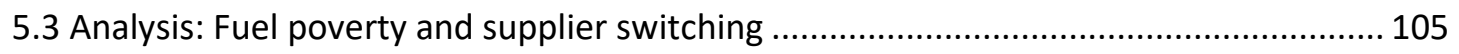

5.3.1 Perceptions of expense and affordability .............................................................. 105

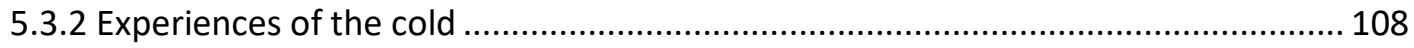

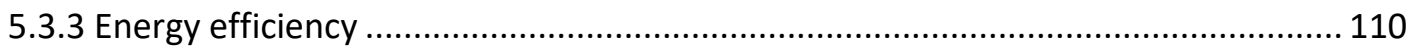

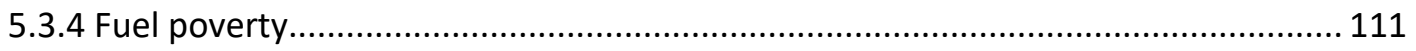

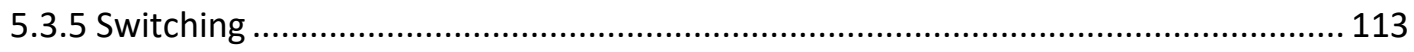

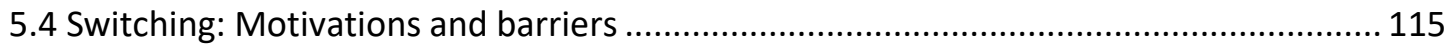

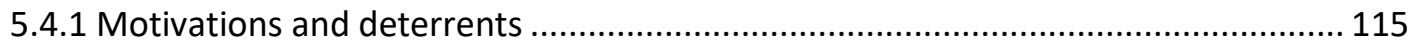

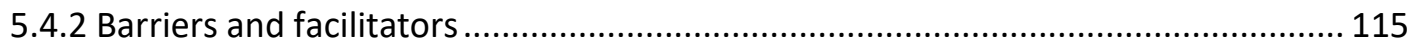

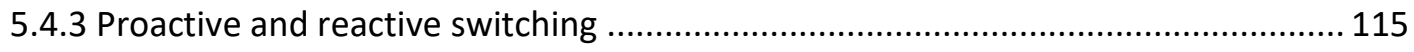




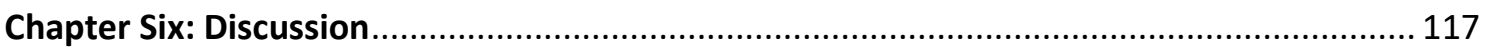

6.1 Geography of fuel poverty: Complex \& colonial .................................................. 118

6.2 Switching: Improving equitable outcomes................................................... 120

6.3 Switching: Motivations, contradictions and processes ....................................... 122

6.3 Strategies for coping with the cold ................................................................. 124

6.4 Defining fuel poverty: A case for re-evaluation .................................................. 127

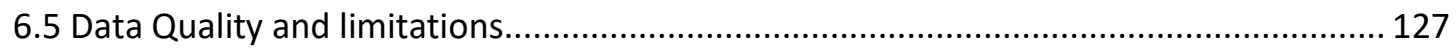

6.6 Recommended policy responses.............................................................. 131

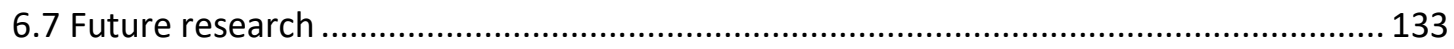

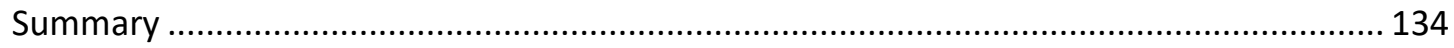

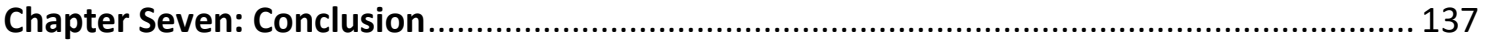

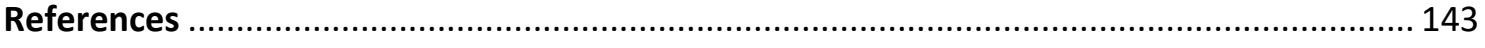

Appendix A: Analysis of electricity prices across New Zealand ................................... 151

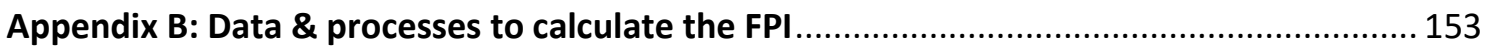

Appendix C: Ethics approval \& Energy Prices and Warm Homes Survey .......................... 165

Appendix C.1: Memorandum of ethics approval ...................................................... 166

Appendix C.2: Pre-notification letter ................................................................... 168

Appendix C.3: Cover letter, information sheet \& survey booklet.................................... 169

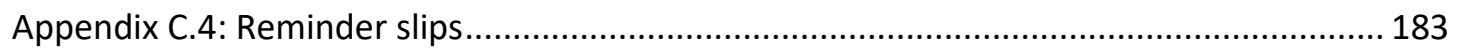

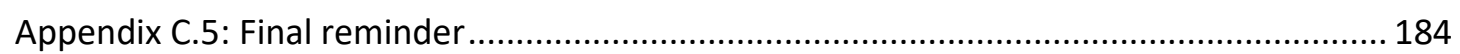

Appendix D: Spatial analysis of FPI factors - Local spatial autocorrelation......................... 185 


\section{List of Figures}

Figure 2.1: Total switches by month in New Zealand (2004-2015) 28

Figure 3.1: $\quad$ Map of New Zealand's main cities and inset map of Wellington 38

Figure 4.1: $\quad$ Spatial distribution of fuel poverty (FPI) by meshblock in 63

Wellington

Figure 4.2: $\quad$ Spatial distribution of solar radiation by meshblock in Wellington 64

Figure 4.3: Spatial distribution of income by meshblock in Wellington 66

Figure 4.4: $\quad$ Spatial distribution of housing quality by meshblock in 68

Wellington

Figure 4.5: Hotspots/coldspots of the FPI by meshblock in Wellington $\quad 70$

Figure 4.6: Grouping Analysis of fuel poverty factors by meshblock in 75 Wellington

Figure 4.7: Grouping Analysis results - Clusters 1, 3, 4 \& 9

Figure 4.8: $\quad$ Fuel poverty profiles - Selected hotspots/coldspots 79

Figure 5.1: Respondents' estimated cost of the most recent total energy bill 94

Figure B.1: Creation of median household income and sources of household 155 income data files

Figure B.2: Creation of building footprint data files 156

$\begin{array}{lll}\text { Figure B.3: } & \text { Creation of HQI data files } & 157\end{array}$

$\begin{array}{lll}\text { Figure B.4: } & \text { Creation of housing age data files } & 158\end{array}$

Figure B.5: Creation of capital value data files 160

Figure B.6: Creation of solar radiation data files 161

$\begin{array}{lll}\text { Figure B.7: } & \text { Creation of FPI data file } & 162\end{array}$ 
$\begin{array}{lll}\text { Figure B.8: } & \text { Calculations for FPI decile scores } & 163\end{array}$

Figure D.1: Hotspots/coldspots of income by meshblock in Wellington 186

Figure D.2: $\quad$ Hotspots/coldspots of median household income by meshblock 187 in Wellington

Figure D.3: $\quad$ Hotspots/coldspots of sources of household income by 188 meshblock in Wellington

Figure D.4: Hotspots/coldspots of housing quality by meshblock in 189 Wellington

Figure D.5: $\quad$ Hotspots/coldspots of capital value by meshblock in Wellington 190

Figure D.6: Hotspots/coldspots of building footprints by meshblock in 191 Wellington

Figure D.7: Hotspots/coldspots of HQI by meshblock in Wellington 192

Figure D.8: Hotspots/coldspots of housing age by meshblock in Wellington 193

Figure D.9: $\quad$ Hotspots/coldspots of solar radiation by meshblock in Wellington 194 


\section{List of Tables}

Table 2.1: Estimated rates of fuel poverty in New Zealand 15

Table 2.2: $\quad$ Push and pull model of switching 24

Table 2.3: $\quad$ Switching profiles in the New Zealand electricity market 30

Table 2.4: $\quad$ Factors influencing switching based on age, income and power 33 bill

Table 3.1: $\quad$ Variables of existing spatial models of fuel poverty based on the 41 hazards-of-place model

Table 3.2: Variables included in the FPI 48

Table 3.3: $\quad$ Mailing protocol for the Energy Prices and Warm Homes Survey 54

Table 3.4: Distribution of surveys by meshblock 60

Table 4.1: $\quad$ Spatial autocorrelation (Moran's I) of FPI and contributing factors 62

Table 4.2: Spatial autocorrelation (Moran's I) of income variables 65

Table 4.3: $\quad$ Spatial autocorrelation (Moran's I) of housing quality variables 67

Table 4.4: $\quad$ Correlations of FPI factors 72

Table 4.5: $\quad$ Correlations of FPI variables 73

Table 4.6: $\quad$ Significant differences of proportions in ethnic groups between 80 hotspots/coldspots

Table 4.7: $\quad$ Significant differences of proportions in age groups between 81 hotspots/coldspots

Table 4.8: $\quad$ Significant differences of proportions in family type between 82 hotspots/coldspots

Table 4.9: $\quad$ Significant differences of proportions in partnerships between 82 
hotspots/coldspots

Table 4.10: Significant differences of proportions in tenure between hotspots/coldspots

Table 4.11: $\quad$ Significant differences of proportions in duration of tenure between hotspots/coldspots

Table 4.12: Significant differences of proportions in fuel for heating between 84 hotspots/coldspots

Table 5.1: $\quad$ Survey response by FPI decile 88

Table 5.2: Sample socio-demographics compared to Wellington 89

Table 5.3: Respondents' perceptions of expense and affordability: descriptives

Table 5.4: Respondents' energy bill information: descriptives 95

Table 5.5: Respondents' experiences of the cold: descriptives 95

Table 5.6: Fuel poverty $\left(\mathrm{FP}_{10}\right)$ profiles compared to sample

Table 5.7: $\quad$ Switching (switched $d_{D}$ ) profiles compared to sample 100

Table 5.8: Correlations of perceptions of expense 102

$\begin{array}{lll}\text { Table 5.9: } & \text { Correlations of perceptions of affordability } & 103\end{array}$

Table 5.10: Correlations of experiences of the cold 104

$\begin{array}{ll}\text { Table 5.11: } & \text { Correlations of energy efficiency } \\ & 104\end{array}$

Table 5.12: Linear regression of FPI with perceptions of expense and 106 affordability

Table 5.13: Logistic regression of $\mathrm{FP}_{10}$ with perceptions of expense and 107

Table 5.14: $\quad$ Multiple logistic regression of switched $D$ with perceptions of expense and affordability

Table 5.15: Linear regression of FPI with experiences of the cold 109

Table 5.16: Multiple logistic regression of switched $D$ with experiences of the cold

Table 5.17: Correlations of energy efficiency with experiences of the cold and perceptions of expense and affordability

Table 5.18: Linear regression of $\mathrm{FPI}$ and logistic regression of $\mathrm{FP}_{10}$ with energy efficiency

Table 5.19: Multiple logistic regression of $\mathrm{FP}_{10}$ with socio-demographics

Table 5.20: Multiple logistic regression of switched $D$ with socio- 
demographics

Table A.1: $\quad$ Data sources and descriptions - ENAs and electricity prices

Table A.2: $\quad$ Breakdown of electricity prices (QSDEP May 2015) by Electricity

152 Network Area (ENA)

Table B.1: $\quad$ Data sources and descriptions - FPI

Table B.2: $\quad$ Coded values for housing age 


\section{List of Acronyms}

\begin{tabular}{ll} 
CBD & Central business district \\
DEM & Digital elevation model \\
FPI & Fuel poverty index \\
GIS & Geographic information systems \\
HQI & Housing quality index \\
IDW & Inverse distance weighted \\
LIHC & Low income high costs \\
MELAA & Middle Eastern/Latin American/African \\
OA & Output area \\
PPM & Prepayment meters \\
QSDEP & Quarterly Survey of Domestic Electricity Prices \\
QV & Quotable Value \\
SAP & Standard Assessment Procedure \\
SFPI & Scottish Fuel Poverty Indicator \\
SOE & State Owned Enterprise \\
TDM & Tailored design method \\
WF & Warm Front \\
WHO & World Health Organization \\
WOF & Warrant of fitness \\
WUNZ:HS & Warm Up New Zealand: Heat Smart \\
\hline
\end{tabular}




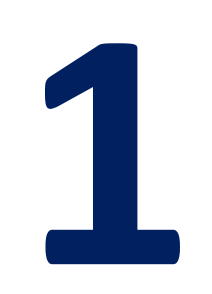

\section{Chapter One: Introduction}

Fuel poverty is a prevalent issue in New Zealand and can have severe health outcomes. Fuel poverty describes the inability of a household to afford adequate energy services within the home if they need to spend more than $10 \%$ of household income on energy services (Boardman, 2010a). Energy services are the outcomes of energy consumption, such as space heating, lighting and water heating. The affordability of energy services is influenced by inadequate income, high energy prices and poor housing energy efficiency. Fuel poverty is considered a unique form of deprivation, as the energy efficiency of the home has a distinctive role in influencing the affordability of adequate energy services (Boardman, 2010a). Fuel poverty in New Zealand is estimated to affect at least 1 in 4 households, and its estimated occurrence doubled between 2001 and 2008 (Howden-Chapman et al., 2012; Lloyd, 2006). Despite its prevalence in New Zealand, fuel poverty is not specifically recognised as an issue by the New Zealand government.

Fuel poverty is most commonly related to space heating and indoor temperatures. The World Health Organization's (WHO) minimum indoor temperature standard of $18^{\circ} \mathrm{C}$ is used as a baseline for adequate indoor temperature (Howden-Chapman et al., 2009). Inadequate heating and temperatures can aggravate respiratory illnesses, impact cardiovascular systems and influence mental health (Liddell \& Guiney, 2015; O'Sullivan, Howden-Chapman, \& Fougere, 2011). Extreme outcomes of inadequate heating related to fuel poverty include hospitalisation and mortality (Howden-Chapman et al., 2012). 
Under-heating is a common practice in New Zealand homes that prevents minimum temperature standards, as recommended by WHO, from being met. Across a range of housing tenures, average temperatures are below the WHO's $18^{\circ} \mathrm{C}$ indoor temperature standard. In owner-occupied houses in New Zealand, Isaacs (2010) recorded an average winter temperature of $17.9^{\circ} \mathrm{C}$, while Lloyd et al.'s (2008) study of New Zealand state houses in Dunedin, recorded average indoor temperatures during the winter of $13.9^{\circ} \mathrm{C}$ in living areas and $13.4^{\circ} \mathrm{C}$ in bedrooms. Howden-Chapman et al. (2007) examined the effects on indoor temperature of retrofitting existing houses in New Zealand with insulation measured average indoor temperatures $14.2^{\circ} \mathrm{C}$ post-intervention. Due to these low indoor temperatures in New Zealand, there is a noticeable increase in hospitalisation and excess winter mortality connected to practices of under-heating and energy inefficient housing (Howden Chapman et al., 2012).

New Zealanders may have a high tolerance for colder indoor temperatures due to an embedded masculine, colonial heritage (Cupples et al., 2007). Cupples et al. (2007) examined the social construction of air pollution and its relation to heating practices. In this study, interviews took place with New Zealand residents and residents who were from overseas. Interviewees from overseas commented that New Zealanders "like suffering from cold", "pride themselves on how shitty their houses are" and thermal discomfort is "just part of being a New Zealander"(Cupples, Guyatt, \& Pearce, 2007, pp. 2888-2889).

A national culture of tolerance towards colder temperatures is compounded by an aversion to energy efficiency measures. In Cupples et al.'s (2007, p. 2889) study, New Zealand residents considered energy efficiency measures such as insulation, doubleglazing and central heating, which are common in other countries, to be an "unnecessary and excessive luxury". These statements support the view of Howden-Chapman et al. (2009, p. 3388), that "heating in New Zealand is generally not treated as a luxury good, but rather as a basic necessity that is, by international standards at least, undervalued". These New Zealand specific perceptions around cold temperatures and energy efficiency contribute to the presence of fuel poverty in New Zealand.

Mechanisms currently endorsed by the New Zealand government which combat factors contributing to fuel poverty include housing energy efficiency improvements, the 
promotion of retail competition and the encouragement of consumers to switch energy suppliers, termed 'supplier switching', although fuel poverty is not specifically mentioned (Ministry of Economic Development, 2011). Improvements in housing energy efficiency, such as installing insulation or clean heating systems, offer a longterm approach to reducing fuel poverty. However, improving housing energy efficiency may not be the most effective solution for households in fuel poverty. The often substantial upfront capital costs to improve energy efficiency may be unaffordable for fuel poor households, who often have low incomes. The influence of housing energy efficiency on the health outcomes of low income households and households who are vulnerable to fuel poverty is also well established. Less is known about the role of energy and how the cost of energy influences fuel poverty.

The low historical cost of electricity in New Zealand is a likely contributing factor to the poor energy efficiency of housing and its effects on fuel poverty (Bertram, 2006). Prior to 1987 , New Zealand's electricity industry was state-owned and electricity prices were "breaking even" (Bertram, 2006, p.219). Following 1987 and under neoliberal economic reform, the electricity industry was restructured and corporatised to increase the reliance on competitive markets which was argued to deliver greater economic efficiencies in the provision of energy (Bertram, 2006). However, the benefits envisaged for residential consumers have not been fully realised.

Since the restructuring of the electricity industry, electricity prices in New Zealand have persistently increased. These increases are mostly concentrated in the residential sector; between 1990 and 2000, household electricity prices increased by $9.1 \%$ and by another 203.3\% between 2000 and 2010 (Chester \& Morris, 2012). In 2015, electricity prices continued to increase and the gap between inflation and electricity prices was widening (Hughes, 2015). These prince increases are impacting households' ability to afford adequate energy services. As annual energy consumption per household has remained stable, households consume the same amount of energy while paying more for that consumption (Howden-Chapman et al., 2012).

Bertram (2015) argues, the restructured electricity industry's governance, legislative and policy setting constrains the ability of the New Zealand government to regulate the price of electricity. As a result, the Government relies on consumers to regulate the 
market. Consumers are encouraged to switch energy suppliers which places downwards pressure on electricity prices and stimulates competition (Ministry of Economic Development, 2011). Switching enables households to benefit from competitive prices and deals provided by other energy suppliers, and supports the reduction in electricity prices through price signals for efficient investment (Ministry of Economic Development, 2011).

In contrast to housing energy efficiency, switching offers fuel poor households a lowcost and short-term approach to improve the affordability of energy services (Anderson, White, \& Finney, 2012). However, overseas evidence suggests that households vulnerable to fuel poverty may not be benefiting from switching (Department of Communications Energy and Natural Resources, 2015). Due to the reliance on switching to regulate electricity prices in New Zealand and the absence of empirical evidence supporting the relationship between fuel poverty and supplier switching, investigation is required to determine the effectiveness of switching in improving the affordability of energy services for fuel poor households. It is important to ascertain whether supplier switching in New Zealand is an effective approach to alleviating fuel poverty by improving the affordability of energy services.

\subsection{Geography of fuel poverty}

The geography of fuel poverty is an important yet undervalued dimension within the literature to date. The approach of this thesis emphasises the role of geography in identifying fuel poverty and exploring its relationship to supplier switching. Conventional factors that influence fuel poverty, namely income, energy demand and housing quality, are not uniformly distributed and influence the manifestation of fuel poverty. High income and low income households are socio-spatially concentrated in particular areas. Urban growth results in high quality housing concentrated on the periphery of urban areas. Varying topography obstructs areas' exposure to sunlight and natural warmth, influencing households' energy demand. While each of these factors are subject to underlying geographic processes, they are also likely to intersect in particular locations. Households vulnerable to fuel poverty are likely to reside in areas 
where low income, low housing quality and high energy demand compound and exacerbate their relative disadvantage.

Factors contributing to fuel poverty not only intersect in particular areas, but also at the specific site of the house. As Boardman (2010a) argues, fuel poverty is a distinctive issue and form of deprivation due to the energy inefficient nature of the house. As such, related foci of existing research on fuel poverty have been the physical dimensions of the house, such as the structural efficiency and heating systems. Analyses of the physical dimensions of housing and fuel poverty tend to separate energy use from society and the social context which determines the demand for energy and where energy consumption takes place (Huber, 2015). This understanding of fuel poverty, "at worst, assume[s] that building users are passive" agents in informing the ways in which adequate energy services within the house are afforded and fuel poverty negotiated (Ellsworth-Krebs, Reid, \& Hunter, 2015, p. 101).

The recent development of energy geographies, however, adopts a more critical and spatial approach to understanding energy services (Calvert, 2015; Huber, 2015). More specifically, it relates the geography of energy to the relationships between both the structural and social contexts that inform how energy is used in particular spaces (Calvert, 2015; Ellsworth-Krebs et al., 2015).

Ellsworth-Krebs et al. (2015) argue that the 'home', as opposed to the 'house', should be the spatial focus of research related to domestic energy use. As a spatial focus, the 'home' captures the interplay between structural and social dimensions of the house and home. Extending the arguments of Ellsworth-Krebs et al. (2015), the affordability of energy services is not solely dependent on the structural efficiency of the house. Rather, the affordability of energy is also connected to the social context and the energy behaviours or practices within this context. The home therefore shapes a household's demand for energy and the ways it is used.

The 'home' has consequently become a site of interest within the literature. Through a focus on the 'home', households are active in their management of energy; their behaviours, habits, preferences and expectations shape the demand for and use of energy services (Shove, 2003). For example, households' switching behaviours influence 
the affordability of electricity and the manifestation of fuel poverty in the home. Thus, structural and social contexts are "co-constructive" in creating the home as a space influencing fuel poverty (Ellsworth-Krebs et al., 2015, p. 102).

Analyses of fuel poverty are often detached from geography. Spatial understandings of the factors that influence fuel poverty are either implicit or absent. Previous research has under-played the "wider spatial and institutional landscapes ... operating at a variety of scales and material sites" in which fuel poverty is embedded (Bouzarovski, Tirado Herrero, Petrova, \& Ürge-Vorsatz, 2015, p. 15)The geography of fuel poverty has also been an under-valued or missing element within the New Zealand literature to date. This thesis emphasises the importance of geography in understanding the relationship between fuel poverty and supplier switching in New Zealand.

\subsection{Problem statement and objectives}

Fuel poverty is influenced by many structural and social factors which operate within and outside of the home. These factors exhibit geographic patterns that are likely to overlap and spatially concentrate in particular areas which contribute to and exacerbate fuel poverty in these locations. In order to improve outcomes for fuel poor households, supplier switching is a low-cost and short-term approach to improving the affordability of energy services. However, overseas evidence suggests households vulnerable to fuel poverty may not benefit from switching. Through a geographic lens, this thesis aims to explore the relationship between fuel poverty and supplier switching, and sheds light how an understanding of the spatial distribution of fuel poverty can be applied to improving the affordability of energy for households in fuel poverty.

The primary objectives are:

- To identify and explore the spatial distribution of fuel poverty;

- To explore the relationship between fuel poverty and supplier switching;

- To explore the reasons why fuel poor households switch energy suppliers;

- To explore the factors that facilitate and inhibit fuel poor households switching energy suppliers. 


\subsection{Thesis structure}

This thesis is divided into six chapters which address the aim of this thesis. Chapter Two reviews two key bodies of literature. First, the literature on fuel poverty is reviewed and the evidence for fuel poverty in New Zealand is examined. Second, literature concerning supplier switching and retail competition in restructured electricity markets is reviewed. Central theories and factors influencing consumers' switching behaviours are identified, as well as the nature of competition and switching in the New Zealand electricity market. These two bodies of literature are then connected, examining the need for an investigation into the relationship between fuel poverty and switching.

Chapter Three discusses the approaches taken to address the research objectives. The use of sequential phases and methods, namely geographic information systems (GIS) and a postal survey, are identified as appropriate to achieving the objectives of this research. Phase one of this research applied a new approach to identifying fuel poverty in New Zealand. Using GIS, a spatial indicator of fuel poverty was calculated which would identify the spatial distribution of fuel poverty at meshblock level in the study area. The indicator calculated in phase one supported the implementation of phase two. The indicator was applied to identify potential survey participants through which a postal survey exploring the relationship between fuel poverty and supplier switching was conducted.

An analysis of the research findings is provided in Chapters Four and Five, respectively addressing both phases of data collection. In Chapter Four a spatial analysis explores the geography of fuel poverty in the study area, identifying a unique spatial distribution informed by the legacies of colonisation. Local socio-spatial trends contributing to fuel poverty are identified and the complex spatial distribution of factors contributing to fuel poverty highlighted. Chapter Five explores the results of the survey and provides an analysis of supplier switching in relation to fuel poverty. From an economically rational perspective, this thesis identifies that households' switching behaviours are counter to expectations, and that fuel poor households and non-fuel poor households may have similar switching behaviours. Finally, the potential for integrating the two datasets is 
determined in order to identify the geographic relationship between fuel poverty and supplier switching.

Chapter Six provides a discussion of the research findings reflecting on the research aim and objectives identified in Chapter One. The complex geography of fuel poverty is discussed and the application of the spatial indicator of fuel poverty calculated in this thesis in coordinating geographically targeted responses to fuel poverty is considered. The contradictions and complexity of households' switching behaviours are then discussed. Where the literature has focused on pre-switching competition, postswitching competition is identified as a new dimension that influences switching behaviours. The variety of coping strategies used by households to afford adequate energy services, in lieu of switching, is discussed. Recommendations for policy and potential avenues for future research are also identified.

Finally, Chapter Seven provides a synthesis of the findings of this research. The key contributions of this thesis are outlined, how these contributions respond to the aims and objectives of this research are addressed, and concludes as to how these findings provide an opportunity to improve equitable outcomes for fuel poor households. 


\section{2}

\section{Chapter Two: Literature Review}

Fuel poverty describes the inability of a household to obtain adequate energy services within the home. However, the term itself is often used interchangeably with energy poverty (Li, Lloyd, Liang, \& Wei, 2014; Moore, 2012). Defining fuel poverty is critical in determining who and where is identified as fuel poor and subsequently targeted in policy (Boardman, 2010a). Therefore, a definition of fuel poverty must be operational and effective in application while capturing the multidimensional nature of this issue. The initial focus of this review establishes the context of fuel poverty for this research. The occurrence of fuel poverty in New Zealand is then reviewed.

The second body of literature informing this research concerns restructured electricity markets, retail competition and switching behaviours. Key arguments and ideas of this literature are outlined. This review argues that current policy approaches to fuel poverty have undervalued the potential for switching to improve the affordability of energy for households in fuel poverty. There is limited academic literature on supplier switching in New Zealand. In this regard, there is a need for future academic inquiry and a gap this thesis addresses. Finally, initial evidence concerning the relationship between fuel poverty and switching is reviewed. 


\subsection{Defining fuel poverty}

Energy poverty is often used in place of fuel poverty, however, the terms are not fully interchangeable. Fuel poverty describes the inability of households in developed countries to afford adequate energy services in the home and the related health outcomes (Li et al., 2014). Energy poverty focuses on developing countries and the lack of access to modern energy services from a development perspective (Li et al., 2014). Solutions to energy poverty involve the development of energy infrastructure and capacity to increase access to energy services, whereas solutions to fuel poverty involve improving the affordability of energy services largely through energy efficiency measures.

In this thesis, the term fuel poverty is used to describe the inability of households in the developed world to afford adequate energy services. The use of fuel poverty is also consistent with the New Zealand literature.

\subsubsection{Definitions of fuel poverty}

Fuel poverty is defined in a number of ways. However, these definitions of fuel poverty do not necessarily measure the same occurrence of fuel poverty. As a result, there are diverse understandings of what fuel poverty is and who the fuel poor are.

\subsubsection{Boardman's definition of fuel poverty}

Boardman's 1991 definition was the first to quantify fuel poverty and is the most commonly used definition. Boardman defined fuel poverty as when households need to spend more than 10 per cent of income on energy services (Boardman, 1991, 2010a). Boardman's definition informed the UK's definition of fuel poverty within statutory obligations to eradicate fuel poverty "as far as reasonably practicable" by 2016 (Hills, 2012, p. 2). 


\subsubsection{Low Income, High Cost definition of fuel poverty}

In 2011, the UK government commissioned a review of fuel poverty within policy, The Hills Review. Hills (2012) recommended adopting a Low Income, High Costs (LIHC) measure of fuel poverty. The LIHC definition identified fuel poverty on a dual attribute basis and defines a household as fuel poor if household income is below the poverty line ${ }^{1}$ and energy costs are higher than the median modelled energy bill.

In 2015, a revised UK fuel poverty strategy aimed "to ensure as many fuel poor homes as reasonably practicable achieve a minimum energy efficiency rating of Band $\mathrm{C}^{2}$, by 2030" and adopted the LIHC definition of fuel poverty (Department of Energy and Climate Change, 2015).

\subsubsection{Vulnerability based definitions to fuel poverty}

The terms 'vulnerable' and 'vulnerability' to fuel poverty frequently feature within the fuel poverty literature, and 'vulnerable households' have been a specific focus of fuel poverty policy in the UK. Yet, whose vulnerability to fuel poverty is being defined, and in doing so legitimised, is infrequently considered. The 2001 UK Fuel Poverty Strategy defined vulnerability as "older householders, families with children and householders who are disabled or suffering from a long term illness", based on their energy needs and likelihood of low income (Moore, 2012, p. 24). In the UK, if a household fits this definition of vulnerability they are able to access policy targeted at fuel poverty. However, targeting vulnerable households is not necessarily the same as targeting fuel poor households.

\footnotetext{
${ }^{1}$ Income below the poverty line is less than $60 \%$ of the national median income after housing costs and equivalised (adjusted for household size and composition) (Hills, 2012).

${ }^{2}$ Houses that are build, sold or rented in the UK require an Energy Performance Certificate (EPC) (UK Government, 2015). The EPC rates the energy efficiency of a property in bands from A (most efficient) to $\mathrm{G}$ (least efficient) according to the Standard Assessment Procedure (SAP).
} 


\subsubsection{Subjective fuel poverty}

Subjective indicators are also used to identify fuel poverty. These indicators are based on self-reported assessments of "feeling fuel poor", feeling cold or shivering (Healy \& Clinch, 2002; Waddams-Price, Brazier, \& Wang, 2012). Subjective assessments of fuel poverty account for households' perceptions, behaviours and knowledge of energy services.

There is, however, a discrepancy in which households that self-report fuel poverty may not be objectively fuel poor and vice-versa (Waddams-Price et al., 2012). Lawson, Williams, and Wooliscroft (2015) identify little overlap between objective and subjective measures of fuel poverty in New Zealand, identifying two distinctive groups of fuel poor households. They conclude that subjective and objective indicators of fuel poverty are not "parallel indicators of the same construct" (Lawson et al., 2015, p. 41). This review, supports Hills (2011) recommendation that subjective indicators of fuel poverty should be used as complementary to objective indicators and as a means of validation.

\subsection{Defining affordable and adequate energy services}

Within the various interpretations of fuel poverty references are made to the affordability and adequacy of energy services. The following section reviews these central themes of fuel poverty.

\subsubsection{Affordable energy services}

According to Boardman's (1991) definition of fuel poverty, energy services are considered affordable when a household needs to spend less than $10 \%$ of total income on energy services. The $10 \%$ threshold was based on research which suggested that energy expenditure greater than twice the median was unaffordable and was calculated from households' median weekly expenditure on fuel in 1988; median fuel expenditure was $5 \%$. The $10 \%$ threshold, however, is often misinterpreted an absolute figure related to the affordability of energy services. 
The concept of 'need to spend' amends the issues surrounding the $10 \%$ threshold as an absolute indicator of energy service affordability. The need to spend concept addresses fuel poverty and affordable energy services by considering what people need to spend as a proportion of their income to obtain adequate energy services, rather than their actual expenditure (Boardman, 2010a). The 'need to spend' concept captures households that limit energy expenditure and consequently spend less than $10 \%$ of their income on energy.

\subsubsection{Adequate energy services}

Boardman's definition of fuel poverty includes all energy services within the home. Yet, fuel poverty is most commonly connected to heating. Boardman (2010a) acknowledges this focus is a practical response to measuring the adequacy of energy services as heating is quantifiable and is related to severe health outcomes. Inadequately heated homes can aggravate respiratory illnesses such as asthma. Based on the health outcomes of inadequate heating, minimum indoor temperatures in relation to fuel poverty are measured against WHO standards of $21^{\circ} \mathrm{C}$ for living rooms, and $18^{\circ} \mathrm{C}$ for other rooms in the home (Liddell \& Morris, 2010).

In contrast, Shove (2003) explores the social construction and subjectivity of warmth, indicating that cultural differences influence what is considered adequate heating and the sensitivity of households to the cold. The social construction of warmth resists specifications of minimum indoor temperature standards. Thus, the adequacy of energy services, specifically warmth, is objective, subjective and context specific.

There is little evidence concerning the inadequacy of other energy services, such as water heating or lighting, and poverty. Adequate water heating and lighting, are more subjective and difficult to quantify compared to heating (Boardman, 2010a; Shove, 2003). 


\subsection{New Zealand definitions of fuel poverty}

In New Zealand, fuel poverty is not officially defined. However, the New Zealand Energy Strategy provides some indication of how the New Zealand government views fuel poverty (Ministry of Economic Development, 2011). While there is no reference to fuel poverty within the Strategy, the Government supports "home energy affordability" and better health outcomes for households in inadequately insulated, cold and damp homes (Ministry of Economic Development, 2011, p. 23). The Strategy does not elaborate on the term 'home energy affordability'. There is limited discussion within the Strategy concerning the affordability of energy services, and a discussion on the adequacy of energy services is absent. I am unaware of any ongoing consultations regarding an official definition of fuel poverty or equivalent in New Zealand.

\subsubsection{The geography of fuel poverty in New Zealand}

Fuel poverty is estimated to affect $25 \%$ of New Zealand households and varies across New Zealand (Table 2.1). In 2008, 47\% of Dunedin's population was estimated to be fuel poor. In contrast, estimates of fuel poverty in northernmost Auckland were 14\%. Rates of fuel poverty decline with northern progression and can be attributed to a climatic gradient based on latitude. A map of New Zealand and these locations is provided in Section 3.1. 
Table 2.1: Estimated rates of fuel poverty in New Zealand

\begin{tabular}{ccc}
\hline Location & $\begin{array}{c}\text { Estimated } \\
\text { fuel poverty (2001) }\end{array}$ & $\begin{array}{c}\text { Estimated } \\
\text { fuel poverty (2008) }\end{array}$ \\
\hline Auckland $^{3}$ & $6 \%-8 \%$ & $14 \%$ \\
Wellington $^{4}$ & $9 \%-14 \%$ & $24 \%$ \\
Christchurch & $18 \%-25 \%$ & $40 \%$ \\
Dunedin & $26 \%-32 \%$ & $47 \%$ \\
\hline New Zealand & $10 \%-14 \%$ & $25 \%$ \\
\hline
\end{tabular}

Source: Lloyd (2006), Howden-Chapman et al. (2012)

While this comparison identifies a simple geography of fuel poverty in New Zealand, further geographic understandings of fuel poverty are limited. Other spatial patterns are likely to underlie this geography of fuel poverty. For example, electricity prices vary across New Zealand; the most expensive electricity unit (kWh) in November 2015 cost 46.3\% more than the cheapest unit. Data for these calculations are provided in Appendix A.

\subsubsection{Fuel poverty: New Zealand evidence}

There is strong evidence for fuel poverty occurring in New Zealand. Fuel poverty is the outcome of disadvantage experienced by households across dimensions of income, housing quality and energy demand. The intersections between these factors reinforces an "energy underclass" in New Zealand (Walker, 2008, p. 4515).

\subsubsection{Income}

Electricity is the most common form of heating in New Zealand (Howden-Chapman et al., 2009). Yet, for some New Zealand households the cost of electricity is unaffordable. The New Zealand Living Standards Report (2006), cited in Howden-Chapman et al.

\footnotetext{
${ }^{3}$ Auckland includes North Shore City, Waitakere City, Auckland City, Manukau City and Papakura City.

${ }^{4}$ Wellington includes Wellington City, Lower Hutt City, Upper Hutt City and Porirua City.
} 
(2009), estimated that 10\% of New Zealand European and 25\% of Māori households fell behind in at least one payment for power, gas or water. Disconnection is a potential outcome of falling behind in payments for electricity and an indicator of fuel poverty.

Rates of disconnection in New Zealand are high, compared to Australia and the UK. In 2006, total registered disconnections were 11,743. Disconnections fell dramatically in 2007 following the publicised death of a consumer who was medically dependent on electricity and was disconnected (O'Sullivan, Howden-Chapman, \& Fougere, 2012). Subsequently, guidelines to protect vulnerable consumers were introduced. Since then however, the rate of disconnection has increased, reaching 11,241 disconnections in 2013 (Electricity Authority, 2015a). At least 9,000 households were also estimated to be disconnected during the winter months in the years from 2007 to 2011 (O'Sullivan, Howden-Chapman, Fougere, Hales, \& Stanley, 2013).

While income influences the affordability of energy, income may not necessarily be related to the indoor temperatures of New Zealand homes. High income households in New Zealand do not heat their house to significantly higher indoor temperatures compared to low income households (Howden-Chapman et al., 2009). In one study, onethird of households with income above the national median of $\$ 60,000$ reported going without heating at some point (Lawson \& Williams, 2012). In the same study, energy expenditure accounted for between $1 \%$ and $52 \%$ of household income, with a median expenditure of 5.5\% (Lawson et al., 2015). This evidence indicates that over $50 \%$ of their sample were spending more than $10 \%$ of their income on energy and fuel poor based on actual energy expenditure.

The New Zealand Deprivation Index (NZDI) is a measure of socio-economic deprivation at meshblock level, the minimum spatial classification used in the New Zealand census. The NZDI divides the population into ten equal deciles based on indicators of socioeconomic deprivation from the New Zealand census. Based on NZDI deciles, the most deprived $10 \%$ (lowest decile) of the population are most affected by fuel poverty. On average, household energy expenditure for the lowest decile accounts for $13.1 \%$ of total income; the highest proportion across all deciles (Howden-Chapman et al., 2009). The most deprived deciles also spend proportionally more of their income on energy, although less in real dollars, compared to the least deprived deciles (Howden-Chapman 
et al., 2012). Expenditure on energy as a proportion of income for other low deciles is increasing and reflects an expansion of fuel poverty into lower-middle NZDI deciles.

\subsubsection{Housing quality}

The quality and energy efficiency of New Zealand housing is poor. Two thirds of New Zealand's housing stock was constructed prior to the introduction of building standards (Howden-Chapman et al., 2009). As a result, ceiling and wall insulation is absent in many houses, under-floor insulation is absent from most houses, and double-glazed windows and central heating are uncommon (Howden-Chapman et al., 2009). The poor energy efficiency of New Zealand homes means households do not consume sufficient energy to achieve adequate indoor temperatures.

Households that live in rental properties may be affected by low quality housing to a greater extent than households in privately owned properties (Phillips, 2012). In New Zealand, the rental property market is lightly regulated and there are currently no requirements for landlords to improve housing quality. Tenants are also unlikely to invest in the structural efficiency of rental properties (Phillips, 2012). Following the New Zealand government's recognition of the influence that energy inefficient housing has on health, schemes such as Warm Up New Zealand: Heat Smart (WUNZ:HS) were introduced and a warrant of fitness (WOF) trialled to address this issue.

WUNZ:HS is a government subsidised scheme targeted at retrofitting insulation and/or installing clean heating systems in low income or vulnerable houses constructed prior to 2000 (Grimes et al., 2012). WUNZ:HS aims to improve the indoor environment of houses by increasing temperatures, reducing damp and draughts, and offering the potential for a reduction in overall energy consumption (Grimes et al., 2012). The uptake of WUNZ:HS has been relatively low with landlords and private rental properties in comparison to owner-occupied households.

The WOF aims to improve the quality of public rental properties based on an insulated, dry, safe and secure home with access to essential amenities (Bosch, 2014). In pilots of the WOF, $96 \%$ of properties failed to meet all 49 criteria of the WOF. In a separate study investigating a WOF for private rental properties, $96 \%$ of properties also failed to meet 
all 31 criteria of the WOF (Bennett, Chisholm, Hansen, \& Howden-Chapman, 2014). In the same private rental properties study, $14 \%$ of properties failed at least one insulation standard, the most common being insufficient insulation thickness or incorrect installation.

\subsubsection{Energy demand}

Energy demand for heating is a powerful driver of fuel poverty. Energy used for heating, on average, accounts for $30-40 \%$ of total energy use in the home (Howden-Chapman et al., 2009; Lloyd, 2006). A households' energy demand for heating is influenced by the location and orientation of the house. The local geography in Wellington and Dunedin, for example, limits the ability of households to access sunlight for natural warmth, which increases energy demand from purchased energy for heating (Lloyd, 2006).

Energy demand is also connected to the needs and practices of households. Vulnerable household members have higher energy needs, as their health is more susceptible to colder temperatures. For some households, under-heating is a sign of fuel poverty. In Dunedin, winter energy bills from households in public rental housing were on average $\$ 120 \pm \$ 40$, (Lloyd, Callau, Bishop, \& Smith, 2008). When these costs are extrapolated to 2008 prices for a whole year, according to the Quarterly Survey of Domestic Electricity Prices (QSDEP) and assuming this figure represents a maximum cost, these costs equate to an average annual energy consumption of $4272 \mathrm{kWh}$. This consumption is below the 2006 national average of 7800kWh (Howden-Chapman et al., 2009; Ministry of Business, 2015).

In New Zealand, prepayment meters (PPMs) are a favoured payment method for low income households to afford adequate energy services (O'Sullivan et al., 2011). PPMs are used by approximately $3 \%$ of New Zealand households, who are likely to be fuel poor (O'Sullivan et al., 2011). However, payment for electricity via PPMs is consistently more expensive compared to other payment methods, such as direct debit (O'Sullivan et al., 2011). Consequently, the energy expenditure of households who use PPMs, and who are also likely to be fuel poor, does not stretch as far as it otherwise could. Despite the higher costs of PPMs, which may enhance existing financial pressures, households have 
reported favouring PPMs as they enable "previously abstract spending on energy services... to become visibly and tangibly connected with the appliance use" (O'Sullivan, Viggers, \& Howden-Chapman, 2014, p. 182).

\subsection{Fuel poverty in restructured electricity markets}

The cost of electricity in restructured electricity markets has severely impacted the ability of households to afford adequate energy services. Following the global rise of the neoliberal economic doctrine, many countries' electricity markets were restructured. Restructuring aimed to minimise state regulation and increase reliance on markets to deliver electricity in the most efficient and cost effective manner. However, in most restructured markets, these aims have not been achieved and electricity prices have generally increased (Anderson, 2009). Moreover, the ability of households who are vulnerable to fuel poverty to afford adequate energy services has been severely impacted (Boardman \& Fawcett, 2002; Waddams-Price, 2005). Fuel poverty is consequently considered by Chester and Morris (2012, p. 435) to be the "hallmark of liberalised electricity sectors".

This thesis argues that restructured electricity markets and the neoliberal economy are central to the manifestation of fuel poverty. The effects of the neoliberal economy are most evident in the electricity market, although also extend to influence housing quality and income. As such, the cost of electricity is a central focus of this thesis.

\subsubsection{Solving fuel poverty: Policy approaches}

In neoliberal economies, state regulation of rising electricity prices is unfavourable. As such, other policy mechanisms are implemented to assist fuel poor households in obtaining affordable and adequate energy services. For these policies to be effective, the precise identification of fuel poor households is critical. Therefore, policy must accurately identify the intended target group and balance 'errors of inclusion' with 'errors of exclusion' (Dubois, 2012). That is, effective policy maximises targeting the intended target group, while minimising targeting of those outside of this group (Sefton, 
2002). As fuel poverty is a multidimensional issue, many factors beyond the conventional dimensions of income, energy prices and housing energy efficiency make it difficult to identify fuel poor households. Thus, policies targeting fuel poverty are "necessarily imperfect" (Dubois, 2012, p. 107).

\subsubsection{Fuel poverty policy case study: Warm Front}

The UK's Warm Front (WF) policy demonstrates the complexity of fuel poverty policy. WF offered grants for insulation and heating retrofits for eligible households to meet the objectives of the 2001 UK Fuel Poverty Strategy; to eradicate fuel poverty amongst vulnerable households by 2010 (Sovacool, 2015). Eligible households were vulnerable to fuel poverty as defined by the UK Fuel Poverty Strategy; older householders, families with children and householders who are disabled or suffering from a long term illness.

However, WF demonstrated high errors of exclusion and errors of inclusion. An estimated $82 \%$ of fuel poor households, however, were not eligible for WF because they were not vulnerable as defined by the UK Fuel Poverty Strategy and did not receive the necessary benefits (Sefton, 2002). A further 78\% of eligible households were not fuel poor (Sefton, 2002). The use of vulnerability as a proxy for fuel poverty resulted in a mismatch between eligible households and those defined as fuel poor (Sovacool, 2015). WF also relied on a self-referral system to access this policy. However, many households did not know they were fuel poor or perceive themselves to be fuel poor or vulnerable, and consequently eligible for WF. Some households also may not have wanted to be identified as fuel poor or vulnerable due to the stigma attached to these terms (Dubois, 2012; Sovacool, 2015).

\subsubsection{Fuel poverty and switching policy}

Sovacool $(2015$, p. 37$)$ argues alternative approaches to policy based on vulnerability and self-referral mechanisms should be used to target fuel poverty so that households "can save energy without sacrificing their social identity or pride". Extending this 
argument, this thesis proposes supplier switching and geographically targeted policies offer this opportunity.

Switching energy companies is an inconspicuous way in which fuel poor households can improve the affordability of energy without the stigma attached to other schemes. By switching, consumers can benefit from competitive prices, encourage innovation and stimulate investment in efficient energy systems, which feeds back into a reduction in the cost of energy (Defeuilley, 2009). By switching energy suppliers, consumers act as a secondary regulator to the commissioned industry regulator.

Geographic targeting offers a spatially refined approach to identifying fuel poor households and minimising errors in the targeting of fuel poverty in policy. Geographic approaches to identifying fuel poverty are increasingly prominent in the literature (e.g. Walker et al., 2012; Fahmy et al., 2011; Morrison \& Shortt, 2008). Based on evidence that fuel poverty is spatially concentrated, geographic approaches can predict where fuel poverty is most likely to occur and prioritise the targeting of these locations in policy (Walker et al., 2012; 2013). Walker et al. (2013) identified the need for significant improvements in the targeting of policy towards areas in greatest need is required. An opportunity exists to investigate the potential for geographic targeting of switching policy.

\subsubsection{Incompatible? Restructured markets and switching policy}

In theory, switching offers households the opportunity to improve the affordability of energy. However, in practice, Sovacool (2015) suggests, policies targeting the affordability of energy may be incompatible with restructured electricity markets. This argument posits that targeting switching in particular areas may subvert the competitive market. Consumers and companies choose to participate in the competitive market. Economically rational consumers who choose to participate and switch reap the benefits, and those that choose not to switch may be disadvantaged. Targeted switching policy introduces the notion that some households shouldn't be disadvantaged by uncompetitive costs despite their choice to not participate in the market. Anderson 
(2009) and Defeuilley (2009) also question the extent to which policy promoting switching, through enforcement or otherwise, is economically efficient.

Policies that aim to encourage supplier switching may not be as effective at encouraging switching as is sometimes assumed. Waterson (2003) questions the extent to which switching behaviours can be influenced through policy, and suggests that individual switching may be a natural behaviour of consumers. However, the state's role in the neoliberal economy is to facilitate conditions that support the competitive market. This role involves supporting consumers who, for example, may not be aware of their ability to switch or know how to participate effectively in competitive markets. Policy that promotes switching therefore must balance the ideals of the competitive market with the responsibilities of the state.

\subsection{Switching behaviours}

Consumers are expected to behave in an economically rational manner, and switch to a cheaper energy supplier by "voting with their wallets" (Anderson, 2009, p. 71). However, many consumers remain averse to switching (Waterson, 2003; Yang, 2014). Consumers' decisions to switch are influenced by many factors. This section reviews a range of consumer segments, models and factors proposed to influence switching behaviours. By understanding which consumers respond to switching and how their decision to switch is made, this knowledge can be applied towards encouraging households to switch who would significantly benefit from improved energy affordability.

\subsubsection{Switching segments}

Consumers can be classified into two main switching segments; active and non-active consumers. The active consumer segment consists of consumers who switch, consumers who re-negotiate offers without switching and consumers who search without switching (Defeuilley, 2009). Non-active switchers are consumers who choose to remain with an incumbent energy supplier. While active switchers reap the direct benefits of switching, they also "impart a positive externality to non-[active consumers] through their 
behaviour" (Waterson, 2003, p. 132). Active switchers facilitate a competitive market from which non-active switchers can benefit despite their non-switching habits.

Yang (2014) and Walsh, Groth, and Wiedmann (2005) challenge the division of the market into two switching profiles. Based on switching behaviours, both studies identify a third consumer segment in addition to active and non-active consumers. This third segment, which Yang (2014, p. 412) labels "apathetic switchers", are consumers who are less certain in their intention to switch and fit somewhere between active and nonactive switchers. Walsh et al. (2005) identifies this group as consumers interested in switching but who are less motivated by the monetary benefits of switching.

\subsubsection{Push and Pull Model of switching}

Bansal et al. (2005) propose a push and pull model to explain the factors influencing consumers' switching behaviours This model has three primary dimensions; push factors, pull factors and status quo effects (for examples, see Table 2.2). Push factors motivate consumers to switch away from their current supplier. In contrast, pull factors are the aspects of an alternative supplier that are attractive to consumers and entice switching. Status quo effects are barriers which produce consumer inertia and result in consumers remaining with the same company (Bansal, Taylor, \& James, 2005; Ek \& Söderholm, 2008). Upholding the status quo allows consumers to remain with what is familiar and avoid unknown future risks. 
Table 2.2: Push and pull model of switching

\begin{tabular}{|c|c|c|}
\hline Push & Pull & Status Quo \\
\hline Quality & Attractiveness of alternative & Attitudes towards switching \\
\hline Satisfaction & & Switching costs \\
\hline Value & & Previous switching \\
\hline Trust & & behaviours \\
\hline Commitment & & Variety-seeking tendencies \\
\hline Price perceptions & & Social influences \\
\hline
\end{tabular}

Source: Bansal et al. (2005)

\subsubsection{Search and switch costs to switching}

Waterson (2003) argues that switching is influenced by search costs and switch costs. Search costs refer to the incurred or perceived costs in deciding to switch, for example the use of cognitive skills or the time taken to investigate and compare switching options (Defeuilley, 2009). Switching costs are the economic, psychological and opportunity costs of switching suppliers, such as contacting a new supplier or negotiating a better deal (Ibáñez, Hartmann, \& Calvo, 2006). Switching occurs when both search and switch costs are minimised, and the real or perceived net gain is greater than the costs incurred. Following an initial switch, search and switch costs should decrease based on a learning effect where subsequent searches and switches incur lower costs (Annala, Viljainen, \& Tuunanen, 2013; Defeuilley, 2009).

\subsubsection{Product differentiation}

Product differentiation can affect switching behaviours (Waterson, 2003). By providing a variety of innovative products, retailers can affect the switching costs and search costs incurred by consumers. While new entrant electricity companies increase competition in the market, in order to challenge the incumbents' consumer share, new entrants must target niche markets or offer innovative products. In a competitive market for a 
homogeneous product, such as electricity, product differentiation is necessitated, yet difficult (Ek \& Söderholm, 2008; Waterson, 2003, p. 139). A company's point of difference increases the attractiveness of switching for particular products. Popular products offered as a point of difference include payment discounts, the "menu of contracts", bundled or package offers, and the availability of online and mobile tools (Defeuilley, 2009, p. 382). However, the consumer shares of incumbent companies remain unchallenged as new entrants' innovations have been reproducible, some of which have become entrenched and widely offered in the market (Defeuilley, 2009).

\subsubsection{Non-monetary factors influencing switching}

Consumers who are averse to switching and low switching rates may indicate "the partial relevancy of economic arguments" (Defeuilley, 2009, p. 377). Non-monetary factors may influence consumers' switching behaviours to a greater extent than costbenefit analyses suggest (He \& Reiner, 2015). For example, cognitive bias (e.g. the preference to maintain the status quo) or loyalty to existing suppliers can act as psychological barriers to switching, resulting in "switching inertia" (Defeuilley, 2009; Yang, 2014, p. 407). As electricity is an intangible good, consumers may also "place lower value on the tangible end product and more value on the process of service delivery" (Walsh et al., 2005, p. 434). Maintaining patron-supplier relations is critical to ensuring loyalty of existing consumers as well as attracting new customers (Yang, 2014).

\subsubsection{Socio-demographic factors}

Socio-demographic factors influence switching behaviours. Gender, age and education are shown to influence the likelihood of consumers switching. For example, males and the higher educated favour competition, while older households require less savings to switch (McDaniel \& Groothuis, 2012). However, He \& Reiner (2015) report little impact of socio-demographics on switching. The relationship between income and switching is ambiguous; some studies report no relationship, and others suggest high income households favour switching (Ek \& Söderholm, 2008; He \& Reiner, 2015; Yang, 2014). 


\subsection{Restructuring in New Zealand}

Since the restructuring ${ }^{5}$ of New Zealand's electricity industry, residential electricity prices have persistently increased. Chester and Morris (2012) calculate residential electricity prices in New Zealand to have increased by 203.3\% between 2000 and 2010 . Despite the fact that commercial and industrial sectors constitute $65 \%$ of the market for electricity, these sectors have not observed parallel price increases (Ministry of Business Innovation and Employment, 2015). As electricity prices have generally increased, the affordability of energy in New Zealand homes has been impacted. In particular, restructuring has not benefited households vulnerable to fuel poverty. However, the ability of the New Zealand government to regulate residential electricity prices is constrained.

Bertram (2015, p. 25) argues "interlocking pieces [of legislation and policy] that are mutually-supporting" limit the regulation of electricity prices in New Zealand. Under the State-Owned Enterprises (SOE) Act 1987, if the Government wishes energy companies operating as SOEs to provide electricity as a social good, compensation for lost profits must be paid by the Government (Bertram, 2015). Energy companies operating as SOEs include Genesis, Meridian and Mighty River Power and have 59\% consumer share of the total residential electricity market (Electricity Authority, 2016). As such, under the current legislation and policy, the pursuit of social directives is an unaffordable option for the Government. The Commerce Act 1986 also legalised oligopoly profits to which a Government response is limited without threat of litigation (Bertram \& Twaddle, 2005).

\subsubsection{Switching in New Zealand: What's My Number}

In the absence of literature on switching in New Zealand, the following review is largely derived from documents published by the Electricity Authority. The Electricity Authority was commissioned to "promote competition in, reliable supply by, and the efficient operation of, the electricity industry for the long-term benefit of consumers" (Electricity Authority, n.d.). The Electricity Authority encourages consumers to switch energy

\footnotetext{
${ }^{5}$ Restructuring is used over liberalisation and deregulation as the New Zealand electricity market has since been re-regulated (Anderson, 2009).
} 
suppliers to promote competition. However, the New Zealand electricity market is characterised by 'sticky' consumers who have not switched away from their default energy supplier and a belief that all electricity suppliers are the same (Electricity Authority, 2012, p. 2). In response, the Electricity Authority launched the What's My Number campaign to promote switching, improved access to switching information and simplified the switching process.

What's My Number has added "competitive pressure" to the market as more consumers choose to shop around and switch energy suppliers (Electricity Authority, 2015e, p. 5). Since What's My Number was launched, over 1.73 million switches have occurred and switching increased by $28 \%$ in one year (Electricity Authority, 2015g). The success of What's My Number is evident in a noticeable spike in switching during 2011 and sustained rates of switching since (Figure 2.2). Switching rates vary throughout New Zealand. Switching rates in the North Island are higher compared to the South Island and show greater variation at lower geographic units, for example regional council boundaries (Electricity Authority, 2015d). Currently, switching is not targeted spatially in areas with lower switching rates. 
Figure 2.1: Total switches by month in New Zealand (2004-2015)

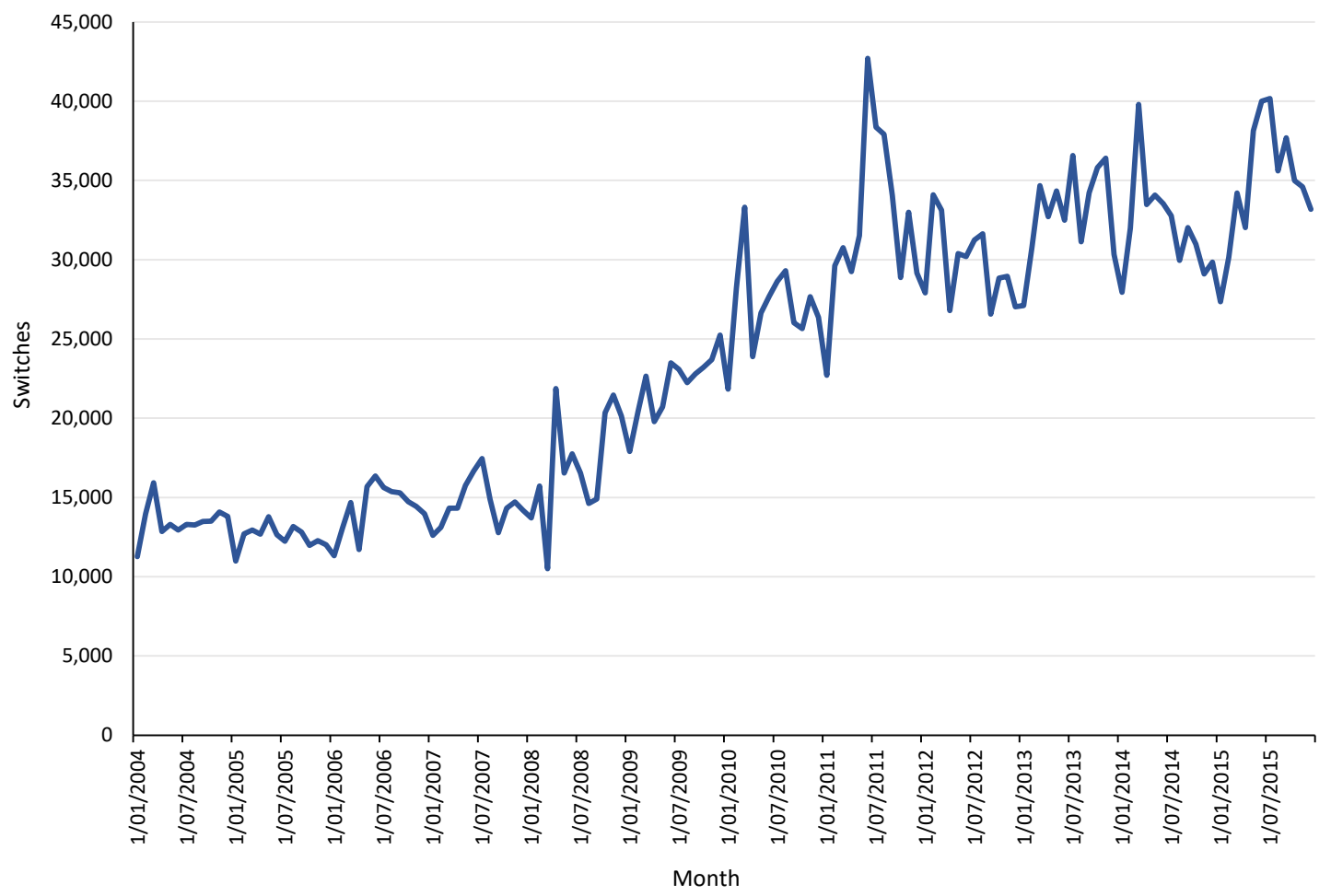

Source: (Electricity Authority, 2015f)

New Zealand's switching rate is high compared to similar electricity markets in Australia, Texas (USA) and Alberta (Canada). The Electricity Authority (2014a) identified 31\% of New Zealand households had switched energy suppliers in the last two years. Switching rates in Australia, Texas and Alberta were $20 \%, 18 \%$ and $16 \%$ respectively. The high switching rate in New Zealand may be the outcome of the promotion of switching through What's My Number and simplification of the switching process.

Retailers have also responded favourably to switching and increased competition in New Zealand. Initial responses included offering greater online payment discounts, sign-up incentives, bundled packages which offer other services alongside electricity, and timeof-use pricing. Several new entrant retailers have also entered the market to create a "competitive fringe" which assists in regulating the market (Electricity Authority, 2015e, p. 9). These new retailers have further encouraged innovation and expanded the range 
of services offered to consumers. In response, incumbent retailers have further improved their competitive offers.

Improved competition and switching in New Zealand's electricity market is recognised for reducing electricity prices by $1.4 \%$ in the latter half of 2011 and providing consumers with an estimated $\$ 8$ million in savings (Electricity Authority, 2015b). However, despite competition and promotion of supplier switching, decreases in the overall cost of electricity have not been realised. Aside from an increase in the relative affordability of energy for households that have switched, universal and long-term improvements in the affordability of electricity remain constrained. It may be inevitable that more households will become fuel poor as electricity prices continue to increase.

Switching and retail competition continue to be promoted in New Zealand with a particular focus on difficult to reach consumers. Although O'Sullivan (2011, p. 739) questions, "how much more successful consumer switching can be in reducing prices when New Zealand's rate of consumer switching is high by comparison with other countries". The overall benefit of retail competition and supplier switching to consumers is therefore contestable.

\subsubsection{Switching profiles}

Switchers in the New Zealand electricity market have been classified into five switching profiles: Bargain Hunters, Gen Y, Mainstream Mums, Affluent Time-Poor Sceptics and Old, Status Quo (Electricity Authority, 2015c). Table 2.3 profiles these segments and their switching behaviours. In New Zealand, switching is characterised by Bargain Hunters or the consumers who proactively seek opportunities to switch energy suppliers. Other segments of the market are less likely to proactively seek opportunities to switch, such as Affluent Time-Poor Sceptics, Gen Y, Mainstream Mums and Old, Status Quo. This knowledge of consumer segments in New Zealand and how their decisions to switch are made can be applied to encouraging switching amongst consumers who are averse to switching. 


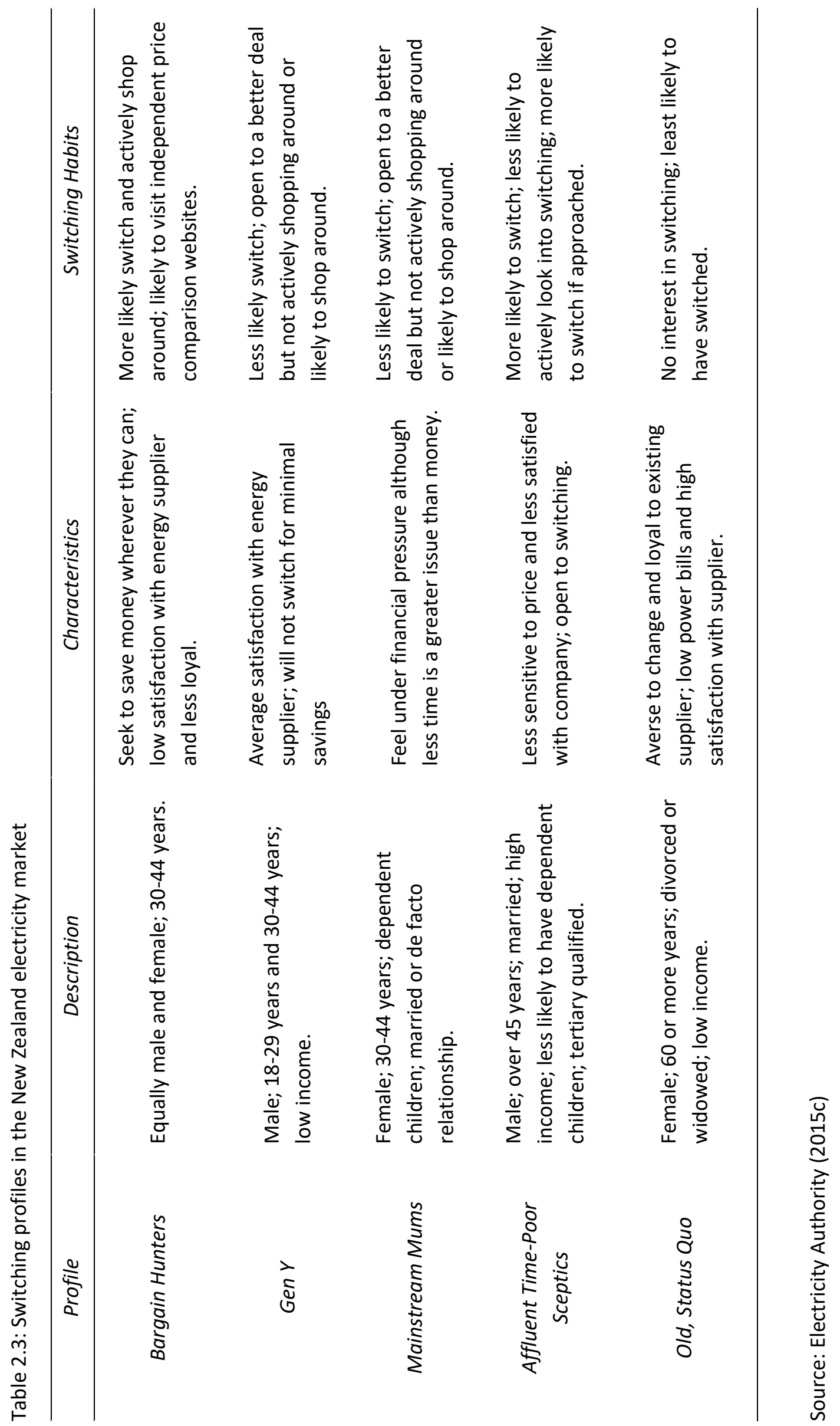




\subsection{Connecting fuel poverty and supplier switching: Initial evidence}

There is limited empirical evidence on the relationship between fuel poverty and switching. Although, suggestions that fuel poor households do not benefit from competition and switching may have some initial credibility.

It is in energy companies' interests to avoid gaining switching consumers that provide minimal returns or pose credit risks. Due to their potential for non-payment, fuel poor households fit this profile and are not attractive consumers for energy companies. Rather, energy companies desire to gain switching consumers who, compared to the fuel poor, are profitable, exhibit inertia, are loyal and unlikely to switch again in the short-term. In the UK, this has led to a "two-tier market" where some consumers are charged higher, less competitive prices (House of Commons, 2012, p. 14).

Boardman (2010b, p. 276) argues the two-tiered market is supported as energy companies "penalise the unwanted consumers in order to attract those that are more profitable". That is, the costs of attracting new customers through competition are subsidised by consumers who are unlikely to switch or those who are "captive consumers" and are unable to switch due to debt (Boardman \& Fawcett, 2002, p. 17). Captive consumers are likely to be fuel poor and, as a result of a two-tiered market, invariably purchase more expensive energy. This practice of subsidising switching through a two-tiered market, follows neoliberal economic principles (Boardman, 2010b). Although, fairer practices would charge these costs to consumers that switch, rather than loyal consumers or potentially fuel poor consumers (Boardman \& Fawcett, 2002).

Fuel poor households spend a larger proportion of their income on energy and are likely to have lower energy expenditure. As such, any financial savings from switching will be nominally lower as a proportion of their expenditure. A $10 \%$ saving, for example, is nominally less for fuel poor households compared to non-fuel poor households with higher energy expenditure. Consequently, there is a lower nominal financial return for fuel poor households from switching. However, due to their propensity for nonpayment, there may be less opportunity for fuel poor households to switch in the first place as existing suppliers seek to collect debt. 
Fuel poor consumers may also switch to more expensive energy suppliers. In the UK, one-fifth of consumers in general are estimated to switch to more expensive energy suppliers (Wilson \& Waddams-Price, 2010) and 50\% of 'poor' households switch to more expensive providers (Hills, 2012). While fuel poor households are distinct from 'poor' households, this evidence indicates the potential disadvantage for fuel poor consumers in the electricity market who also experience income poverty. Walker \& Day (2012) suggest the discrepancy in benefits from switching between fuel poor and non-fuel poor households may be due to an information gap. Access to and the interpretation of information related to switching may favour non-fuel poor households to a greater extent.

In New Zealand, households who are vulnerable to fuel poverty may be less likely to switch. Table 2.4 reviews the switching behaviours of consumers demonstrating vulnerability to fuel poverty in New Zealand and indicates few factors motivate these households to switch. The only factor motivating households with low income and low power bills to switch is the belief that they are not getting the best value for money. Older households are likely to switch as they are less satisfied with the service. Although, these households are also less likely to seek information on switching, shop around for better deals and proactively switch. Older and low income households are also less likely to be confident in the outcomes of switching.

For households who are vulnerable to fuel poverty in New Zealand, PPMs are a popular and useful means of payment for energy services. However, the use of PPMs to pay for energy services may leave these consumers facing a double burden; high energy costs and less competition in the market. 
Table 2.4: Factors influencing switching based on age, income and power bill

\begin{tabular}{|c|c|}
\hline Profile & Switching behaviours \\
\hline $\begin{array}{l}\text { Younger } \\
\text { householders }\end{array}$ & $\begin{array}{l}\text { - } \quad \text { Proactive switcher; } \\
\text { - Likely to shop around; } \\
\text { - Sought information on switching; } \\
\text { - } \quad \text { Believe it's worthwhile reviewing best } \\
\text { deal; } \\
\text { - } \quad \text { Not getting best value for money. }\end{array}$ \\
\hline $\begin{array}{c}\text { Older } \\
\text { householders }\end{array}$ & - Low satisfaction with service. \\
\hline Lower income & $\begin{array}{l}\text { - Switch for lower savings; } \\
\text { - Not getting best value for money. }\end{array}$ \\
\hline Higher income & $\begin{array}{l}\text { - Likely to shop around; } \\
\text { - Seek information on switching. }\end{array}$ \\
\hline Lower power bill & $\begin{array}{l}\text { - Switch for lower savings; } \\
\text { - } \quad \text { Not getting best value for money. }\end{array}$ \\
\hline Higher power bill & $\begin{array}{l}\text { - Proactive switcher; } \\
\text { - Sought information on switching; } \\
\text { - Believe it's worthwhile reviewing best } \\
\text { - deal; } \\
\text { - } \quad \text { Low satisfaction with service; } \\
\text { - }{ }^{-} \text {getting best value for money. }\end{array}$ \\
\hline
\end{tabular}

Source: Electricity Authority (2014a)

\section{Summary}

The term fuel poverty has varying definitions. These definitions have implications for who is identified as fuel poor and subsequently targeted in policy responses to fuel poverty. Fuel poverty is generally measured against Boardman's definition; households are fuel poor if they need to spend more than $10 \%$ of household income on energy services to obtain WHO indoor temperature standards. Central to the definition of fuel poverty is an understanding of affordable and adequate energy services, which are also objective, subjective and context specific. 
Geographic differences in fuel poverty across New Zealand demonstrate the effect of location on fuel poverty. However, an understanding of this geography and how this influences the identification of fuel poor households is limited. Geographic approaches offer a spatially refined method to identify fuel poor households. Understanding the spatial distribution of fuel poverty has benefit in identifying fuel poor areas that require greater assistance and minimise errors in the targeting of fuel poverty policy.

In restructured electricity markets, electricity prices have generally increased and opportunities to regulate the price of electricity are restricted. This thesis proposes that switching offers fuel poor households an opportunity to improve the affordability of energy while also positioning consumers as a secondary regulator of the electricity market. Although, initial evidence indicates that the suggestion fuel poor households are not benefiting from switching has some credibility.

In the absence of empirical evidence of the relationship between fuel poverty and switching, and in particular in New Zealand where fuel poverty is under-recognised, further investigation is warranted. The limited academic inquiry into switching also indicates a need for further research in this area. This thesis provides insight to the relationship between fuel poverty and supplier switching, and assesses whether fuel poor households and areas in most need of affordable energy are accessing mechanisms in place to support them. A geographic approach offers a strong means to identifying fuel poverty and assessing whether fuel poor households are, in fact, benefiting from switching. 


\section{3}

\section{Chapter Three: Methodology}

Fuel poverty is a complex issue and difficult to identify due to the multiple structural and social factors contributing to its manifestation. This research used a geographic lens to understand the relationship between fuel poverty and supplier switching, and was conducted in two sequential phases. A sequential approach allowed the second method to build on the results of the first method.

Phase one of this research used GIS to calculate a spatial indicator of fuel poverty for Wellington. Geographic approaches to fuel poverty are increasingly prominent in the literature and have been effective at identifying fuel poverty. Identifying and understanding the spatial manifestation of fuel poverty requires a conceptual and practical approach that accounts for both the social and structural factors which influence fuel poverty. As such, the spatial index of fuel poverty calculated in this thesis was composed of numerous variables accounting for structural and social dimensions of fuel poverty.

In phase two, a postal survey, was conducted to explore the relationship between fuel poverty and supplier switching. This survey examined switching behaviours in greater detail and connected these to the geography fuel poverty. The approaches to conducting the Energy Prices and Warm Homes Survey (EPWHS) are detailed in the final section of this chapter. This chapter details how these methods were designed and implemented to explore the relationship between fuel poverty and switching in the study area, Wellington. 
This research was approved by the Human Ethics Committee at Victoria University of Wellington. A copy of the memorandum is supplied in Appendix B.

\subsection{Study area}

This research is based in Wellington City (henceforth Wellington), see Figure 3.1, as the proportion of households in fuel poverty has remained similar to the national rate over time. Fuel poverty was estimated to affect $9 \%-14 \%$ of Wellington's population in 2001 , compared to $10 \%-14 \%$ nationally (Lloyd, 2006). Estimates of fuel poverty in Wellington in 2008 increased to $24 \%$ compared to $25 \%$ nationally (Howden-Chapman et al., 2012).

Wellington is the capital of New Zealand and is located on the south-west of the North Island of New Zealand (-41.24'S, $\left.174.76^{\prime} \mathrm{E}\right)$. Wellington has a temperate climate with distinctive seasons. The average temperature is $13.2^{\circ} \mathrm{C}$ and monthly maximums and minimums ranged between $15-25^{\circ} \mathrm{C}$ and $2-9^{\circ} \mathrm{C}$ (MetService, 2015). In 2014, total sunlight hours were 2,057 (NIWA, 2015).

The local topography and urban form impacts fuel poverty in Wellington. Wellington lies on an active tectonic plate boundary and has varying local topography. This topography influences the sunlight hours households receive and the potential for fuel poverty to occur in particular locations (Lloyd, 2006). The urban form and multi-storey buildings, particularly within Wellington's central business district (CBD), also influence the sunlight hours neighbouring areas receive.

Wellington's socio-demographic composition will impact rates of fuel poverty. Based on the 2013 census, the population of Wellington is wealthier and more educated than that of New Zealand (Statistics New Zealand, 2013c). Higher proportions of residents identify as New Zealand European/Pākehā and Asian. Fewer residents identify as Māori and Pacific Peoples, who are often cited in deprivation statistics. Wellington has a larger population of residents aged 20-39 years and a lower dependent population under the age of 19. Based on wealth, residents have a greater ability to afford energy expenditure, although a higher cost of living may negate this advantage. Lower rates of home ownership in Wellington limit the capacity of some households to improve the energy efficiency of their home and alter their experiences of fuel poverty. 
Figure 3.1: Map of New Zealand's main cities and inset map of Wellington

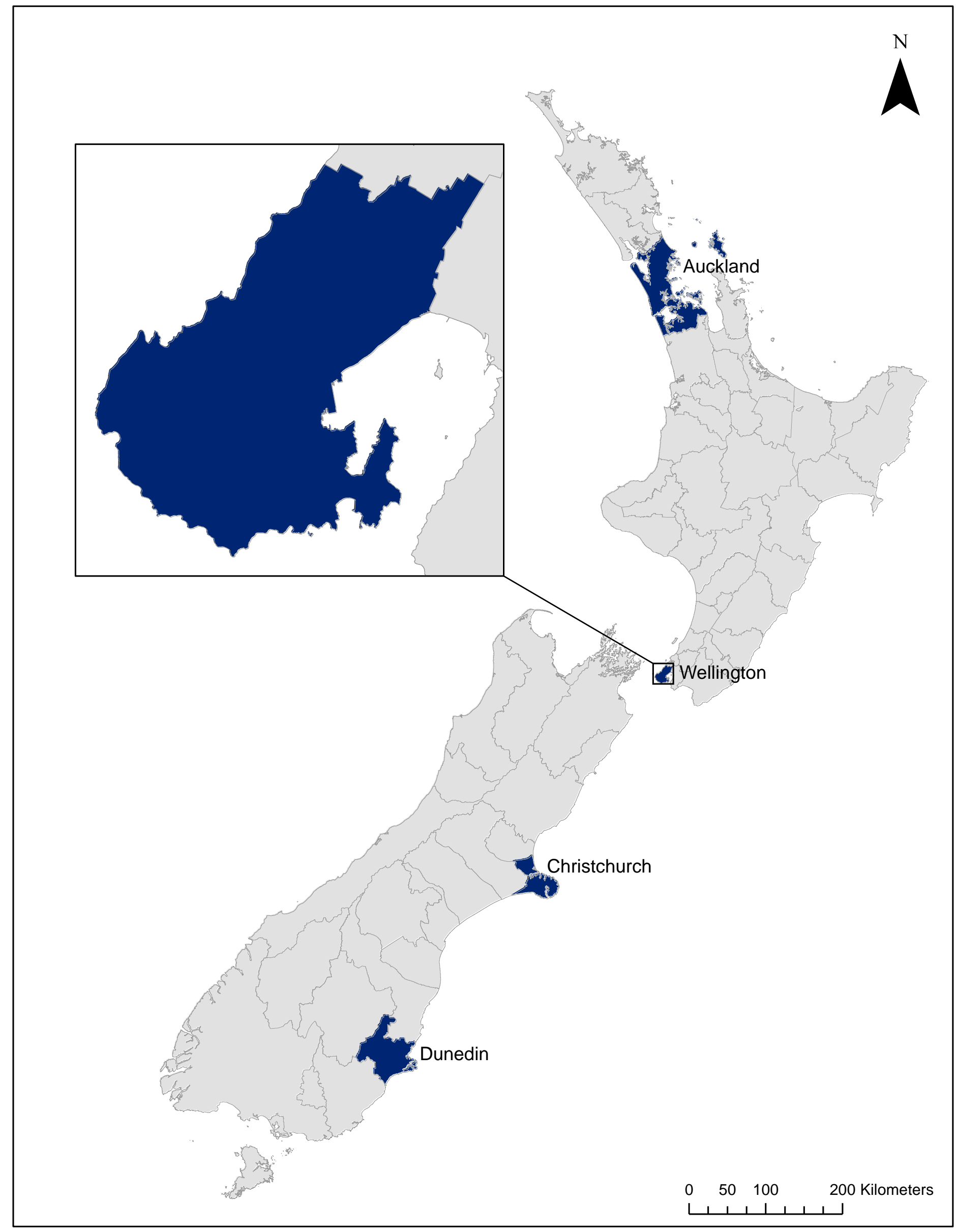


Energy supply also differs in Wellington compared to other regions in New Zealand. Electricity is the main source of heating, although there is also a greater use of reticulated gas and fewer low-cost alternative energy sources (Howden-Chapman et al., 2009). The high reliance on electricity in Wellington and the economies of scale makes Wellington an attractive and strategic location for energy suppliers to compete. Seventeen electricity suppliers operate in Wellington, including the main suppliers that operate nation-wide (Electricity Authority, 2014c). Experiences of switching in Wellington may provide a general insight to experiences of switching and competition across New Zealand.

\subsection{Phase one}

In order to identify fuel poverty in Wellington, the spatial distribution of fuel poverty was calculated. To do so, a model which includes multiple variables is required to reflect the distinctiveness of fuel poverty. GIS has been an effective approach to exploring the spatial distribution of fuel poverty (Fahmy, Gordon, \& Patsios, 2011; Morrison \& Shortt, 2008; Walker, McKenzie, Liddell, \& Morris, 2012). GIS can process and manipulate issues with complex spatial dimensions. As such, GIS is an appropriate method to identify the spatial distribution of fuel poverty in this research.

Previous spatial models were reviewed to inform an approach suitable to identifying the spatial distribution of fuel poverty in Wellington. The following section explores existing spatial models of fuel poverty and how they informed the development of the fuel poverty index (FPI) calculated in this research. Data sources and processes followed in ESRI's ArcGIS (v.10.2) to calculate the FPI are detailed in Appendix B.

\subsubsection{Geographic framework}

The fuel poverty literature does not have a complementary geographical framework to inform a spatial indicator of fuel poverty. In their spatial indicator of fuel poverty for Northern Ireland, Walker et al. (2012) applied the hazards-of-place model. The hazards- 
of-place model is a common framework for understanding geographic elements of vulnerability.

The hazards-of-place model understands vulnerability to be multidimensional, geographically variable and exacerbated by the inequitable distribution of resources (Zakour \& Gillespie, 2013). As fuel poverty is a multidimensional, geographically variable and exacerbated by the inequitable distribution of resources, the hazards-of-place model is suitable for informing the development of a spatial indicator of fuel poverty as a part of this research.

Three dimensions of vulnerability are recognised in the hazards-of-place model (Cutter et al., 2003; Zakour \& Gillespie, 2013):

1. Biophysical vulnerability - the frequency and severity of natural hazards in a location.

2. Built environment vulnerability - the age and quality of buildings and infrastructure.

3. Social vulnerability - human challenges that expose people to risk (e.g. social difference).

Based on these dimensions, Table 3.1 provides an overview of how variables used in existing spatial models of fuel poverty correspond with these three dimensions. In two cases, Baker et al. (2003) and Fahmy et al. (2003), it was unclear which other components factored into the social vulnerability dimension; these are identified as 'Other'. How these dimensions were measured in existing spatial models of fuel poverty are explored in the following sections. Each section concludes with a description of how the measurement of these dimensions have informed the FPI calculated in this thesis. The final section provides a summary of the FPI, the variables included and variables weights. 
Table 3.1: Variables of existing spatial models of fuel poverty based on the hazards-ofplace model

\begin{tabular}{|c|c|c|c|c|c|}
\hline & & \multicolumn{2}{|c|}{ Social vulnerability } & \multirow{2}{*}{$\begin{array}{l}\text { Biophysical } \\
\text { vulnerability } \\
\text { Energy demand }\end{array}$} & \multirow{2}{*}{$\begin{array}{l}\text { Built environme } \\
\text { vulnerability } \\
\text { Housing quality }\end{array}$} \\
\hline & Location & Income & Other & & \\
\hline Baker et al. (2003) & England & $x$ & $x$ & & \\
\hline Morrison \& Shortt (2008) & Scotland & $x$ & & & $x$ \\
\hline Fahmy et al. (2011) & England & $x$ & $x$ & & \\
\hline Walker et al. (2012) & $\begin{array}{l}\text { Northern } \\
\text { Ireland }\end{array}$ & $x$ & & $x$ & $x$ \\
\hline Walker et al. (2013) & $\begin{array}{c}\text { Northern } \\
\text { Ireland }\end{array}$ & $x$ & & $x$ & $x$ \\
\hline
\end{tabular}

\subsubsection{Spatial scale and geographic units}

Spatial models of fuel poverty have been calculated at a range of geographic scales. In the UK, output areas (OAs) permit analysis at the lowest geographic scale for which data is available, containing approximately 125 households (Walker et al., 2012).

In this thesis, fuel poverty was calculated at meshblock level which are the equivalent geographic unit in New Zealand to OAs in the UK. Meshblocks are smaller geographic units compared to OAs and contain, on average, between 30 and 60 dwellings (Statistics New Zealand, 2015). Meshblocks are the lowest scale at which data from the $2013 \mathrm{New}$ Zealand census is publicly available. Meshblocks support the spatial refinement of the FPI calculated in this thesis.

\subsubsection{Income}

The definition of income as it relates to fuel poverty is debated and has critical implications for the spatial distribution of fuel poverty which, all else constant, varies based on the definition of income (Fahmy et al., 2011). Income, which is equivalised (adjusted for household size and composition) and calculated after housing costs, may 
provide the most appropriate indication of fuel poverty (Moore, 2012). The most appropriate definition of income to identify fuel poverty relates to whether energy is perceived to be a necessary or discretionary expense.

In the UK census, income data is not collected and proxies are used as indicators of income. For example, in the English Fuel Poverty Indicator proxies for low income are unemployment and lack of car ownership. Whereas the Scottish Fuel Poverty Indicator (SFPI) identifies low income households based on social grade $E^{6}$ (Baker, Starling, \& Gordon, 2003; Morrison \& Shortt, 2008). Walker, Liddell, McKenzie, and Morris (2013, p. 786) calculate low income based on social welfare benefits. Low income was also calculated based on 'income deprivation' (households below average income) through a microsimulation methodology and 'passport' benefits as a measure of fuel poverty based on definitions of vulnerability; pension credit, disability living allowance and child benefit (Walker et al., 2013).

In this thesis, income data collected in the 2013 New Zealand census is used. A meshblocks' median household income ${ }^{7}$ and count of households receiving selected social welfare benefits are included in the FPI. Social welfare benefits ${ }^{8}$ include superannuation $(s)^{9}$, unemployment benefit, domestic purposes benefit, invalids benefit, sickness benefit and student allowance. Low median household income and high dependency on social welfare are indicators of the inability of households within a meshblock to afford adequate energy services.

In the New Zealand census, where meshblocks have low populations or responses to questions, data is not published or suppressed to protect privacy. Median household income based on fewer than 6 households in a meshblock is not published (Statistics New Zealand, 2013a). Counts of households receiving social welfare benefits were either suppressed or where fewer than 3 households receive benefits were randomly rounded

\footnotetext{
${ }^{6}$ Individuals older than 16 years of age on a state benefit, unemployed or lowest grade workers.

${ }^{7}$ Household income is not equivalised and is calculated based on sum of the median value of the income bracket indicated by each household member 15 years and over (Statistics New Zealand, 2013).

${ }^{8}$ Following the 2013 census, New Zealand's social welfare system was reformed. The unemployment benefit and sickness benefit were replaced by Jobseeker Support; the invalids benefit was replaced by Supported Living Payments; the domestic purposes benefit was replaced by Sole Parent Support or Jobseeker Support (dependent on age of the youngest child) (Work and Income, 2013).

${ }^{9}$ Inclusive of New Zealand superannuation or veterans' pension, other superannuation, pensions or annuities.
} 
by 3 (Statistics New Zealand, 2013a). Where data has been suppressed or not published, these meshblocks have been assigned the median household income or median count of households on benefits for Wellington.

\subsubsection{Housing quality}

In the UK, EPCs provide a standardised measure of energy efficiency rated in bands from A (most efficient) to $G$ (least efficient) (Department of Energy and Climate Change, 2014). While EPCs are calculated in Scotland, Morrison \& Shortt (2008) held reservations about applying the SAP scores in their fuel poverty model based on differences in the construction of housing in Scotland. In Walker et al.'s (2013) fuel poverty indicator for Northern Ireland, housing energy efficiency data could not be obtained.

In both studies, proxies for housing quality were necessary. In the absence of other housing energy efficiency data, Morrison \& Shortt (2008) used a local survey and council dataset to identify a model for housing quality at household level based on tenure, type of water heating, property type, year of construction and urban-rural location. Walker et al.'s (2013) used the value, size, type and age of dwellings as proxies for housing quality based on the following assumptions:

- Value - Expensive houses are more energy efficient. Mean property valuation was calculated for each OA.

- $\quad$ Size - Energy use is proportional to the size of the dwelling; smaller households require less energy and larger households require more energy, all other factors being equal. Property size was calculated from dwelling floor space based on the footprint. The mean building footprint was calculated for each OA.

- Age - Energy efficiency varies by dwelling age; older dwellings are less energy efficient than newer dwellings. Dwelling age was ranked from least efficient to most efficient. OAs that had a higher proportion of older housing scored higher on this factor.

- Type - Rates of heat loss increase in detached dwellings and have higher energy as a result. Dwellings were ranked by type. No rationale was provided for the ranking of housing energy efficiency by type. 
Where a mains gas connection was present, Walker et al. (2013) also moderated the housing element component of the index (which also included energy demand) by 0.95 to account for the lower cost of gas.

In New Zealand, housing energy efficiency data is not collected. Consequently, this thesis used proxies in line with Walker et al.'s (2013) model to construct a housing quality factor. Housing quality comprised average capital value, average building footprint $\left(\mathrm{m}^{2}\right)$, building age and a housing quality index (HQI). Capital value, building footprint and age are inclusive of non-residential buildings. The HQI includes only properties that people were living in when matched to addresses from the National Health Index. In the vast majority of cases, these were residential properties.

Capital value is the price expected to be paid for a property at the date of valuation based on the total value of the property and the land (Wellington City Council, n.d.). A high capital value is assumed to reflect desirable locations and properties (e.g. sunlight and housing quality) afforded by high income households (Daglish, de Róiste, Saglam, \& Law, 2015). Households residing in properties with high capital value are not expected to be fuel poor. Average capital value for each meshblock was calculated in ArcGIS.

Smaller houses have a lower energy demand for space heating than larger houses, and are expected to have lower rates of fuel poverty (Walker et al., 2013). Building footprints are used to represent housing area. The area of building footprints was calculated in ArcGIS and averaged across meshblocks to determine an average building footprint.

In New Zealand, older buildings are generally of lower quality being built before the introduction of building standards in 1978 (Howden-Chapman et al., 2009). Newer buildings are likely to be more energy efficient. The lowest modal building age by decade of construction or re-modification of properties in each meshblock was calculated and attributed as the average building age in each meshblock.

Pearson, Barnard, Pearce, Kingham, and Howden-Chapman (2014, p. 183) devised the HQI based on data held by Quotable Value (QV) on the "general condition" of properties. The general condition of properties is measured on a scale of 'superior', 'average' or 'poor' based on visual inspection of the exterior. QV's assessment of the general condition of properties is shown to be comparative to standardised assessments of 
housing quality conducted by the Building Research Association of New Zealand (Pearson et al., 2014). The HQI is limited in its use based on the assessors' subjectivity in examining property exteriors and the majority of properties rated as 'average' (Pearson et al., 2014). Quality is not based on the property's efficiency and many ratings may be out of date. As the HQI includes approximately $67 \%$ of New Zealand dwellings, and in the absence of alternative data in New Zealand, the HQI is a suitable proxy for housing quality. HQI values for each area unit were assigned to the meshblocks that compose each area unit.

\subsubsection{Energy demand}

Walker et al. (2012) and Walker et al. (2013) calculated 'heating burden' as an indicator of energy demand. Heating burden is the relationship between the cost of fuel and heating demand. Heating demand for each OA is based on the number of degree days, which assume that below a threshold outdoor temperature $\left(15.5^{\circ} \mathrm{C}\right)$ heating is needed, moderated by the cost of fuel (Walker et al., 2012).

To calculate heating burden, in both studies, mean winter temperature (December to March) from 17 and 18 meteorological stations, respectively, were spatially interpolated using the inverse distance weighted (IDW) function of ArcGIS. A second mean temperature was calculated from daily sea level temperature (January 2000 to April 2010) adjusted for the effect of elevation on temperature using a 50m digital elevation model (DEM). These indicators of temperature were then averaged. The sum of the daily difference between average temperature and threshold temperature was the total degree days. Days where temperatures were above the threshold were coded zero.

The cost of fuel (300 litres of oil) was then obtained from a random sample of 45 and 131 fuel suppliers, respectively, across Northern Ireland. Prices were mapped by IDW interpolation from the point location of each supplier. The cost of fuel and heating demand datasets were then combined using Raster Calculator and Zonal Statistics to average heating burden over each OA in Northern Ireland. Walker et al. (2013) also account for urban heat island effects (the temperature differences of urban areas relative to the surrounding rural area). 
In this thesis, solar radiation is used as a proxy for household energy demand. Compared to modelling energy demand through spatial interpolation of few and sparsely distributed weather stations, solar radiation modelled in ArcGIS provides an accurate measure of energy demand based on the absence of natural warmth. Houses that receive lower solar radiation require more energy to keep warm and are more likely to be fuel poor. Solar radiation is also assumed to be related to desirable locations where higher income households and higher quality housing are located.

ESRI's Spatial Analysis tool Area Solar Radiation was used to calculate solar radiation in Wellington. There is excellent agreement between this tool and measured solar radiation (Fu \& Rich, 1999). Default parameters were used based on previous applications of Area Solar Radiation in Wellington, which are also set to minimise error when applied to complex topography (Fu \& Rich, 1999; Shakes, 2012). A 1m DEM, the highest resolution available, was also used to minimise errors. Solar radiation was calculated for the months of winter (Days 152 (June 1st) to 243 (August 31 ${ }^{\text {st }}$ ) in 2014). Latitude was held constant $\left(-41^{\circ} \mathrm{S}\right)$. Mean solar radiation at meshblock level was calculated using Zonal Statistics.

Area Solar Radiation does not account for cloud cover and surface albedo (surface potential to reflect solar radiation). As the DEM does not include Wellington Harbour, a large source of albedo effects due to the reflection of water, it was not necessary to account for albedo. Cloud cover is continually changing and complex to model, and this level of detail was considered excessive for the FPI and excluded.

\subsubsection{Weights}

To determine weights of variables included in the spatial model of fuel poverty for Northern Ireland, Walker et al. (2012) assigned factor (e.g. income) weights based on an intuitive and a-priori process as no similar standards existed. To determine the weights for individual variables of each factor, weights were calculated using Relative Risk Ratio calculations in MedCalc. Weights in Walker et al.'s (2013) were also assigned weights on an a-priori basis. 
In this research, weights were assigned in line with Walker et al.'s (2013) method. However, weights in the FPI were adjusted to place greater importance on housing quality. This factor had a higher weight in the FPI than Walker et al.'s $(2012 ; 2013)$ study as it is argued to make fuel poverty a distinctive issue. Observed data was also assigned a higher weighting than modelled data. FPI variables and variable weights are summarised in Table 3.2.

Table 3.2: Variables included in the FPI

\begin{tabular}{ccccc}
\hline Factor & Variables & Percentage & Weight & Sum \\
\hline \multirow{4}{*}{ Income } & Median household income & $15 \%$ & 0.15 & \\
& Superannuation(s) & $5 \%$ & 0.05 & \\
& Unemployment benefit & $5 \%$ & 0.05 & \\
& Domestic purposes benefit & $5 \%$ & 0.05 & $40 \%$ \\
& Invalids benefit & $2.5 \%$ & 0.025 & \\
& Sickness benefit & $5 \%$ & 0.05 & \\
& Student allowance & $2.5 \%$ & 0.025 & \multirow{2}{*}{ HQI } \\
Housing quality & Building footprint & $10 \%$ & 0.1 & \\
& Age & $10 \%$ & 0.1 & $20 \%$ \\
& Capital value & $10 \%$ & 0.1 & \\
\hline \multirow{2}{*}{ Energy demand } & Solar radiation & $20 \%$ & 0.2 & \\
\hline
\end{tabular}

\subsubsection{Fuel poverty index (FPI)}

In sum, phase one involved the manipulation of quantitative geospatial data in ESRI's ArcGIS to calculate the FPI for Wellington. Based on the hazards-of-place model, the FPI consists of three dimensions; income, housing quality and energy demand. To calculate the FPI, attribute values were standardised by Z-score values. Z-score values for sources 
of household income and building footprints were inverted so that low benefit numbers and small footprints were the least fuel poor. Z-score values were then multiplied by their weight and summed to provide a final index value which was divided into deciles. Decile values were applied according to the NZDI so that a high decile value (e.g. 10) represents the top $10 \%$ most fuel poor areas in Wellington.

\subsection{Spatial analysis}

To identify patterns in the spatial distribution of fuel poverty, spatial statistics were calculated which account for the spatial relationships between data. The spatial statistics used in this thesis are detailed in the following sections. Combined, this spatial analysis and the use of these statistics offer greater insight into the geography of fuel poverty and the geographic patterns underlying the spatial distribution of fuel poverty in Wellington.

\subsubsection{Spatial autocorrelation}

Spatial autocorrelation determines the spatial distribution of a single variable by measuring the spatial relationship between attributes. Spatial autocorrelation identifies whether attributes are clustered, dispersed or independent of location. It is a statistical interpretation of the spatial distribution of a variable based on the spatial relationships between attributes (e.g. proximity or contiguity) (Schabenberger \& Gotway, 2005).

A common method of measuring spatial autocorrelation is Moran's I, which is used to determine a global measure of the spatial relationship of attributes in the entire study area (Getis \& Ord, 1992). Moran's I is similar to Pearson's correlation coefficient; the output value ranges between -1 and 1 , where negative values represent spatial dispersion and positive values represent spatial clustering. Moran's I was calculated for the FPI in Wellington to determine whether fuel poverty is spatially clustered. 


\subsubsection{Local spatial autocorrelation}

Local measures of spatial dependency capture the similarity of values in neighbouring areas and provide localised measures of clustering. Tests for local spatial autocorrelation can determine "pockets" of spatial dependency that are not reflected in global statistics (Anselin, 1995; Getis \& Ord, 1992, p. 190).The Getis-Ord Gi statistic is a measure of local spatial autocorrelation that determines spatial clusters of high values or low values of a variable (Getis \& Ord, 1992). A high Gi statistic indicates that there is a spatial concentration of high values, whereas a low value indicates a spatial clustering of low values (Anselin, 1995; Chang, 2012).

The outcome of local spatial autocorrelation is a hotspot map. Hotspots are "one or several contiguous sites where the local indicators are unusually large or small" (Schabenberger \& Gotway, 2005, p. 24). Hotspots are located where the local spatial autocorrelation of an attribute is significantly similar to others in the study area (Ord \& Getis, 1995, p. 287). The term coldspots is used to contrast the interpretation of spatial clusters of low values.

Conversely, Anselin Local Moran's I is a local measure of the clustering of similar and dissimilar values, thus identifying spatial outliers (Anselin, 1995). Conventional statistics to identify outliers do not provide an indication of how similar or dissimilar attributes are in comparison to their neighbours (Schabenberger \& Gotway, 2005). Anselin Local Moran's I is interpreted similarly to Moran's I; positive Z-scores indicate that neighbouring attributes are similar, and dissimilar when Z-scores are negative (Anselin, 1995).

\subsubsection{Grouping analysis}

Measures of spatial autocorrelation and Pearson's correlation coefficient provide an understanding of the relationships between one and two variables respectively. In ArcGIS, Grouping Analysis is an exploratory tool that identifies spatial relationships and underlying spatial patterns between multiple variables (ESRI, n.d.). This tool groups data for multiple variables into clusters so that data in each cluster are "as similar as possible, 
and all the clusters themselves are as different as possible" (ESRI, n.d.). Grouping Analysis was used to identify areas with similar values in the distribution of fuel poverty across multiple factors. The resulting clusters were used to explore the breakdown and composition of fuel poverty in particular areas.

The Calinski-Harabasz pseudo F-statistic was calculated to evaluate the optimal number of clusters into which variables were grouped. This statistic assesses the optimal number of clusters that maximises within-group similarity and between-group difference in variables (Moore \& Dixon, 2015). The highest pseudo F-statistic for clusters 2 through to 15 determines the optimal number of clusters. An $R^{2}$ value calculated for each variable indicates the effect of the variable in dividing the study area into clusters.

\subsubsection{Fuel poverty: National factors}

The spatial distribution of factors at a national scale and other geographic units are likely to influence the spatial distribution of fuel poverty across New Zealand. To explore the potential of these factors at a national scale, geographic differences in electricity prices across New Zealand were explored.

Geographic differences in electricity prices across New Zealand were calculated based on the relationship between the Electricity Network Area (ENA) centroid and electricity price data from the QSDEP (see Appendix A). An ENA is the area in which distribution lines companies operate. The centroid for each ENA was calculated in ArcGIS and the resulting Y-coordinate matched to QSDEP data for that area from May 2015. Some ENA boundaries and ENAs as listed in the QSDEP were not identical. For example, the QSDEP listed Unison as the ENA for Napier, Taupo and Rotorua, and provided electricity prices for each region. However, the ENA boundary for Unison did not distinguish between these three areas, and was represented as a single area. Average electricity prices across these areas were calculated to represent the price of electricity for this ENA. This process was repeated for ENAs with similar issues (see Appendix A).

Correlation tests were conducted to ascertain latitudinal differences in electricity prices across New Zealand according to the individual price components (e.g. retail, 
transmission and distribution) and the sum of these of electricity prices. Spatial autocorrelation was also calculated for the sum and component breakdown of electricity prices across New Zealand.

\subsection{Phase two}

In order to explore the relationship between fuel poverty and supplier switching, a survey was conducted among Wellington residents. An effective survey would collect data to quantify this relationship and allow integrative analysis with the FPI developed in phase one. In order for the survey conducted in this thesis to be effective, previous survey methods were reviewed to identify techniques that could inform the survey. This section presents the model and techniques applied in developing and implementing the Energy Prices and Warm Homes Survey (EPWHS) conducted in this thesis.

When targeting large samples and contact details required for Internet surveys are unknown, postal surveys are an effective survey method (Dillman, Smyth, \& Christian, 2009). Mail surveys return consistently higher response rates than other survey methods, can be designed to minimise coverage and sampling errors, and can reduce bias from researcher-administrated surveys (e.g. door-to-door surveys) (Dillman et al., 2009). For these reasons, a mail survey was chosen as the survey method to explore the relationship between fuel poverty and supplier switching. A Qualtrics Internet survey was also used to support the mail survey method.

\subsubsection{Survey design and implementation}

To encourage participation in the EPWHS, aspects of the tailored design method (TDM) were applied. The TDM is a guideline for conducting surveys which applies ideas of social exchange to encourage survey completion (Dillman et al., 2009). According to the TDM, three ideas are central to encouraging participation in surveys; establish trust with participants, increase the benefits of participation and reduce the costs of participation. How these ideas were applied in the design and implementation of the EPWHS are detailed in the following sections. 
When requesting households to complete the survey and to establish participants' trust, information was provided about the purpose of the survey and what participation would involve. The privacy and confidentiality of information was emphasised. As part of the recruitment procedure, identification numbers were assigned to addresses so that the information collected was traceable to the respondent's address and allow follow up contacts to be sent to appropriate addresses. However, all information provided by respondents was confidential and no information was published that had the potential to identify individual respondents or households; information was reported in an aggregated and anonymous form. Efforts were made to personalise all correspondence. In the absence of names to address letters to householders, correspondence was addressed 'Dear Wellington City Resident' and hand-signed. The connection to Victoria University of Wellington was stressed to promote the research's legitimacy. For example, envelopes with Victoria University of Wellington were used as well as the University's letterhead.

In line with the TDM and to reduce the cost of participation, the survey was designed to be short, easy, topically interesting and convenient for households to complete and return. Questions were designed to be easy to understand and open-ended questions were minimised. Requests for sensitive information (e.g. income) were minimised and followed the "foot-in-the-door" technique, where these requests followed simpler questions (Dillman et al., 2009, p. 372). The survey was printed to create a 12 page A5 booklet and included 44 questions over 8 pages. The remaining pages included front and back pages, and a consent form. Visual elements, for example bolded, italicised or underlined text, were used to emphasise key instructions or points in questions. Contrasting grayscale backgrounds were used to distinguish between questions. The use of reverse print was limited to section headings. A prepaid return envelope and ballpoint pen were also provided with the survey. On average, the survey booklet and online survey took between 10 and 20 minutes to complete.

To increase the benefit of participating in their survey, the importance of this research topic and the participants' contribution was highlighted. As compensation for completing the survey, and once their survey was returned, respondents were entered into a draw to win 1 of 4 vouchers for a supermarket of their choice. Voucher winners 
were drawn using a random number generator corresponding to the households' identification number.

The EPWHS was conducted over the last month of winter and first week of spring (August $1^{\text {st }} 2015$ and September $6^{\text {th }} 2015$ ). Conducting the survey over this period (i.e. winter) meant responses were likely to be a good reflection of fuel poverty as the time when households are most sensitive to electricity prices. The survey was to be completed by a household member, over 18 years of age, who paid or knew about the energy bill. Multiple contacts with potential respondents were used to maximise responses to the survey (Table 3.3).

Respondents provided informed consent to participate in this research. An amendment to the ethics approval for this thesis was approved so to accept surveys where respondents' consent was not indicated but implied through the return of a completed survey (see Appendix B). 


\begin{tabular}{ll} 
A pre-notification letter was distributed which informed \\
Pre-notification letter & $\begin{array}{l}\text { households they would shortly receive a survey, appealed } \\
\text { for their help in completing the survey and signified the } \\
\text { importance of the topic. }\end{array}$ \\
\hline Survey booklet & $\begin{array}{l}\text { One week later, the survey booklet was distributed to } \\
\text { households with a cover letter, information sheet, prepaid } \\
\text { return envelope and a ballpoint pen. Included with the } \\
\text { cover letter was the option to complete the survey online. }\end{array}$
\end{tabular}

\begin{tabular}{|c|c|}
\hline Reminder slips & $\begin{array}{l}\text { Reminder slips were distributed within a week of the } \\
\text { survey booklet. Households that had already completed } \\
\text { and returned their surveys were thanked and households } \\
\text { yet to complete the survey were reminded to do so. }\end{array}$ \\
\hline Final reminder & $\begin{array}{l}\text { Three weeks after the reminder slips, households were } \\
\text { sent a letter appealing to them to complete the survey. } \\
\text { Households were only given the option to complete the } \\
\text { survey online at this stage. }\end{array}$ \\
\hline
\end{tabular}

A pilot survey was conducted targeting different age groups, tenure, income brackets and education levels. Feedback from the pilot was incorporated into the final survey and detailed where relevant in the following sections. Based on the adverse reactions of participants in previous research to the term fuel poverty (O'Sullivan, 2009), the EPWHS and correspondence with participants in this research avoided the term fuel poverty or similar. This decision aimed to reduce the influence of preconceived notions of poverty on participation and responses. Instead, information relating to this research and the EPWHS provided a more general description of fuel poverty relating to participants' thoughts on the cost of energy and how their homes are heated.

A copy of the postal survey is supplied in Appendix B. 


\subsubsection{Energy Prices and Warm Homes Survey (EPWHS)}

In the EPWHS, participants were led through 8 sections of the survey covering 6 themes: switching behaviours, perceptions of expense and affordability, experiences of the cold, coping strategies, energy efficiency and socio-demographics. Questions from previous research were used and amended where appropriate to facilitate comparison of results. In order to identify fuel poor households, objective and subjective measures were used. Participants were asked to provide information from their most recent energy bill and the bill payers' total net income, from which fuel poverty based on actual expenditure could be calculated. Measures of subjective fuel poverty were based on perceptions of expense and affordability, and experiences of the cold (see Sections 3.4.2.2 and 3.4.2.3).

\subsubsection{Switching behaviours}

Effective operation of a competitive retail electricity market relies on active consumer participation. However, many economic and non-economic factors impact switching behaviours (Yang, 2014). Participants were asked how many times they had switched energy suppliers in the last two years. A number of multiple choice questions were asked to identify the reasons why participants did or did not switch (e.g. lack of time, satisfaction with current supplier) and identify facilitators and barriers to switching (e.g. ease or difficulty of finding information about switching). Questions and responses were amended from the Electricity Authority (2014a).

Active and non-active participation in the electricity market was identified based on the frequency of investigating which energy company has the best offer. Proactive participation was measured according to how participants' most recent switch occurred, for example, whether the participant approached an energy company themselves or were approached by an energy company, in the latter case switching is reactive. A second indicator of proactive behaviour asked whether participants would switch energy suppliers in the next year, even if energy prices were to remain the same. Participants were also asked to indicate the savings required to make switching worthwhile and whether these savings would be directed towards heating their home more. Relationship management is an important dimension of switching. Single-choice 
and multiple choice questions explored the extent to which deals or discounts were offered to participants and demonstrated an active strategy to retain consumers.

\subsubsection{Perceptions of expense and affordability}

Consumers are expected to behave in an economically rational manner and switch energy suppliers if energy expenditure is perceived to be expensive or unaffordable (Anderson, 2009). Participants were asked their opinion on how expensive or cheap electricity and gas heating are in general, and more specifically how expensive or cheap and affordable or unaffordable their most recent total energy bill was. Opinions were measured on a 5-point Likert scale, ranging from 1='very expensive' to $5=$ 'very cheap' and $1=$ 'very affordable' to $5=$ 'very unaffordable'. Participants were asked to rate their agreement with statements relating to their ability to heat their home and afford the energy bill. For example, 'we cannot afford to heat our home to a temperature we want'. Opinions were measured a 5-point Likert scale, ranging from 1='strongly agree' to $5=$ 'strongly disagree'. These questions were devised for this research.

Participants were also asked to estimate the cost of their most recent total energy bill on a linear incremental scale, provide information from their most recent energy bill on the cost and usage of electricity and gas, identify their current and previous energy companies, and their bill payment method.

\subsubsection{Experiences of the cold}

Experiences of thermal comfort (cold and warm temperatures) are subjective; people feel cold in different circumstances (Shove, 2003). Subjective fuel poverty was identified according to how often respondents had felt cold in their house during the winter. Physiological and atmospheric indicators, provide an indication of the indoor temperature of participants' homes during the winter. Shivering is a physiological response to cold temperatures at which the body attempts thermoregulation (Healy \& Clinch, 2002; Howden-Chapman, 2015), and seeing your breath inside ('dragon breath') is an atmospheric indicator of the temperature at which it is cold enough to condense 
exhaled water vapour (Cupples et al., 2007). Participants were asked how often they had shivered and how often they had seen their breath inside during the winter. These three indicators were measured on a frequency scale ranging from 1='never' to $4=$ 'always'. A multiple choice question also asked participants to identify any reasons for these experiences of the cold. These questions were adopted from O'Sullivan (2013).

\subsubsection{Coping strategies}

Other than switching, participants were asked to identify how affordable and adequate energy services are obtained. Multiple choice questions were asked on how participants keep their home warm and the cost of their energy bill low. Questions were adopted from O'Sullivan (2013), supported by evidence from Anderson et al. (2012) and Brunner, Spitzer, and Christanell (2012).

Self-imposed limitations on energy use, for reasons other than the cost of energy, were investigated through an open-ended question. The need for this question was apparent following the pilot survey. Pilot participants indicated the reasons why they used coping strategies to keep warm and the cost of the energy bill low were broader than the cost of energy. These reasons included, for example, environmental concerns or feeling a sense of guilt and/or burden to other household members when consuming energy in the home.

\subsubsection{Energy efficiency}

Fuel poverty is related to the energy efficiency of a dwelling. Participants were asked to rate the energy efficiency of their dwelling on a 5-point Likert scale, ranging from 1=very good to 5 =very poor. This section also asked participants to identify any existing measures of energy efficiency in their home and to indicate the sources of heating used in their home. 


\subsubsection{Socio-demographics}

Socio-demographic information was collected to profile fuel poor households and switching respondents. Questions were asked in a similar format to the New Zealand census to permit comparison to Wellington's population (Statistics New Zealand, 2013b). Socio-demographic information collected included sex, ethnicity, income, sources of household income, tenure and the number of household members under and over 18 years of age. Participants were given the option to identify with multiple ethnicities and asked to list sources of income for all household members. Participants were asked to provide the bill payers' total net income, and were given the option to identify their pay cycle and income over this period. Annual income was then calculated from the information provided by participants.

\subsubsection{Study sites and sample size}

To calculate the necessary sample size to allow generalisation of the results of the EPWHS to the general population, Dillman et al.'s (2003, p. 56) probability sampling formula was used. Based on this formula, a total of 279 responses were necessary. This calculation was based on a population of 71,871 total occupied dwellings in Wellington (Statistics New Zealand, 2013), a 95\% confidence interval, 5\% margin of error and a 0.24 probability of being fuel poor in Wellington (Howden-Chapman et al., 2012). To achieve this response, approximately 1000 surveys needed to be distributed. This figure is based on the average (initial) response rates to mail surveys conducted in New Zealand and overseas on similar topics to this research (Blackwell, 2009; Bond, 2013; Ek \& Söderholm, 2008; McDaniel \& Groothuis, 2012; O'Sullivan, 2013; Phillips, 2012; Yang, 2014). The average response rate was $28 \%$ and $25 \%$ for New Zealand studies only.

Surveys were distributed to meshblocks identified by the FPI calculated in phase one of this research. Surveys were delivered to households in meshblocks with a majority residential land use as determined by the researcher. To obtain a sample with a range of experiences, surveys were distributed to meshblocks across all deciles. However, fuel poor households are likely to have low incomes and low income households are less likely to respond to mail surveys (Gibson, Koepsell, Diehr, \& Hale, 1999). A nonresponse 
bias would occur if fuel poor households did not respond to this survey (Dillman et al., 2003). To ensure that fuel poor households responded, a greater number of surveys were distributed to meshblocks with high FPI decile scores.

In total, the survey was distributed to 974 households in 60 different meshblocks (Table 3.4), covering 32 area units (approximately equivalent to suburbs). Where fewer than 20 addresses in a meshblock were deliverable, the remainder were distributed in other meshblocks or an additional meshblock was targeted.

Table 3.4: Distribution of surveys by meshblock

\begin{tabular}{ccc}
\hline FPI decile & $\begin{array}{c}\text { Number of } \\
\text { meshblocks }\end{array}$ & $\begin{array}{c}\text { Number of } \\
\text { households }\end{array}$ \\
\hline 1 & 9 & 140 \\
2 & 7 & 109 \\
3 & 6 & 101 \\
4 & 6 & 98 \\
5 & 6 & 100 \\
6 & 5 & 100 \\
7 & 6 & 93 \\
8 & 7 & 107 \\
9 & 4 & 65 \\
10 & 4 & 61 \\
\hline Total & 60 & 974 \\
\hline
\end{tabular}

\subsubsection{Data handling}

Raw survey data was entered into IBM SPSS Statistics (v.22). Online surveys were downloaded directly from Qualtrics. The accuracy of data entry was cross-checked from a random sample of $10 \%$ of returned surveys. Six responses were entered incorrectly. Errors of the same type were cross-checked across the entire sample. In total, 13 corrections were made, resulting that $0.059 \%$ of data was entered incorrectly. Some 
respondents mistakenly turned two pages at once resulting in missing data; their responses were retained.

\section{Summary}

This research was conducted in two sequential phases which allowed the second method to build on the results of the first. Phase one of this research involved the calculation of the FPI, a spatial indicator of fuel poverty. The FPI calculated in this thesis offers a new approach to identifying fuel poverty in New Zealand. Based on existing spatial models of fuel poverty, the FPI identifies the spatial distribution of fuel poverty in Wellington at meshblock level.

The hazards-of-place model was suitable for informing the FPI as the three dimensions of the model correspond to the three factors influencing fuel poverty: income, housing quality and energy demand. Data for median household income and sources of household income from the 2013 New Zealand census was used as an indicator social vulnerability to fuel poverty. In the absence of housing energy efficiency data proxies for housing quality were used including capital value, age, building footprint and HQI. Solar radiation is a reliable and appropriate indicator of energy demand. Finally, these factors were weighted and divided into deciles to represent fuel poverty in Wellington.

The second phase of this research used the FPI to identify survey participants through which a mail survey, the EPWHS, was conducted exploring Wellington households' switching behaviours. In order to maximise the effectiveness of the EPWHS, aspects of the TDM were applied in the design and implementation of this survey. Within the EPWHS, 6 themes were explored relating to households switching behaviours and dimensions of fuel poverty. The results of these methods and their integration are explored in the following chapters. 


\section{4}

\section{Chapter Four: Phase One Results}

Phase one of this research applied a new approach to identifying fuel poverty. The spatial distribution of fuel poverty in Wellington was identified using GIS methods based on the FPI indicator calculated in this thesis. In this chapter, a spatial analysis of the FPI is undertaken. Some initial results of the spatial patterns of fuel poverty are provided, before exploring in greater detail the spatial distribution of factors that contribute to the manifestation of fuel poverty in particular areas. The relationships between factors contributing to the FPI are investigated and the potential for their effects to compound and exacerbate the conditions contributing to fuel poverty are explored. Areas identified as fuel poor, and conversely non-fuel poor, are investigated and a socio-spatial profile of fuel poverty in Wellington is established.

For the statistical tests reported in this chapter, exact values of statistical significance are provided at the 0.05 and 0.01 level only. Statistical significance at the 0.001 or lower level is reported as $p<0.001$. In tables, asterisks are used to indicate statistical significance at the 0.05 level $(*)$, at the 0.01 level $\left({ }^{* *}\right)$ and at the 0.001 or lower level $(* * *)$.

\subsection{Spatial distribution of fuel poverty}

The spatial distribution of fuel poverty at meshblock level in Wellington is reflected in Figure 4.1. This figure indicates that fuel poverty is not uniformly distributed in 
Wellington. Spatial autocorrelation (Moran's I) was calculated for FPI deciles based on the contiguity of meshblocks at edges and corners. The FPI produced a Moran's I value of $0.38(Z=29.71, p<0.001)$ indicating a significant moderate pattern of spatial clustering. This finding suggests that adjoining meshblocks are more likely to have similar values and there is a less than $0.1 \%$ chance that the spatial clustering of fuel poverty in Wellington is random.

From Figure 4.1, it is unclear which factors included in the FPI exert the greatest influence on the spatial distribution of fuel poverty. The spatial distribution of income, housing quality and solar radiation was calculated to identify any compounding or divergent influences on the spatial distribution of fuel poverty (Table 4.1). Each factor's standardised values were multiplied by their proportional weightings within the FPI to a sum of $100 \%$. These values were then divided into deciles to represent the spatial distribution of solar radiation, income and housing quality (respectively Figures 4.2-4.4). The decile figures calculated for the spatial distribution of each factor were used to calculate Moran's I.

There is a degree of spatial dependency across all factors; solar radiation $(I=0.46, Z=36.2$ $p<0.001)$, income $(I=0.19, Z=14.9, p<0.001)$ and housing quality $(I=0.47, Z=37.5$, $\mathrm{p}<0.001)$. There is a less than $0.1 \%$ chance that the spatial distribution of solar radiation, income and housing quality and in Wellington is random.

Table 4.1: Spatial autocorrelation (Moran's I) of FPI and contributing factors

\begin{tabular}{ccccc}
\hline Variable & Moran's $I$ & $(E(I))$ & Z-Score & $p$-Value \\
\hline Fuel poverty index & 0.38 & -0.000159 & 29.71 & $0.000^{* * *}$ \\
Solar radiation & 0.46 & -0.000495 & 36.16 & $0.000^{* * *}$ \\
Income & 0.19 & -0.000495 & 14.90 & $0.000^{* * *}$ \\
Housing quality & 0.47 & -0.000495 & 37.48 & $0.000^{* * *}$
\end{tabular}

* Significant at the 0.05 level

** Significant at the 0.01 level

$* * *$ Significant at the 0.001 level 


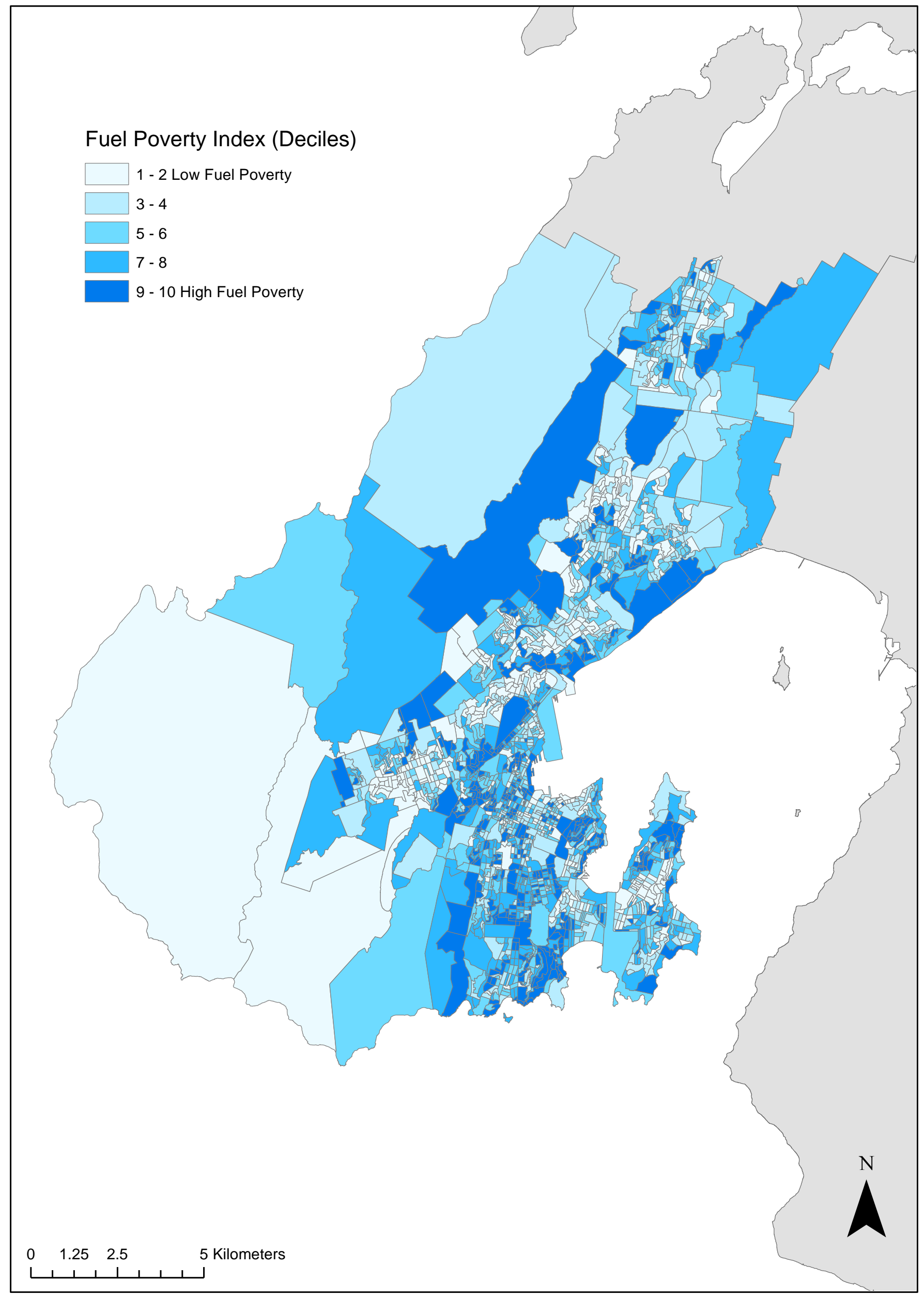




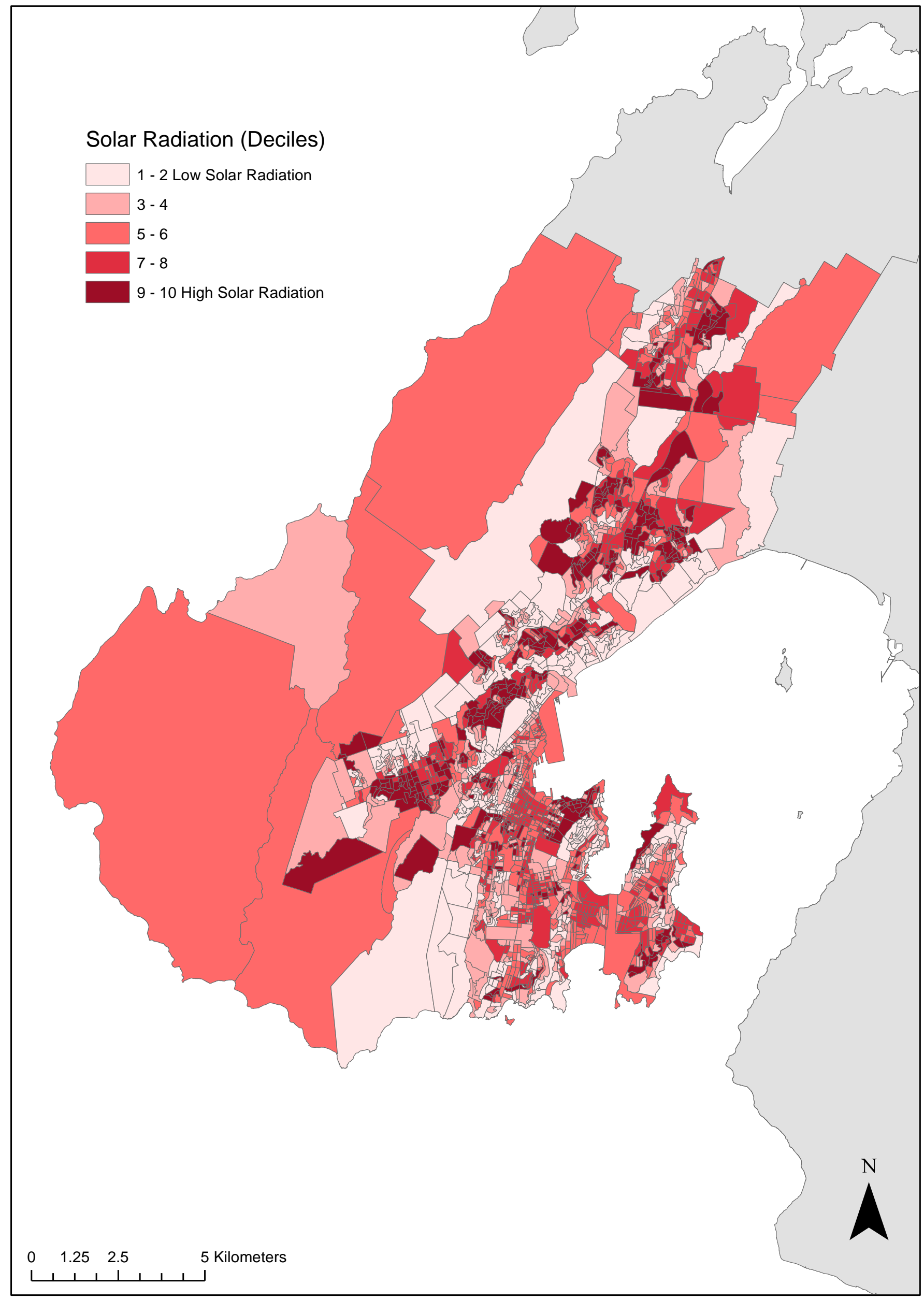


The spatial clustering of income and housing quality may be affected by the variables that contribute to these factors. Income and housing quality were disaggregated and Moran's I calculated for the contributing variables, Table 4.2 and Table 4.3 respectively. Moran's I statistics indicate weak spatial clustering of median household income $(I=0.23$, $Z=18, p<0.001)$ and social welfare income $(I=0.10, Z=8.2, p<0.001)$ (Table 4.2). In both cases, low spatial autocorrelations are counter to expectations. It was expected that meshblocks with high median household incomes would cluster with meshblocks of similar median household incomes. The same relationship would be expected for low median household incomes.

Table 4.2: Spatial autocorrelation (Moran's I) of income variables

\begin{tabular}{ccccc}
\hline Variable & Moran's I & $(E(I))$ & Z-Score & $p$-Value \\
\hline Median household income & 0.23 & -0.000495 & 17.96 & $0.000^{* * *}$ \\
Sources of household income & 0.10 & -0.000495 & 8.23 & $0.000^{* * *}$ \\
\hline
\end{tabular}


Figure 4.3: Spatial distribution of income by meshblock in Wellington

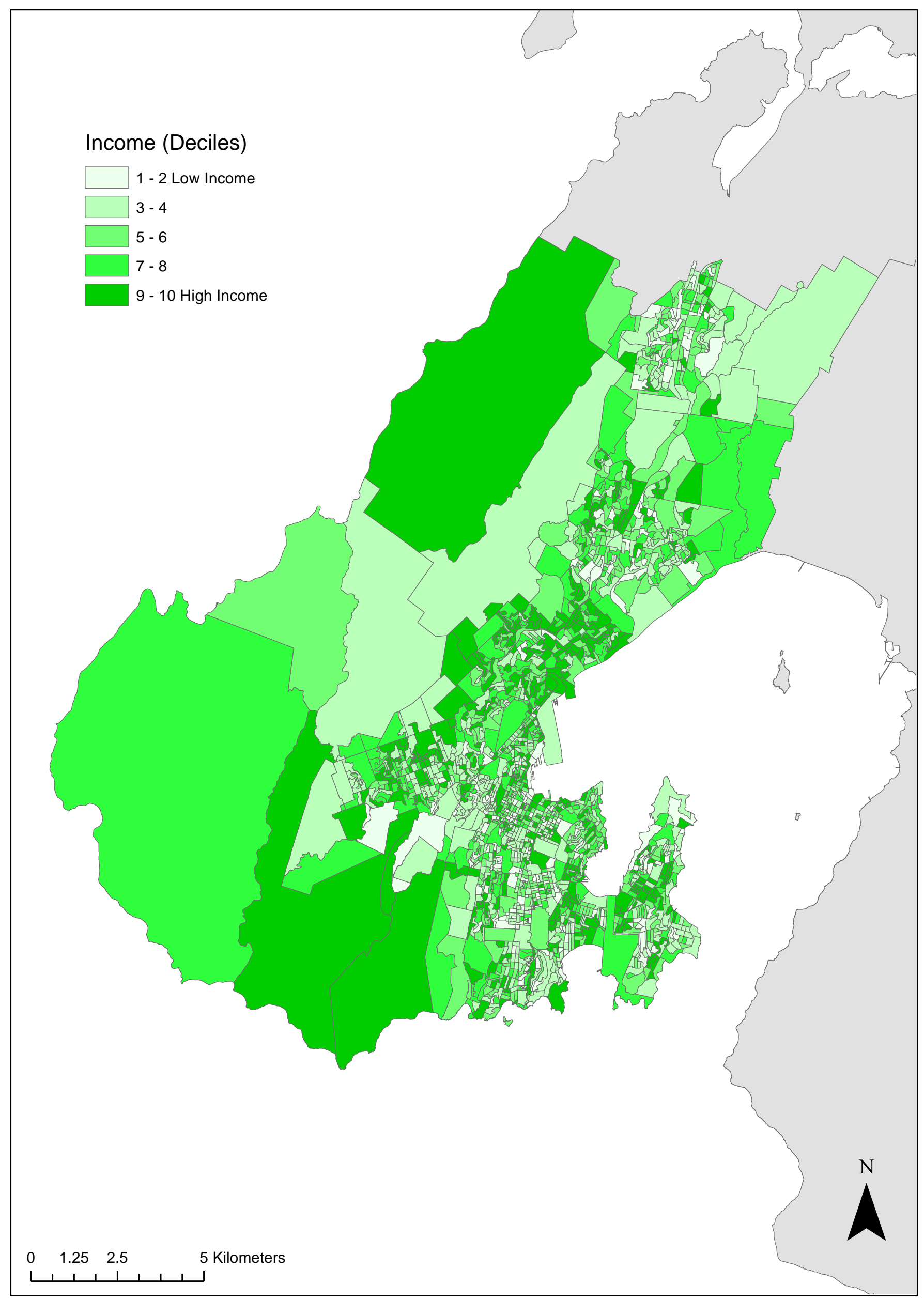


The Moran's I results for housing quality variables indicate capital value exhibits the greatest degree of spatial clustering at meshblock level $(I=0.45, Z=35.4, p<0.001)$. The age of housing also exhibits a moderate degree of spatial dependency $(I=0.42, Z=33.1, p<0.001)$. Building footprints exhibit a low degree of spatial dependency $(I=0.23, Z=18.22, p<0.001)$, while the $\mathrm{HQI}$ had the lowest degree of spatial clustering $(I=0.19, Z=2.87, p=0.004)$.

Table 4.3: Spatial autocorrelation (Moran's I) of housing quality variables

\begin{tabular}{ccccc}
\hline Variable & Moran's I & $(E(I))$ & Z-Score & $p$-Value \\
\hline Building footprint & 0.23 & -0.000495 & 18.22 & $0.000^{* * *}$ \\
HQI $^{10}$ & 0.19 & -0.000495 & 2.87 & $0.004^{* *}$ \\
Capital value & 0.45 & -0.000495 & 35.36 & $0.000^{* * *}$ \\
Age & 0.42 & -0.000495 & 33.06 & $0.000^{* * *}$ \\
\hline
\end{tabular}

\footnotetext{
* Significant at the 0.05 level

** Significant at the 0.01 level

*** Significant at the 0.001 level
}

The Moran's I results indicate fuel poverty, as well as all three factors that constitute the FPI, are spatially clustered. This outcome indicates that fuel poverty, and factors contributing to fuel poverty, concentrate in particular areas. Although, no indication is provided as to whether these factors coincide in the same areas.

The spatial distribution of fuel poverty at a national scale is likely to be more complex. For example, electricity prices vary across New Zealand. Electricity prices in neighbouring electricity network areas are significantly dissimilar (Moran's I=-0.29, Z=-2.01, p=0.04), and no significant correlation exists between latitude and electricity prices ( $r=0.148, p=0.434)$.

\footnotetext{
${ }^{10} \mathrm{As} \mathrm{HQI}$ is calculated at area unit level, spatial autocorrelation was calculated at this level.
} 
Figure 4.4: Spatial distribution of housing quality by meshblock in Wellington

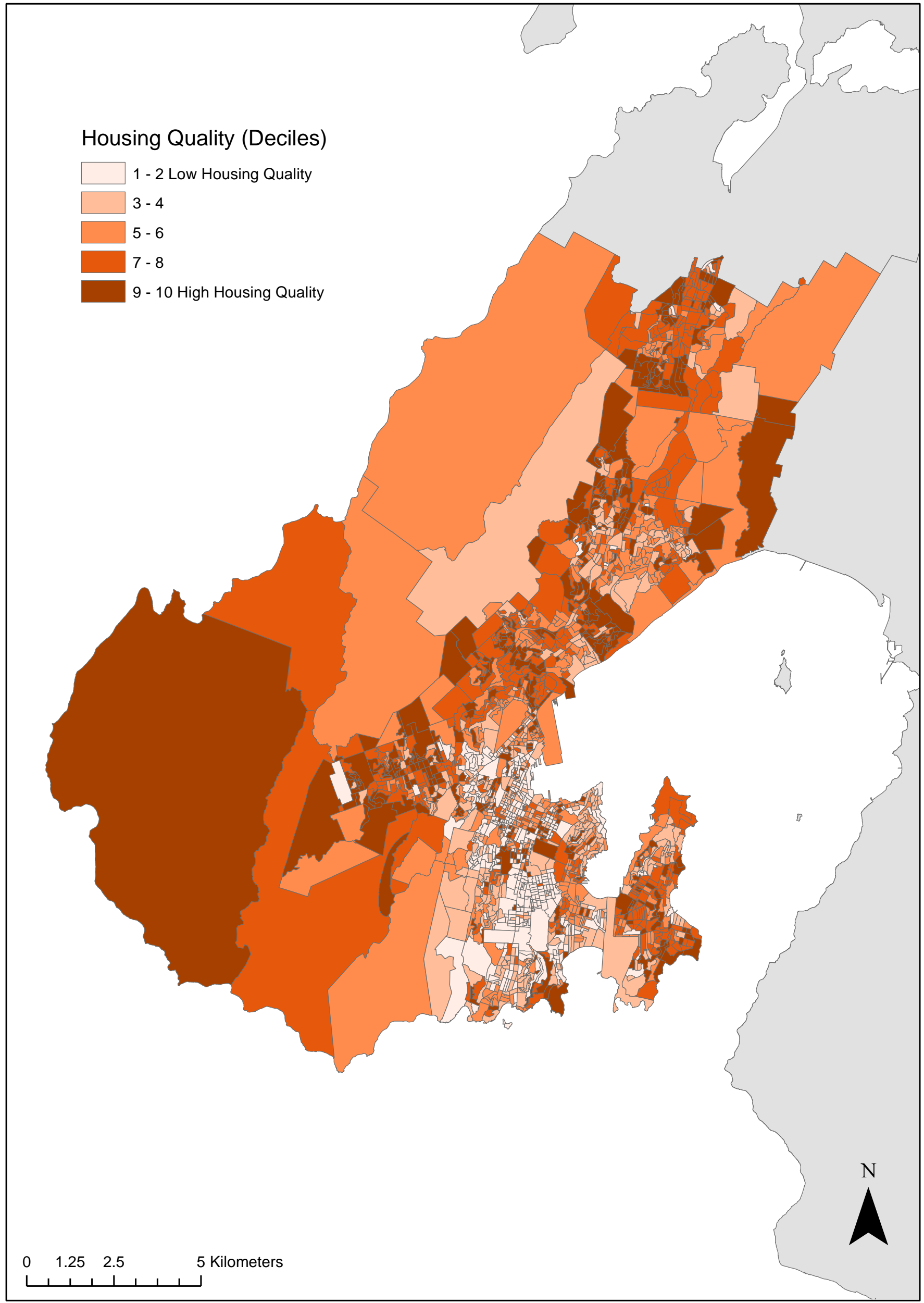




\subsection{Local spatial autocorrelation}

Local spatial autocorrelation (Getis-Ord Gi) was calculated to determine where statistically significant pockets of spatially similar attributes are located. For these calculations the FPI was inverted so that coldspots would represent clusters of fuel poverty. Conversely, non-fuel poor meshblocks would be represented by hotspots. Selected hotspots and coldspots identified from the local spatial autocorrelation calculations were profiled to explore the socio-demographic composition of fuel poor and non-fuel poor areas (see Section 4.5).

Figure 4.5 demonstrates fuel poverty coldspots and hotspots in Wellington. Interpretation of coldspots/hotspots is conducted at the area-unit level, one level higher than the minimum spatial classification used in the New Zealand census. Coldspots, areas of fuel poverty, are observed in:

- Miramar, Haitaitai, Northland, Island Bay, Berhampore, Melrose-Houghton Bay, Mitchelltown, Kelburn and Te Kainga.

Hotspots, areas of low fuel poverty, are observed in:

- Karori, Miramar, Oriental Bay, Wadestown, Wilton, Churton Park, Tawa, Rangoon Heights and Ngaio.

Spatial outliers in the distribution of fuel poverty were identified by calculating Anselin Local Moran's I. Few spatial outliers were identified in the distribution of the FPI. In total, 27 out of 2023 meshblocks (1.3\%) were outliers and few were contiguous with other outlying meshblocks. Similarly, few meshblocks were identified as outliers and were contiguous with other outlying meshblocks for income $(n=48,2.4 \%)$, housing quality $(n=39,1.9 \%)$ and solar radiation $(n=26,1.3 \%)$. 
FPI Hotspots and Coldspots

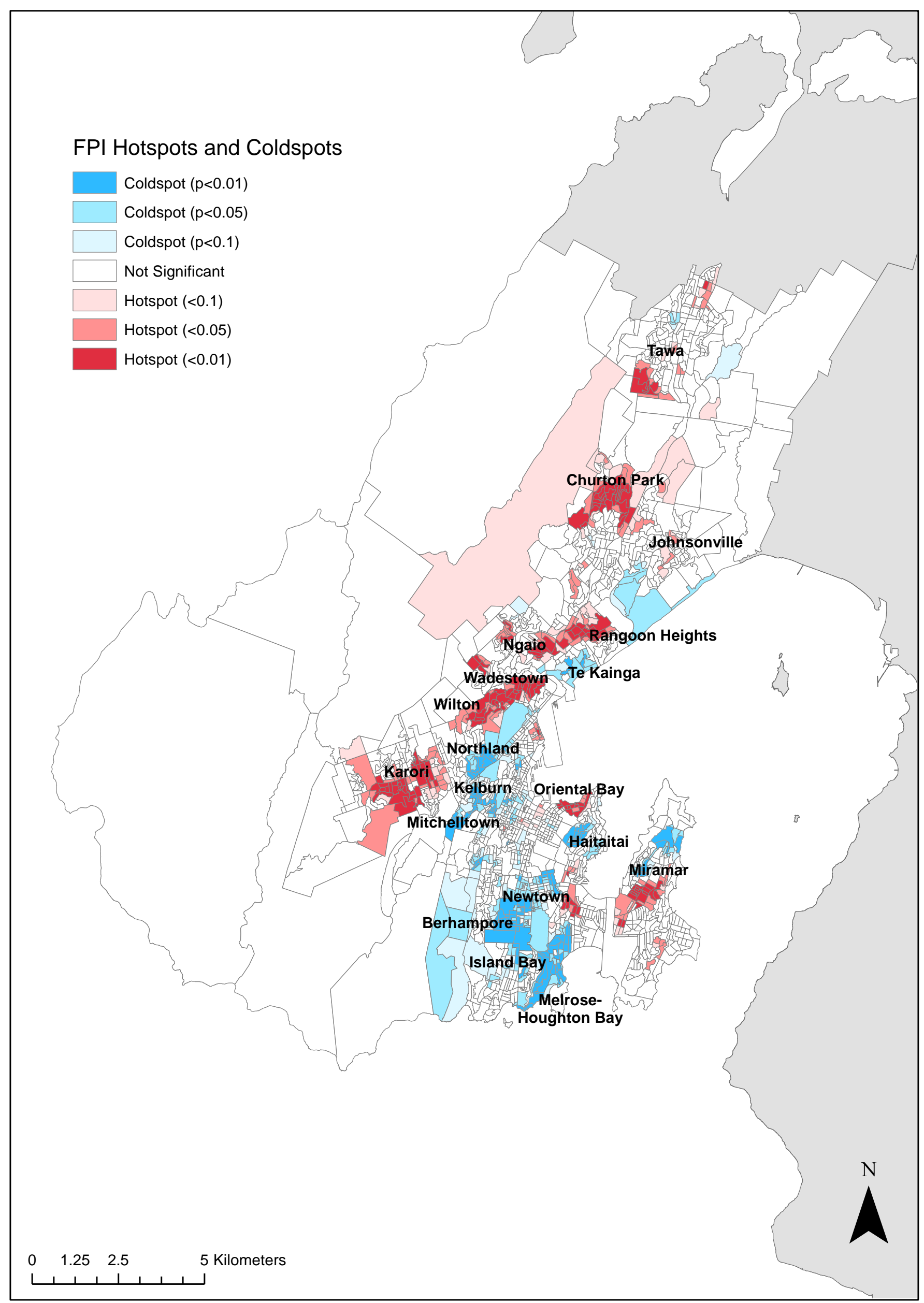


Spatial patterns in the distribution of individual variables included in the FPI and relationships between these distributions may be obscured by the local spatial autocorrelation calculated in Figure 4.5. Local spatial autocorrelation was calculated for each factor and variable included in the FPI. The hotspot/coldspot maps of these calculations are presented in Appendix D.

The results of these analyses identify areas where variables included in the FPI spatially cluster, and that the spatial clustering of variables do not necessarily coincide. For example, some clusters of low income are only explained by low median household income or high numbers of social welfare benefits. In other cases, both low median household income and greater reliance on social welfare contribute to the presence of fuel poverty in meshblocks.

These results also indicate that spatial clustering of variables follow geographic patterns. Low housing quality is located in historic residential suburbs of Wellington and high housing quality is prominent in the outer residential suburbs. This clustering is evidenced by the concentration of smaller and older properties that also have low HQI scores in these areas. Conversely, these areas are also likely to have a relatively high capital value. Properties with a high capital value are located near the CBD or institutional buildings are present within these meshblocks, for example Victoria University of Wellington located in Kelburn. For solar radiation, areas with predominantly east facing slopes received significantly less solar radiation than west facing slopes.

\subsection{Correlation of FPI factors}

Measures of spatial autocorrelation and local spatial autocorrelation assess if attributes cluster. However, beyond this assessment no indication of the relationships between variables is provided. To test the relationships between factors included in the $\mathrm{FPI}$, correlations were calculated based on factor deciles (Table 4.4). Housing quality and income are significantly but weakly correlated $(r=0.181, p<0.001)$. No significant correlations were identified between solar radiation and income or housing quality. 
Table 4.4: Correlations of FPI factors

\begin{tabular}{lcc}
\hline & Solar radiation & Housing quality \\
\hline Housing quality & .016 & \\
Income & -.016 & $.181^{* * *}$ \\
\hline * Significant at the 0.05 level & \\
** Significant at the 0.01 level \\
*** Significant at the 0.001 level
\end{tabular}

Based on the variables that contribute to income and housing quality, many factors may be influencing the correlation between these factors. The disaggregated variables contributing to housing quality and income were tested for correlations (see Table 4.5).

There is a weak correlation between median household income and sources of household income $(r=0.14, p<0.001)$, indicating that as median household income increases the number of households not receiving social welfare benefits increases. This relationship is expected. Median household income $(r=0.31, p<0.001)$ and sources of household income $(r=0.14$, $\mathrm{p}<0.001)$ are both correlated to HQI. This indicates that meshblocks with higher median household incomes and fewer social welfare recipients, on average, live in higher quality housing. This evidence supports the assumption that higher income allows investment in higher quality housing.

The average age of properties in a meshblock is negatively correlated to median household income $(r=-0.12, p<0.001)$. Households with higher incomes are located in meshblocks with, on average, older properties and reflects ongoing urban geographic processes of residential sorting in Wellington (Morrison, 2000). This result suggests that high income households live in housing where they pay a premium for location and proximity to the $\mathrm{CBD}$, which are older and were constructed during Wellington's colonial settler period. Housing age and capital value are negatively correlated $(r=-0.04, p=0.047)$ indicating that meshblocks with older housing have higher capital value. A negative correlation between housing age and average building footprint resulted $(r=-0.37, p<0.001)$. This relationship may demonstrate the colonial characteristics of older housing that are smaller and multi-storied; calculations of the building footprint do not account for multiple stories. Age is also positively correlated to $\mathrm{HQI}$, indicating newer housing is of higher quality $(r=0.06, p=0.004)$. The average age of housing in 
a meshblock is a key determinant of the building footprint, $\mathrm{HQI}$ and capital value of housing as well as median household income and sources of household income.

Interestingly, solar radiation was negatively correlated to capital value $(r=-0.69, p=0.002)$. This result indicates that as average capital value increases, average received solar radiation decreases. This is a counter-intuitive relationship as areas of high solar radiation are assumed to be desirable and have higher capital value. Building elevation may be a factor influencing this relationship. No other correlations to solar radiation were significant.

Table 4.5: Correlations of FPI variables

\begin{tabular}{ccccccc}
\hline & Solar radiation & $\begin{array}{c}\text { Median } \mathrm{HH} \\
\text { income }\end{array}$ & $\begin{array}{c}\text { Sources of HH } \\
\text { income }\end{array}$ & $\begin{array}{c}\text { Building } \\
\text { footprint }\end{array}$ & HQI & Capital value \\
\hline Median HH income & -.010 & & & & \\
Sources HH income & .007 & $.144^{* * *}$ & & & \\
Building footprint & -.003 & -.034 & -.002 & & \\
HQI & .041 & $.308^{* * *}$ & $.141^{* * *}$ & $-.098^{* * *}$ & \\
Capital value & $-.069^{* *}$ & -.003 & .038 & $-.454^{* * *}$ & .018 & \\
Age & -.006 & $-.116^{* * *}$ & $.084^{* * *}$ & $-.370^{* * *}$ & $.064^{* *}$ & $-.044^{*}$ \\
\hline
\end{tabular}

* Significant at the 0.05 level

** Significant at the 0.01 level

*** Significant at the 0.001 level

\subsection{Grouping Analysis of FPI factors}

Pearson's correlation provides an understanding of the relationships between two variables. Grouping Analysis was used to identify the spatial relationship between multiple variables with similar values in the FPI (see section 3.6.2). Based on the pseudo F-statistic, two clusters $(F=169.98)$ were identified as the optimal number of clusters to compare. While providing the optimal number of clusters, two clusters were not ideal for comparison based on the evidenced variability in the spatial distribution of income, housing quality and solar radiation in Wellington. 
As an alternative method to identify the number of clusters to compare, the results of Grouping Analysis calculated for 3 to 15 clusters were compared. The output for 10 clusters $(F=52.3)$ was chosen for further analysis based on the well-rounded profiles of the clusters identified. For example, a cluster with mean values for income, housing quality and solar radiation similar to the global median and representative of Wellington was identified. Other clusters had varied means across these factors or means that were consistently above and below the global median. Calculating Grouping Analysis for more than 10 clusters did not significantly improve the spatial differentiation of clusters and calculations for fewer than 10 clusters showed significant variation in the locations of clusters identified. Figure 4.6 identifies the distribution of the 10 clusters. Housing quality $\left(R^{2}=0.35\right)$ was the strongest explanatory variable influencing the division of meshblocks into 10 clusters, compared to solar radiation $\left(R^{2}=0.19\right)$ and income $\left(R^{2}=0.17\right)$. 
Figure 4.6: Grouping Analysis of fuel poverty factors by meshblock in Wellington

Grouping Analysis Clusters

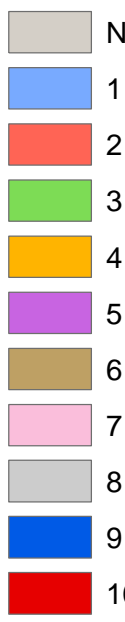

Non-contiguous Meshblock

\section{.}

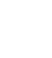

.

.

.

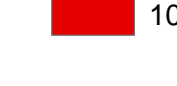

$\begin{array}{lll}0 & 1.25 & 2.5\end{array}$ 
Four clusters were identified for a more detailed exploration of the relationship between multiple fuel poverty variables to illustrate their effect on the spatial distribution of the FPI. Clusters 1, 3, 4 and 9 (see Figure 4.6) were identified to explore these relationships and effects in greater detail based on the 'description' of mean decile values within each cluster compared to the global median, depicted in Figure 4.7.

Cluster 9 has mean decile values similar to the global median for Wellington; housing quality $(M=4.5)$, solar radiation $(M=5.3)$, and income $(M=5.5)$. This cluster is representative of Wellington and is an area where fuel poverty, based on mean values, is unlikely to occur. In contrast, Cluster 3 and Cluster 4 respectively represent groups where decile values, across all three factors, are consistently below and consistently above the global median. Cluster 3 represents an area that is likely to be fuel poor based on the clustering of, on average, low housing quality $(M=2.6)$, solar radiation $(M=4.1)$ and income $(M=3.8)$. Whereas, Cluster 4 is an area less likely to be fuel poor with, on average, high housing quality $(M=6.7)$, solar radiation $(M=9.1)$ and income $(M=6.3)$.

Cluster 1 is an area of interest as mean decile values for income, housing quality and solar radiation greatly vary. On average, Cluster 1 is an area of high housing quality $(M=8.3)$, low solar radiation $(\mathrm{M}=3.6)$ and income similar to the global median $(\mathrm{M}=6.2)$. Low solar radiation contributes to fuel poverty in this area by increasing energy demand. Although, the average housing quality is high and average income, similar to the median for Wellington, may offset higher energy demand in this area and influence the spatial manifestation of fuel poverty in this area.

Results of the Grouping Analysis demonstrate that the spatial relationship of multiple factors contributing to fuel poverty varies. The presence of one or two factors conducive to fuel poverty in an area does not necessarily suggest the presence of a third factor. Cluster 1 demonstrates this variation; the presence of low solar radiation is not compounded by the presence of low housing quality and low income. Although in some clusters, for example Cluster 3, all three factors contributing to the FPI are on average low and contributes to the manifestation of fuel poverty in this area. There are also significant differences in decile values for each factor within the clusters identified. Within each cluster, decile values for income, housing quality and solar radiation ranged from a minimum of 1 to a maximum of 10 . 


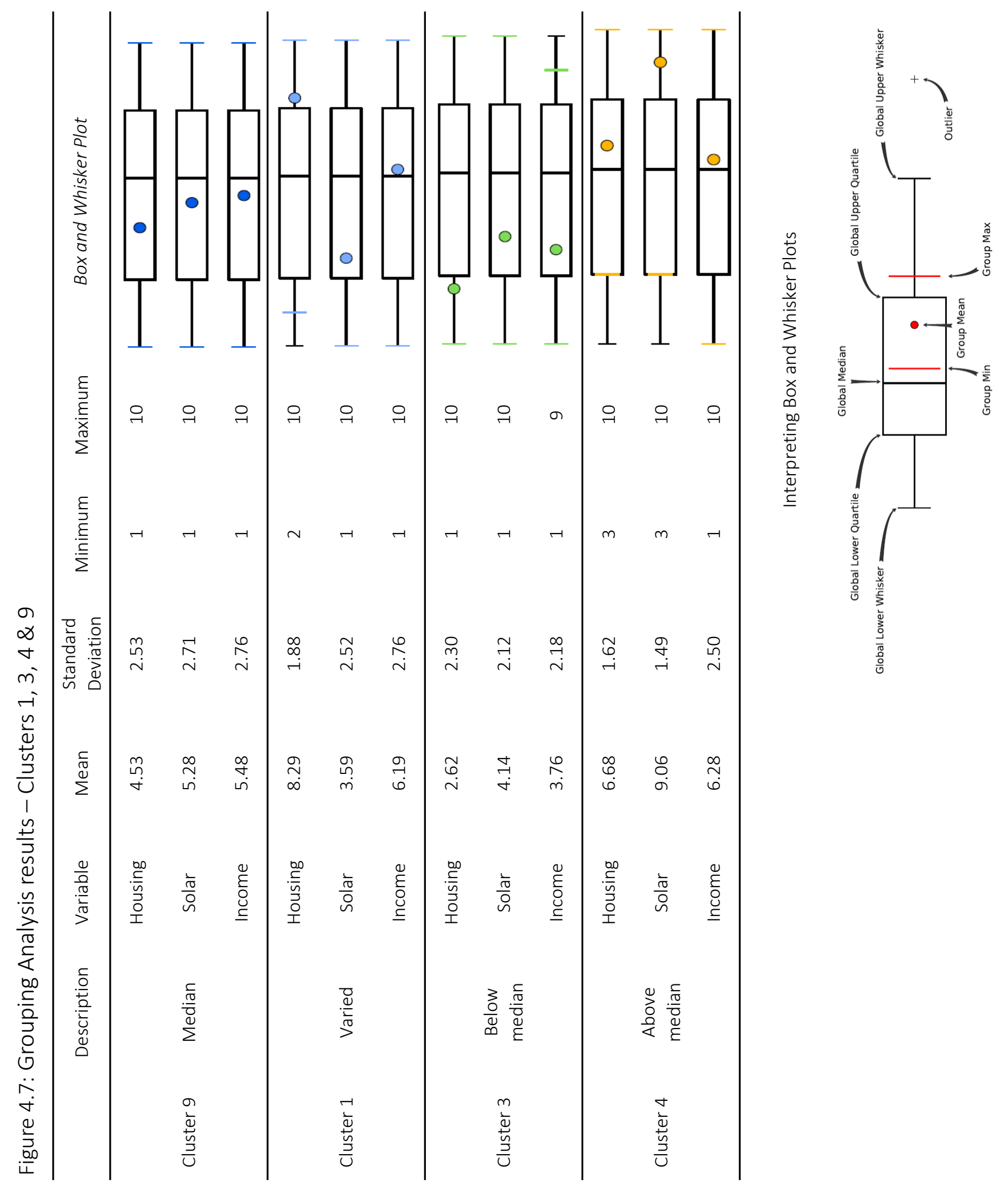




\subsection{Fuel poverty profiles}

This section explores the socio-demographic profiles of selected hotspots and coldspots of FPI deciles (Figure 4.8). Significant differences in proportions were calculated to identify whether particular socio-demographic groups are more exposed to fuel poverty in coldspots compared to hotspots. All coldspots and hotspots were selected for comparison based on their proximity, with the exception of Island Bay and Karori South. Tables 4.7 to 4.13 present the Z-score results of these calculations, where the higher/lower the positive/negative value, the greater the concentration/deficit of the variable measured in that coldspot is compared to the hotspot. Fuel poverty profiles were established based on ethnicity, age group, family type and partnership, number of usual residents, tenure and duration of tenure, and sources of heating. 


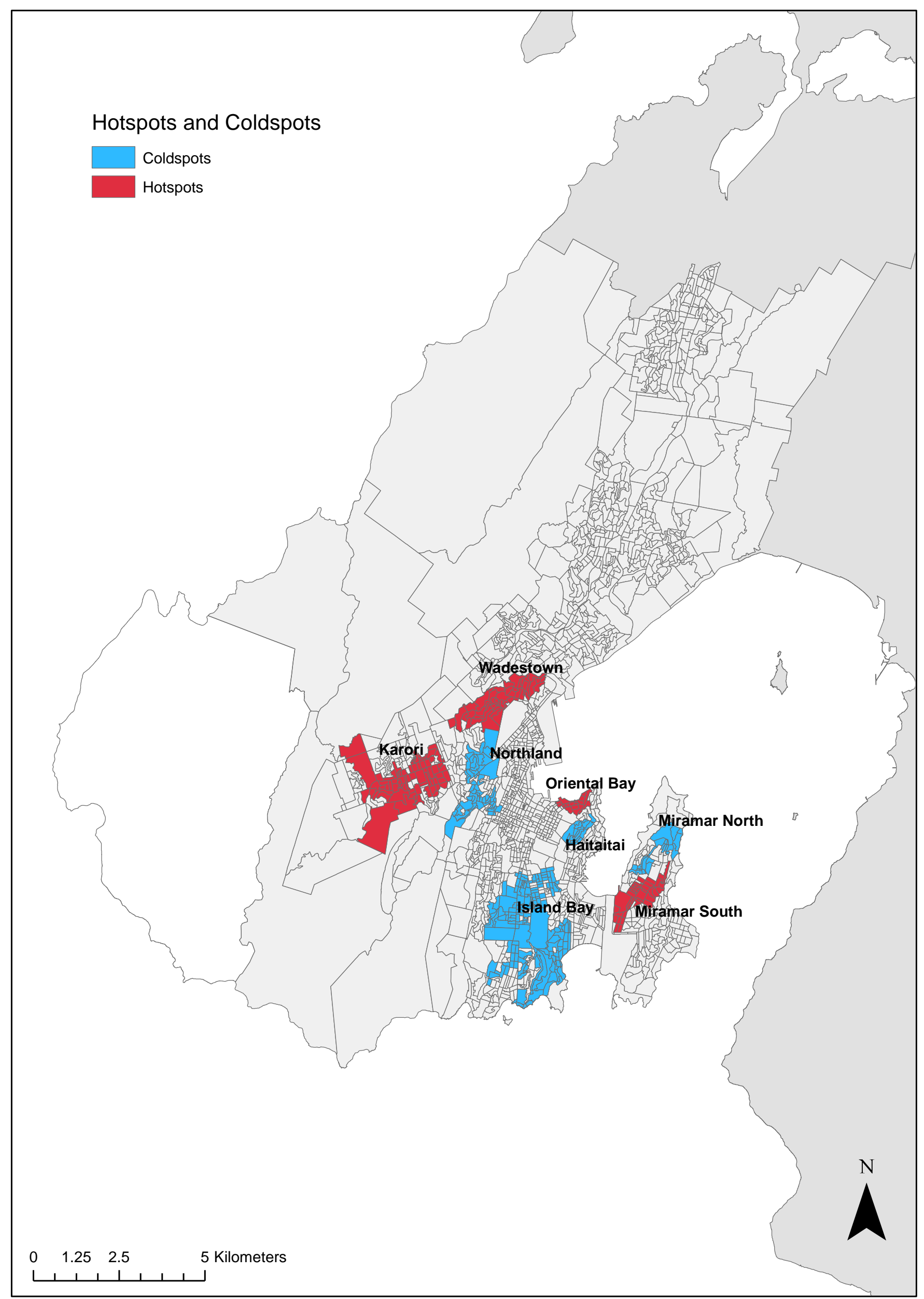




\subsubsection{Ethnicity}

Māori ( $Z=9.92, p<0.001)$, Pacific Peoples $(Z=12.68, p<0.001)$ and Middle Eastern, Latin American and African (MELAA) $(Z=15.39, p<0.001)$ ethnicities are over-represented in fuel poverty coldspots, including Miramar North, Haitaitai and Island Bay (Table 4.6). Significantly fewer New Zealand European/Pākehā/New Zealander $(Z=-5.27, p<0.001)$ and Asian $(Z=-9.79, p<0.001)$ households live in coldspots. These results indicate that Māori, Pacific Peoples and MELAA ethnicities consistently reside in fuel poverty coldspots, whereas New Zealand European and Asian ethnicities are more likely to live in hotspots.

Table 4.6: Significant differences of proportions in ethnic groups between hotspots/ coldspots

\begin{tabular}{lcccccc}
\hline \multicolumn{1}{c}{ Ethnicity } & & Coldspots & $\begin{array}{c}\text { Miramar } \\
\text { North }\end{array}$ & Haitaitai & Northland & Island Bay \\
\hline New Zealand & Z-Score & -5.27 & -4.38 & -0.50 & -1.79 & -13.10 \\
European & $\mathrm{p}$-Value & $<0.001^{* * *}$ & $<0.001^{* * *}$ & 0.309 & $0.037^{*}$ & $<0.001^{* * *}$ \\
\hline \multirow{2}{*}{ Maori } & Z-Score & 9.92 & 2.46 & 2.51 & -1.37 & 11.78 \\
& p-Value & $<0.001^{* * *}$ & $0.007^{* *}$ & $0.006^{* *}$ & 0.086 & $<0.001^{* * *}$ \\
\hline \multirow{2}{*}{ Pacific Peoples } & Z-Score & 12.68 & -0.08 & 0.80 & -2.69 & 15.31 \\
& p-Value & $<0.001^{* * *}$ & 0.468 & 0.213 & $0.004^{* *}$ & $<0.001^{* * *}$ \\
\hline \multirow{2}{*}{ Asian } & Z-Score & -9.79 & -8.57 & -1.05 & 2.62 & -4.04 \\
& p-Value & $<0.001^{* * *}$ & $<0.001^{* * *}$ & 0.148 & $0.004^{* *}$ & $<0.001^{* * *}$ \\
\hline \multirow{2}{*}{ MELAA } & Z-Score & 15.39 & 8.79 & 1.19 & 0.34 & 12.56 \\
& p-Value & $<0.001^{* * *}$ & $<0.001^{* * *}$ & 0.116 & 0.368 & $<0.001^{* * *}$ \\
\hline \multirow{2}{*}{ Other } & Z-Score & -0.87 & -0.24 & -0.50 & 0.99 & -3.58 \\
& p-Value & 0.192 & 0.405 & 0.307 & 0.160 & $<0.001^{* * *}$ \\
\hline
\end{tabular}

* Significant at the 0.05 level

** Significant at the 0.01 level

*** Significant at the 0.001 level 


\subsubsection{Age group}

Fewer people aged under 15 years $(Z=-19.2, p<0.001)$ and older than 65 years $(Z=-21.1$, $p<0.001)$, and more people aged between 15 and 64 years $(Z=26.2, p<0.001)$ live in coldspots compared to hotspots (Table 4.7). This pattern is also largely consistent for Haitaitai, Northland and Island Bay. That fewer people under 15 years and over 65 years of age live in coldspots is counter to expectations. It was expected that households vulnerable to fuel poverty, characterised by the presence of children or older people, are more exposed to fuel poverty and would live in coldspots.

Table 4.7: Significant differences of proportions in age groups between hotspots/ coldspots

\begin{tabular}{lcccccc}
\hline \multicolumn{1}{c}{ Age group } & & Coldspots & $\begin{array}{c}\text { Miramar } \\
\text { North }\end{array}$ & Haitaitai & Northland & Island Bay \\
\hline $\begin{array}{l}\text { Under 15 } \\
\text { years }\end{array}$ & Z-Score & -19.19 & 1.01 & 6.19 & -12.59 & -6.92 \\
\hline p-Value & $<0.001^{* * *}$ & 0.157 & $<0.001^{* * *}$ & $<0.001^{* * *}$ & $<0.001^{* * *}$ \\
\hline Z-Score & 26.19 & -1.41 & 6.09 & 17.96 & 13.89 \\
\hline $\begin{array}{l}\text { 65 years } \\
\text { and over }\end{array}$ & Z-Value & $<0.001^{* * *}$ & 0.079 & $<0.001^{* * *}$ & $<0.001^{* * *}$ & $<0.001^{* * *}$ \\
\hline
\end{tabular}

* Significant at the 0.05 level

** Significant at the 0.01 level

*** Significant at the 0.001 level

\subsubsection{Family type and partnership}

Table 4.8 indicates that couples without children $(Z=10.4, p<0.001)$ and one parent families with children $(Z=3.64, p<0.001)$ are more likely to live in coldspots than couples with children $(Z=-12.8, p<0.001)$ (Table 4.9). More couples with children live in Haitaitai $(Z=6.41, p<0.001)$ and Northland $(Z=3.57, p<0.001)$ and fewer in Island Bay $(Z=-8.29$, $p<0.001)$ compared to their respective hotspots. These results demonstrate fewer children may live in fuel poverty than expected, however one parent families may be more vulnerable to fuel poverty. 
Table 4.8: Significant differences of proportions in family type between hotspots/ coldspots

\begin{tabular}{|c|c|c|c|c|c|c|}
\hline Family Type & & Coldspots & $\begin{array}{c}\text { Miramar } \\
\text { North }\end{array}$ & Haitaitai & Northland & Island Bay \\
\hline \multirow{2}{*}{$\begin{array}{l}\text { Couple with } \\
\text { children }\end{array}$} & Z-Score & -12.78 & 0.60 & 6.41 & 3.59 & -8.29 \\
\hline & $p$-Value & $<0.001^{* * *}$ & 0.550 & $<0.001^{* * *}$ & $<0.001^{* * *}$ & $<0.001 * * *$ \\
\hline \multirow{2}{*}{$\begin{array}{l}\text { Couple } \\
\text { without } \\
\text { children }\end{array}$} & Z-Score & 10.38 & -0.79 & -7.58 & -4.51 & 3.68 \\
\hline & $p$-Value & $<0.001^{* * *}$ & 0.431 & $<0.001^{* * *}$ & $<0.001^{* * *}$ & $<0.001^{* * *}$ \\
\hline \multirow{2}{*}{$\begin{array}{l}\text { One parent } \\
\text { with } \\
\text { children }\end{array}$} & Z-Score & 3.64 & 0.19 & 2.78 & 1.95 & 6.56 \\
\hline & $p$-Value & $<0.001^{* * *}$ & 0.846 & $0.003^{* *}$ & $0.026 *$ & $<0.001^{* * *}$ \\
\hline
\end{tabular}

The proportion of couples without children in coldspots may be related to partnership. Fewer married couples live in coldspots $(Z=-44.96, p<0.001)$; also demonstrated in Haitaitai, Northland and Island Bay (Table 4.9). This evidence indicates that married couples are less likely to live in fuel poor coldspots.

Table 4.9: Significant differences of proportions in partnerships between hotspots/ coldspots

\begin{tabular}{|c|c|c|c|c|c|c|}
\hline Partnership & & Coldspots & $\begin{array}{c}\text { Miramar } \\
\text { North }\end{array}$ & Haitaitai & Northland & Island Bay \\
\hline \multirow{2}{*}{ Married } & Z-Score & -44.96 & 2.19 & -4.44 & -20.18 & -27.30 \\
\hline & $\mathrm{p}$-Value & $<0.001 * * *$ & $0.014 *$ & $<0.001 * * *$ & $<0.001 * * *$ & $<0.001 * * *$ \\
\hline
\end{tabular}

\subsubsection{Tenure and duration of tenure}

Fewer households in coldspots own or partly own their dwelling $(Z=-52.4, p<0.001)$ (Table 4.10). This is also reflected in Haitaitai $(Z=-1.08, p=0.036)$, Northland $(Z=-24.84$, $p<0.001)$ and Island Bay $(Z=-31.39, p<0.001)$. 
Table 4.10: Significant differences of proportions in tenure between hotspots/coldspots

\begin{tabular}{lcccccc}
\hline \multicolumn{1}{c}{ Tenure } & Coldspots & $\begin{array}{c}\text { Miramar } \\
\text { North }\end{array}$ & Haitaitai & Northland & Island Bay \\
\hline $\begin{array}{l}\text { Own or Partly } \\
\text { Own }\end{array}$ & Z-Score & -52.36 & -1.60 & -1.80 & -24.84 & -31.39 \\
& p-Value & $<0.001^{* * *}$ & 0.055 & $0.036^{*}$ & $<0.001^{* * *}$ & $<0.001^{* * *}$ \\
\hline
\end{tabular}

* Significant at the 0.05 level

** Significant at the 0.01 level

*** Significant at the 0.001 level

The duration of tenure supports patterns of fuel poverty based on tenure (Table 4.11). More households with a tenure of less than 4 years $(Z=34.95, p<0.001)$ or between $5-$ 15 years $(Z=1.67, p=0.048)$ live in coldspots.

Table 4.11: Significant differences of proportions in duration of tenure between hotspots/coldspots

\begin{tabular}{ccccccc}
\hline $\begin{array}{c}\text { Duration of } \\
\text { Tenure }\end{array}$ & Coldspots & $\begin{array}{c}\text { Miramar } \\
\text { North }\end{array}$ & Haitaitai & Northland & Island Bay \\
\hline \multirow{2}{*}{ 0-4 years } & Z-Score & 34.95 & -1.72 & 1.49 & 16.14 & 13.86 \\
& p-Value & $<0.001^{* * *}$ & $0.040^{*}$ & 0.069 & $<0.001^{* * *}$ & $<0.001^{* * *}$ \\
\hline \multirow{2}{*}{5 -15 years } & Z-Score & 1.67 & 0.60 & 6.13 & -9.77 & -12.77 \\
& p-Value & $0.048^{*}$ & 0.275 & $<0.001^{* * *}$ & $<0.001^{* * *}$ & $<0.001^{* * *}$ \\
\hline \multirow{2}{*}{$30+$ years } & Z-Score & -6.23 & 3.20 & 0.11 & -9.16 & -2.73 \\
& p-Value & $<0.001^{* * *}$ & $<0.001^{* * *}$ & 0.455 & $<0.001^{* * *}$ & $0.003^{* *}$ \\
\hline
\end{tabular}

* Significant at the 0.05 level

** Significant at the 0.01 level

*** Significant at the 0.001 level

These results indicate the absence of homeownership and shorter tenures may be connected to fuel poverty coldspots. This relationship is consistent with the literature in that homeownership affords greater opportunity to improve housing conditions. Fuel poor households may reside in rental properties with insecure tenure resulting in a limited ability to improve the quality of their house. 


\subsubsection{Fuel used for heating}

No significant difference exists between coldspots and hotspots use of electricity for heating. Overall, households in coldspots are less likely to use gas mains ( $Z=-14.61$, $p<0.001)$ and wood $(Z=-10.00, p<0.001)$ as fuel for heating (Table 4.12). This evidence is also true for Island Bay including electricity $(Z=-2.56, p=0.005)$. Houses in Northland are less likely to use wood $(Z=8.83, p<0.001)$, and more likely to use mains gas $(Z=2.12$, $p=0.017)$. In contrast, houses in Miramar North $(Z=6.40, p<0.001)$ and Haitaitai $(Z=5.14$, $p<0.001)$ coldspots are more likely to use wood for heating. This evidence suggests that households in fuel poverty may have less access to alternative fuels to electricity as a source of heating. The use of gas mains for heating may reflect the presence of gas network infrastructure in Wellington.

Table 4.12: Significant differences of proportions in fuel for heating between hotspots/ coldspots

\begin{tabular}{llccccc}
\hline $\begin{array}{c}\text { Fuel for } \\
\text { heating }\end{array}$ & & Coldspots & $\begin{array}{c}\text { Miramar } \\
\text { North }\end{array}$ & Haitaitai & Northland & Island Bay \\
\hline \multirow{2}{*}{ Electricity } & Z-Score & -1.01 & 0.84 & -1.00 & -2.51 & -2.56 \\
& p-Value & 0.157 & 0.202 & 0.159 & $0.006^{* *}$ & $0.005^{* *}$ \\
\hline \multirow{2}{*}{ Mains gas } & Z-Score & -14.61 & -4.86 & 2.12 & 4.51 & -15.53 \\
& $\mathrm{p}$-Value & $<0.001^{* * *}$ & $<0.001^{* * *}$ & $0.017^{*}$ & $<0.001^{* * *}$ & $<0.001^{* * *}$ \\
\hline \multirow{2}{*}{ Wood } & Z-Score & -10.00 & 6.40 & 5.14 & -8.83 & -8.02 \\
& $\mathrm{p}$-Value & $<0.001^{* * *}$ & $<0.001^{* * *}$ & $<0.001^{* * *}$ & $<0.001^{* * *}$ & $<0.001^{* * *}$ \\
\hline * Significant at the 0.05 level & & & & \\
** Significant at the 0.01 level \\
*** Significant at the 0.001 level
\end{tabular}




\section{Summary}

The results of this analysis suggest that:

- Fuel poverty, and its constituent factors (e.g. income, housing quality and energy demand) spatially cluster.

- Income and housing quality are correlated, although they do not correlate with solar radiation.

- Housing age is correlated to all variables apart from solar radiation, suggesting it is a key determinant of the presence of other factors contributing to of fuel poverty.

- While fuel poverty spatially clusters the variables that determine fuel poverty do not necessarily coincide.

- In coldspots, compared to hotspots, there are: more Māori, Pacific Peoples and MELAA households; fewer people under 15 years and over 65 years of age; fewer households owning or partly owning their dwelling; more households with 1 or 2 usual residents; fewer households using alternative fuel sources to electricity to heat their home. 


\section{5}

\section{Chapter Five: Phase Two Results}

Phase two of this thesis explored the switching behaviours of Wellington households through a postal survey. The results of the statistical analysis of phase two provided in this chapter build on the results of phase one. Objective, subjective and spatial measures of fuel poverty are applied to explore the relationship between fuel poverty and switching. First, some socio-demographic descriptives of the sample and a general indication of responses are provided. A profile of fuel poor and switching households in this sample is then established. Initial relationships between fuel poverty and switching are investigated through correlation tests. Then, the results of a regression analysis of the relationships between variables of fuel poverty and switching are provided. Finally, the factors that influence households' decisions to switch energy suppliers and proactive switching are investigated.

For the statistical tests reported in this chapter, exact values of statistical significance are provided at the 0.05 and 0.01 level only. Statistical significance at the 0.001 or lower level is reported as $p<0.001$. In tables, asterisks are used to indicate statistical significance at the 0.05 level $(*)$, at the 0.01 level $\left({ }^{* *}\right)$ and at the 0.001 or lower level $(* * *)$.

\subsection{Descriptive Results}

The final survey response was $42.7 \%$. This response reflects the value of applying the TDM, discussed in Chapter Three. A total of 420 out of 974 surveys were returned, of 
which 416 were usable. Surveys removed from the analysis were duplicates (e.g. respondents completed both the mail and online survey) or incomplete. The majority of surveys $(84.6 \%, n=352)$ were returned by post and the remainder were completed online $(15.4 \%, n=64)$. The number of surveys returned from households by FPI decile varied (Table 5.1). There was a higher response from high deciles, where fuel poverty is likely to occur. A higher number of surveys were distributed to meshblocks with high FPI decile scores to compensate for expected lower rates of participation; the opposite occurred.

Table 5.1: Survey response by FPI decile

\begin{tabular}{ccccc}
\hline FPI & $\begin{array}{c}\text { Surveys } \\
\text { distributed }\end{array}$ & $\begin{array}{c}\text { Surveys } \\
\text { returned }\end{array}$ & $\begin{array}{c}\text { Returned surveys } \\
\text { as \% of decile }\end{array}$ & $\begin{array}{c}\text { Returned surveys } \\
\text { as \% of total }\end{array}$ \\
\hline 1 & 61 & 21 & $34.4 \%$ & $5.0 \%$ \\
2 & 65 & 26 & $40.0 \%$ & $6.3 \%$ \\
3 & 107 & 41 & $38.3 \%$ & $9.9 \%$ \\
4 & 93 & 40 & $43.0 \%$ & $9.6 \%$ \\
5 & 100 & 30 & $30.0 \%$ & $7.2 \%$ \\
6 & 100 & 45 & $45.0 \%$ & $10.8 \%$ \\
7 & 98 & 51 & $52.0 \%$ & $12.3 \%$ \\
8 & 101 & 39 & $38.6 \%$ & $9.4 \%$ \\
9 & 109 & 53 & $48.6 \%$ & $12.7 \%$ \\
10 & 140 & 70 & $50.0 \%$ & $16.8 \%$ \\
\hline Total & 974 & 416 & - & $100 \%$ \\
\hline
\end{tabular}

\subsubsection{Socio-demographics}

Respondents' demographics differed to Wellington's population based on the $2013 \mathrm{New}$ Zealand census (Table 5.2). More females (58.4\%) responded to the survey and the majority of respondents were New Zealand European/Pākehā/New Zealander ${ }^{11}$ (84.3\%). Other major ethnicities included Asian (9.0\%), Other European (6.2\%) and Māori (5.3\%). Pacific Peoples (1.0\%) and MELAA (0.7\%) ethnicities had the lowest representation.

11 Ethnicity does not add to $100 \%$ as respondents were given the option to identify with multiple ethnicities. 'Other' ethnicities were reclassified according to Statistics New Zealand classifications (Statistics New Zealand, 2005). New Zealander was classified as New Zealand European/Pākehā. 
Table 5.2: Sample socio-demographics compared to Wellington

\begin{tabular}{ccc}
\hline & Sample & Wellington \\
\hline \multirow{2}{*}{ Gender } & & \\
Female & $58.4 \%$ & $51.5 \%$ \\
Male & $39.9 \%$ & $48.5 \%$ \\
Inconclusive & $1.7 \%$ & - \\
Ethnicity & & \\
New Zealand European/Päkehā & $84.3 \%$ & \\
Māori & $5.3 \%$ & $76.4 \%$ \\
Pacific Peoples & $1.0 \%$ & $7.9 \%$ \\
Asian & $9.0 \%$ & $4.9 \%$ \\
MELAA & $0.7 \%$ & $15.7 \%$ \\
Other European & $6.1 \%$ & $2.5 \%$ \\
& & - \\
\hline
\end{tabular}

\section{Tenure}

Privately owned

$80.6 \%$

$59.1 \%$

Private rental property

$18.0 \%$

Public rental property

$1.0 \%$

Other arrangements

$0.5 \%$

\begin{tabular}{lcc} 
Sources of Income & & \\
Salary or wages & $80.5 \%$ & $79.6 \%$ \\
Jobseeker support & $1.4 \%$ & $4.9 \%$ \\
Supported living payment & $2.1 \%$ & $5.3 \%$ \\
Sole parent support & $0.7 \%$ & $2.2 \%$ \\
Accommodation supplement & $1.0 \%$ & - \\
Working for families & $2.6 \%$ & - \\
New Zealand pension or & $25.2 \%$ & $16.1 \%$ \\
superannuation & & \\
Student allowance or living & $1.3 \%$ & $3.1 \%$ \\
costs & $2.4 \%$ & - \\
& & \\
\hline & & \\
Income & & $7.6 \%$ \\
Less than $\$ 20,000$ & $3.8 \%$ & $6.5 \%$ \\
\$20,001 - \$30,000 & $7.4 \%$ & $11.8 \%$ \\
\$30,001 - \$50,000 & $15.3 \%$ & $11.9 \%$ \\
$\$ 50,001-\$ 70,000$ & $14.7 \%$ & $17.3 \%$ \\
\$70,001 - \$100,000 & $22.6 \%$ & $44.9 \%$ \\
More than \$100,001 & $36.2 \%$ &
\end{tabular}

Data Source: Statistics New Zealand (2013c) 
Sources of household income ${ }^{12}$ from salary or wages were similar to Wellington (80.5\%). Households receiving New Zealand pension or superannuation were over-represented (25.2\%) and other sources of social welfare (9.1\%) under-represented. Based on the number of households receiving the New Zealand pension or superannuation, a quarter of the sample had at least one person 65 years or older in the household.

Income data collected in this survey differed to the New Zealand census as participants were asked to provide the combined annual net income for the bill payers'. Almost $60 \%$ of respondents $(58.8 \%)$ were from households where the bill payers' combined annual net income was greater than $\$ 70,001$. Households earning less than $\$ 20,000$ and more than $\$ 100,001$ are under-represented; income brackets between these figures are overrepresented. Respondents were more likely to privately own their house $(80.6 \%)^{13}$, than live in private rental properties (18\%) or public rental properties (1\%).

\subsubsection{Switching}

In the last two years, $66.6 \%$ of respondents had not switched energy companies and $33.4 \%$ had switched at least once. Of the respondents who switched, $83.2 \%$ switched once, $4.9 \%$ twice and $0.7 \%$ three times. In New Zealand, $87 \%$ of households switch once, 9\% of households switch twice and $4 \%$ switch three or more times (Electricity Authority, 2014a).

Respondents switched because they were offered a better deal (63.3\%), felt no sense of loyalty to their energy company (31.4\%), felt they were not getting the best value for money (27\%), and because they moved house $(24.8 \%)$. Other reasons were cited by $15.3 \%$ of respondents, for example, switching to companies with mobile phone applications and switching from companies partially privatised by the government.

Respondents who did not switch in the last two years, did not switch because it was a hassle (42.8\%), there are only small price difference between energy companies (35.1\%),

\footnotetext{
${ }^{12}$ Sources of income does not add to $100 \%$ as respondents were asked to indicate all sources of household income.

13 Includes housing owned with or without a mortgage and those held in a family trust with or without a mortgage.
} 
it is time consuming (33\%), their current energy supplier offers electricity and gas (26.1\%), and it is not worth it or there are no overall savings (23.9\%). All respondents knew that they could switch their energy companies. Thirty-seven respondents (13.4\%) reported other reasons for not switching energy companies, including perceiving no long-term savings, being unable to switch as no smart meter is installed, and having their current company match other offers.

The ease of switching varied; $45.3 \%$ and $52.6 \%$ of respondents respectively thought it was a quick and easy process. Switching was easy when respondents did not have to pay extra charges (36.5\%), they knew specific information about their energy bills ( $27 \%)$, and it was easy to find information (25.6\%). Respondents found switching difficult because it was time consuming (13.1\%), their old energy company tried to win their custom back (8.8\%) and because it was a hassle (8\%).

There was a relatively even split of proactive and reactive switching. One quarter of respondents switched through an energy companies' website or Powerswitch, and 23.5\% switched when respondents approached an energy company over the phone. Switching through door-to-door salespersons occurred amongst $26.5 \%$ of respondents and few switched as a result of being approached over the phone by an energy company (14\%).

A majority of respondents $(38.9 \%)$ had not looked into their options to change energy company in the past year and almost one third (32.2\%) indicated they were yet to investigate which energy company would provide them the best deal. If energy prices remained the same, $13.9 \%$ of respondents would change their energy company in the next year.

To make switching worthwhile, $57.4 \%$ of respondents would need to save up to $\$ 50$ per month, amounting to a maximum annual saving of $\$ 600$. The current average annual savings across New Zealand are $\$ 161.56$ (Elecitricity Authority, 2014). Thirty percent of respondents would switch for annual savings of more than $\$ 600$. A further $4.8 \%$ indicated that they would not change their energy companies and $4.3 \%$ would change for reasons other money, for example customer service, ethical and environmental 
record and to simplify invoicing. When asked how respondents would use these savings $51.9 \%$ indicated they would not heat their home more.

\subsubsection{Perceptions of expense and affordability}

On average, respondents thought that electricity $(80.5 \%, M=2.0)$, gas heating $(66.8 \%$, $M=2.3$ ), and their total energy bill (73.4\%, $M=2.1$ ) was expensive (Table 5.3). Respondents also thought that their estimated total energy bill was somewhat affordable $(M=2.6)$. Respondents were of the opinion that their total energy bill is expensive, but affordable.

When asked about their current ability to afford the energy bill and heat their home, the majority of respondents could afford to: heat their home, heat their home to a temperature they wanted; heat their home to a temperature they wanted some of the time; or afford the energy bill if energy prices increase (Table 5.3). Approximately $43 \%$ of respondents agreed that if their income decreased they would be unable to afford the energy bill. 


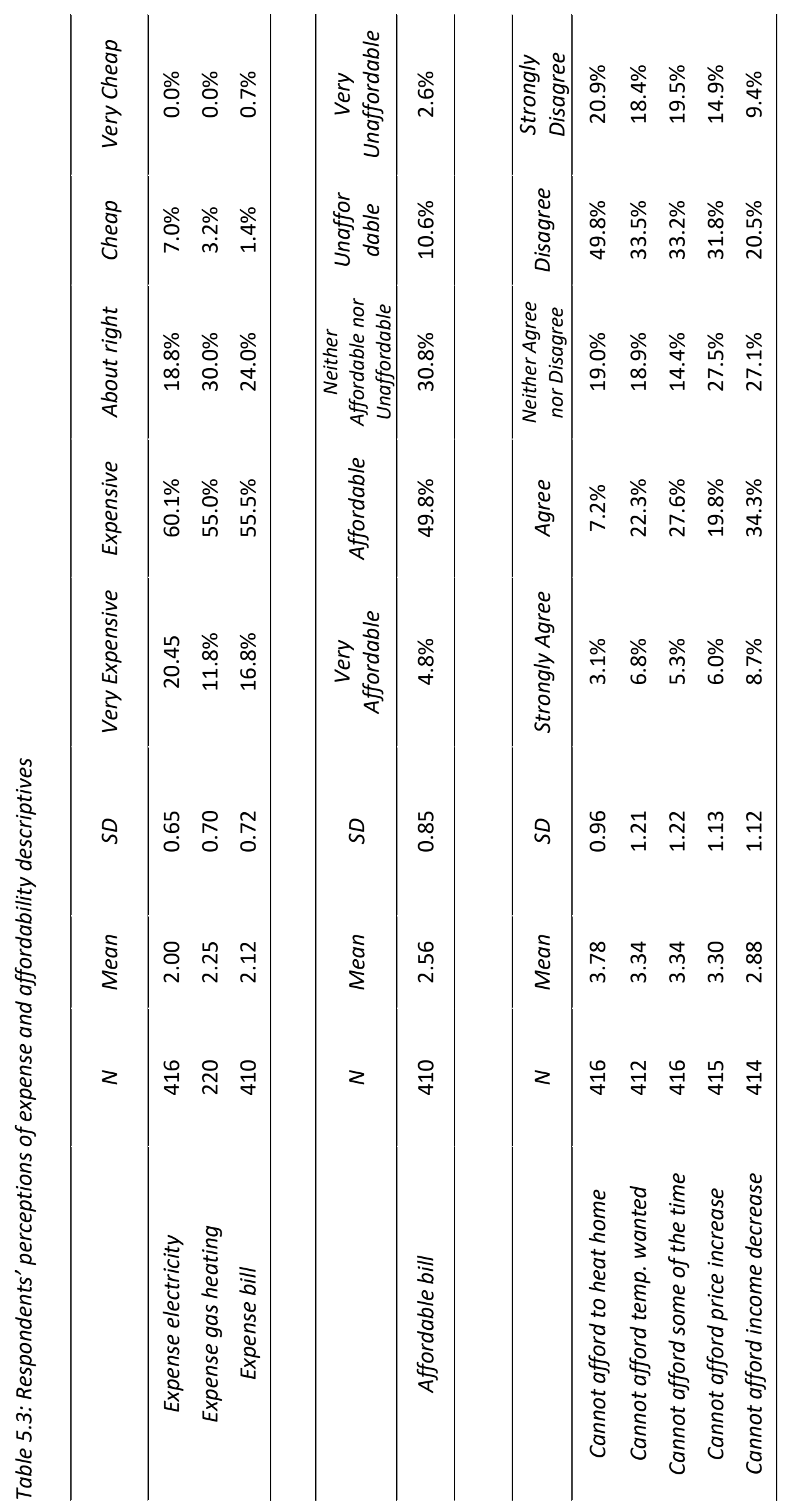


Respondents were asked to estimate the cost of their most recent energy bill (Figure 5.1). Over half of respondents (53.6\%) estimated their most recent total energy bill was between $\$ 201$ and $\$ 400$. Almost 5\% of respondents estimated their energy bills to be higher than $\$ 601$.

Figure 5.1: Respondents' estimated cost of the most recent total energy bill

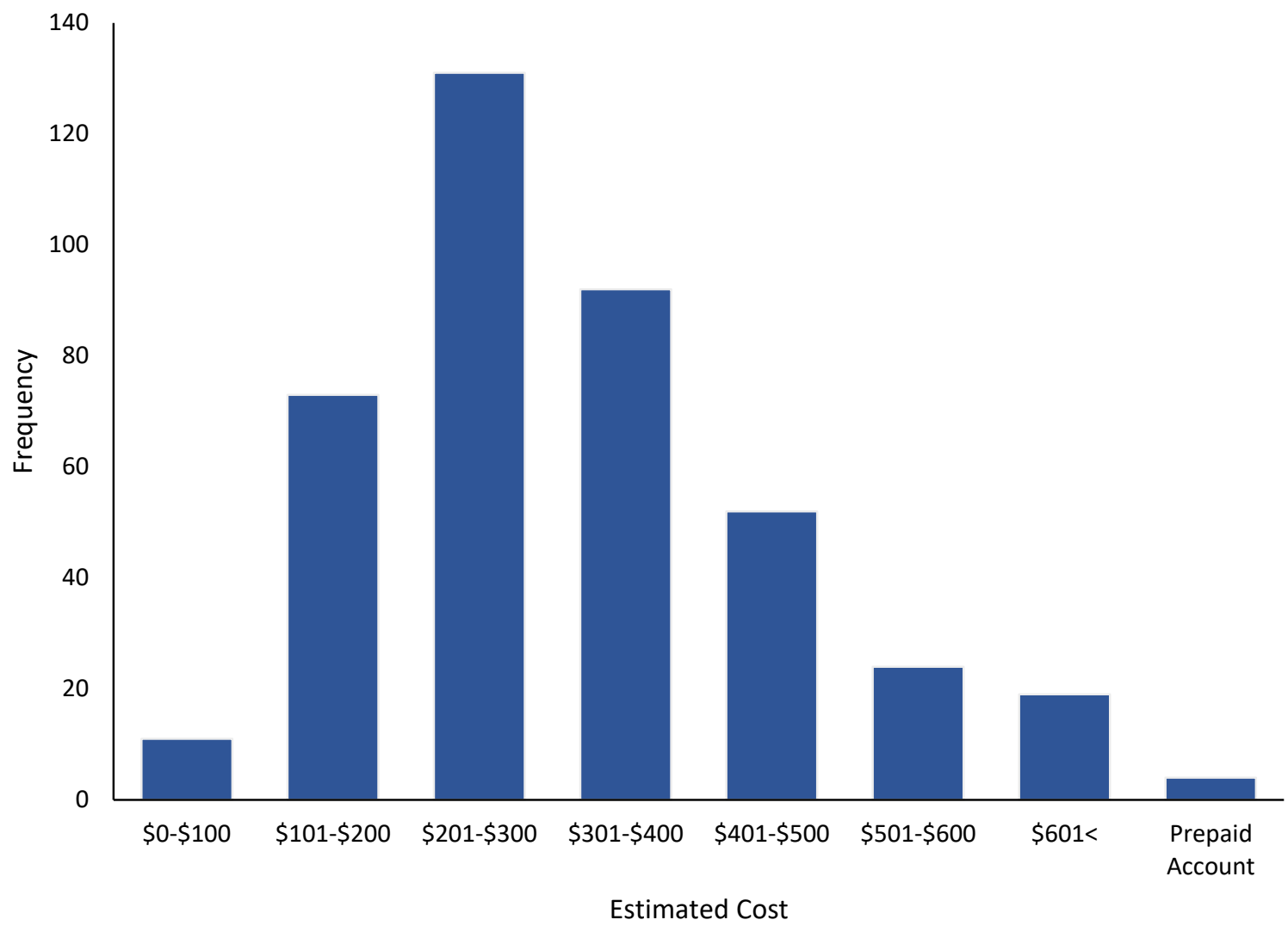

Respondents were also asked to provide information from their most recent energy bill (Table 5.4). Data provided by respondents was used to calculate the average electricity bill (NZD\$248.65, $n=390$ ) and the average gas bill (NZD\$154.84, $n=215)$. On average, respondents received a NZD\$43.09 $(n=315)$ discount on their energy bills. Average electricity and gas consumption was respectively $868 \mathrm{kWh}(\mathrm{n}=345)$ and $1428 \mathrm{kWh}$ $(n=179)$. 
Table 5.4: Respondents' energy bill information descriptives

\begin{tabular}{cccccc}
\hline & Mean & SD & Median & Minimum & Maximum \\
\hline Real electricity bill & $\$ 248.65$ & 123.53 & $\$ 230.14$ & $\$ 31.75$ & $\$ 985.00$ \\
Real gas bill & $\$ 154.84$ & 125.63 & $\$ 109.00$ & $\$ 5.00$ & $\$ 712.95$ \\
Real discount & $\$ 43.36$ & 29.93 & $\$ 36.58$ & $\$ 1.84$ & $\$ 223.22$ \\
Electricity units & $868 \mathrm{kWh}$ & 538 & $756 \mathrm{kWh}$ & $22 \mathrm{kWh}$ & $4500 \mathrm{kWh}$ \\
Gas units & $1428 \mathrm{kWh}$ & 1417 & $942 \mathrm{kWh}$ & $11 \mathrm{kWh}$ & $3513 \mathrm{kWh}$ \\
\hline
\end{tabular}

\subsubsection{Experiences of the cold}

On average, respondents felt their house had been cold 'sometimes' $(M=2.31)$ during the winter (Table 5.5). Respondents had shivered, on average, at least once during the day/night in their home ( $M=2.31)$, and had seen their breath (dragon breath) at least once during the day/night $(M=1.75)$. Respondents indicated their houses felt cold during the winter because they try to keep the cost of heating low (44.4\%) and any heat disappeared (38\%). One third (33.8\%) of respondents cited other reasons for their house feeling cold during the winter, for example, arriving home to an unheated house, underheating the house and poor housing energy efficiency.

Table 5.5: Respondents' experiences of the cold descriptives

\begin{tabular}{cccccccc}
\hline & $N$ & Mean & SD & Never & Sometimes & Often & Always \\
\hline Felt cold & 415 & 2.31 & 0.81 & $13.7 \%$ & $50.6 \%$ & $27.0 \%$ & $8.7 \%$ \\
Shivered & 358 & 2.31 & 1.26 & $41.1 \%$ & $13.7 \%$ & $18.4 \%$ & $26.8 \%$ \\
Dragon breath & 358 & 1.75 & 1.12 & $64.0 \%$ & $10.1 \%$ & $12.6 \%$ & $13.4 \%$ \\
\hline
\end{tabular}




\subsubsection{Coping strategies}

The primary means of keeping warm in the winter was by using heaters (91.6\%). Although, respondents also indicated using blankets or wearing extra clothing (76.9\%) and closing doors to keep the heat in one area of the house (70.7\%) in order to keep warm. Other methods (27.4\%) to keep warm included closing curtains early, physical exercise (indoors or outdoors), going out to local malls or libraries, staying at work longer, and families sleeping together in one room.

To keep the cost of the energy bill low, budgets were used by $23.3 \%$ of respondents and 19.2\% monitored how much energy they used. Prepayment meters were used by 7 respondents. Some respondents did not take any action to keep the cost of their energy bill low (29.3\%) and $8.9 \%$ spent as much time away from home as possible. Only $10.6 \%$ of respondents indicated that they switched energy companies to keep costs low. Other methods (38.5\%) used by households to keep the energy bill low were occupying and heating minimal space in the home by closing doors, avoiding energy use by being physically active or using energy in other spaces (e.g. showering at work or the gym), under-heating the home when children are not present and turning off lights and appliances at the wall.

Respondents that limited energy use for reasons other than cost $(37.5 \%)$ overwhelmingly and unprompted cited environmental concerns $(n=112,72.3 \%)$ as the main reason. Respondents were concerned about their environmental footprint, sustainability and energy conservation.

\subsubsection{Energy efficiency}

On average, respondents rated the energy efficiency of their house as 'good' ( $M=2.9)$. Housing energy efficiency was rated below average by $28.2 \%$ of respondents. Only $9.5 \%$ rated their housing energy efficiency as very good.

The main source of heating was electricity (84.4\%), including heat pumps, and over a third indicated that mains gas was used (36.1\%). A fireplace was used by $23.2 \%$ of respondents. 


\subsubsection{Fuel poverty profiles}

To explore the socio-demographic profile of households in fuel poverty, a household was identified as fuel poor if their actual energy expenditure was greater than $10 \%$ of household income. Energy expenditure provided by respondents from their most recent energy bill was summed (excluding discount) and calculated as a proportion of monthly income. Households that spent over $10 \%$ of monthly income on the total energy bill were considered objectively fuel poor ( $\left.\mathrm{FP}_{10}\right)$. Based on actual energy expenditure being greater than $10 \%$ of household income, 61 households or $14.7 \%$ of the survey sample were fuel poor. This is compared to $24 \%$ in Wellington and $25 \%$ in New Zealand.

The profile of fuel poor households was compared to the sample by calculating significant differences of proportions (Table 5.6). For variables that did not meet the assumptions of this test, the proportion as a percentage of the total fuel poor households are included. In comparison to the total sample, fuel poor households are more likely to live in private rental properties $(Z=1.832, p=0.034)$, and have a bill payers' combined annual net income greater than $\$ 100,001(Z=2.323, p=0.010)$. The result of high income households being significantly fuel poor is counter to what is expected. Households with low incomes are expected to be fuel poor. This outcome may be related to the use of actual energy expenditure to calculate fuel poverty rather than Boardman's definition.

Fuel poverty occurred in $15.3 \%$ of privately owned homes and $22.9 \%$ of private rental properties; fuel poverty was not present in public rental properties. Of households with at least one occupant under 18 years of age, $24.1 \%$ were fuel poor and $24.6 \%$ of households with only one person under 18 years of age were in fuel poverty. Households with two or more residents over 18 years of age were more likely to be fuel poor (67.2\%). Of households receiving social welfare support, $37.7 \%$ were fuel poor. 
Table 5.6: Fuel poverty (FP10) profiles compared to sample

\begin{tabular}{|c|c|c|}
\hline & Fuel Poverty & Sample \\
\hline \multicolumn{3}{|l|}{ Gender } \\
\hline Female & $50.8 \%$ & $58.4 \%$ \\
\hline Male & $49.2 \%$ & $39.9 \%$ \\
\hline Inconclusive & - & $1.7 \%$ \\
\hline
\end{tabular}

\section{Ethnicity}

New Zealand European/Pākehā

$85.2 \%$

$84.3 \%$

Māori

$4.9 \%$

$5.3 \%$

Pacific Peoples

$1.6 \%$

$1.0 \%$

Asian

$4.9 \%$

$9.0 \%$

MELAA

$1.6 \%$

$0.7 \%$

Other European

$9.8 \%$

$6.1 \%$

\section{Tenure}

Privately owned

$72.1 \%$

$80.6 \%$

Private rental property

$27.9 \% *$

$18.0 \%$

Public rental property

$0.0 \%$

$1.0 \%$

Other arrangements

$0.0 \%$

$0.5 \%$

\section{Sources of Income}

Salary or wages

$82.0 \%$

$80.5 \%$

Jobseeker support

$1.6 \%$

$1.4 \%$

Supported living payment

$0.0 \%$

$2.1 \%$

Sole parent support

$3.3 \%$

$0.7 \%$

Accommodation supplement

$1.6 \%$

$1.0 \%$

Working for families

$6.6 \%$

$2.6 \%$

New Zealand pension or

$23.0 \%$

$25.2 \%$

superannuation

Student allowance or living costs

$\begin{array}{ll}4.9 \% & 1.3 \% \\ 3.3 \% & 2.4 \%\end{array}$

None of the above

$3.3 \%$

$2.4 \%$

\section{Income}

Less than $\$ 20,000$

$\$ 20,001-\$ 30,000$

$1.9 \%$

$3.1 \%$

$\$ 30,001-\$ 50,000$

$45.6 \%$

$6.1 \%$

$\$ 50,001-\$ 70,000$

$13.2 \%$

$12.5 \%$

$\$ 70,001-\$ 100,000$

$13.2 \%$

$10.3 \%$

More than $\$ 100,001$

\footnotetext{
* Significant at the 0.05 level

** Significant at the 0.01 level

*** Significant at the 0.001 level
} 


\subsubsection{Switching profiles}

Table 5.7 develops a profile of households most likely to have switched in the last two years. Supplier switching was coded so that switching was a dichotomous variable indicating whether or not respondents had switched suppliers in the last two years (Switched $\mathrm{D}_{\mathrm{D}}$ ). The profile of switchers (Switched $\mathrm{D}$ ) was compared to the total survey sample by calculating significant differences of proportions. For variables that did not meet the assumptions of this test, the proportion as a percentage of the total fuel poor households is provided.

Switchers in the sample were less likely to be homes owners $(Z=-1.765, p=0.038)$ and more likely to be households living in private rental properties $(Z=2.23, p=0.013)$. Households with at least one member of the household receiving a New Zealand pension or superannuation were less likely to be switchers compared to their proportion of the total sample $(Z=-2.02, p=0.022)$. Of respondents that switched at least once, 23 of 137 (16.8\%) were fuel poor. In the last two years, 38 fuel poor respondents did not switch energy suppliers. 
Table 5.7: Switching (switched ${ }_{D}$ ) profiles compared to sample

\begin{tabular}{lcc}
\hline Variable & Switchers & Sample \\
\hline \multirow{2}{*}{ Gender } & & \\
$\quad$ Female & $57.8 \%$ & $58.4 \%$ \\
$\quad$ Male & $42.2 \%$ & $39.9 \%$ \\
$\quad$ Inconclusive & - & $1.7 \%$ \\
\hline
\end{tabular}

\section{Ethnicity}

$\begin{array}{lcc}\text { New Zealand European/Pākehā } & 82.3 \% & 84.3 \% \\ \text { Māori } & 6.7 \% & 5.3 \% \\ \text { Pacific Peoples } & 1.5 \% & 1.0 \% \\ \text { Asian } & 8.0 \% & 9.0 \% \\ \text { MELAA } & 0 \% & 0.7 \% \\ \text { Other European } & 8.0 \% & 6.1 \%\end{array}$

Tenure

Privately owned

$72.6 \% *$

$80.6 \%$

Private rental property

$26.7 \% *$

$18.0 \%$

Public rental property

$0.7 \%$

$1.0 \%$

Other arrangements

$0.7 \%$

$0.5 \%$

\section{Sources of Income}

Salary or wages

$85.4 \%$

$80.5 \%$

Jobseeker support

$2.2 \%$

$1.4 \%$

Supported living payment

$3.6 \%$

$2.1 \%$

Sole parent support

$0.7 \%$

$0.7 \%$

Accommodation supplement

$1.5 \%$

$1.0 \%$

Working for families

$2.9 \%$

$2.6 \%$

New Zealand pension or

$16.8 \% *$

$25.2 \%$

superannuation

Student allowance or living costs

$3.6 \%$

$1.3 \%$

None of the above

$1.5 \%$

$2.4 \%$

\section{Income}

Less than $\$ 20,000$

$7.3 \%$

$3.8 \%$

$\$ 20,001-\$ 30,000$

$5.5 \%$

$7.4 \%$

$\$ 30,001-\$ 50,000$

$11.8 \%$

$15.3 \%$

$\$ 50,001-\$ 70,000$

$14.5 \%$

$14.7 \%$

$\$ 70,001-\$ 100,000$

$22.7 \%$

$22.6 \%$

More than $\$ 100,001$

$38.2 \%$

$36.2 \%$

\footnotetext{
* Significant at the 0.05 level

** Significant at the 0.01 level

*** Significant at the 0.001 level
} 


\subsection{Correlations}

Correlation tests were calculated to determine the relationship between variables measured in the survey, fuel poverty and supplier switching. Fuel poverty is represented by the FPI and $\mathrm{FP}_{10}$ as calculated in Section 4.2 and Section 5.1.7, respectively. Switching was represented by an ordinal variable (Switched ${ }_{L}$ ) which was calculated based on the frequency of switching. Income and real energy bill information are included in these calculations as low income and low power bills are indicators of fuel poverty and consumers who are less likely to switch.

\subsubsection{Perceptions of expense and affordability}

Perceptions of expense are not correlated to switching or annual income. Although, switching is correlated with perceptions of unaffordability $(r=0.11, p=0.022)$. FPI is negatively correlated to estimates of the total energy bill $(r=-0.15, p=0.002)$ indicating that more fuel poor households have lower energy bills. Conversely, $\mathrm{FP}_{10}$ is positively correlated to estimates of the total energy bill $(r=0.32, p<0.001)$.

The cost of respondents' most recent electricity bill, gas bill and discount, were all strongly correlated to perceptions of expense and affordability (Table 5.8). Households are more likely to think energy is expensive when the cost of their real bill is higher. The perceived affordability of the electricity bill $(r=0.185, p<0.001)$ and gas bill $(r=0.248$, $p<0.001$ ) decreases with higher bill costs. Households are more likely to think their total energy bill is expensive $(r=-0.28, p<0.001)$ and unaffordable $(r=0.25, p<0.001)$ the greater the real discount received. 
Table 5.8: Correlations of perceptions of expense

\begin{tabular}{cccccc}
\hline & $\begin{array}{c}\text { Expense } \\
\text { electricity }\end{array}$ & $\begin{array}{c}\text { Expense gas } \\
\text { heating }\end{array}$ & $\begin{array}{c}\text { Est. energy } \\
\text { bill }\end{array}$ & $\begin{array}{c}\text { Expense } \\
\text { bill }\end{array}$ & $\begin{array}{c}\text { Affordable } \\
\text { bill }\end{array}$ \\
\hline$F P I$ & 0.031 & 0.002 & $-0.152^{* *}$ & 0.018 & -0.012 \\
$F P_{10}$ & -0.082 & -0.115 & $0.319^{* * *}$ & -0.091 & $0.145^{* *}$ \\
Switched & 0.004 & 0.011 & -0.071 & 0.033 & $0.114^{*}$ \\
$\begin{array}{c}\text { Annual income } \\
\text { Real electricity } \\
\text { bill }\end{array}$ & 0.003 & 0.068 & -0.012 & -0.005 & 0.052 \\
$\begin{array}{c}\text { Real gas bill } \\
\text { Real Discount }\end{array}$ & $-0.170^{* * *}$ & $-0.147^{* *}$ & $0.650^{* * *}$ & $-0.294^{* * *}$ & $0.185^{* * *}$ \\
$\begin{array}{l}\text { * Significant at the } 0.05 \text { level } \\
* * \text { Significant at the } 0.01 \text { level } \\
* * * \text { Significant at the } 0.001 \text { level }\end{array}$ & $-0.136^{*}$ & $-0.188^{*}$ & $0.671^{* * *}$ & $-0.281^{* * *}$ & $0.250^{* * *}$ \\
\hline
\end{tabular}

Households with higher real electricity bills $(r=-0.11, p=0.036)$ and gas bills $(r=-0.18$, $p=0.007$ ) are more likely to agree that they will be unable to afford the energy bill if their income decreases (see Table 5.9). Switching occurs more frequently if households cannot afford to heat their home $(r=-0.14, p=0.006)$; heat their home to a temperature they want $(r=-0.16, p=0.001)$; or some of the time cannot heat their home to a temperature they want $(r=-0.14, p=0.005)$. 
Table 5.9: Correlations of perceptions of affordability

\begin{tabular}{|c|c|c|c|c|c|}
\hline & $\begin{array}{c}\text { Cannot } \\
\text { afford to } \\
\text { heat home }\end{array}$ & $\begin{array}{c}\text { Cannot } \\
\text { afford temp. } \\
\text { wanted }\end{array}$ & $\begin{array}{l}\text { Cannot } \\
\text { afford some } \\
\text { of the time }\end{array}$ & $\begin{array}{l}\text { Cannot } \\
\text { afford price } \\
\text { increase }\end{array}$ & $\begin{array}{c}\text { Cannot } \\
\text { afford } \\
\text { income } \\
\text { decrease }\end{array}$ \\
\hline$F P I$ & 0.000 & 0.004 & -0.016 & -0.013 & -0.022 \\
\hline$F P_{10}$ & 0.024 & -0.023 & -0.021 & -0.018 & -0.021 \\
\hline Switched $_{L}$ & $-0.135^{* *}$ & $-0.158 * * *$ & $-0.137 * *$ & -0.094 & 0.066 \\
\hline Annual income & 0.018 & -0.013 & -0.019 & 0.003 & -0.017 \\
\hline $\begin{array}{l}\text { Real electricity } \\
\text { bill }\end{array}$ & -0.054 & -0.069 & -0.020 & -0.047 & $-0.106^{*}$ \\
\hline Real gas bill & 0.042 & 0.029 & -0.058 & -0.13 & $-0.184 * *$ \\
\hline Real Discount & -0.007 & -0.03 & -0.038 & -0.036 & 0.095 \\
\hline
\end{tabular}

\subsubsection{Experiences of the cold}

Seeing your breath condense inside was positively correlated to FPI ( $r=0.11, p=0.038)$ and negatively correlated to the cost of electricity $(r=-0.17, p=0.002)$ (Table 5.10). This suggests that fuel poverty increases with lower energy expenditure and the frequency of seeing your breath inside. Switching is positively correlated with feeling cold $(r=0.12$, $p=0.013)$, shivering $(r=0.11, p=0.047)$, and with seeing your breath condense inside $(r=0.27, p<0.001)$. This suggests that the more often a respondent experiences the cold, the more regularly they switched in the past two years. 
Table 5.10: Correlations of experiences of the cold

\begin{tabular}{cccc}
\hline & Felt cold & Shivered & Dragon breath \\
\hline$F P I$ & $0.134^{* *}$ & 0.078 & $0.109^{*}$ \\
$F P_{10}$ & 0.039 & -0.023 & -0.04 \\
Switched & $0.123^{*}$ & $0.106^{*}$ & $0.266^{* * *}$ \\
Annual income & -0.063 & 0.041 & -0.055 \\
Real electricity bill & -0.023 & -0.046 & $-0.165^{* *}$ \\
Real gas bill & $-0.183^{* *}$ & -0.05 & -0.126 \\
\hline
\end{tabular}

* Significant at the 0.05 level

** Significant at the 0.01 level

*** Significant at the 0.001 level

\subsubsection{Energy efficiency}

Energy efficient households are less likely to be fuel poor. Energy efficiency is only correlated to FPI $(r=0.19, p<0.001)$ and $\mathrm{FP}_{10}(r=0.1, p=0.042)$ (Table 5.11). That is as fuel poverty increases, in both measures, the less energy efficient a respondent is likely to describe their house. Energy efficiency is not related to switching.

Table 5.11: Correlations of energy efficiency

\begin{tabular}{cc}
\hline & Energy efficiency \\
\hline$F P I$ & $0.186^{* * *}$ \\
$F P_{10}$ & $0.100^{*}$ \\
Switched & 0.031 \\
Annual income & -0.069 \\
\hline $\begin{array}{l}\text { * Significant at the } 0.05 \text { level } \\
\text { ** Significant at the } 0.01 \text { level } \\
\text { *** Significant at the } 0.001 \text { level }\end{array}$ &
\end{tabular}




\subsection{Analysis: Fuel poverty and supplier switching}

This section explores the relationship between fuel poverty and supplier switching. Fuel poverty is measured based on the $\mathrm{FPI}$ and $\mathrm{FP}_{10}$, and analysed with reference to switching (switched $d_{D}$ ). Logistic regression was used to determine the relationship between switching and the FPI. No significant odds ratio was identified $(\operatorname{Exp}(B)=0.97, p=0.454)$. A chi-square test was performed for $\mathrm{FP}_{10}$ and switched $\mathrm{D}_{\mathrm{D}}$; no significant relationship was determined $(x 2=0.76, p=0.382)$. These results suggest that there is no relationship between switching and fuel poverty.

As a small sample of households were identified as fuel poor and switchers, there is insufficient evidence to draw conclusions from the integration of survey data and the FPI in ArcGIS. With a larger and more comprehensive dataset, the identification of the spatial distribution and uptake of switching, at meshblock level may be possible.

These tests broadly answered the research question. However, other responses may provide greater insight to this relationship. The following section tests these relationships by calculating the extent to which responses provide an indication of fuel poverty, before testing these against switching.

\subsubsection{Perceptions of expense and affordability}

It is expected that households in fuel poverty perceive the cost of their energy bill to be expensive and unaffordable. From this perspective, these consumers are also expected to behave in an economically rational manner and switch energy suppliers.

Linear regression tests determined no significant relationship between the FPI and perceptions of expense and affordability (Table 5.12). Although, the estimated cost of the most recent energy bill is negatively related to the $\operatorname{FPI}(\beta=-0.15, p=0.002)$; as the estimated cost of a households' energy bill decreases households are more likely to live in fuel poor meshblocks according to the FPI. A multiple linear regression test accounting for any possible relationship between perceptions of expense and affordability, and the FPI returned no significant relationships. 
Table 5.12: Linear regression of FPI with perceptions of expense and affordability

\begin{tabular}{|c|c|c|c|c|}
\hline & \multicolumn{2}{|c|}{ Linear regression } & \multicolumn{2}{|c|}{ Multiple linear regression } \\
\hline & $\beta$ & $\mathrm{R}^{2}$ & $\beta$ & $\mathrm{R}^{2}$ \\
\hline & & & & 0.050 \\
\hline Expense electricity & 0.031 & 0.001 & -0.057 & \\
\hline Expense gas heating & 0.002 & 0.000 & 0.030 & \\
\hline Est. energy bill & $-0.152 * *$ & 0.023 & -0.148 & \\
\hline Expense bill & 0.018 & 0.000 & -0.060 & \\
\hline Affordable bill & -0.012 & 0.000 & -0.070 & \\
\hline Cannot afford to heat home & 0.000 & 0.000 & -0.006 & \\
\hline Cannot afford temp. wanted & 0.004 & 0.000 & 0.279 & \\
\hline Cannot afford some of the time & -0.016 & 0.000 & -0.185 & \\
\hline Cannot afford price increase & 0.013 & 0.000 & 0.039 & \\
\hline Cannot afford income decrease & -0.022 & 0.000 & -0.054 & \\
\hline
\end{tabular}

A logistic regression test determined a significant relationship between $\mathrm{FP}_{10}$, total energy bill affordability $(\operatorname{Exp}(B)=1.56, p=0.004)$ and the estimated cost of the energy bill $(\operatorname{Exp}(B)=1.85, p<0.001)$ (Table 5.13). These results suggest that respondents who are fuel poor according to their actual energy expenditure as a proportion of their income are more likely to think their energy bill is unaffordable. The estimated cost of the total energy bill remained a significant explanatory variable of $\mathrm{FP}_{10}$ in a multiple logistic regression test $(\operatorname{Exp}(B)=2.28, p<0.001)$. Furthermore, $28.6 \%$ of the variance in $\mathrm{FP}_{10}$ is explained by these variables. 
Table 5.13: Logistic regression of FP 10 with perceptions of expense and affordability

\begin{tabular}{ccccc}
\hline & \multicolumn{2}{c}{ Logistic regression } & \multicolumn{2}{c}{$\begin{array}{c}\text { Multiple logistic } \\
\text { regression }\end{array}$} \\
\hline & $\operatorname{Exp}(\mathrm{B})$ & $\mathrm{R}^{2}$ & $\mathrm{Exp}(\mathrm{B})$ & $\mathrm{R}^{2}$ \\
\hline Expense electricity & & & & 0.286 \\
Expense gas heating & 0.693 & 0.012 & 0.515 & \\
Est. energy bill & 0.642 & 0.013 & 1.055 \\
Expense bill & $1.847^{* * *}$ & 0.162 & $2.275^{* * *}$ \\
Affordable bill & 0.690 & 0.015 & 2.094 \\
Cannot afford to heat home & $1.561^{* *}$ & 0.035 & 1.403 \\
Cannot afford temp. wanted & 1.074 & 0.001 & 1.209 & \\
Cannot afford some of the time & 0.948 & 0.001 & 1.185 & \\
Cannot afford price increase & 0.956 & 0.001 & 1.156 & \\
Cannot afford income decrease & 0.948 & 0.001 & 1.257
\end{tabular}

* Significant at the 0.05 level

** Significant at the 0.01 level

*** Significant at the 0.001 level

While there were no significant relationships between $\mathrm{FPI}, \mathrm{FP}_{10}$ and perceptions of expense and affordability, logistic regression tests were performed to determine whether these variables were in any way related to supplier switching. It is assumed that households that think their energy bills are expensive and unaffordable would have switched energy companies to improve the affordability of energy.

Logistic regression was used to test the relationship between switching (switched $D$ ) and perceptions of expense and affordability (Table 5.14). Disagreement with the statement 'We will not be able to afford the energy bill if my income decreases' was determined to be a significant predictor of switching $(\beta=1.653, p=0.024)$. This suggests households who are able to afford the energy bill, even if their income decreases, are more likely to switch. When the relationship between these variables was accounted for, $7.3 \%$ of the variance in the data is explained. No other significant relationships were identified. Thus, counter to expectations, households' perceptions towards the expense and affordability of energy are not significant explanatory variables of switching. 


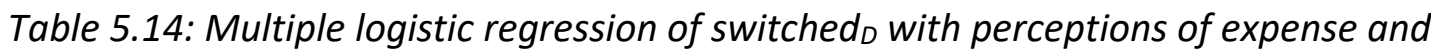
affordability

\begin{tabular}{|c|c|c|}
\hline & $\operatorname{Exp}(B)$ & $\mathrm{R}^{2}$ \\
\hline & & 0.073 \\
\hline Expense electricity & 0.724 & \\
\hline Expense gas heating & 0.950 & \\
\hline Est. energy bill & 0.890 & \\
\hline Expense bill & 1.040 & \\
\hline Affordable bill & 1.308 & \\
\hline Cannot afford to heat home & 1.468 & \\
\hline Cannot afford temp. wanted & 0.662 & \\
\hline Cannot afford some of the time & 1.112 & \\
\hline Cannot afford price increase & 0.706 & \\
\hline Cannot afford income decrease & $1.653^{*}$ & \\
\hline
\end{tabular}

\subsubsection{Experiences of the cold}

Fuel poor households are expected to live in inadequately heated homes and experience subjective, physiological and atmospheric indicators of low indoor temperatures. A linear regression test confirms that there is a moderate positive relationship $(\beta=0.46$, $p=0.006$ ) between the FPI and feeling the house has been cold (Table 5.15). There is also a relationship between the FPI and seeing your breath condense inside $(\beta=0.28$, $p=0.038)$. These results suggest that feeling cold and seeing your breath condense inside are fairly good predictors of fuel poverty based on the FPI. A multiple regression test was run to control for the relationship between experiences of the cold. No significant relationships were found. 
Table 5.15: Linear regression of FPI with experiences of the cold

\begin{tabular}{ccccc}
\hline & \multicolumn{2}{c}{ Linear regression } & \multicolumn{2}{c}{ Multiple linear regression } \\
\hline B & $\mathrm{R}^{2}$ & $\mathrm{~B}$ & $\mathrm{R}^{2}$ \\
\hline Felt cold & $0.462^{* *}$ & 0.018 & 0.016 \\
Shivered & 0.175 & 0.006 & 0.026 & \\
$\begin{array}{l}\text { Dragon breath } \\
\text { R Significant at the } 0.05 \text { level } \\
\text { ** Significant at the } 0.01 \text { level } \\
* * * \text { Significant at the } 0.001 \text { level }\end{array}$ & 0.012 & 0.072 & \\
\end{tabular}

A logistic regression test was performed on $\mathrm{FP}_{10}$ and experiences of the cold. No significant relationships were identified between $\mathrm{FP}_{10}$, feeling cold, shivering or seeing your breath condense inside. Likewise, multiple logistic regression testing the relationship between $\mathrm{FP}_{10}$ and experiences of the cold identified no significant odds ratios.

A logistic regression test analysed the relationship between switching and experiences of the cold. The likelihood of switching significantly increased when respondents experienced their breath condensing inside $(\operatorname{Exp}(B)=1.40, p=0.001)$. Despite the observation that feeling cold is related to the FPI, it is not related to supplier switching $(\operatorname{Exp}(B)=1.15, p=0.294)$. When the relationship between these variables is accounted for, seeing your breath inside remains a statistically significant explanatory variable $(\operatorname{Exp}(B)=1.43, p=0.005)$ (Table 5.16).

Table 5.16: Multiple logistic regression of switched $D$ with experiences of the cold

\begin{tabular}{cc}
\hline $\operatorname{Exp}(B)$ & $R^{2}$ \\
\hline & 0.009
\end{tabular}

Felt Cold $\quad 1.265$

Shivered $\quad 0.846$

Dragon Breath $1.425^{* *}$

* Significant at the 0.05 leve

** Significant at the 0.01 level

*** Significant at the 0.001 level 


\subsubsection{Energy efficiency}

It is expected that households living in energy inefficient households will experience the cold more often and perceive energy to be more expensive and unaffordable. These households are more likely to be fuel poor. All experiences of the cold were positively correlated to energy efficiency (Table 5.17); that is households with lower rated energy efficiency are more likely to experience these conditions. Poor energy efficiency is the only variable to which shivering is correlated. Energy efficiency is correlated to all perceptions of expense and affordability. These relationships are as expected; energy is perceived to be cheaper and more affordable the greater the energy efficiency of the home.

Table 5.17: Correlation of energy efficiency with experiences of the cold and perceptions of expense and affordability

\begin{tabular}{cc}
\hline & Energy efficiency \\
\hline Felt cold & $0.614^{* * *}$ \\
Shivered & $0.391^{* * *}$ \\
Dragon breath & $0.411^{* * *}$ \\
Expense electricity & $-0.168^{* *}$ \\
Expense gas heating & $-0.184^{* *}$ \\
Est. energy bill & 0.027 \\
Expense bill & $-0.165^{* *}$ \\
Affordable bill & $0.232^{* * *}$ \\
Cannot afford to heat home & $-0.360^{* * *}$ \\
Cannot afford temp. wanted & $-0.414^{* * *}$ \\
Cannot afford some of the time & $-0.381^{* * *}$ \\
Cannot afford price increase & $-0.238^{* * *}$ \\
Cannot afford income decrease & $-0.224^{* * *}$ \\
\hline * Significant at the 0.05 level \\
$* *$ Significant at the 0.01 level \\
$* * *$ Significant at the 0.001 level
\end{tabular}


A linear regression test determined a weak positive relationship between FPI and the energy efficiency of the house as described by the respondent $(\beta=0.186, p<0.001)$ (Table 5.18). In line with expectations, this result suggests that households in fuel poverty are more likely to rate the energy efficiency of their home as poor. A logistic regression test also determined that the likelihood of being fuel poor also increases with lower ratings of energy efficiency $(\operatorname{Exp}(B)=1.31, p=0.043)$.

Table 5.18: Linear regression of FPI and logistic regression of $F P_{10}$ with energy efficiency

\begin{tabular}{|c|c|c|c|c|}
\hline & \multicolumn{2}{|c|}{ FPI } & \multicolumn{2}{|c|}{$\mathrm{FP}_{10}$} \\
\hline & $\beta$ & $\mathrm{R}^{2}$ & $\operatorname{Exp}(B)$ & $\mathrm{R}^{2}$ \\
\hline Energy Efficiency & $0.186 * * *$ & 0.034 & $1.309 *$ & 0.018 \\
\hline
\end{tabular}

While households with low energy efficiency are likely to be fuel poor, a logistic regression test determined no significant relationship between housing energy efficiency and switching $(\operatorname{Exp}(B)=1.06, p=0.533)$. That is households in energy inefficient homes, who are also likely to be fuel poor, are no more likely to switch energy suppliers compared to non-fuel poor households.

\subsubsection{Fuel poverty}

The results of earlier tests suggest that the estimated cost of households' total energy bill, perceiving the total energy bill to be unaffordable, feeling cold and seeing your breath inside are significant indicators of fuel poverty. To measure predictors of fuel poverty while accounting for the relationships across all variables, a multiple logistic regression test against $\mathrm{FP}_{10}$ was conducted. This test accounted for relationships between experiences of the cold, perceptions of expense and affordability, energy efficiency and socio-demographic data (Table 5.19). In SPSS, socio-demographic data was classified as categorical. 
Table 5.19: Logistic regression of $F P_{10}$ with socio-demographics

\begin{tabular}{|c|c|c|}
\hline & $\beta$ & $\mathrm{R}^{2}$ \\
\hline & & 0.384 \\
\hline Felt cold & 1.239 & \\
\hline Shivered & 0.784 & \\
\hline Dragon breath & 1.068 & \\
\hline Expense electricity & 0.478 & \\
\hline Expense gas heating & 1.149 & \\
\hline Est. energy bill & $2.506 * * *$ & \\
\hline Expense bill & $3.401^{*}$ & \\
\hline Affordable bill & 1.823 & \\
\hline Cannot afford to heat home & 1.841 & \\
\hline Cannot afford temp. wanted & 1.631 & \\
\hline Cannot afford some of the time & 0.491 & \\
\hline Cannot afford price increase & 1.585 & \\
\hline Cannot afford income decrease & 1.193 & \\
\hline Energy efficiency & 1.352 & \\
\hline NZ European/Other Euro (Cat.) & 0.848 & \\
\hline Māori/Pacific (Cat.) & 0.773 & \\
\hline Asian/MELAA (Cat.) & 0.741 & \\
\hline Tenure (Own) (Cat.) & $5.087^{*}$ & \\
\hline Salary/Wages (Cat.) & 2.736 & \\
\hline Social Welfare (Cat.) & 0.429 & \\
\hline
\end{tabular}

The estimated cost of a households' total energy bill $(\operatorname{Exp}(B)=2.51, p<0.001)$, considering the total energy bill to be cheap $(\operatorname{Exp}(B)=3.4, p=0.025)$, and home ownership $(\operatorname{Exp}(B)=5.087, p=0.025)$ are significant predictors of fuel poverty. Perceptions of expense of the estimated total energy bill are marginally significant $(\operatorname{Exp}(B)=2.5$, $p=0.051$ ). The variables explained $38.4 \%$ of the variance in the data, with socio- 
demographic data accounting for $7.8 \%$ of the variance. These results suggest that the greatest predictor of fuel poverty is the estimated cost of households' energy bills. Although, interestingly considering the energy bill to be cheap and home ownership are also significant explanatory variables, which are counter to expectations.

As the FPI is a measure of fuel poverty constructed from data external to the survey, no variables were significant determinants of the FPI.

\subsubsection{Switching}

Previous calculations of significant explanatory variables for switching had low $R^{2}$ values. This indicates that other factors may have a greater influence on the probability of switching. Explanations for the influence of other variables on the likelihood of switching were sought by investigating socio-demographic and real energy bill data (Table 5.20).

The results of a logistic regression test indicate that seeing your breath condense inside is the only significant explanatory variable of switching with an odds ratio of $\operatorname{Exp}(B)=2.490(p=0.014)$. That is, the probability of switching increases the more often you see your breath inside. This result supports earlier results, that respondents' perceptions of the cold are increasing their probability of switching energy companies, rather than the perceived expense and/or affordability of the energy bill. These variables also explain $32.7 \%$ of the variance in switching, of which socio-demographic data explains $5.1 \%$.

A final test was included to account for measures of fuel poverty by including both the $\mathrm{FPI}$ and $\mathrm{FP}_{10}$. These variables provide only a minor improvement to the explanation of variance in the data $(2.1 \%)$. Seeing your breath condense inside remained a significant predictor of fuel poverty $(\beta=2.757, p=0.007)$, although the probability of supplier switching increased with disagreement to the statement 'We cannot afford to heat our home' $(\beta=3.572, p=0.045)$. 
Table 5.20: Multiple logistic regression of switched $D$ with socio-demographics

\begin{tabular}{|c|c|c|}
\hline & $\operatorname{Exp}(B)$ & $\mathrm{R}^{2}$ \\
\hline & & 0.327 \\
\hline Felt cold & 1.145 & \\
\hline Shivered & 0.878 & \\
\hline Dragon breath & $2.490 *$ & \\
\hline Expense electricity & 1.506 & \\
\hline Expense gas heating & 0.664 & \\
\hline Est. energy bill & 0.753 & \\
\hline Expense bill & 0.519 & \\
\hline Affordable bill & 1.393 & \\
\hline Cannot afford to heat home & 2.239 & \\
\hline Cannot afford temp. wanted & 0.776 & \\
\hline Cannot afford some of the time & 0.951 & \\
\hline Cannot afford price increase & 0.544 & \\
\hline Cannot afford income decrease & 1.857 & \\
\hline Energy efficiency & 0.526 & \\
\hline Real electricity bill & 1.001 & \\
\hline Real gas bill & 1.000 & \\
\hline Real discount & 1.001 & \\
\hline Annual income & 1.000 & \\
\hline NZ European/Other Euro (Cat.) & 0.531 & \\
\hline Māori/Pacific (Cat.) & 1.166 & \\
\hline Asian/MELAA (Cat.) & 0.327 & \\
\hline Tenure (Own) (Cat.) & 1.269 & \\
\hline Salary/Wages (Cat.) & 1.129 & \\
\hline Social Welfare (Cat.) & 4.031 & \\
\hline
\end{tabular}

* Significant at the 0.05 level

** Significant at the 0.01 level

$* * *$ Significant at the 0.001 level 


\subsection{Switching: Motivations and barriers}

This section explores the final research objectives; why fuel poor households switch energy suppliers and the factors that facilitate or inhibit switching. Fuel poor households may switch for significantly different reasons compared to non-fuel poor households. To determine the significance of these reasons, chi-square tests were calculated. These tests were based on the dichotomous $\mathrm{FP}_{10}$ variable and whether respondents indicated that reason for switching. This is a small sample $(n<30)$ and many of the explanatory variables failed to meet the statistical tests' assumptions. A larger sample would offer greater clarification of these results.

\subsubsection{Motivations and deterrents}

The probability that fuel poor households have not switched increases when switching is perceived to be hassle $\left(\chi^{2}=6.19, p=0.013\right)$. No other significant differences were identified between fuel poor and non-fuel poor households' reasons for switching. To gain a general understanding of why households switched energy suppliers and the factors that deterred switching, see section 5.1.4.

\subsubsection{Barriers and facilitators}

Results of chi-square tests suggest that fuel poor households do not face any barriers to switching that are significantly different to non-fuel poor households. Of the variables that met the assumptions of the test, no significant differences were identified that made switching easier for fuel poor households compared to non-fuel poor households. To gain a general understanding of the factors that promote switching and barriers that prevent switching, see section 5.1.4.

\subsubsection{Proactive and reactive switching}

Proactive switching behaviours of fuel poor households were explored. A dichotomous variable classified respondents as proactive switchers if respondents approached an energy company over the phone or used an energy company's website/Powerswitch to 
switch. Reactive switchers were respondents who switched after being approached by an energy company over the phone or through a door-to-door salesperson. Fuel poor households are no more likely to be proactive switchers than non-fuel poor households $\left(\chi^{2}=0.674, p>0.05\right)$.

The regularity in which respondents investigated the best deal provided an indication of active participation in the market. Responses were coded so that more regular investigation represented greater participation. From a logistic regression test, fuel poor households are no more active in the market than non-fuel poor households $(\operatorname{Exp}(B)=1.125, p=0.564)$.

\section{Summary}

These results reveal:

- Fuel poor $\left(\mathrm{FP}_{10}\right)$ households are more likely to live in private rental properties and have combined bill payers' annual net incomes greater than $\$ 100,001$. The latter result is counter to expectations, as low income households should be fuel poor.

- Switchers are more likely to live in private rental properties, and are less likely to live in privately owned homes. Households receiving a New Zealand pension or superannuation are also less likely to switch.

- There is no significant relationship between switching and spatial or objective measures of fuel poverty.

- The estimated cost of the most recent energy bill is consistently a significant explanatory variable of fuel poverty.

- Seeing your breath condense inside is consistently and significantly the only explanatory variable of switching.

- There appears to be no significant differences between fuel poor and non-fuel poor households' motivations or deterrents to switching.

- There appears to be no significant differences between fuel poor and non-fuel poor households' perceptions on the ease or difficulty of switching. 


\section{6}

\section{Chapter Six: Discussion}

Supplier switching offers fuel poor households a short-term approach to improve energy affordability. This thesis explored the relationship between fuel poverty and switching in Wellington according to suggestions that fuel poor households were, in fact, not benefiting from switching. This chapter discusses the main findings of this research. First, the influence of Wellington's colonial history on the spatial manifestation of fuel poverty is discussed. The colonial legacies are exemplified in socio-spatial trends in residential sorting and have important implications for the identification of fuel poverty in Wellington. Second, in Wellington, switching appears to be an inequitable approach to improving the affordability of energy for fuel poor households. This chapter discusses the potential for implementing geographically targeted policy to support equitable outcomes for fuel poor households. Third, the switching behaviours of households in Wellington are discussed. This research found that fuel poor and non-fuel poor households may have similar switching behaviours and their motivations for switching are also complex, contradictory and counter to economically rational behaviour. Fourth, the range of strategies used by households in Wellington to support achieving adequate energy services, in lieu of switching, is discussed. These strategies are critical for the management of vulnerability to fuel poverty and are linked to national cultures of energy use in New Zealand. This chapter concludes with a discussion of some of the 
limitations of this research, implications of these findings for policy and potential directions for future research.

\subsection{Geography of fuel poverty: Complex \& colonial}

Fuel poverty is a distinctive and multidimensional issue, and consequently complex to measure. In this thesis, the FPI was calculated and used as a spatial indicator of fuel poverty, which can provide an effective means of identifying the fuel poor. The FPI offers a new and spatially refined approach to identifying fuel poverty in New Zealand and was applied to Wellington. The range of factors accounted for within the FPI (such as income, housing quality and energy demand) offers an alternative approach for identifying fuel poverty compared to expenditure based measures.

This study found that, based on the FPI, fuel poverty spatially clusters in Wellington. However, the spatial distribution of fuel poverty is also complex and varied. Variables included within the FPI exhibit distinctive spatial distributions and their contribution to the spatial manifestation of fuel poverty do not necessarily coincide (see Appendix D). The varying spatial distributions of variables included in the FPI supports the use of a spatial indicator to identify fuel poverty and the geography of fuel poverty Wellington.

As this research highlights, the spatial distribution of fuel poverty in Wellington is unique. The colonial history of Wellington and geographic processes occurring in a postcolonial context have a significant influence on the spatial distribution of fuel poverty. These geographic processes are particularly evident in socio-spatial trends in residential sorting. In this research, high income households are more likely to live in meshblocks with, on average, older, smaller properties with high capital values. Morrison (2000) highlights this socio-spatial distribution, documenting the movement of high income households back into Wellington's city centre to reside in the previously depopulated inner-city, colonial, residential suburbs. He argues that high income households aim to secure their income through the purchase and gentrification of Wellington's inner-city properties. By purchasing inner-city properties and through 
gentrification the value of properties in these inner-city colonial suburbs rapidly appreciates which forces low income households to relocate away from these areas.

The spatial outcomes of residential sorting indicate that relationships between factors contributing to fuel poverty do not necessarily occur as expected. While high income households have the ability to 'choose' their place of residence, these households' choice may not necessarily relate to residence in a 'better' location. The findings of this research suggest that, a 'better' location in Wellington may be related to demands broader than what is assumed to make a location desirable in this research, such as housing quality and sunlight hours. Proximity to employment and amenities, or demand for character and heritage housing from Wellington's colonial settler period may be influencing high income households' decision to reside in areas of Wellington characterised by older and smaller residential properties.

Some of the relationships between solar radiation, income and housing quality were also counter to expectations. It was expected that high income households would not be fuel poor based on their ability to afford high quality housing in desirable areas, such as areas which receive high sunlight hours. This research hypothesised that high income would correlate with high quality housing and high solar radiation. However, while high quality housing was correlated with high income, solar radiation was not significantly correlated with either.

The lack of correlation between solar radiation and income or housing quality may reflect that Wellington is different to other contexts. This relationship may also indicate that solar radiation may not be the most appropriate measure of energy demand and an alternative indicator may yield different results. For example, previous research has used aspect as an indicator for sunlight (Daglish et al., 2015). The combination of aspect and solar radiation in a composite indicator of energy demand may yield different results.

The spatial distribution of fuel poverty and contributing factors at a national scale in New Zealand is likely to be more complex and interesting. For example, the geographic differences in electricity prices across New Zealand and spatial dissimilarity of prices in 
neighbouring ENAs identified in this research are likely to influence the geography of fuel poverty. Spatial differences in the price of electricity may result in significant contrasts in the occurrence of fuel poverty in neighbouring areas. Although, analyses of fuel poverty at a national scale may also highlight underlying regional inequalities, ruralurban divides and climatic differences that influence the spatial distribution of fuel poverty.

Analysis of the spatial distribution of fuel poverty in Wellington has identified a unique geography of fuel poverty. The identification of a significant influence of Wellington's colonial history on the geography of fuel poverty in Wellington is an important contribution of this thesis. Additionally, evidence that relationships between factors related to fuel poverty do not necessarily occur as expected challenges our existing understandings of fuel poverty, the influences of factors (such as housing age and household income) on the geography of fuel poverty, and relationships between those factors and fuel poverty.

\subsection{Switching: Improving equitable outcomes}

From the FPI calculated and the survey conducted in this thesis, it appears that there is no significant between supplier switching and expenditure-based or spatial measures of fuel poverty. From an economically rational perspective, one would expect consumers to switch based on the price differences between companies and the savings opportunities available through competition. In particular, fuel poor consumers are expected to behave in an economically rational manner and switch to benefit from improved energy affordability. This result supports the suggestions and evidence which motivated this research, namely that fuel poor households who are in most need of improved energy affordability are not benefiting from supplier switching (Department of Energy and Climate Change, 2015).

In this research, switching does not appear to be an equitable approach to improving energy affordability. This study found that fuel poor households were not switching at greater rates compared to non-fuel poor households. Thus, switching behaviours may 
be the same for both sets of households. Equitable outcomes in the restructured competitive market may be improved by targeting switching amongst specific consumer groups, such as low income and elderly households who are vulnerable to fuel poverty, and are also less likely to switch. Minimising the search and switch costs for these consumer segments (e.g. Old, Status Quo) should be an effective approach. This is the current focus of What's My Number; targeting consumers that "had not yet responded to the campaign" (Electricity Authority, 2014, p. 1).

Competition and switching promotes a two-tiered market. Energy companies desire the acquisition of desirable consumers (i.e. those that will switch and not switch again) and shedding undesirable consumers or areas from their profile. To achieve this, energy companies may offer a competitive price or non-competitive price to consumers based on their switching profile and fit with identified consumer segments. While, no evidence reported by the Electricity Authority suggests that particular consumers are being targeted through price discrimination (Electricity Authority, 2015c), it is uncertain whether a two-tiered market manifests spatially and favours particular locations. However, upon evidence that a two-tiered market exists in New Zealand and is disadvantaging consumer participation in the market, re-evaluation of the competitive market processes should be considered.

Targeting fuel poverty through policy approaches, such as switching, is one option to improve the affordability of adequate energy services and health outcomes for fuel poor households. Specific targeting of fuel poor households in switching policy would ensure that those in greatest need are the true beneficiaries. However, the complexity of fuel poverty may hinder the effectiveness of fuel poverty policy (Dubois, 2012). Identifying clusters of fuel poverty (e.g. coldspots) can assist with the implementation of geographically targeted switching policy. Baker et al. (2007), cited in Walker et al. (2012), discuss the principle of 'geographic equity'. This principle argues that policy should be spatially equitable and implemented so that households in greatest need receive the greatest benefit. This approach would ensure that fuel poor households, those in most need of affordable energy, benefit from competitive markets and improved energy 
affordability. The regulatory effects of participation in the market may also be supported as fuel poor consumers who are characterised as sticky consumers begin to participate.

However, in New Zealand's neoliberal regulatory environment, this policy approach to improving equitable outcomes for fuel poor households may not be effective. Support for fuel poor households in the competitive market to gain benefits from switching may be seen as interference with market and "unwarranted state intervention into personal choice and liberty" (Department of Communications Energy and Natural Resources, 2015, p. 20). The competitive market favours consumers who participate in the market. As such, supporting fuel poor households, or those who are not benefiting from switching, introduces the notion that some consumers should not incur the costs of their decision to not participate in the market.

\subsection{Switching: Motivations, contradictions and processes}

From the survey conducted in this thesis, it appears there may be no significant difference between the factors that motivate or inhibit fuel poor and non-fuel poor household to switch suppliers. In general, however, some dimensions of fuel poverty were significant at improving the likelihood of switching or were indicated to be problematic by the majority of respondents. Some households' switching behaviours were also not influenced by financial incentives.

In this research, most households stated their switching was financially motivated. The majority of respondents reported switching because they were offered a better deal or better value for money. However, households' perceptions of the expense and affordability of energy were not related to switching and some households perceived little economic benefit from switching. This finding represents a contradiction in households' switching behaviours. However, being offered a better deal or better value for money may also represent non-financial factors. A better deal, for example, may not be seen as financial, but related to convenience or customer services. The contradiction reflected in this finding offers support for non-monetary factors having a significant influence on consumers switching behaviours. 
Consumers may place a higher value on their time than the potential benefits of switching. Many households reported that they had not switched because it was time consuming or a hassle. Small savings, relative to the costs of searching for the best deal, also appear to be of little interest to households in Wellington. On average, respondents indicated savings nearly four times the average for New Zealand ( $\$ 161.56)$ would be needed to make switching worthwhile (Elecitricity Authority, 2014). High savings may be required to compensate households for lost time in switching energy suppliers. This figure is high compared to North Carolina (USA), where McDaniel and Groothuis (2012) identify a minimum savings threshold of $\$ 200$ which would motivate households to switch.

Based on the survey results, it appeared that seeing one's breath indoors was the only variable that significantly improved the likelihood of switching. This relationship suggests that switching may be triggered by an atmospheric indication of cold homes, a visual manifestation of unaffordable energy services. Conversely, switching may be a behaviour dominated by 'bargain hunters' (Electricity Authority, 2015c). Households that fit these consumer segments or personalities are likely to have thrifty energy behaviours and low energy expenditure. These households, despite switching and assuming financial savings are gained, would not direct any nominal financial benefit towards the increased consumption of energy services, such as heating. Although, the potential for switching to contribute to improved energy services may be offset as majority of households indicated they would not heat their home to higher temperatures with these savings.

Post-switching competition may be discouraging consumers' participation in the market and switching behaviours. The findings of this research indicate that switching is considered difficult when previous energy suppliers contact households, post-switching, to win their business back. When this occurs it is known as a 'save' or 'win-back'14. The

\footnotetext{
${ }^{14}$ Saves occur during the switching process and result in switchers withdrawing their decision to switch because their energy company succeeds in maintaining their business (Electricity Authority, 2014b). Winbacks occur within the first 10 days following a switch in which the losing retailer is able to convince the consumer to switch back (Electricity Authority, 2014b).
} 
literature on switching behaviours focuses on the processes related to consumers' decision to switch. However, post-switching processes also appear to influence decisions to switch. Through a learning-effect from an initial switch the costs of switching may increase if post-switching competition is experienced and viewed as difficult.

The difficultly of switching associated with saves and win-backs is less understood, particularly from a consumers' perspective. However, the process in which postswitching competition is conducted may influence the difficulty of switching associated with saves and win-backs. Previous research indicates consumers' switching behaviours are more likely to be influenced by tangible processes of consumer engagement and relationship management than the intangible delivery of electricity (Walsh et al., 2005). Furthermore, switching is related to loyalty, satisfaction and trust with the energy company, which Yang (2014) argues is maintained through the effective management of relationships with consumers. Thus, the process of engaging consumers in competition and switching, particularly post-switching, may negatively impact consumers' future decisions to switch and participate in the market.

Understanding consumer segments and tailoring campaigns towards the reasons which motivate their switching behaviours is one method to promote switching. In this study, seeing one's breath indoors was the only variable to significantly improve the odds of switching. This result has implications for What's My Number campaigns which tend to focus on the monetary savings of switching. The effectiveness of these campaigns may be improved by targeting non-monetary dimensions of switching such as experiences of the cold and the realities of unaffordable energy services.

\subsection{Strategies for coping with the cold}

In lieu of switching energy suppliers, respondents reported using a range of coping strategies to keep the cost of the energy bill low and obtain adequate energy services. These strategies constitute everyday actions that are often tied to social norms, behaviours and perceptions which shape the way energy is used within the home 
(Shove, 2003). The consequences of inadequate energy services are more severe for fuel poor households. As such, coping strategies used by fuel poor households to keep the cost of the energy bill low may involve a more conscious "process of trading, juggling and manipulation whether of clothes, activity and daily routine" (O'Sullivan et al., 2014; Shove, 2003, p. 6). However, the consistency in which some of these strategies were reported suggests that particular coping strategies may be normal in Wellington and related to national cultures informing energy use in New Zealand.

In this research, respondents indicated a strong use of "sufficiency strategies". Sufficiency strategies are "all actions geared towards reducing energy consumption through cutbacks and sacrifices" (Brunner et al., 2012, p. 55). Common sufficiency strategies used by respondents in this research included heating and using one room, and the opening and closing of doors to control the flow of heat. These strategies indicate a spatial rationing of heating and subsequent "spatial shrink" where households restrict occupancy to rooms in the house that are heated (Liddell \& Guiney, 2015, p. 197). For these households, sufficiency strategies create a particular geography of the home. This geography limits households' occupancy to spaces of warmth, while also supporting the construction of the home as a space of resilience and adaptation to fuel poverty (Anderson et al., 2012; Brunner et al., 2012). Respondents also resorted to coping strategies outside of their home, for example in public indoor spaces. This represents a spatial expansion of the impacts of fuel poverty and strategies to obtain adequate energy services.

While the majority of respondents commented on limiting or manipulating space heating in the home as a strategy to obtain adequate energy services, few reported on limiting the use of lighting and water heating. This may be related to an inability to articulate and quantify adequate lighting and water heating (Shove, 2003). Respondents did, however, comment on turning off or regulating the use of non-essential items (e.g. lights and appliances at the wall). These "switch-off habits" are promoted by EECA and are estimated to save households $\$ 200$ annually (Energy Efficiency and Conservation Authority, 2015). 
Participants in Brunner et al.'s (2012) study in Austria reflected on the connection between their upbringing and coping strategies. In Austria, conserving energy and not being wasteful is a widespread social norm. In this research, some respondents reported being a "born-budgeter" and "naturally frugal". In Wellington, these personalities or attitudes towards energy use, connected to their upbringing, appear to provide some sense of justification for coping with the cold and limiting energy use. For these households, frugality may offer integrity, self-respect, or a sense of achievement in the management of household resources (Anderson et al., 2012). Some respondents also reported teaching their children about using resources wisely. This may form part of an inter-generational process in which energy practices informed by parents' upbringings are passed down to children and reinforce cultures of energy use in New Zealand.

However, the presence of children may also encourage parents to keep their house warm. Many respondents recognised the effects of cold homes on the health of their children and reported sacrificing their personal warmth to keep their children warm and healthy. Being an adult may offer some justification for under-heating or living in the cold, despite the potential for severe health outcomes. One respondent commented, "lacking small children I see no real reason to keep my home warmer than it is". This respondent also reporting not being tempted to install insulation for the same reason.

In Brunner et al.'s (2012) study, fuel poor households' energy use is informed by an environmental awareness. In this research, energy conservation for environmental reasons led many households to limit their energy use. While it cannot be concluded from this research that fuel poor households exhibit a stronger environmental conscience, respondents did overwhelmingly cite (unprompted) environmental reasons for limiting their energy use. Respondents were firm believers that "warming the house $=$ warming the world". This belief is despite the fact that $80 \%$ of New Zealand's electricity is generated from renewable resources. However, without sufficient investment in renewable sources, these attitudes are also accurate as increased energy use leads to a greater reliance on non-renewable sources. The environmental attitudes demonstrated by respondents may be related to a national identity shaped by the 'clean and green' environment which also informs energy use within the home (Cupples et al., 2007). 
Energy use within the home, in particular heating, is considered "flexible and amenable to daily variation" (Anderson et al., 2012, p. 41). To obtain adequate energy services, coping strategies and flexible energy use are critical approaches used by households to manage their vulnerability to fuel poverty. Coping strategies demonstrate households' to be active in the negotiation of fuel poverty in forms of resilience that manage the affordability and adequacy of energy services in the home.

\subsection{Defining fuel poverty: A case for re-evaluation}

Based on this research, the application of Boardman's 10\% threshold in New Zealand to calculate fuel poverty requires re-evaluation. The $10 \%$ threshold was used in this research as an indicator of fuel poverty based on actual expenditure; fuel poverty occurs when households do not have adequate energy services for 10 per cent of income. In this research, fuel poor households were more likely to have incomes greater than $\$ 100,001$. This outcome is contrary to expectations as fuel poor households are expected to have low incomes. This result indicates that fuel poor households, in this research, may be incorrectly identified.

This research makes the case for the use of Boardman's definition to identify fuel poverty in New Zealand; a household is fuel poor if they need to spend more than $10 \%$ of income to afford adequate energy services (Lloyd, 2006; Howden-Chapman et al., 2012). As New Zealand has a culture of under-heating homes, the 'need to spend' concept is particularly important in this context as it captures households who are fuel poor and spend less than $10 \%$ of income on energy services. However, identifying these households requires data currently unavailable in New Zealand.

\subsection{Data Quality and limitations}

Predicting the spatial distribution of a multidimensional issue such as fuel poverty proves challenging and is subject to the parameters set by the research. Identification of fuel poverty is constrained by the method of measurement, and the accuracy and 
quality of data. The complexity of identifying fuel poverty results in policies targeted towards its eradication being "necessarily imperfect" (Dubois, 2012, p. 107). Consequently, many fuel poor households remain hidden in the spatial distribution of fuel poverty.

Data on individuals' income and sources of income is collected in the New Zealand census. This data from the most recent census conducted in 2013 is publicly available at meshblock level from Statistics New Zealand. In this study, meshblocks were used which are the lowest geographic scale at which data is publicly available. Meshblocks offer a refined analysis of fuel poverty and are appropriate for identifying the spatial distribution of fuel poverty within Wellington.

In this thesis, the use of income data from the census provides an accurate reflection of households' income. This is in comparison to Walker et al.'s (2013) study, for example, where a measure of income deprivation is based on relative poverty calculated through microsimulation rather than actual household income.

Housing quality data is not currently available in New Zealand. As such, proxies offered a suitable measure of housing quality in the FPI. Data on housing capital value and housing age provided by Wellington City Council were from the most recent request for this data, prior to this research. Housing age was provided by decade dating to $1880-89$ and included a category for re-modified buildings. Building footprints do not account for multiple-level housing, although all structures except buildings (e.g. garages, verandas) were excluded from this analysis. Capital value, housing age and building footprints include non-residential buildings in their calculations. For a discussion on the suitability and limitations of the HQI see Section 3.3.5.

Proxies of housing quality provide only an indication of the factors they represent and may reflect other factors to a greater extent. For example, capital value is assumed to reflect desirable locations and properties, however in this research it was negatively correlated with solar radiation. Capital value may provide a greater indication of other factors, for example the property market (e.g. housing scarcity) or proximity to employment and other services. Consideration for the local context is required in the 
case that variables may not represent the factors or relationships they are intended to model.

Compared to modelling energy demand through spatial interpolation of sparsely distributed weather stations (e.g. Walker et al., 2013), solar radiation provides an accurate measure of energy demand. There is excellent agreement between observed solar radiation and solar radiation as modelled in ArcGIS (Fu \& Rich, 1999), and the accuracy of modelled solar radiation was maximised by using a $1 \mathrm{~m}$ DEM, the highest spatial resolution available. Solar radiation for the months of winter was used to model energy demand. Calculating solar radiation for a full year may influence the results and observed distribution of solar radiation.

Re-evaluation of weights assigned in spatial indicators of fuel poverty is required as they may not reflect real variable relationships. The FPI was largely informed by Walker et al.'s (2013) fuel poverty model for Northern Ireland. In line with their method, proxies were used to represent income, housing quality and energy demand and weights for variables included in the FPI were assigned using a-priori methods. In this research, assigned weights were adjusted to place greater importance on housing quality, argued to make fuel poverty a distinctive issue. Observed data was also assigned a higher weighting than modelled data. In doing so, assumptions were made about variables' contribution to fuel poverty. For example, some variables in the FPI were weighted equally. These weights assume variables have an equal contribution to the spatial distribution of fuel poverty and may not accurately reflect the real variable relationships.

The focus of this thesis also restricted analysis of fuel poverty through the FPI to three central dimensions: income, energy demand and housing quality. Broader factors are likely to exert an influence on the spatial distribution of fuel poverty. Expanding the FPI calculated in this thesis to include a wider range of variables will improve the accuracy of identifying fuel poverty using spatial indicators. Given improved data collection and quality at a national level, the accuracy of fuel poverty models will also improve.

Previous spatial indicators of fuel poverty, as well as the FPI in this research, have been mapped onto planar surfaces. However, a model that accounts for elevation may 
provide new insight into the spatial distribution of fuel poverty in topographically complex areas. This aspect is particularly important for Wellington. The $1 \mathrm{~m}$ DEM accounted elevation effects to some extent. However, other factors that affect solar radiation, such as shading from tall buildings or vegetation foliage, which may influence the distribution of solar radiation are not accounted for in the DEM. In ArcGIS, consideration for the effects of elevation, such as aspect and shade, can also be applied to future indicators of energy demand.

There are inaccuracies of measuring fuel poverty at an aggregated spatial scale. For example, aggregated data may obscure a "hidden geography of fuel poverty" (Morrison \& Shortt, 2008, p. 712). There is also the risk of falsely applying an understanding of the FPI and spatial distribution to all households; an error known as ecological fallacy (Morrison \& Shortt, 2008). This situation occurs when statements are made about individual households which the aggregated data represents. In this way, fuel poverty indices are restricted to a prediction of where fuel poverty may occur, rather than its actual occurrence. Morrison and Shortt (2008) and Walker et al. (2012) reflect on the consequences of aggregated data and ecological fallacy. Both studies query the extent to which fuel poverty is measurable at any level other than the household level. However, the FPI calculated in this thesis provides an effective tool at predicting the distribution of fuel poverty at the lowest geographic unit for which data is publicly available. Although, identification of fuel poverty at a household level will be required to separate fuel poor from non-fuel poor households in the implementation of equitable policy.

Application of Boardman's 10\% threshold based on actual energy expenditure limited the identification of fuel poverty. Identification of fuel poverty based on actual energy expenditure is shown to underestimate the proportion of households that are fuel poor (Moore, 2012). However, the data to apply Boardman's definition and the need to spend concept is not available in New Zealand.

Data collected in the EPWHS was based on questions from the New Zealand census and previous research (see Section 3.5.2). While the response rate to this survey reflected 
the successful application of the TDM, few respondents who were fuel poor had also switched energy companies $(n=23)$. As a result, the assumptions of some statistical tests in Chapter Five were not met. This limited the identification of significant relationships between fuel poverty and switching. Distributing surveys amongst a larger sample would remedy this limitation by identifying more fuel poor households who have also switched in order to improve the potential to identify significant relationships between fuel poverty and switching behaviours.

\subsection{Recommended policy responses}

As it appears, retail competition and switching has not restrained overall increases in the price of electricity in New Zealand. If electricity price increases are unabated by switching behaviours, increasingly unaffordable energy may be an inevitable outcome for greater numbers of New Zealand households. Any future benefits of switching to improve energy affordability may be subsequently minimal. Mechanisms to support a reduction in the cost of electricity or price stabilisation are necessary, although legally constrained in New Zealand. In light of this political context, findings from this research have the potential to inform responses to improving the affordability of energy services for fuel poor households in New Zealand.

In the absence of housing energy efficiency data in New Zealand, this thesis used proxies as indicators for housing quality. Introducing measures of housing energy efficiency based on standardised assessments, for example the UK's EPC and SAP (see Section 3.2.4), tied to the purchase and sale of property, and prioritised access to policy would be advantageous. New Zealand households would benefit from a measure of housing energy efficiency as it would offer some motivation for home owners and landlords to invest in housing energy efficiency. A measure of housing energy efficiency would also benefit future analyses of fuel poverty in New Zealand and improve the accuracy of predicting fuel poverty. This measure would also support geographic targeting of policy. The WOF currently being developed for public rental properties in New Zealand has the potential to act as an equivalent to EPCs if expanded to all properties. The Government's 
approach to the WOF should be revised to allow its future development as a measure of housing energy efficiency, in line with established procedures such as the SAP.

This research supports previous research which indicate the significant influence of nonmonetary factors on switching behaviours. This result indicates that the promotion of switching through the What's My Number campaign should be re-evaluated. What's My Number promotes switching based on the expectation that consumers behave in an economically rational manner. In this study, experiences of the cold, such as seeing your breath inside, is a significant explanatory variable of switching behaviours in Wellington. Targeting experiential motivations for switching in What's My Number campaigns may increase switching rates. Through this approach, switching is related to the tangible outcomes of an inability to afford adequate energy services and households may associate the possibilities of improved energy affordability, such as additional warmth, with switching.

Based on international comparisons, switching rates in New Zealand are high and relatively efficient. However, the opportunity exists to improve switching rates by improving the efficiency of switching. In this research, the primary barriers to switching were the time consuming nature and hassle associated with switching. These barriers may be related to both pre-switching search costs and switch costs, as well as postswitching competition. If promoting increased switching and competition remains an objective of the Electricity Authority, identifying and acting towards the minimisation of these main barriers is necessary. Reducing the barriers to switching would improve the switching rate and benefit to consumers, as well as support the regulation of electricity prices.

This research found that fuel poor and non-fuel poor households are generally not proactive in their switching behaviours, rather they are responsive to being approached by energy companies. Thus, active participation in the electricity market is low and consumers switching behaviours are reactive. Reactive switching behaviours may be tied to the low support for households to establish habitual switching behaviours. For example, there is little incentive for consumers to switch during the summer and What's 
My Number campaigns are released during the winter to promote switching during a time when households are more sensitive to electricity prices. In this research, switching was connected to when people were moving house. This result may be explained by the need for energy companies to be notified about the change in a households' billing address. It may be that seasonal campaigns and switching when moving house lead to consumers switching once a year or less, and establishing infrequent switching behaviours. Encouraging habitual switching behaviours may be effective at improving the affordability of energy for some households, and facilitating greater competition and price regulation.

\subsection{Future research}

Further research into the geography of fuel poverty in New Zealand will provide greater insight to the occurrence of fuel poverty in New Zealand. From this research, it is evident that the occurrence of fuel poverty in Wellington is significantly influenced by Wellington's colonial history and geographic processes occurring in a postcolonial setting. Many countries where fuel poverty has been documented, lie outside of a postcolonial context. As such, future analyses of the unique postcolonial setting, and the associated structural and social processes are critical in expanding our understanding of fuel poverty in New Zealand.

Considerations for ethnicity have not featured prominently within the literature to date, although are central to postcolonial analyses. In New Zealand, no research has specifically considered the experiences of fuel poor Māori and only assumed a relationship based on deprivation statistics. This research indicates that Māori and other minority ethnicities are significantly more likely to live in fuel poor areas. Māori households may also use alternative coping strategies to keep warm, such as sleeping "marae style", as commented by one respondent in this research, or a greater reliance on social networks for support, in particular whanau. Future research would benefit by exploring the connection between ethnicity, fuel poverty, and energy use in the home. 
While spatial outliers of fuel poverty were identified in Wellington, outliers may be less pronounced at lower geographic scales, for example at meshblock level. Investigation into the profiles of spatial outliers of fuel poverty may provide insight to these anomalies in the spatial distribution of fuel poverty. At higher geographic scales, for example a national level, spatial outliers may be more pronounced and provide a more interesting understanding of the geography of fuel poverty. However, national analyses may also reflect underlying regional inequalities.

This research supports evidence that switching is related to non-monetary factors. Furthermore, the literature has a limited understanding of consumers' post-switching interactions with the market. Consideration for these dimensions and their influence on switching behaviours will provide insight into ways in which switchers interact with the market. Such an investigation will also provide insight as to whether post-switching competition, for example saves and win-backs, is detrimental to the ability of new entrant retailers to compete in the market and impact consumers' future switching behaviours. These understandings will provide insight into how households, and in particular fuel poor households, can be supported in switching.

\section{Summary}

This thesis offers support to suggestions that fuel poor households may not benefit from supplier switching. In Wellington, switching appears to be an inequitable approach to improving energy affordability. Improving equitable outcomes may be achieved through the promotion of switching using geographically targeted methods, although this option may be an unfavourable imposition of state power in the competitive market and inefficiencies.

The complexity of identifying fuel poverty in Wellington is demonstrated in the geography of fuel poverty. This research demonstrated a lack of overlap between variables assumed to be related in Wellington. Wellington's colonial history also has an important role in the spatial manifestation of fuel poverty and is particularly evident in 
socio-spatial trends in residential sorting. Thus, the geography of fuel poverty in Wellington is unique and complex.

From this research, fuel poor and non-fuel poor households appear to have similar switching behaviours. That is, fuel poor households in most need of affordable energy do not switch at a higher rate. From an economically rational perspective, this is counter to expectations. Switching behaviours also appear to be affected by the processes behind switching, such as post-switching competition.

Many households used coping strategies to obtain adequate energy services in their home. These strategies also create particular geographies associated with fuel poverty. In the use of coping strategies, households are active agents in creating a space of resilience to fuel poverty as well as this space of resilience extending beyond the home into public spaces. There is evidence that national and personal identities influence energy use in the home and that these cultures are passed down through generations.

There is a need to establish an official definition of fuel poverty in New Zealand. The improved collection and quality of data will support the identification of fuel poverty and the implementation of responses recommended in this thesis to support equitable outcomes. In this regard, future research will support greater recognition of fuel poverty and equitable outcomes for fuel poor households in New Zealand. 


\section{7}

\section{Chapter Seven: Conclusion}

The aim of this thesis was to explore the relationship between fuel poverty and supplier switching. Suggestions that fuel poor households, in most need of affordable energy, were not benefiting from supplier switching and the limited empirical supporting this relationship warranted further investigation. Switching offers fuel poor households a low-cost opportunity to improve the short-term affordability of energy while also avoiding the stigma attached to other policies targeting fuel poverty. A geographic lens was used to explore the relationship between fuel poverty and supplier switching which sought to provide new insight to understandings of fuel poverty in New Zealand and address the relative absence of geography within the fuel poverty literature.

This thesis addressed four main objectives. First, explore the spatial distribution of fuel poverty in Wellington. Second, explore the relationship between fuel poverty and supplier switching. Third, explore the reasons why fuel poor households switch energy suppliers. Fourth, explore the factors that facilitate and inhibit fuel poor households from switching energy suppliers. To address these objectives a spatial indicator of fuel poverty was calculated and a postal survey conducted. The following chapter summarises the findings of this research and responds to the overarching aim of this thesis.

The geography of fuel poverty in Wellington demonstrates a pattern of spatial clustering. Further evidence for the spatial clustering of fuel poverty was identified in this thesis based on the spatial coincidence of variables included in the FPI. Yet, complex 
and contradictory patterns in the geography of fuel poverty are also evident. Some variables included in the FPI are stronger predictors of fuel poverty in some locations compared to others and others do not spatially coincide. These findings indicate that dimensions influencing the geography of fuel poverty in Wellington may not entirely follow the expected relationships.

The geography of fuel poverty in Wellington is unique due to the colonial history and ongoing geographic processes occurring in postcolonial Wellington. As evidenced in socio-spatial trends in residential sorting, factors expected to contribute to the spatial manifestation of fuel poverty in some locations are not necessarily related as expected. Thus, the geography of fuel poverty is locally contingent and embedded within unique spatial and temporal contexts.

Identifying the geography of fuel poverty has emphasised the complexity of predicting the occurrence of fuel poverty. The geography of fuel poverty is dependent on the variables used to calculate fuel poverty, each subject to unique geographies, as well as the spaces, scales and geographical units used to measure fuel poverty. Additionally, this thesis provided evidence suggesting that geographic differences in electricity prices and other factors are likely to make identifying the spatial distribution of fuel poverty across a national scale more complex and interesting. In addressing the first research objective, a greater understanding of identifying fuel poor households has been achieved by understanding the geography of fuel poverty in Wellington.

In response to the second objective of this research, a spatial relationship between fuel poverty and supplier switching was not identified when measured against fuel poverty deciles according to the FPI. No further relationship between switching and fuel poverty was identified when measured based on actual energy expenditure. Thus, there is no objective or spatial relationship between fuel poverty and switching. This thesis supports evidence that fuel poor households, in comparison to non-fuel poor households, are not benefiting from switching.

The final research objectives explored factors that motivated switching and factors that facilitated a households' ability to switch. From an economically rational perspective, the absence of a relationship between fuel poverty and supplier switching indicates that 
fuel poor households are not behaving in an economically rational manner. Fuel poor households, in particular, would be expected to behave in an economically rational manner and switch due to an inability to afford adequate energy services for $10 \%$ of total income. The results of this research suggest that the switching behaviours of fuel poor and non-fuel poor households, based on actual energy expenditure, appear to be similar.

Households' switching behaviours and the financial reasoning behind switching are complex, and contradictory. Counter to expectations, households' perceptions towards the expense and affordability of the energy and their energy bills were not related to their switching behaviours. Yet respondents to the survey reported financial motivations as the main reason for switching energy suppliers. Minimum savings required to make switching worthwhile were also in excess of the national average, suggesting New Zealanders may hold unrealistic expectations about the potential financial benefits of switching or require high financial compensation for switching.

This thesis also indicates that switching is influenced by non-monetary factors. Seeing your breath inside ('dragon breath') during the winter was the only explanatory variable that consistently and significantly improved the likelihood that households had switched. The relationship between switching and seeing your breath condense inside may be explained by seeing one's breath inside being a physical manifestation of energy unaffordability. Alternatively, switching may be a behaviour dominated by 'bargain hunters' and 'born budgeters'. Households that fit these consumer segments or personalities are likely to under heat their homes regardless of the financial benefit of switching.

Fuel poor households in this research do not experience any significant disadvantage in the market that would otherwise limit or prevent switching behaviours. Similarly, no factors greatly improved households' propensity to switch. The process of switching may, however, have a greater influence on a household's likelihood of switching. Switching was thought to be a hassle, time consuming and post-switching competition to win-back consumers' business made switching difficult. Consumers may be more 
sensitive to the processes of switching and engagement in the market rather than delivery of electricity as a good itself.

Switching appears to be a reactive process connected to active competition between energy companies, rather than a proactive process or one of consumer stimulated competition. That is, while consumers can choose their energy supplier, and are largely aware of that choice, any choice may not be proactively applied in decisions to switch. Switching is motivated by competition between companies and corporate agendas, rather than based on consumers' needs for affordable energy and their recognition of the potential for switching and competition to improve energy affordability.

The expectation for households to behave in an economically rational manner may be insufficient to encourage households to switch energy suppliers and improve equitable outcomes for fuel poor households therein. Switching energy suppliers is also not a common strategy used to improve the affordability of energy services by households to improve the affordability of adequate energy services. Rather, the use of coping strategies is common to ensure affordable and adequate energy services in the home are met.

Many of the coping strategies used by households were related to established norms and behaviours in New Zealand. These supported evidence for a local culture of tolerance and coping with energy inefficient housing and high energy prices. These strategies reflect householders as active agents in the negotiation of fuel poverty and the construction of the home as a space of resilience to fuel poverty. The use of coping strategies to improve the affordability of adequate energy services challenges households' vulnerability to fuel poverty and represents consumers as active in the negotiation of fuel poverty.

The evidence for spatial clustering of fuel poverty in Wellington and no significant difference between consumers switching behaviours, motivations and barriers to switching offers support for the implementation of geographically targeted fuel poverty policy. Application of geographically targeted policy should consider 'geographic equity' to ensure that households masked by the aggregation of statistics elsewhere are included in policy, or excluded in the opposite circumstances. However, the complexity 
and multidimensional nature of fuel poverty makes the identification of fuel poverty and targeting of policy difficult. Based on the unavailability of data, geographic analyses at meshblock level offer a refined method for targeting fuel poor households within policy. Although, additional screening for fuel poverty will be required to ensure precise targeting of policy.

This thesis aimed to explore suggestions that fuel poor households were not benefiting from supplier switching in the context of Wellington, New Zealand. This research was warranted as supplier switching offers fuel poor households a low-cost and short-term opportunity to improve the affordability of energy within the home. A geographic approach was taken to identify fuel poverty. In doing so the spatial distribution and geography of fuel poverty in Wellington was identified. The suggestion that fuel poor households are not benefiting from supplier switching is supported by both objective and spatial measures of fuel poverty. The opportunity exists to apply geographic targeting to promote switching in areas vulnerable to fuel poverty and in most need of improved energy affordability. Expanding campaigns promoting switching in New Zealand so that non-monetary factors, such as experiences of the cold, are targeted alongside economically rational behaviour may entice more households to switch energy suppliers and lead to improved outcomes. Geographic understandings of fuel poverty can support the implementation of targeted policy aimed at improving the affordability of energy services and the overall reduction of fuel poverty in New Zealand. 


\section{References}

Anderson, J. (2009). Electricity restructuring: a review of efforts around the world and the consumer response. The Electricity Journal, 22(3), 70-86.

Anderson, W., White, V., \& Finney, A. (2012). Coping with low incomes and cold homes. Energy Policy, 49, 40-52.

Annala, S., Viljainen, S., \& Tuunanen, J. (2013). Rationality of supplier switching in retail electricity markets. International Journal of Energy Sector Management, 7(4), 459-477.

Anselin, L. (1995). Local indicators of spatial association-LISA. Geographical analysis, 27(2), 93115.

Baker, W., Starling, G., \& Gordon, D. (2003). Predicting fuel poverty at the local level: Final report on the development of the Fuel Poverty Indicator. Centre for Sustainable Energy. Retrieved 15 Decemeber 2015, from www.cse.org.uk/downloads/file/fuelpoverty-indicator-report.pdf

Bansal, H. S., Taylor, S. F., \& James, Y. S. (2005). "Migrating" to new service providers: Toward a unifying framework of consumers' switching behaviors. Journal of the Academy of Marketing Science, 33(1), 96-115.

Bennett, J., Chisholm, E., Hansen, R., \& Howden-Chapman, P. (2014). Results from a Rental Housing Warrant of Fitness Pre-Test. Retrieved 13 October 2015, from http://wellington.govt.nz/ /media/your-council/news/files/2014/rental-housingwof.pdf

Bertram, G. (2006). Restructuring the New Zealand electricity sector 1984-2005. In F. P. Sioshansi \& W. Pfaffenberger (Eds.), Electricity Market Reform: An International Perspective (pp. 203-234). Oxford, UK: Elsevier.

Bertram, G. (2015). Neoliberalism and energy poverty: why corporatisation, deregulation and privatisation doubled the cost of electricity for New Zealand households. Lecture to mark 100 years of Continuing Education at Victoria University. Retrieved 03 December 2015, from

http://www.geoffbertram.com/fileadmin/publications/How\%20neoliberalism\%20dou bled\%20the\%20price\%20of\%20electricity.pdf

Bertram, G., \& Twaddle, D. (2005). Price-cost margins and profit rates in New Zealand electricity distribution networks since 1994: the cost of light handed regulation. Journal of Regulatory Economics, 27(3), 281-308.

Blackwell, S. (2009). Electricity Conservation in Context: A Mixed Methods Study of Residential Conservation Behaviour During an Electricity Shortage in New Zealand. (Master of Environmental Studies), Victoria University of Wellington. Retrieved from http://hdl.handle.net/10063/1099 
Boardman, B. (1991). Fuel poverty: from cold homes to affordable warmth. London, UK: Belhaven Press.

Boardman, B. (2010a). Fixing fuel poverty: challenges and solutions. London, UK: Routledge.

Boardman, B. (2010b). Liberalisation and fuel poverty. In I. Rutledge \& P. Wright (Eds.), UK Energy Policy and the End of Market Fundamentalism (pp. 225-280). Oxford, UK: Oxford University Press.

Boardman, B., \& Fawcett, T. (2002). Competition for the Poor: Liberalisation of Electricity Supply and Fuel Poverty: Lessons from Great Britain for Northern Ireland Environmental Change Institute, University of Oxford. Oxford, UK.

Bond, S. (2013). Assessing New Zealand Householders' Home Use Behaviours: How Energy Efficient are they? Pacific Rim Property Research Journal, 19(1), 17-41.

Bosch, M. (2014). Trial of Rental Housing Warrant of Fitness Scheme with Housing New Zealand. Retrieved 13 October 2015, from http://www.mbie.govt.nz/infoservices/housing-property/pdf-document-library/trial-rental-housing-wof-schemehousing-nz-report.pdf

Bouzarovski, S., Tirado Herrero, S., Petrova, S., \& Ürge-Vorsatz, D. (2015). Unpacking the spaces and politics of energy poverty: path-dependencies, deprivation and fuel switching in post-communist Hungary. Local Environment, 1-20.

Brunner, K.-M., Spitzer, M., \& Christanell, A. (2012). Experiencing fuel poverty. Coping strategies of low-income households in Vienna/Austria. Energy Policy, 49, 53-59.

Calvert, K. (2015). From 'energy geography'to 'energy geographies' Perspectives on a fertile academic borderland. Progress in Human Geography. doi: $10.1177 / 0309132514566343$

Chang, K. (2012). Introduction to Geographic Information Systems (6th ed.). New York, USA: McGaw-Hill.

Chester, L., \& Morris, A. (2012). A new form of energy poverty is the hallmark of liberalised energy sectors. Australian Journal of Social Issues, 46(4), 435-459.

Cupples, J., Guyatt, V., \& Pearce, J. (2007). "Put on a jacket, you wuss": cultural identities, home heating, and air pollution in Christchurch, New Zealand. Environment and Planning A, 39(12), 2883.

Daglish, T., de Róiste, M., Saglam, Y., \& Law, R. (2015). Commuting and Residential Decisions in Greater Wellington Region. Institute for the Study of Competition and Regulation. Wellington, New Zealand. Retrieved from http://hdl.handle.net/10063/4184

Defeuilley, C. (2009). Retail competition in electricity markets. Energy Policy, 37(2), 377-386.

Department of Communications Energy and Natural Resources. (2015). Towards a New Affordable Energy Strategy for Ireland. Retrieved 03 February 2015, from http://www.dcenr.gov.ie/energy/Lists/Consultations\%20Documents/Affordable\%20En ergy\%20Consultation\%20Paper.pdf

Department of Energy and Climate Change. (2014). Standard Assessment Procedure. Retrieved 03 January 2016, from www.gov.uk/guidance/standard-assessmentprocedure

Department of Energy and Climate Change. (2015). Cutting the cost of keeping warm: A fuel poverty strategy for England. Retrieved 07 December 2015, from www.gov.uk/government/uploads/system/uploads/attachment data/file/408644/cut ting the cost of keeping warm.pdf

Dillman, D. A., Smyth, J. D., \& Christian, L. M. (2009). Internet, mail, and mixed-mode questionnaires: The tailored design method. New Jersey, USA John Wiley \& Sons, Inc.

Ek, K., \& Söderholm, P. (2008). Households' switching behavior between electricity suppliers in Sweden. Utilities Policy, 16(4), 254-261.

Elecitricity Authority. (2014). Residential savings. Retrieved 26 January 2016, from http://emi.ea.govt.nz/r/ybl23 
Electricity Authority. (2012). What's My Number: A changing landscape for New Zealand electricity consumers. Retrieved 31 March 2015, from www.ea.govt.nz/dmsdocument/15534

Electricity Authority. (2014a). International comparison of activity, behaviour and attitudes towards electricity industry: A quantitative study. Retrieved 31 March 2015, from www.ea.govt.nz/dmsdocument/19155

Electricity Authority. (2014b). Proposed Code amendment - Saves and early win-backs: Consultation Paper. Retrieved 03 January 2016, from www.ea.govt.nz/dmsdocument/18175

Electricity Authority. (2014c). What's My Number: Competition and choice - a review of the 2013 campaign. Retrieved 03 January 2016, from www.ea.govt.nz/dmsdocument/18331

Electricity Authority. (2015a). Disconnections for non-payment: January 2006 - June 2015. Retrieved 07 December 2015, from http://www.emi.ea.govt.nz/Datasets/download?directory=\%2FDatasets\%2FRetail\%2F Disconnections\%2F20150930.disconnection for non payment.pdf

Electricity Authority. (2015b). Electricity prices falling as competitive market pressure increases [Press release]. Retrieved from http://www.ea.govt.nz/about-us/media-andpublications/media-releases/2015/17-september/

Electricity Authority. (2015c). Overview - Shopping Around for Electricity Retailers: A Quantitative Study among the General Public. Retrieved 07 December 2015, from www.ea.govt.nz/dmsdocument/19368

Electricity Authority. (2015d). Relative switching. Retrieved 04 January 2016, from http://www.emi.ea.govtnz/r/x4j5x

Electricity Authority. (2015e). Residential Electricity Market Performance: Empowering Decisions - 2014 in Review. Retrieved 3 December 15, from www.ea.govt.nz/monitoring/residential-electricity-market-performance/2014/

Electricity Authority. (2015f). Switching trends. Retrieved 07 December 2015, from http://www.emi.ea.govt.nz/r/xhasd

Electricity Authority. (2015g). What's My Number Campaign Statistics. Retrieved 30 November 2015, from www.ea.govt.nz/about-us/what-we-do/whats-mynumber/campaign-statistics/

Electricity Authority. (2016). Market share snapshot. Retrieved 26 January 2016, from http://www.emi.ea.govt.nz/r/w1w3c

Electricity Authority. (n.d.). What we do. Retrieved 07 December 2015, from https://www.ea.govt.nz/about-us/what-we-do/

Ellsworth-Krebs, K., Reid, L., \& Hunter, C. J. (2015). Home-ing in on domestic energy research:"House," "home," and the importance of ontology. Energy Research \& Social Science, 6, 100-108.

Energy Efficiency and Conservation Authority. (2015). Switch off and save. Retrieved 03 January 2016, from www.energywise.govt.nz/resources-and-tools/the-energyspot/switch-off-and-save/

ESRI. (n.d.). How Grouping Analysis works. Retrieved 15 November 2015, 2015, from http://pro.arcgis.com/en/pro-app/tool-reference/spatial-statistics/how-groupinganalysis-works.htm

Fahmy, E., Gordon, D., \& Patsios, D. (2011). Predicting fuel poverty at a small-area level in England. Energy Policy, 39(7), 4370-4377.

Fu, P., \& Rich, P. M. (1999). Design and implementation of the Solar Analyst: an ArcView extension for modeling solar radiation at landscape scales. Proceedings of the Nineteenth Annual ESRI User Conference. Retrieved from http://www.researchgate.net/publication/266576778 
Getis, A., \& Ord, J. K. (1992). The analysis of spatial association by use of distance statistics. Geographical analysis, 24(3), 189-206.

Gibson, P. J., Koepsell, T. D., Diehr, P., \& Hale, C. (1999). Increasing response rates for mailed surveys of Medicaid clients and other low-income populations. American Journal of Epidemiology, 149(11), 1057-1062.

Grimes, A., Denne, T., Howden-Chapman, P., Arnold, R., Telfar-Barnard, L., Preval, N., \& Young, C. (2012). Cost Benefit Analysis of the Warm Up New Zealand: Heat Smart Programme. Ministry of Economic Development. Wellington, New Zealand. Retrieved from http://www.healthyhousing.org.nz/wp-content/uploads/2012/05/NZIF CBA reportFinal-Revised-0612.pdf

He, X., \& Reiner, D. (2015). Why do more British consumers not switch energy suppliers? The role of individual attitudes. University of Cambridge. Cambridge, UK. Retrieved from http://www.eprg.group.cam.ac.uk/wp-content/uploads/2015/09/1515-PDF.pdf

Healy, J. D., \& Clinch, J. P. (2002). Fuel poverty, thermal comfort and occupancy: results of a national household-survey in Ireland. Applied Energy, 73(3), 329-343.

Hills, J. (2012). Getting the measure of fuel poverty: Final Report of the Fuel Poverty Review. Retrieved 12 October 2014, from http://sticerd.Ise.ac.uk/dps/case/cr/CASEreport72.pdf

Howden-Chapman, P. (2015). Home Truths: Confronting New Zealand's Housing Crisis (Vol. 37): Bridget Williams Books.

Howden-Chapman, P., Matheson, A., Crane, J., Viggers, H., Cunningham, M., Blakely, T., . . . O'Dea, D. (2007). Effect of insulating existing houses on health inequality: cluster randomised study in the community. Bmj, 334(7591), 1-9.

Howden-Chapman, P., Viggers, H., Chapman, R., O'Dea, D., Free, S., \& O'Sullivan, K. (2009). Warm homes: drivers of the demand for heating in the residential sector in New Zealand. Energy Policy, 37(9), 3387-3399.

Howden-Chapman, P., Viggers, H., Chapman, R., O'Sullivan, K., Barnard, L. T., \& Lloyd, B. (2012). Tackling cold housing and fuel poverty in New Zealand: a review of policies, research, and health impacts. Energy Policy, 49, 134-142.

Huber, M. (2015). Theorizing Energy Geographies. Geography Compass, 9(6), 327-338.

Hughes, G. (2015, August 12). Power price rise eclipses inflation. Retrieved 12 August 2015, from www.greens.org.nz/news/press-releases/power-price-rise-eclipses-inflation

Ibáñez, V. A., Hartmann, P., \& Calvo, P. Z. (2006). Antecedents of customer loyalty in residential energy markets: Service quality, satisfaction, trust and switching costs. The Service Industries Journal, 26(6), 633-650.

Isaacs, N. C., Michael; Burrough, Lisa; Pollard, Andrew; Saville-Smith, Kay; Fraser, Ruth; Rossouw, Pieter; Jowett, John. (2010). Energy Use in New Zealand Homes: Final Report on the Household Energy End-use Project (HEEP). Retrieved 08 August 2016, from http://www.branz.co.nz/cms show download.php?id=a9f5f2812c5d7d3d53fdaba15f2 c14d591749353

Lawson, R., \& Williams, J. (2012). The Nature of Fuel Poverty in New Zealand. Annual conference of the Australia and New Zealand Academy of Marketing, Adelaide.

Retrieved from http://www.otago.ac.nz/centresustainability/research/energy/otago055642.pdf

Lawson, R., Williams, J., \& Wooliscroft, B. (2015). Contrasting approaches to fuel poverty in New Zealand. Energy Policy, 81, 38-42.

Li, K., Lloyd, B., Liang, X.-J., \& Wei, Y.-M. (2014). Energy poor or fuel poor: What are the differences? Energy Policy, 68, 476-481.

Liddell, C., \& Guiney, C. (2015). Living in a cold and damp home: frameworks for understanding impacts on mental well-being. Public health, 129(3), 191-199. 
Liddell, C., \& Morris, C. (2010). Fuel poverty and human health: a review of recent evidence. Energy Policy, 38(6), 2987-2997.

Lloyd, B. (2006). Fuel poverty in New Zealand. Social Policy Journal of New Zealand, 27, 142155.

Lloyd, C., Callau, M., Bishop, T., \& Smith, I. (2008). The efficacy of an energy efficient upgrade program in New Zealand. Energy and Buildings, 40(7), 1228-1239.

McDaniel, T. M., \& Groothuis, P. A. (2012). Retail competition in electricity supply-Survey results in North Carolina. Energy Policy, 48, 315-321.

MetService. (2015). Wellington City: Historical Data. Retrieved 03 January 2016, from http://www.metservice.com/towns-cities/wellington/wellington-city

Ministry of Business, Innovation and Employment,. (2015). Electricity cost and price monitoring. Retrieved 05 January 2016, from http://www.mbie.govt.nz/infoservices/sectors-industries/energy/energy-data-modelling/statistics/prices/electricityprices

Ministry of Business Innovation and Employment. (2015). Energy in New Zealand. Retrieved 28 October 2015, from http://www.mbie.govt.nz/info-services/sectorsindustries/energy/energy-data-modelling/publications/energy-in-newzealand/Energy\%20-in-New-Zealand-2015.pdf

Ministry of Economic Development. (2011). New Zealand Energy Strategy 2011-2021: Devloping our energy potential and the New Zealand Energy Efficiency and Conservation Strategy 2011-216. Retrieved 27 October 2015, from http://www.mbie.govt.nz/info-services/sectors-industries/energy/energystrategies/documents-image-library/nz-energy-strategy-Ir.pdf

Moore, R. (2012). Definitions of fuel poverty: Implications for policy. Energy Policy, 49, 19-26.

Moore, T. W., \& Dixon, R. W. (2015). A Spatiotemporal Analysis and Description of Hurricane Ivan's (2004) Tornado Clusters. Papers in Applied Geography, 1(2), 192-196.

Morrison, C., \& Shortt, N. (2008). Fuel poverty in Scotland: Refining spatial resolution in the Scottish Fuel Poverty Indicator using a GIS-based multiple risk index. Health \& place, 14(4), 702-717.

Morrison, P. S. (2000). Turning inside-out? Residential growth in the Wellington region. In J. McConchie, D. Winchester \& R. Willis (Eds.), Dynamic Wellington (pp. 271-284). Wellington: Institute of Geography: Victoria University of Wellington.

NIWA. (2015). Annual Climate Summary. Retrieved 03 January 16, from www.niwa.co.nz/sites/niwa.co.nz/files/2014 Annual Climate Summary.pdf

O'Sullivan, K., Howden-Chapman, P., \& Fougere, G. (2012). Death by disconnection: the missing public health voice in newspaper coverage of a fuel poverty-related death. Kotuitui: New Zealand Journal of Social Sciences Online, 7(1), 51-60.

O'Sullivan, K., Howden-Chapman, P. L., Fougere, G. M., Hales, S., \& Stanley, J. (2013). Empowered? Examining self-disconnection in a postal survey of electricity prepayment meter consumers in New Zealand. Energy Policy, 52, 277-287.

O'Sullivan, K., Viggers, H., \& Howden-Chapman, P. (2014). The influence of electricity prepayment meter use on household energy behaviour. Sustainable Cities and Society, 13, 182-191.

O'Sullivan, K. C. (2009). 'Gee my account is in credit!' Qualitative component of the Warm Homes Pilot Study. (Master of Public Health), University of Otago. Retrieved from http://hdl.handle.net/10523/367

O'Sullivan, K. C. (2013). Power and Control: A multiphase mixed methods investigation of prepayment metering and fuel poverty in New Zealand. (Doctor of Philosophy), University of Otago. Retrieved from http://hdl.handle.net/10523/4451 
O'Sullivan, K. C., Howden-Chapman, P. L., \& Fougere, G. (2011). Making the connection: The relationship between fuel poverty, electricity disconnection, and prepayment metering. Energy Policy, 39(2), 733-741.

Ord, J. K., \& Getis, A. (1995). Local spatial autocorrelation statistics: distributional issues and an application. Geographical analysis, 27(4), 286-306.

Pearson, A. L., Barnard, L. T., Pearce, J., Kingham, S., \& Howden-Chapman, P. (2014). Housing quality and resilience in New Zealand. Building Research \& Information, 42(2), 182190.

Phillips, Y. (2012). Landlords versus tenants: Information asymmetry and mismatched preferences for home energy efficiency. Energy Policy, 45, 112-121.

Schabenberger, O., \& Gotway, C. A. (2005). Statistical Methods for Spatial Data Analysis. Florida, USA: Chapman \& Hall/CRC.

Shove, E. (2003). Comfort, cleanliness and convenience: The social organization of normality. Oxford, UK: Berg Publishers.

Statistics New Zealand. (2013a). 2013 Census confidentiality rules and how they are applied. Retrieved 03 January 2016, from http://www.stats.govt.nz/Census/2013census/methodology/confidentiality-how-applied.aspx\#rule1

Statistics New Zealand. (2013b). 2013 Census forms and guide notes. Retrieved 03 January 2016, from http://www.stats.govt.nz/Census/2013-census/info-about-thecensus/forms-guidenotes.aspx

Statistics New Zealand. (2013c). QuickStats about Wellington City. Retrieved 03 January 2016, from http://www.stats.govt.nz/Census/2013-census/profile-and-summaryreports/quickstats-about-aplace. aspx ? request value $=14438 \&$ tabname $=\& s c$ device $=$ pdf

Statistics New Zealand. (2015). Geographic hierarchy. Retrieved 05 January 2016, from http://www.stats.govt.nz/methods/classifications-and-standards/geographichierarchy.aspx

UK Government. (2015). Energy Performance Certificates. Retrieved 04 January 2016, from https://www.gov.uk/buy-sell-your-home/energy-performance-certificates

Waddams-Price, C. (2005). The effect of liberalizing UK retail energy markets on consumers. Oxford Review of Economic Policy, 21(1), 128-144.

Waddams-Price, C., Brazier, K., \& Wang, W. (2012). Objective and subjective measures of fuel poverty. Energy Policy, 49, 33-39.

Walker, G. (2008). Decentralised systems and fuel poverty: Are there any links or risks? Energy Policy, 36(12), 4514-4517.

Walker, R., Liddell, C., McKenzie, P., \& Morris, C. (2013). Evaluating fuel poverty policy in Northern Ireland using a geographic approach. Energy Policy, 63, 765-774.

Walker, R., McKenzie, P., Liddell, C., \& Morris, C. (2012). Area-based targeting of fuel poverty in Northern Ireland: An evidenced-based approach. Applied Geography, 34, 639-649.

Walsh, G., Groth, M., \& Wiedmann, K.-P. (2005). An examination of consumers' motives to switch energy suppliers. Journal of Marketing Management, 21(3-4), 421-440.

Waterson, M. (2003). The role of consumers in competition and competition policy. International Journal of Industrial Organization, 21(2), 129-150.

Wellington City Council. (n.d.). Rating valuations. Retrieved 03 January 2016, from http://wellington.govt.nz/services/rates-and-property/rates/rates-explained/howrates-are-calculated/rating-valuations

Work and Income. (2013). New benefit categories - 15 July 2013. Retrieved 13 June 2015, from http://www.workandincome.govt.nz/individuals/benefit-changes/new-benefitcategories.html

Yang, Y. (2014). Understanding household switching behavior in the retail electricity market. Energy Policy, 69, 406-414. 
Zakour, M. J., \& Gillespie, D. F. (2013). Vulnerability described geographically. In M. J. Zakour \& D. F. Gillespie (Eds.), Community disaster vulnerability (pp. 103-116). New York, USA: Springer. 


\section{A}

\section{Appendix A: Analysis of electricity prices across New Zealand}

This appendix provides supporting data and methodological processes for the geographic differences in electricity prices across New Zealand calculated in Section 2.3.1 and Section 3.3.4. Tables A.1 contains the data and data sources used in the statistical tests in these sections. Table A.2 contains the data used to calculate geographic differences in electricity prices across New Zealand. An asterisk $\left({ }^{*}\right)$ denotes ENAs where average electricity prices have been calculated across multiple ENAs based on the discrepancy between the QSDEP data and ENAs outlined in Section 2.3.1.

Table A.1: Data sources and descriptions - ENAs and electricity prices

\begin{tabular}{lll}
\hline \multicolumn{1}{c}{ Data } & \multicolumn{1}{c}{ Description } & \multicolumn{1}{c}{ Source } \\
\hline $\begin{array}{l}\text { Electricity network } \\
\text { boundaries (2012) }\end{array}$ & $\begin{array}{l}\text { Digital boundary files of electricity } \\
\text { lines companies' distribution area }\end{array}$ & Critchlow \\
$\begin{array}{l}\text { Quarterly survey of } \\
\text { domestic electricity } \\
\text { prices (May 2015) }\end{array}$ & $\begin{array}{l}\text { Breakdown of electricity prices by } \\
\text { electricity lines companies' } \\
\text { distribution area }\end{array}$ & Ministry for Business, \\
\hline
\end{tabular}




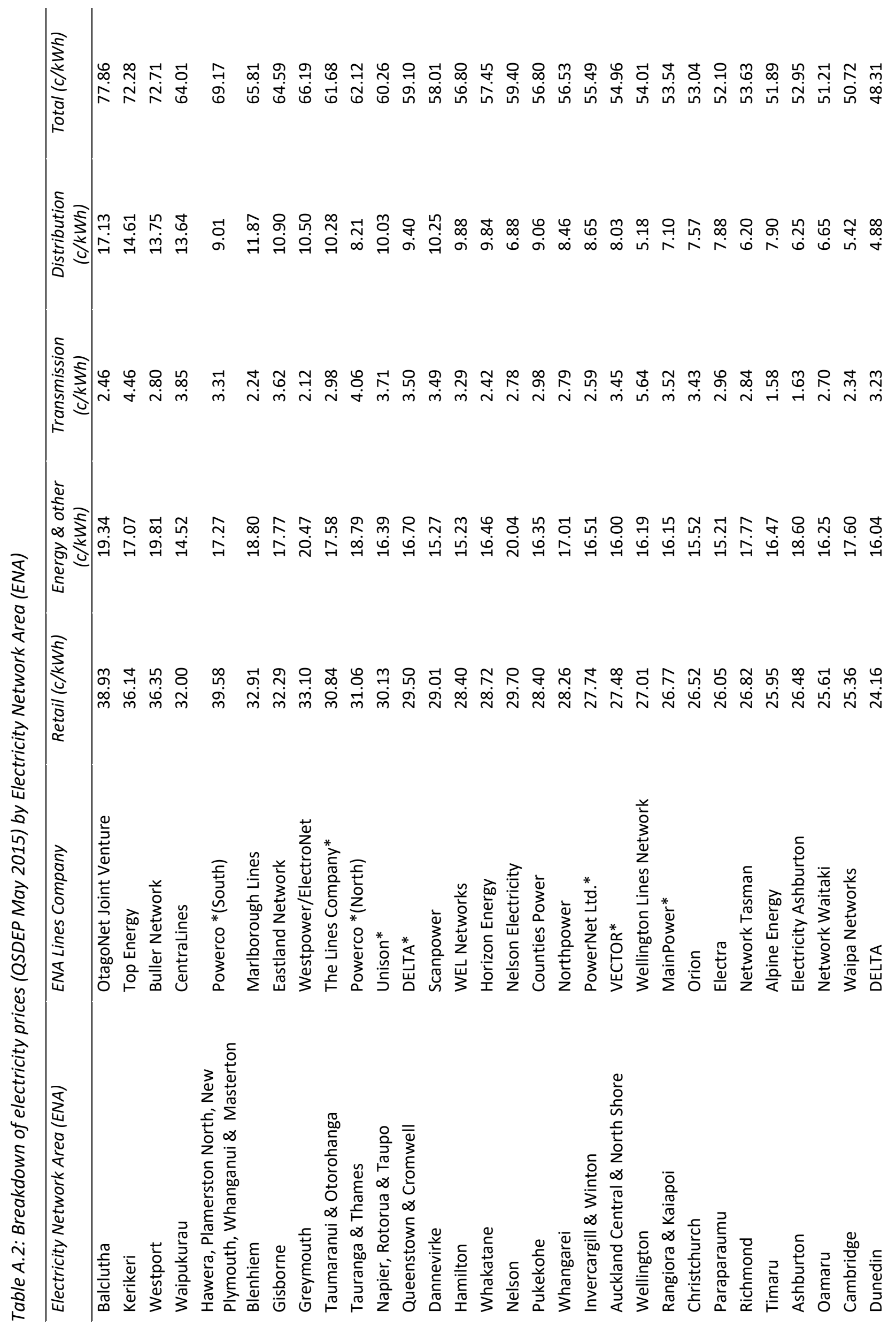




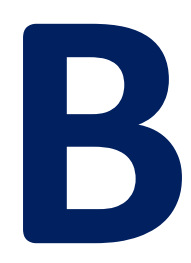

\section{Appendix B: Data \& processes to calculate the FPI}

Appendix B provides supporting documentation for the FPI calculated in this thesis. Table B.1 lists the data and the data sources used in the FPI. Figures B.1 through to B.9 demonstrate the steps followed in calculating the FPI. Only the Wellington City Council administrative boundary was used. 
Table B.1: Data sources and descriptions - FPI

\begin{tabular}{|c|c|c|}
\hline Data & Description & Source \\
\hline $\begin{array}{l}\text { Digital boundary } \\
\text { shapefiles New } \\
\text { Zealand } 2013\end{array}$ & $\begin{array}{l}\text { Shapefile of high definition New } \\
\text { Zealand digital land boundaries } \\
\text { clipped to land (NZTM) }\end{array}$ & $\underline{\text { Statistics New Zealand }}$ \\
\hline $\begin{array}{l}\text { Digital boundary } \\
\text { shapefiles New } \\
\text { Zealand } 2006\end{array}$ & $\begin{array}{l}\text { Shapefile of New Zealand digital } \\
\text { land boundaries (NZGM) }\end{array}$ & $\underline{\text { Statistics New Zealand }}$ \\
\hline $\begin{array}{l}\text { Wellington Region } \\
2013 \text { census dataset }\end{array}$ & $\begin{array}{l}2013 \text { New Zealand Census data of } \\
\text { the Wellington Region by } \\
\text { geographic area. }\end{array}$ & $\underline{\text { Statistics New Zealand }}$ \\
\hline Rateable value & $\begin{array}{l}\text { Rateable and capital value data by } \\
\text { meshblock for New Zealand. }\end{array}$ & $\begin{array}{l}\text { Quotable Value (QV) } \\
\text { provided by the Institute for } \\
\text { the Study of Competition } \\
\text { and Regulation }\end{array}$ \\
\hline $\begin{array}{l}\text { Wellington City } \\
\text { building footprints }\end{array}$ & $\begin{array}{l}\text { Footprints of Wellington City } \\
\text { buildings (2012) }\end{array}$ & $\underline{\text { Koordinates.com }}$ \\
\hline $\begin{array}{l}\text { Wellington City } 1 \mathrm{~m} \\
\text { DEM }\end{array}$ & 1m DEM of Wellington City & $\underline{\text { Koordinates.com }}$ \\
\hline $\begin{array}{l}\text { Housing Quality } \\
\text { Index (HQI) }\end{array}$ & $\begin{array}{l}\text { A national index of housing quality } \\
\text { by } 2006 \text { census area unit }\end{array}$ & $\begin{array}{l}\text { Lucy Telfar-Barnard; co- } \\
\text { author of Pearson et al. } \\
\text { (2014) }\end{array}$ \\
\hline Land parcels & $\begin{array}{l}\text { Land parcels and addresses in } \\
\text { Wellington City }\end{array}$ & Wellington City Council \\
\hline Building age & $\begin{array}{l}\text { General age of Wellington City } \\
\text { buildings }\end{array}$ & Wellington City Council \\
\hline Capital value & $\begin{array}{l}\text { Capital value of land parcels in } \\
\text { Wellington City }\end{array}$ & Wellington City Council \\
\hline
\end{tabular}


Figure B.1: Creation of median household income and sources of household income data files
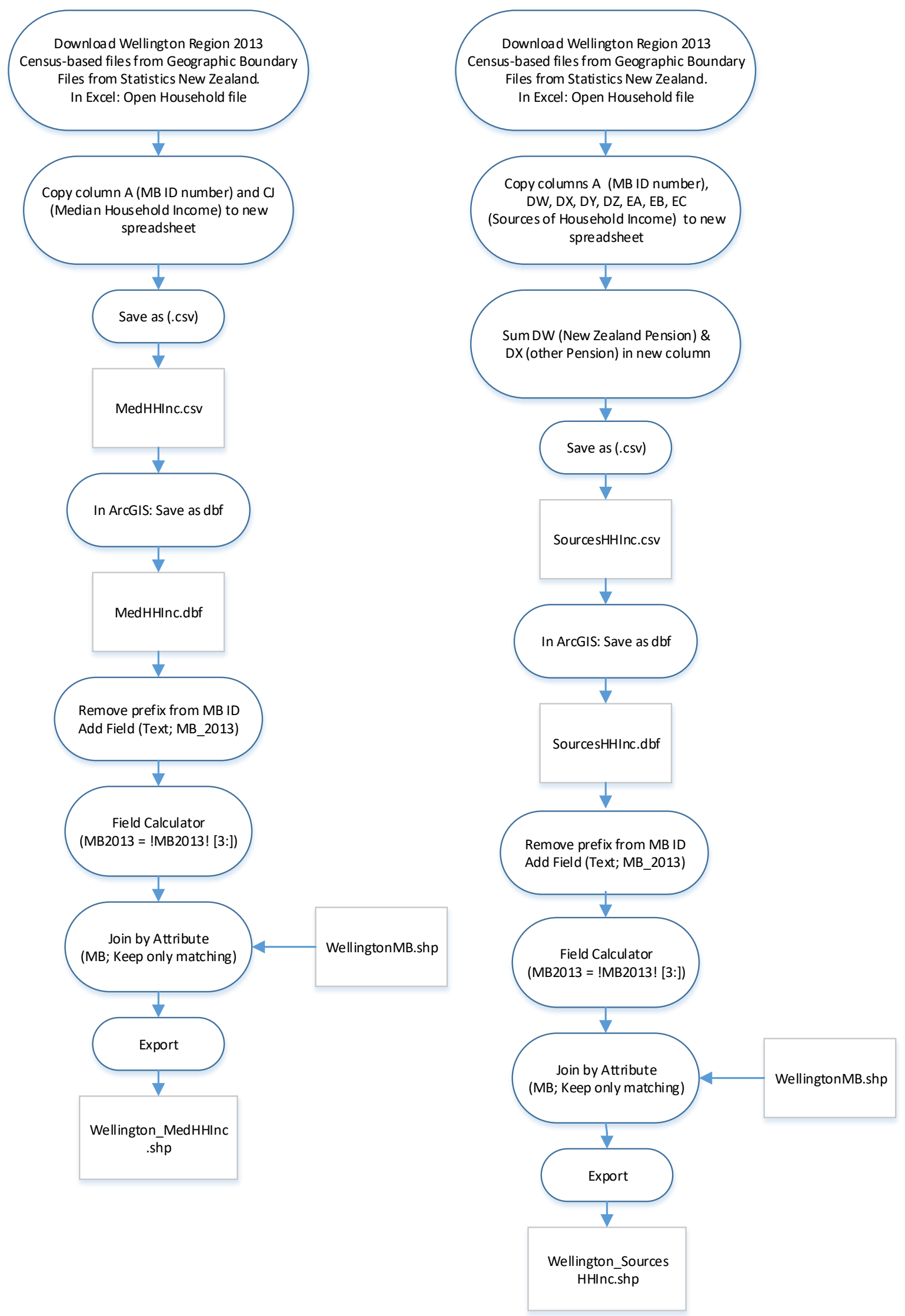
Figure B.2: Creation of building footprint data files

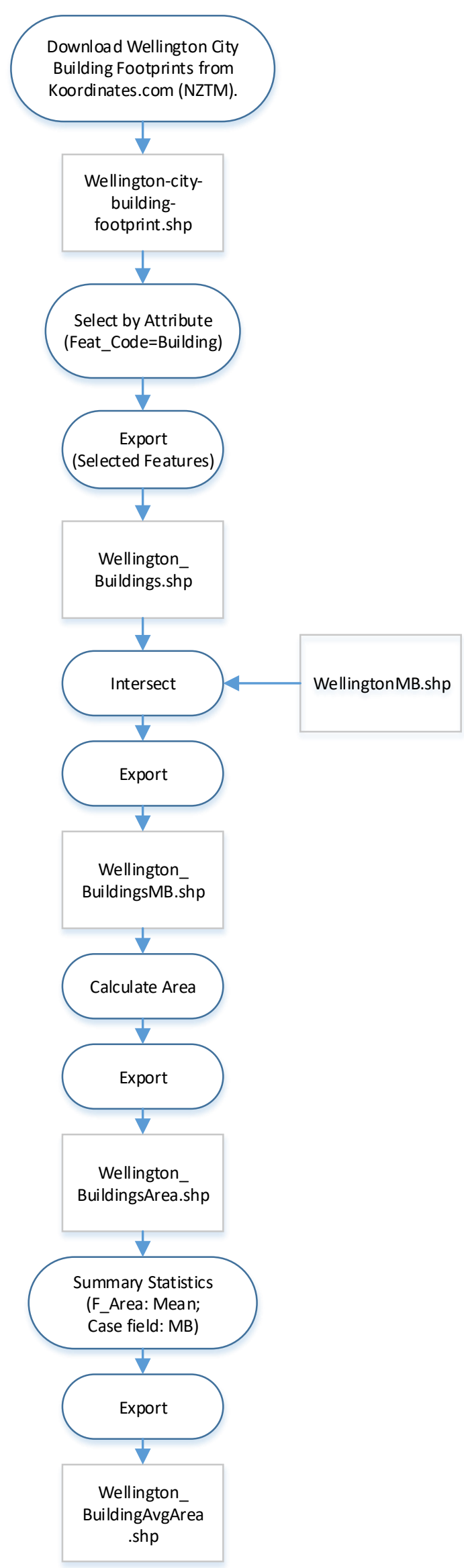


Figure B.3: Creation of HQI data files

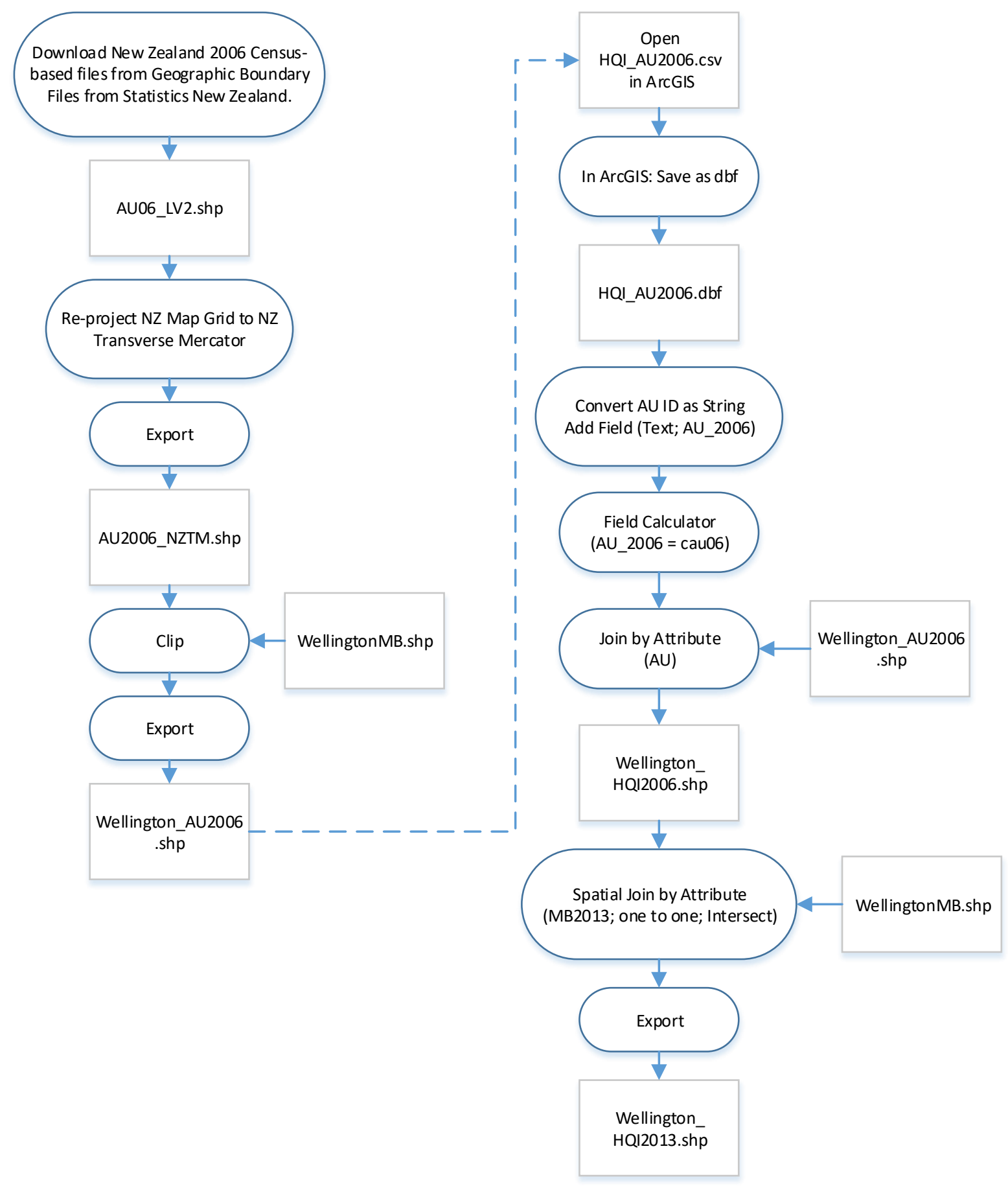


Figure B.4: Creation of housing age data files

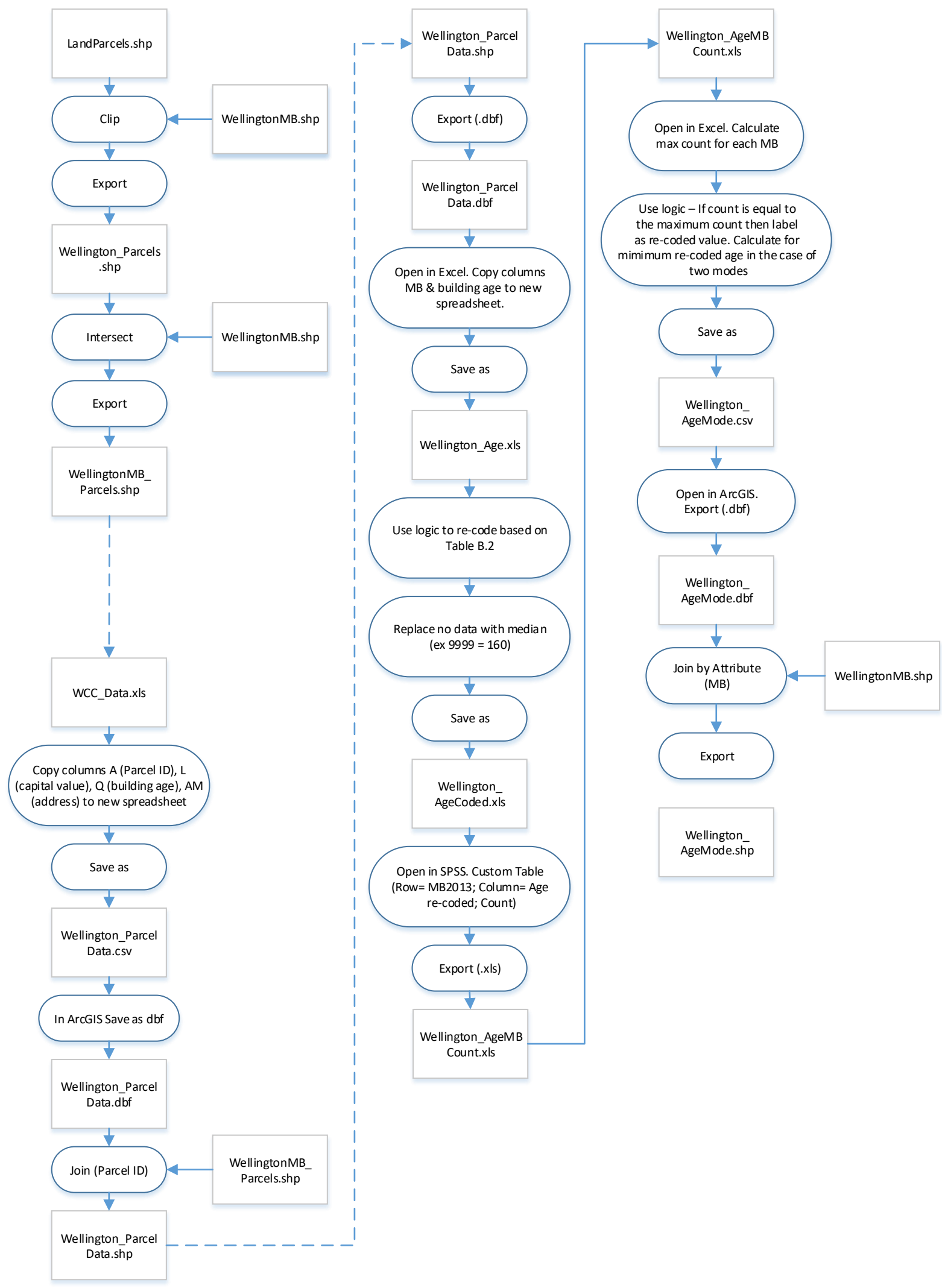


Table B.2: Coded values for housing age

\begin{tabular}{cc}
\hline Age description & Coded value \\
\hline Prior to 1880 & 0.7 \\
$1880-1889$ & 0.8 \\
$1890-1899$ & 0.9 \\
$1900-1909$ & 1.0 \\
$1910-1919$ & 1.1 \\
Prior to 1920 & 1.19 \\
$1920-1929$ & 1.2 \\
$1930-1939$ & 1.3 \\
$1940-1949$ & 1.4 \\
$1950-1959$ & 1.5 \\
$1960-1969$ & 1.6 \\
$1970-1979$ & 1.7 \\
$1980-1989$ & 1.8 \\
$1990-1999$ & 1.9 \\
2000-2009 & 2.0 \\
2010-2019 & 2.1 \\
Mixed/Remod & 2.5 \\
No date & 9999 \\
\hline \multirow{2}{*}{ Median (excluding 'No date') } & 1.6 \\
\hline
\end{tabular}


Figure B.5: Creation of capital value data files

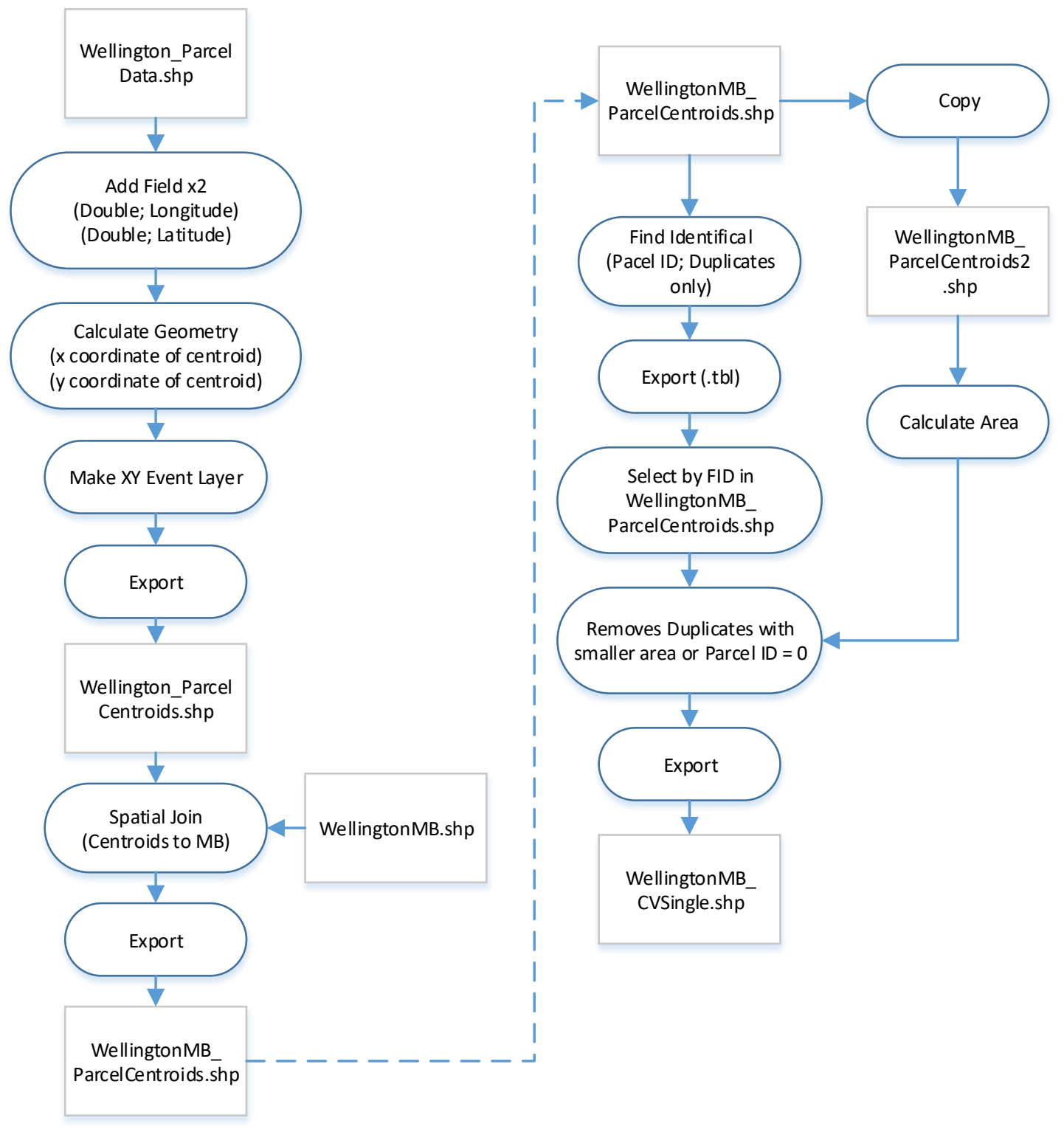


Figure B.6: Creation of solar radiation data files

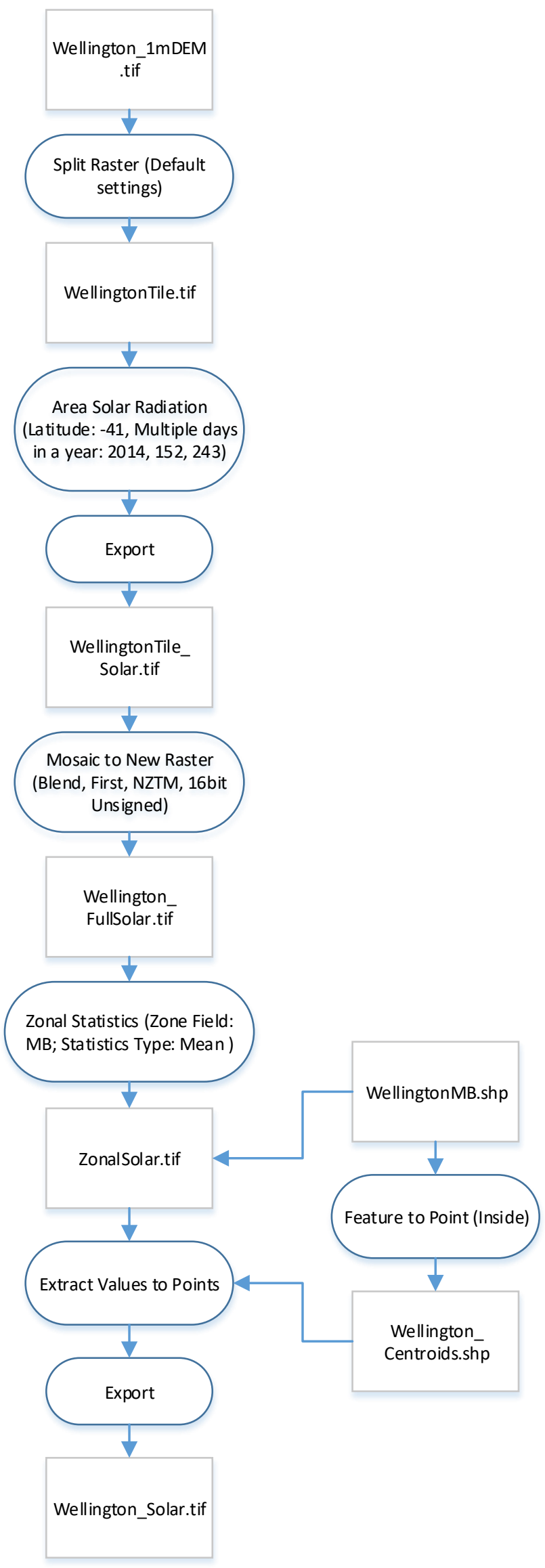


Figure B.7: Creation of FPI data file

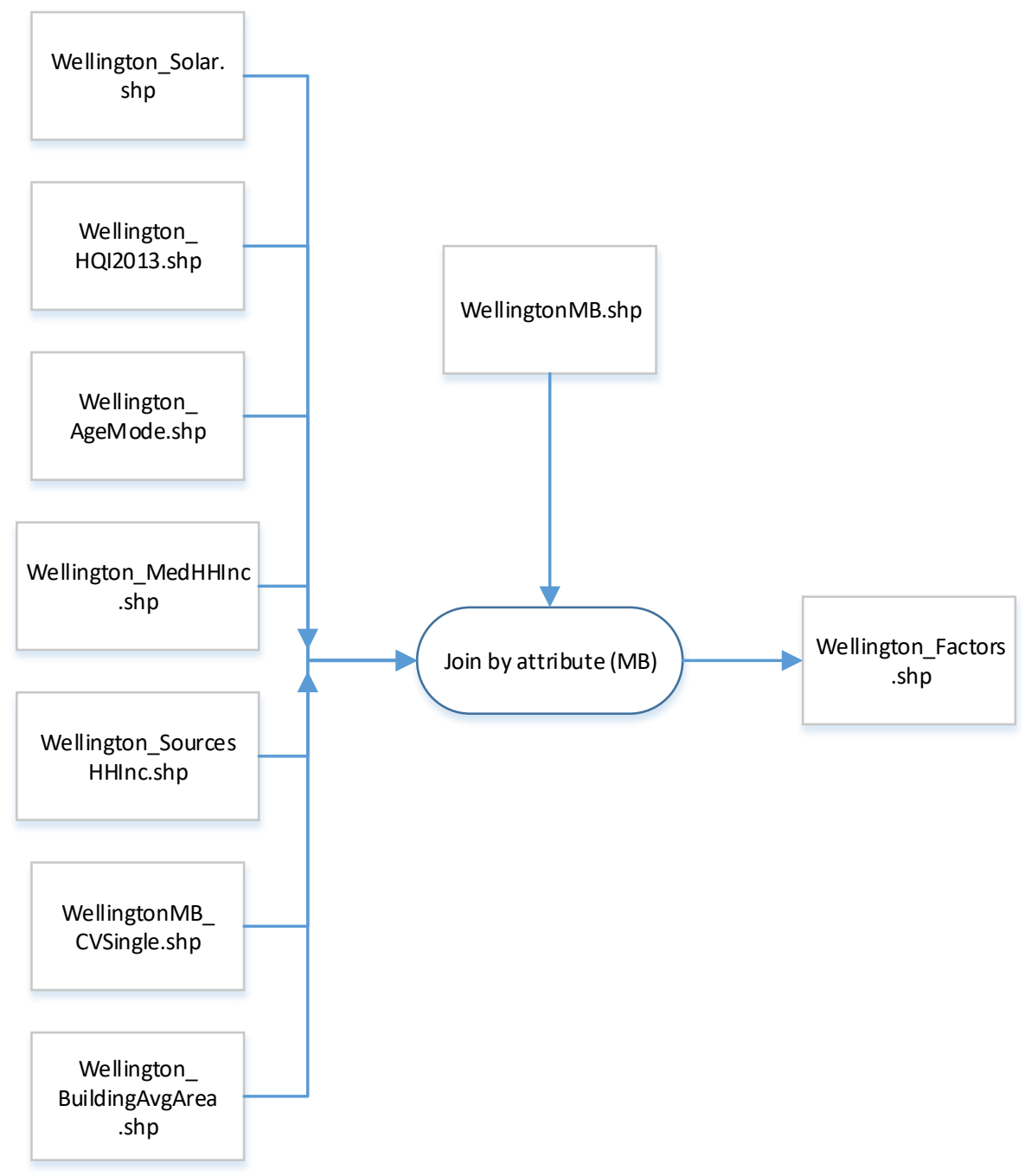


Figure B.8: Calculations for FPI decile scores

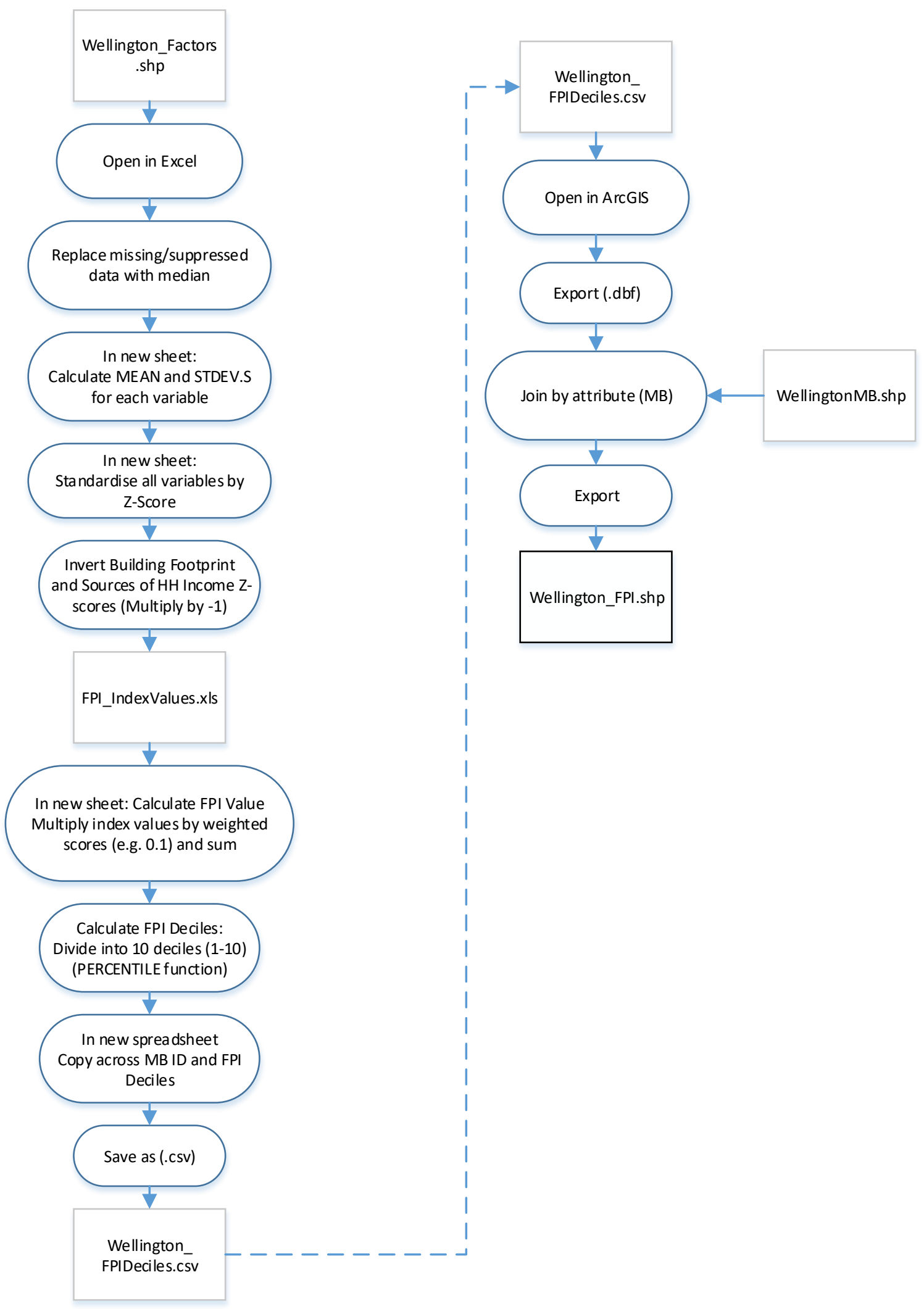




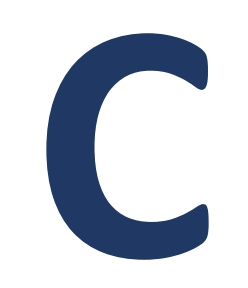

\section{Appendix C: Ethics approval \& Energy Prices and Warm Homes Survey}

This appendix provides a copy of the memorandum of ethics approval provided by the Human Ethics Committee at Victoria University of Wellington. A copy of the EPWHS and correspondence sent to survey participants during the recruitment process are also provided.

Appendix C.1: Memorandum of ethics approval

p. 172

Appendix C.2: Pre-notification letter

p. 174

Appendix C.3: Cover letter, information sheet \& survey booklet

p. 175

Appendix C.4: Reminder slips

p. 189

Appendix C.5: Final reminder

p. 190 
MEMORANDUM

Phone 0-4-4635480

Email susan.corbett@vuw.ac.nz

\begin{tabular}{l|l}
\hline TO & Sam McLean \\
\hline COPY TO & Wokje Abrahamse \\
\hline FROM & AProf Susan Corbett, Convener, Human Ethics Committee \\
\hline DATE & 1 June 2015 \\
\hline PAGES & 1 \\
\hline & $\begin{array}{l}\text { Ethics Approval: 21930 } \\
\text { SUBting the cold: Connecting fuel poverty and energy prices in } \\
\text { New Zealand }\end{array}$ \\
\hline
\end{tabular}

Thank you for your application for ethical approval, which has now been considered by the Standing Committee of the Human Ethics Committee.

Your application has been approved from the above date and this approval continues until 9 March 2016. If your data collection is not completed by this date you should apply to the Human Ethics Committee for an extension to this approval.

Best wishes with the research.

Kind regards

Susan Corbett

Convener, Victoria University Human Ethics Committee 


\section{MEMORANDUM

\begin{tabular}{l|l}
\hline TO & Sam McLean \\
\hline COPY TO & Wokje Abrahamse \\
\hline FROM & AProf Susan Corbett, Convener, Human Ethics Committee \\
\hline
\end{tabular}

\begin{tabular}{l|l}
\hline DATE & 16 July 2015 \\
\hline PAGES & 1 \\
\hline
\end{tabular}

\begin{tabular}{l|l}
\hline SUBJECT & $\begin{array}{l}\text { Ethics Approval: } 21930 \\
\text { Costing the cold: Connecting fuel poverty and energy prices in } \\
\text { New Zealand }\end{array}$ \\
\hline
\end{tabular}

Thank you for your request to amend your ethics approval. This has now been considered and the request granted.

Your application has approval until 9 March 2016. If your data collection is not completed by this date you should apply to the Human Ethics Committee for an extension to this approval.

Best wishes with the research.

Kind regards

\section{Susan Corbett}

Convener, Victoria University Human Ethics Committee 


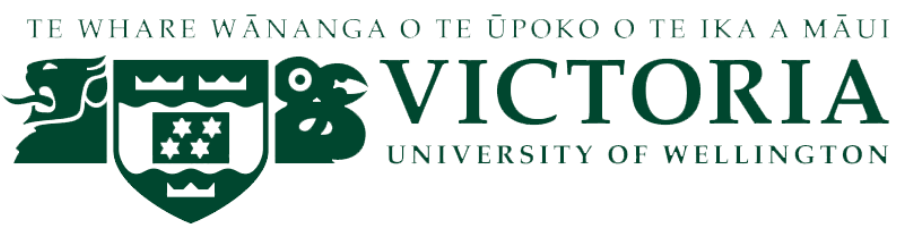

24 July 2015

Dear Wellington City Resident,

\section{Invitation to Participate in Research Energy Prices and Warm Homes Survey 2015}

My name is Sam McLean and I am currently conducting my Masters research project at Victoria University of Wellington. This project aims to understand what people think about the cost of energy and how homes are heated in Wellington City. I am writing to you to ask for your help with this research by sharing your thoughts and opinions on this important topic.

Approval for this research has been obtained from Victoria University of Wellington's Human Ethics Committee.

\section{How can you help?}

Please help me with my research project by completing the confidential survey you will receive next week. The survey will take between 10 and 20 minutes to complete. Your thoughts and opinions are important to this research.

\section{How did I find you?}

Your address has been randomly selected from addresses in Wellington City.

\section{What happens next?}

Next week you will receive a confidential survey to complete about the cost of energy and how you heat your home. Please take the time to complete this survey.

I hope that you can use this opportunity to share your thoughts and opinions.

If you have any questions, please email sam.mclean@vuw.ac.nz or phone 027

Sincerely, 


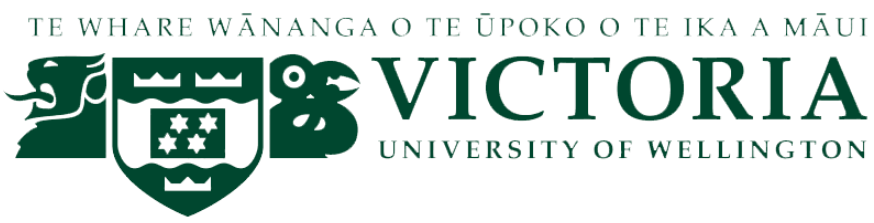

31 July 2015

Dear Wellington City Resident,

ID Number:

\section{Energy Prices and Warm Homes Survey 2015}

My name is Sam McLean and I am currently conducting my Masters research project at Victoria University of Wellington. This project aims to understand what people think about the cost of energy and how homes are heated in Wellington City. By completing and returning the enclosed survey you will be helping me with my research project.

Approval for this project has been obtained from Victoria University of Wellington's Human Ethics Committee.

\section{Completing the survey}

This confidential survey will take between 10 and 20 minutes to complete. Any household member who is an adult (18 years and over) and pays or knows about the energy bill at this address may complete this survey. By completing and returning the survey, you will be automatically entered into the draw to win 1 of 4 supermarket vouchers valued at $\$ 40.00$.

\section{Enclosed you will find:}

- A Participant Information Sheet explaining the research project and survey;

- The survey and consent form to be completed;

- A prepaid envelope to return your survey to Victoria University of Wellington;

To complete the survey online, please follow this link: http://tinyurl.com/energysurvey2015.

\section{Need more information?}

Please read the enclosed Participant Information Sheet. If you have any questions, please contact me or my supervisors at the details below.

Thank you for your time and support for my research project. I hope you enjoy this opportunity to share your thoughts and opinions on this important topic.

Sincerely, 


\section{Participant Information Sheet Energy Prices and Warm Homes Survey 2015}

You are invited to participate in the Energy Prices and Warm Homes Survey. This survey is being conducted as part of Sam McLean's Masters research project at Victoria University of Wellington. This project aims to understand what people think about the cost of energy and how homes are heated in Wellington City.

The confidential survey enclosed gives you the opportunity to share your thoughts and opinions on this important topic and help me understand how Wellington City residents think about energy.

Approval for this project has been obtained from Victoria University of Wellington's Human Ethics Committee.

\section{Why is the study being done?}

We need energy for our everyday lifestyle, but in winter energy can be expensive. In winter, we make decisions about how we use energy to be able to afford our energy bills. For example we might close doors to heat only one or two rooms, or wear extra clothing. This survey is being conducted to understand what people think about the cost of energy and how they heat their homes.

\section{What will I have to do if I participate?}

Please complete the enclosed survey and return it to Sam McLean at Victoria University of Wellington in the prepaid return envelope provided. The survey will take between 10 and 20 minutes to complete.

As a token of appreciation for your time, you will be entered into the draw to win 1 of 4 supermarket vouchers valued at $\$ 40.00$. To enter the draw, simply complete and return the survey to Sam McLean at Victoria University of Wellington. At the end of the survey, please indicate the supermarket you would like for the voucher.

\section{Who can complete the survey?}

Any household member who is an adult (18 years and over) and pays or knows about the energy bill at this address may complete the survey.

\section{When and where is the study being done?}

This survey is being completed by randomly selected households in Wellington City between 1st August 2015 and 6th September 2015. 


\section{About the survey}

The survey has 8 short sections. The kinds of questions asked as an example are: How many times have you changed energy companies in the past two years? In your opinion, how expensive or cheap is the cost of electricity?

You will not be disadvantaged if you choose not to answer certain questions.

\section{What information will be collected?}

Information will only be collected from the survey you complete. Only Sam McLean and his research supervisors, Wokje Abrahamse and Mairéad de Róiste, will see your completed survey. At the end of the project, any personal information will be immediately destroyed, apart from any raw data that will be retained and kept in locked storage for 5 years, after which it will be destroyed. Any data that is stored electronically will only be accessible by Sam McLean, Wokje Abrahamse and Mairéad de Róiste on a password protected computer.

\section{Is the survey confidential?}

All the information and opinions you provide are confidential. Once your survey has been processed your ID number will be removed from your survey so that your responses cannot be connected to your address. The information you provide will be related to the meshblocks Statistics New Zealand use in the New Zealand Census. The information you provide will be attached to the meshblock you live in and not your address.

The results of the research project will be published and will be available in the Victoria University of Wellington Library. The answers you provide will be published in an anonymous and aggregated form; your address will not appear in any publications and no one will be able to identify you.

\section{Can I find out the results?}

Yes. The final report will be completed in March 2016. However, preliminary results can be made available to you. Please indicate if you would like a copy of the results from the survey in the appropriate space.

\section{Who can I contact if I have questions?}

If you have any questions or would like to discuss any part of this research, the survey or your participation in it, please contact me or my supervisors at the details below.

Sam McLean

$$
\text { sam.mclean@vuw.ac.nz or } 027
$$

Supervisors:

Dr Wokje Abrahamse

wokje.abrahamse@vuw.ac.nz

Dr Mairéad de Róiste mairead.deroiste@vuw.ac.nz

Thank you for your time and support for this research project. Please take some time to complete this survey. 


\section{Energy Prices and \\ Warm Homes Survey}

To be completed by an adult (age 18 and over) who pays or knows about the household energy bill.

Please return by $6^{\text {th }}$ September 2015

Answer every question by ticking the appropriate circle/boxes or writing an answer in the space provided.

Answer the questions to the best of your knowledge, even if you are unsure on how to answer.

All the information that you provide will be kept confidential.

This survey will take between 10 and 20 minutes to complete. 


\section{Consent Form}

Please read this section carefully as it includes information about the privacy of data and consent to participate in this research.

\section{You understand that:}

- I have read the Participant Information Sheet. I have understood this information. I can seek further information if needed at the contact details listed below.

- Participation is voluntary. I may withdraw from this research at any point before I return my completed survey without providing reasons and I will not be affected in any way.

- My answers will only be seen and accessed by Sam McLean and his research supervisors, Wokje Abrahamse and Mairéad de Róiste. Any written or electronic information I provide will be retained and securely kept for 5 years and then destroyed.

- The results of this research will be published, used for academic journals and at conferences. Any information or opinions I provide will be published in an anonymous and aggregated form. I consent to the use of the responses that I provide in this survey.

I consent to take part in this research. Please tick the box.

Please tick the box if you would like a summary of the survey results.

Sam McLean: sam.mclean@vuw.ac.nz or 027 xxx xxxx

Supervisors:

Wokje Abrahamse:

wokje.abrahamse@vuw.ac.nz

Mairéad de Róiste: mairead.deroiste@vuw.ac.nz 
SECTION 1: This section asks questions about how warm you feel in your house.

\begin{tabular}{|c|c|c|c|}
\hline \multicolumn{2}{|c|}{$\begin{array}{l}\text { Q1. So far this winter, have you felt your house has } \\
\text { been cold? } \\
\text { [Tick one circle] }\end{array}$} & \multicolumn{2}{|c|}{$\begin{array}{l}\text { Yes, always } \\
\text { Yes, often } \\
\text { Yes, sometimes } \\
\text { Never [Go to Q5.] }\end{array}$} \\
\hline \multicolumn{2}{|c|}{$\begin{array}{l}\text { Q2. So far this winter, how many times was your } \\
\text { house cold enough that you shivered inside? } \\
\text { [Tick one circle] }\end{array}$} & \multicolumn{2}{|c|}{$\begin{array}{l}\text { One day/night } \\
\text { Two or three days/nights } \\
\text { Four or more days/nights } \\
\text { Never }\end{array}$} \\
\hline \multicolumn{2}{|c|}{$\begin{array}{l}\text { Q3. So far this winter, how many times did you 'see } \\
\text { your breath' ("dragon breath") inside when it was } \\
\text { cold? } \\
\text { [Tick one circle] }\end{array}$} & \multicolumn{2}{|c|}{$\begin{array}{l}\text { One day/night } \\
\text { Two or three days/nights } \\
\text { Four or more days/nights } \\
\text { Never }\end{array}$} \\
\hline $\begin{array}{l}\text { Q4. Why has your house felt } \\
\text { cold so far this winter? } \\
\text { [Tick all boxes that apply] }\end{array}$ & \multicolumn{3}{|c|}{$\begin{array}{l}\text { I try to keep the cost of heating low } \\
\text { It is difficult to heat my home or any heat disappears } \\
\text { I like to have the windows open } \\
\text { There is a heater in only one room } \\
\text { Other household members like it cooler than I do } \\
\text { I think it is healthy to keep your body cooler } \\
\text { Other, please specify: }\end{array}$} \\
\hline \multicolumn{4}{|c|}{$\begin{array}{l}\text { SECTION 2f This section asks questions about the cost of energy and your } \\
\text { energy bill. }\end{array}$} \\
\hline \multicolumn{3}{|c|}{$\begin{array}{l}\text { Q5. In your opinion, how expensive or cheap is the cost of } \\
\text { electricity? } \\
\text { [Tick one circle] }\end{array}$} & $\begin{array}{ll}O & \text { Very expensive } \\
0 & \text { Expensive } \\
0 & \text { About right } \\
0 & \text { Cheap } \\
0 & \text { Very cheap }\end{array}$ \\
\hline \multicolumn{3}{|c|}{$\begin{array}{l}\text { Q6. In your opinion, how expensive or cheap is the cost of } \\
\text { gas heating? } \\
\text { [Tick one circle] }\end{array}$} & $\begin{array}{l}\text { We do not have gas heating } \\
0 \text { Very expensive } \\
0 \text { Expensive } \\
0 \text { About right } \\
0 \text { Cheap } \\
\text { Very cheap }\end{array}$ \\
\hline
\end{tabular}




\begin{tabular}{|c|c|}
\hline $\begin{array}{l}\text { Q7. Thinking of your most recent total } \\
\text { energy bill (electricity and gas } \\
\text { combined), approximately how much did } \\
\text { this cost? } \\
\text { [Tick one circle] }\end{array}$ & $\begin{array}{ll}O & \$ 0-\$ 100 \\
O & \$ 101-\$ 200 \\
O & \$ 201-\$ 300 \\
O & \$ 301-\$ 400 \\
O & \$ 401-\$ 500 \\
O & \$ 501-\$ 600 \\
O & \$ 600 \text { or more } \\
O & \text { I topped-up my prepaid account. Please } \\
& \text { estimate last month's total cost: } \$ \\
& \text { I don't know [Go to } Q 9 . \text { ] }\end{array}$ \\
\hline $\begin{array}{l}\text { Q8. In your opinion, how expensive or } \\
\text { cheap is the cost of your most recent } \\
\text { total energy bill? } \\
\text { [Tick one circle] }\end{array}$ & $\begin{array}{l}\text { Very expensive } \\
\text { Expensive } \\
\text { About right } \\
\text { Cheap } \\
\text { Very cheap }\end{array}$ \\
\hline $\begin{array}{l}\text { Q9. In your opinion, how affordable or } \\
\text { unaffordable is your most recent total } \\
\text { energy bill? } \\
\text { [Tick one circle] }\end{array}$ & $\begin{array}{l}\text { Very affordable } \\
\text { Affordable } \\
\text { Neither affordable nor unaffordable } \\
\text { Unaffordable } \\
\text { Very unaffordable }\end{array}$ \\
\hline
\end{tabular}

Section 3: This section asks questions about changing energy companies and reasons for changing.

\begin{tabular}{|c|c|}
\hline $\begin{array}{l}\text { Q10. In the last two years, how } \\
\text { many times have you changed } \\
\text { energy companies? } \\
\text { [Tick one circle] }\end{array}$ & $\begin{array}{l}\text { One time } \\
\text { Two times } \\
\text { Three times } \\
\text { Four or more times } \\
\text { I have not changed in the last two years [Go to Q16.] } \\
\text { I don't know [Go to Q16.] }\end{array}$ \\
\hline $\begin{array}{l}\text { Q11. On the most recent } \\
\text { occasion you changed energy } \\
\text { company, what were your } \\
\text { reasons for changing? } \\
\text { [Tick all boxes that apply] }\end{array}$ & $\begin{array}{l}\text { I was offered a better deal } \\
\text { I was not getting the best value for my money } \\
\text { My new energy company provides electricity and gas } \\
\text { My new energy company offers flexibility on when and } \\
\text { how to pay } \\
\text { I moved house } \\
\square \text { I did not want to be on a contract } \\
\square \text { I feel no sense of loyalty to my energy company } \\
\square \text { My new energy company has FlyBuys or another points } \\
\text { scheme } \\
\text { I received a high or inaccurate bill } \\
\square \text { Based on a recommendation from family or friends } \\
\text { My new energy company produces electricity from } \\
\text { renewable sources } \\
\square \text { Other, please specify: }\end{array}$ \\
\hline
\end{tabular}



changed energy company, why did you find it easy to change?

[Tick all boxes that apply]
Q12. On the most recent occasion you

I I did not find it easy to change

口 I knew specific information about my energy bill

I It was easy to find information

It was easy to find the best deal

It was a quick process

It was an easy process

I did not have to pay extra charges

- There were no problems with my new energy bills

口 Other, please specify:

I I did not find it difficult to change

- My old energy company tried to keep my business or 'win me back'

- I needed to know specific information about my energy bill

Q13. On the most recent occasion you changed energy company, why did you find it difficult to change?

[Tick all boxes that apply]

Q14. On the most recent occasion you changed energy company, how did this happen?

[Tick one circle]

- It was difficult to find information

It was difficult to find the best deal

It was time consuming

It was a hassle

I had to pay extra charges

There were problems with my new energy bills

Other, please specify:
O I approached an energy company over the phone

O An energy company approached me over the phone

O Through a door-to-door salesperson

On an energy company's website or Powerswitch

Other, please specify:

I can't remember

Approaching another company over the phone

O Being approached by an energy company over the phone

O Being approached by a door-to-door salesperson

O Looking on an energy company's website or Powerswitch

O I don't know

\section{Go to Q17.}


Q16. Why have you not changed energy companies in the last two years?

[Tick all boxes that apply]

Q17. To make changing energy company worthwhile, how much money would you need to save on your total energy bill each month?

[Tick one circle]
I have not been offered a better deal

I am getting the best value for my money

My current energy company offers electricity and gas

My current energy company offers flexibility on when and how to pay

It is time consuming

It is a hassle

It is not worth it or there are no overall savings

- There are only small price differences between energy companies

口 I am on a contract and can't change

I I would have to pay extra charges

I I feel a sense of loyalty to my energy company

My current energy company has FlyBuys or another points scheme

- There might be a problem with the continuity of supply

There was no information on other deals

I I did not know that you can change energy company

a I never thought about it

$\square$ Other, please specify:

O $\$ 0-\$ 20$

O $\$ 21-\$ 50$

O $\$ 51-\$ 100$

O $\$ 101-\$ 150$

O $\$ 151-\$ 200$

O Over $\$ 201$

O I would change for reasons other than money. Please specify:

I don't know [Go to Q19.]

O I won't change energy company [Go to Q21.]

\begin{tabular}{|c|c|}
\hline $\begin{array}{l}\text { Q18. Would you use any savings on your } \\
\text { total energy bill to heat your home more? } \\
\text { [Tick one circle] }\end{array}$ & $\begin{array}{l}O \text { Yes } \\
\text { O No } \\
\text { O It depends. Please specify: } \\
\text { O I don't know }\end{array}$ \\
\hline $\begin{array}{l}\text { Q19. How often do you look into which } \\
\text { energy company offers you the best deal } \\
\text { for your total energy bill? } \\
\text { [Tick one circle] }\end{array}$ & $\begin{array}{ll}O & \text { At least once a month } \\
O & \text { Every } 1 \text { to } 3 \text { months } \\
O & \text { Every } 4 \text { to } 6 \text { months } \\
O & \text { Every } 6 \text { months to } 1 \text { year } \\
O & \text { Longer than once year [Go to Q21.] } \\
O & \text { I am yet to investigate my options [Go to Q21.] }\end{array}$ \\
\hline
\end{tabular}

Q20. If energy prices remain the same, do you see yourself changing energy companies in the next year? [Tick one circle]

$\begin{array}{ll}\text { O } & \text { Yes } \\ \text { O } & \text { No } \\ \text { O } & \text { Maybe } \\ \text { O I I don't know }\end{array}$




\begin{tabular}{|l|l}
$\begin{array}{l}\text { Q21. Who is your current electricity } \\
\text { company? } \\
\text { [Enter your answer in the space provided] }\end{array}$ & $\begin{array}{l}\text { O Current company: } \\
\text { O I Ion't know }\end{array}$ \\
\hline $\begin{array}{l}\text { Q22. Who was your previous electricity } \\
\text { company? }\end{array}$ & $\begin{array}{l}\text { O I don't have a previous electricity company } \\
\text { O Previous company: } \\
\text { O I I can't remember } \\
\text { [Enter your answer in the space provided] }\end{array}$ \\
\hline
\end{tabular}

\section{You're halfway through the survey. Thank you for continuing.}

\section{SECTION 4: This section asks questions about scenarios and whether you agree with them.}

To what extent do you agree with the statements below? [Tick one circle for each statement]

Q23. We cannot afford to heat our home.

\begin{tabular}{c|c|c|c|c}
$\begin{array}{c}0 \\
\text { Strongly agree }\end{array}$ & $\begin{array}{c}\text { O } \\
\text { Agree }\end{array}$ & $\begin{array}{c}\text { Neither agree nor } \\
\text { disagree }\end{array}$ & $\begin{array}{c}0 \\
\text { Disagree }\end{array}$ & $\begin{array}{c}0 \\
\text { Strong disagree }\end{array}$ \\
\hline
\end{tabular}

Q24. We cannot afford to heat our home to a temperature we want.

\begin{tabular}{c|c|c|c|c} 
Strongly agree & $\begin{array}{c}O \\
\text { Agree }\end{array}$ & $\begin{array}{c}\text { Neither agree nor } \\
\text { disagree }\end{array}$ & $\begin{array}{c}O \\
\text { Disagree }\end{array}$ & $\begin{array}{c}O \\
\text { Strong disagree }\end{array}$
\end{tabular}

Q25. Some of the time we cannot afford to heat our home to a temperature we want.

\begin{tabular}{|c|c|c|c|c|}
\hline $\begin{array}{c}\mathrm{O} \\
\text { Strongly agree }\end{array}$ & $\begin{array}{c}\bigcirc \\
\text { Agree }\end{array}$ & $\begin{array}{c}\text { Neither agree nor } \\
\text { disagree }\end{array}$ & $\begin{array}{c}O \\
\text { Disagree }\end{array}$ & $\stackrel{\bigcirc}{\text { Strong disagree }}$ \\
\hline
\end{tabular}

Q26. We will not be able to afford the energy bill if energy prices increase.

\begin{tabular}{|c|c|c|c|c|}
\hline $\begin{array}{c}\mathrm{O} \\
\text { Strongly agree }\end{array}$ & $\begin{array}{c}O \\
\text { Agree }\end{array}$ & $\begin{array}{c}\text { O } \\
\text { Neither agree nor } \\
\text { disagree }\end{array}$ & $\begin{array}{c}\text { O } \\
\text { Disagree }\end{array}$ & Strong disagree \\
\hline
\end{tabular}

Q27. We will not be able to afford the energy bill if my income decreases.

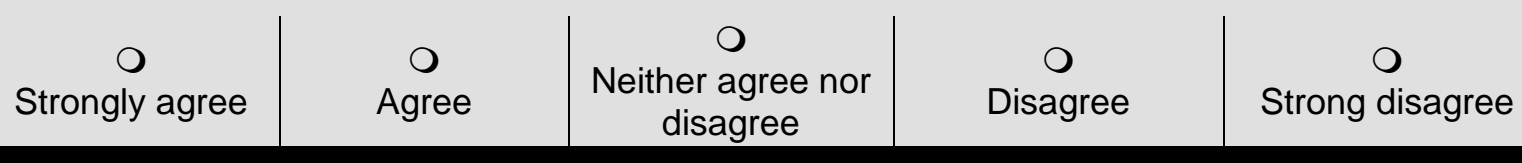

Section 5: This section asks questions about things you may do to control your energy bill and why you do them.

Q28. How did you keep warm this winter?

[Tick all boxes that apply]
I turned the heater(s) on

I wore extra clothing or I used blankets

I closed doors to keep heat in one area

- I stayed in bed longer

- Other, please specify: 
Q29. To keep the cost of your energy bill low what do you do? [Tick all boxes that apply]
I change my energy company

I I monitor how much energy is used (e.g. Smart Meters or Online)

I I use prepayment meters (e.g. GLO-BUG or PrePay)

I budget

I I spend as much time as possible away from home

Other, please specify:

I don't take any action

Q30. For reasons other than the cost of energy, do you limit your energy use?

[Tick one circle]

O Yes

O No [Go to Q32]

Q31. Please briefly comment on why you limit your energy use for reasons other than the cost of energy. [Enter your answer in the space provided]

\section{Section 6: This section asks questions about special offers from your energy company and paying your energy bill.}

Q32. In the last 6 months, has your energy company offered you any special offers, discounts or deals? [Tick one circle]

$$
\begin{aligned}
& \text { O Yes } \\
& \text { O No } \\
& \text { O I can't remember }
\end{aligned}
$$

\begin{tabular}{|c|c|}
\hline $\begin{array}{l}\text { Q33. Mark as many boxes as } \\
\text { you need to show which of the } \\
\text { following apply to you. } \\
\text { [Tick all boxes that apply] }\end{array}$ & $\begin{array}{l}\text { I am on a fixed term or fixed rate contract } \\
\text { I have paid a 'bond' to my energy company } \\
\text { I get a discount for paying my energy bill before a specified } \\
\text { date or on time (e.g. Prompt Payment) } \\
\text { I have my electricity and gas bill with the same company } \\
\text { I get a discount for having electricity and gas with one } \\
\text { energy company (e.g. Dual Fuel discount) } \\
\text { None of the above } \\
\text { I don't know }\end{array}$ \\
\hline $\begin{array}{l}\text { Q34. How do you pay your } \\
\text { energy bill? } \\
\text { [Tick one circle] }\end{array}$ & $\begin{array}{l}\text { Direct debit (exact amount owing) } \\
\text { Automatic payments (same amount each payment) } \\
\text { Prepaid or top-up packs (e.g. GLO-BUG or PrePay) } \\
\text { Internet banking } \\
\text { Credit card } \\
\text { I pay in cash or by cheque } \\
\text { Other, please specify: } \\
\text { I don't know }\end{array}$ \\
\hline
\end{tabular}




\section{Section 7: This section asks questions about the heating and energy}

efficiency of your house.

Q35. How would you describe the energy efficiency of this house? [Tick one circle]

Very good

O Good

O Average

O Poor

Very poor
Q36. Which of the following does this house currently have?

[Tick all boxes that apply]
Full wall insulation

- Some wall insulation

Full ceiling insulation

Some ceiling insulation

- Full under-floor insulation

- Some under-floor insulation

Draft proofed windows and doors

Double glazed windows (more than $50 \%$ of windows in living areas and bedrooms)

- HRV or DVS

Other, please specify:

I don't know

None of the above

Electricity (including heat pumps)

G Gas (mains)

Gas (bottled)

- Fireplace (e.g. wood, coal, pellet)

Other, please specify:

We don't use any form of heating in this house

\section{There is one more section to answer.}

\begin{tabular}{|c|c|}
\hline $\begin{array}{l}\text { Q38. Are you: } \\
\text { [Tick one circle] }\end{array}$ & $\begin{array}{l}\text { Male } \\
\text { O Female }\end{array}$ \\
\hline $\begin{array}{l}\text { Q39. Which ethnic group do you belong } \\
\text { to? } \\
\text { [Tick all boxes that apply] }\end{array}$ & 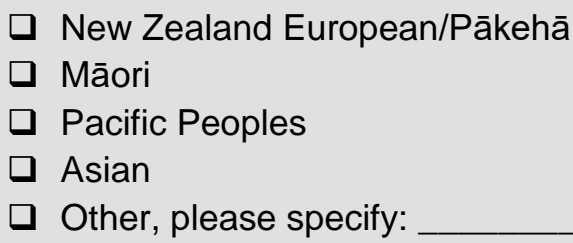 \\
\hline
\end{tabular}




\begin{tabular}{|c|c|c|c|}
\hline $\begin{array}{l}\text { Q40. Do you own or rent this hou } \\
\text { [Tick one circle] }\end{array}$ & & $\begin{array}{l}\text { We own it, with } \\
\text { We own it, witho } \\
\text { It is in a family tr } \\
\text { It is a private ren } \\
\text { It is a publicly rer } \\
\text { Zealand) } \\
\text { Other, please sp }\end{array}$ & $\begin{array}{l}\text { mortgage } \\
\text { it a mortgage } \\
\text { st (with or without a mortgage) } \\
\text { al property } \\
\text { tal property (e.g. Housing New } \\
\text { cify: }\end{array}$ \\
\hline \multicolumn{2}{|c|}{$\begin{array}{l}\text { Q41. How many people live in this } \\
\text { house? } \\
\text { [Enter your answers in the spaces provided] }\end{array}$} & \multicolumn{2}{|c|}{$\begin{array}{l}\text { people } 18 \text { years and over live here } \\
\text { people under } 18 \text { years live here }\end{array}$} \\
\hline $\begin{array}{l}\text { Q42. Which of the following do } \\
\text { any members of your household } \\
\text { receive? } \\
\text { [Tick all boxes that apply] }\end{array}$ & \multicolumn{3}{|c|}{$\begin{array}{l}\text { Salary or wages } \\
\text { Jobseeker support (unemployment benefit) } \\
\text { Supported living payment (sickness or disability benefit) } \\
\text { Sole parent support (domestic purposes benefit) } \\
\text { Accommodation supplement } \\
\text { Working for families } \\
\text { New Zealand pension or superannuation } \\
\text { Student allowance or living costs } \\
\text { None of the above } \\
\text { I don't know }\end{array}$} \\
\hline $\begin{array}{l}\text { Q43. What is the combined } \\
\text { income of the bill payer(s) after } \\
\text { tax? } \\
\text { [Enter your answer and tick one circle] }\end{array}$ & $\$$ & $\$$ & $\begin{array}{ll}O & \text { Every week } \\
\text { Every two weeks } \\
\text { Every three weeks } \\
\text { Monthly } \\
\text { Annually }\end{array}$ \\
\hline \multirow{4}{*}{$\begin{array}{l}\text { Q44. From your latest energy } \\
\text { bill, can you please provide the } \\
\text { following information? } \\
\text { [Enter information in the spaces } \\
\text { provided] }\end{array}$} & \multicolumn{3}{|c|}{ Bill month } \\
\hline & \multicolumn{3}{|c|}{$\begin{array}{l}\text { Electricity used } \\
\text { [Circle units or kWh] }\end{array}$} \\
\hline & \multicolumn{3}{|c|}{$\begin{array}{l}\text { Gas used } \\
\text { [Circle units or kWh] }\end{array}$} \\
\hline & \multicolumn{3}{|c|}{ Early Payment Discount (\$) } \\
\hline
\end{tabular}


To enter the draw for 1 of $\mathbf{4}$ supermarket vouchers valued at $\$ \mathbf{4 0 . 0 0}$, please tick the circle next to the supermarket you would like for the voucher.

O Pak'n'Save

O Countdown

O New World

You will automatically be entered into the draw once you return your completed survey.

If you have any comments on this research project, the questions asked or the survey, please write these here:

Thank you very much for taking the time to complete this survey. Your responses are important in helping me complete my Masters research project.

Please fold your survey booklet in half along the line on the next page. Ensure that you return your survey booklet in the prepaid return envelope to Sam McLean at Victoria University of Wellington. 
Appendix C.4: Reminder slips

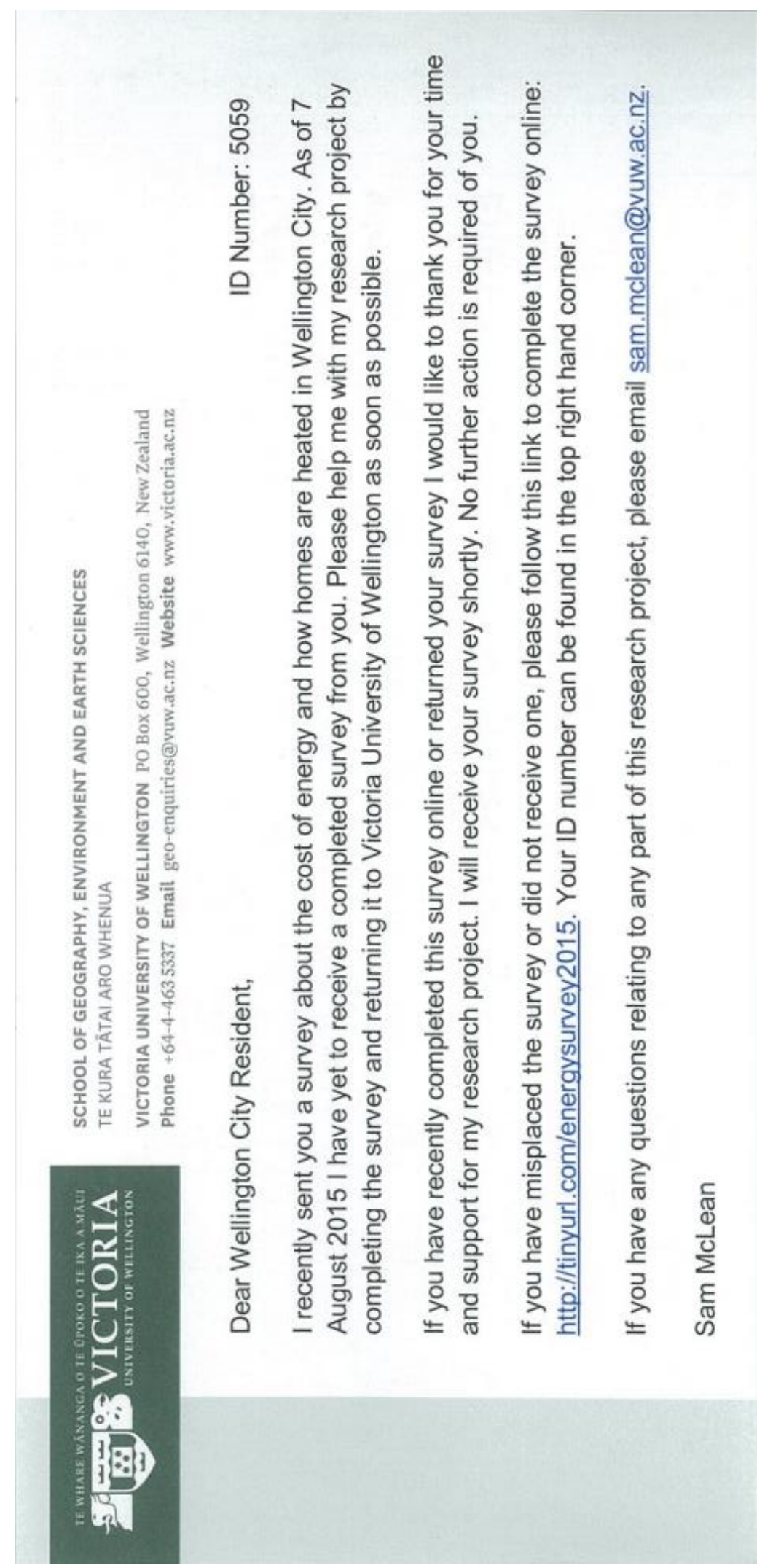




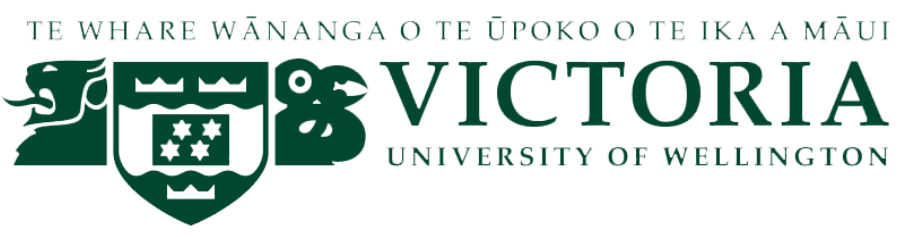

28 August 2015

Dear Wellington City Resident,

ID Number:

\section{REMINDER \\ Energy Prices and Warm Homes Survey 2015}

At the beginning of August, I sent you a letter asking if you could complete a survey on what people in Wellington City think about the cost of energy and how homes are heated. My records show that I have not received a completed survey from you. By completing this confidential survey you will be helping me with my Masters research project at Victoria University of Wellington.

Please follow this link to complete the survey online: http://tinyurl.com/energysurvey2015. Your ID number is XXXXX. Please complete the survey by Sunday $6^{\text {th }}$ September 2015. I hope that you are able to complete this survey shortly.

If you have recently completed and returned your survey, I would like to thank you for your time and support of my research project. No further action is required of you.

Approval for this project has been obtained from Victoria University of Wellington's Human Ethics Committee.

\section{Completing the survey}

Any household member who is an adult (18 years and over) and pays or knows about the energy bill at this address may complete the survey. The survey will take between 10-20 minutes to complete. By completing the survey you will go into the draw to win 1 of 4 supermarket vouchers valued at $\$ 40.00$.

\section{Need more information?}

Please read the enclosed Participant Information Sheet. If you have any questions, please contact me or my supervisors at the details below.

Thank you for your time and support for my research project. I hope you enjoy this opportunity to share your thoughts and opinions on this important topic. 


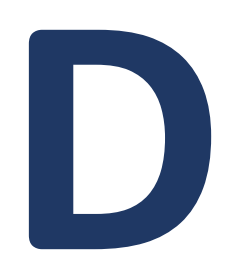

\section{Appendix D: Spatial analysis of FPI factors - Local spatial autocorrelation}

This appendix contains the results of local spatial autocorrelation (Getis-Ord Gi) calculated for each factor and variable included in the FPI (See Section 3.3.2). Figures D.1 to D.9 present FPI variables following their associated factor. For example, Figures D.1, D.2 and D.3 respectively demonstrate the spatial clustering of income followed by median household income and sources of household income. 
Income Hotspots and Coldspots

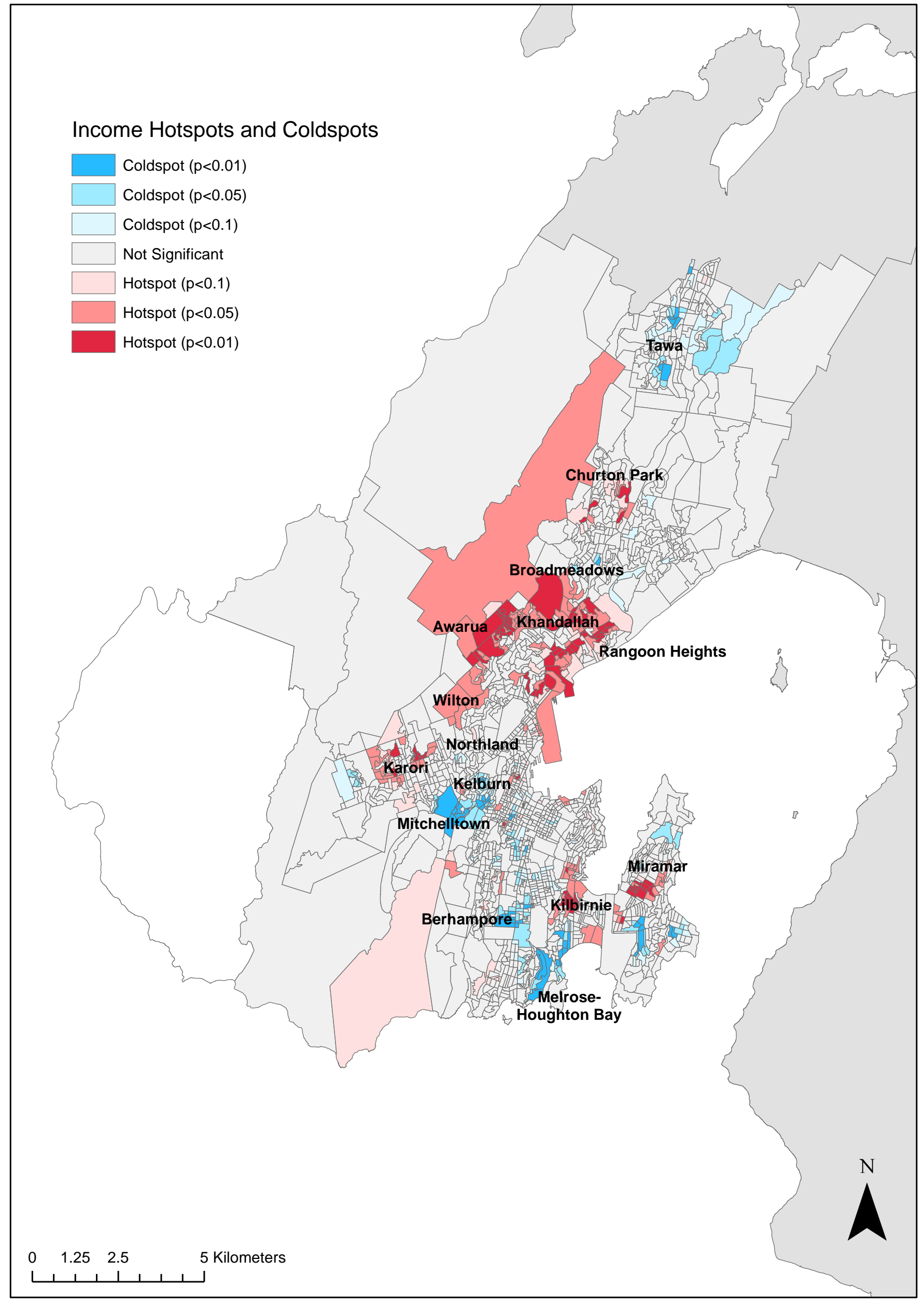


Median Household Income Hotspots and Coldspots

\begin{tabular}{|c|}
\hline Coldspot $(p<0.01)$ \\
\hline Coldspot $(p<0.05)$ \\
\hline Coldspot $(p<0.1)$ \\
\hline Not Significant \\
\hline Hotspot $(p<0.1)$ \\
\hline Hotspot $(p<0.05)$ \\
\hline Hotspot $(p<0.01)$ \\
\hline
\end{tabular}

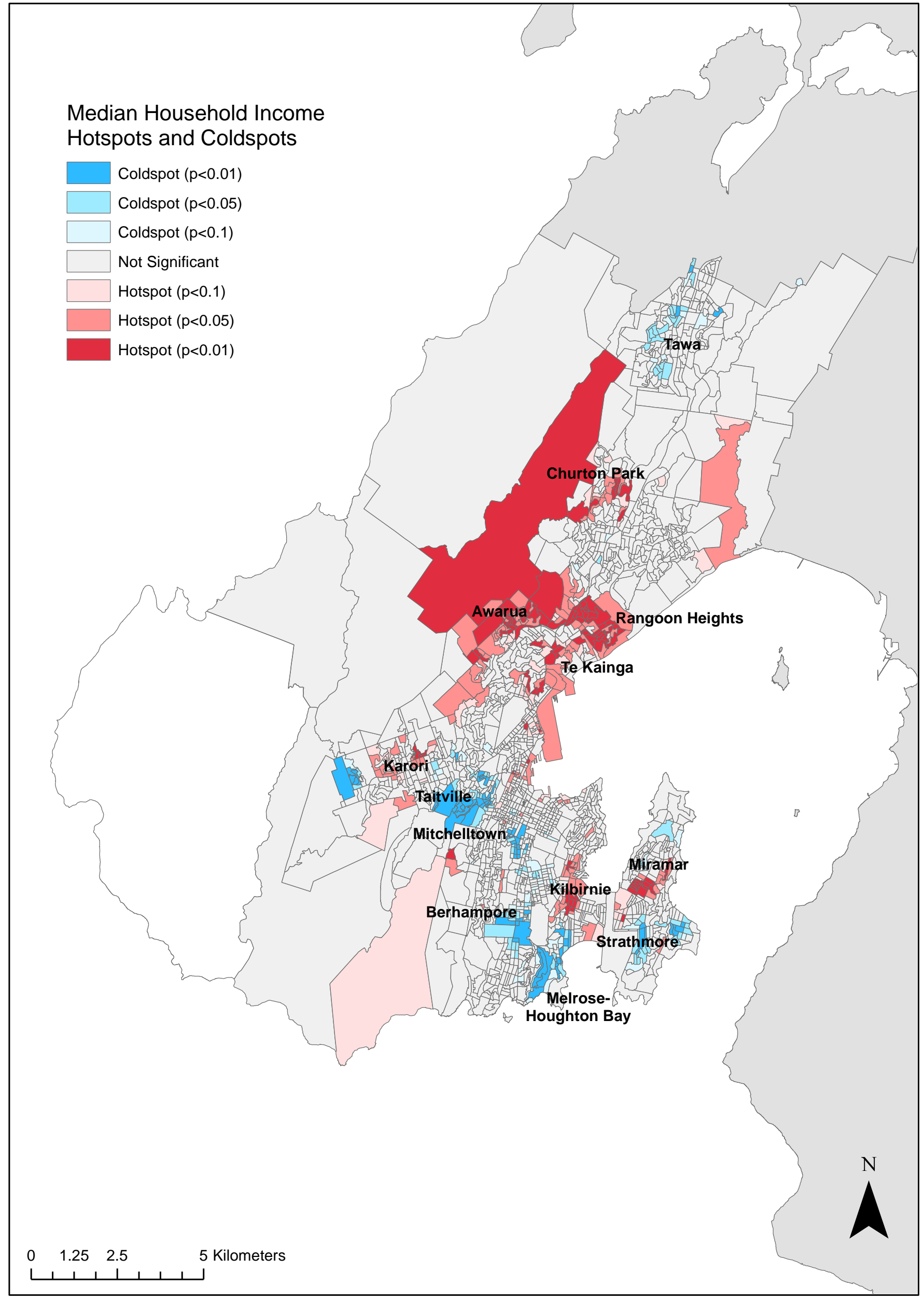




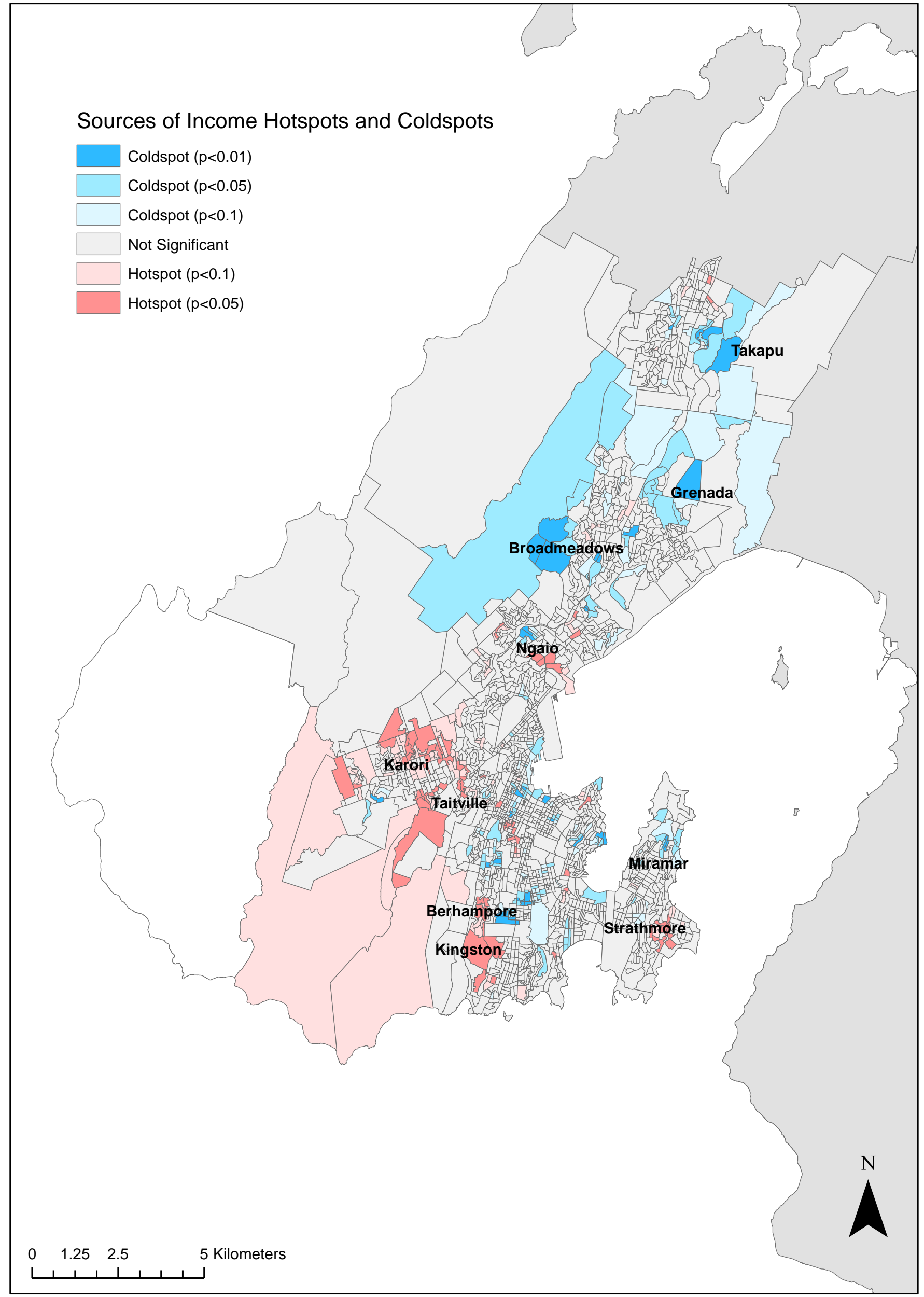




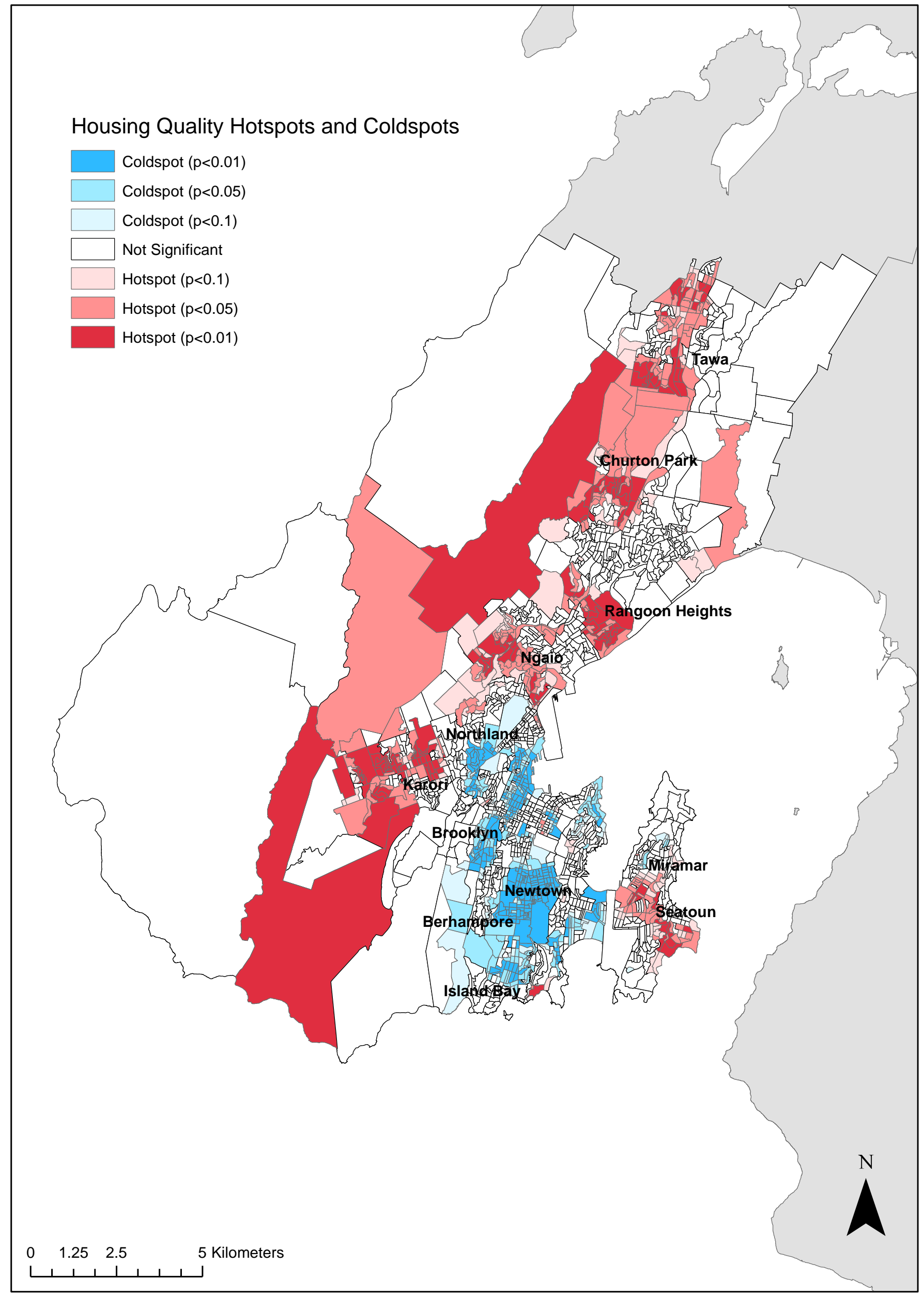




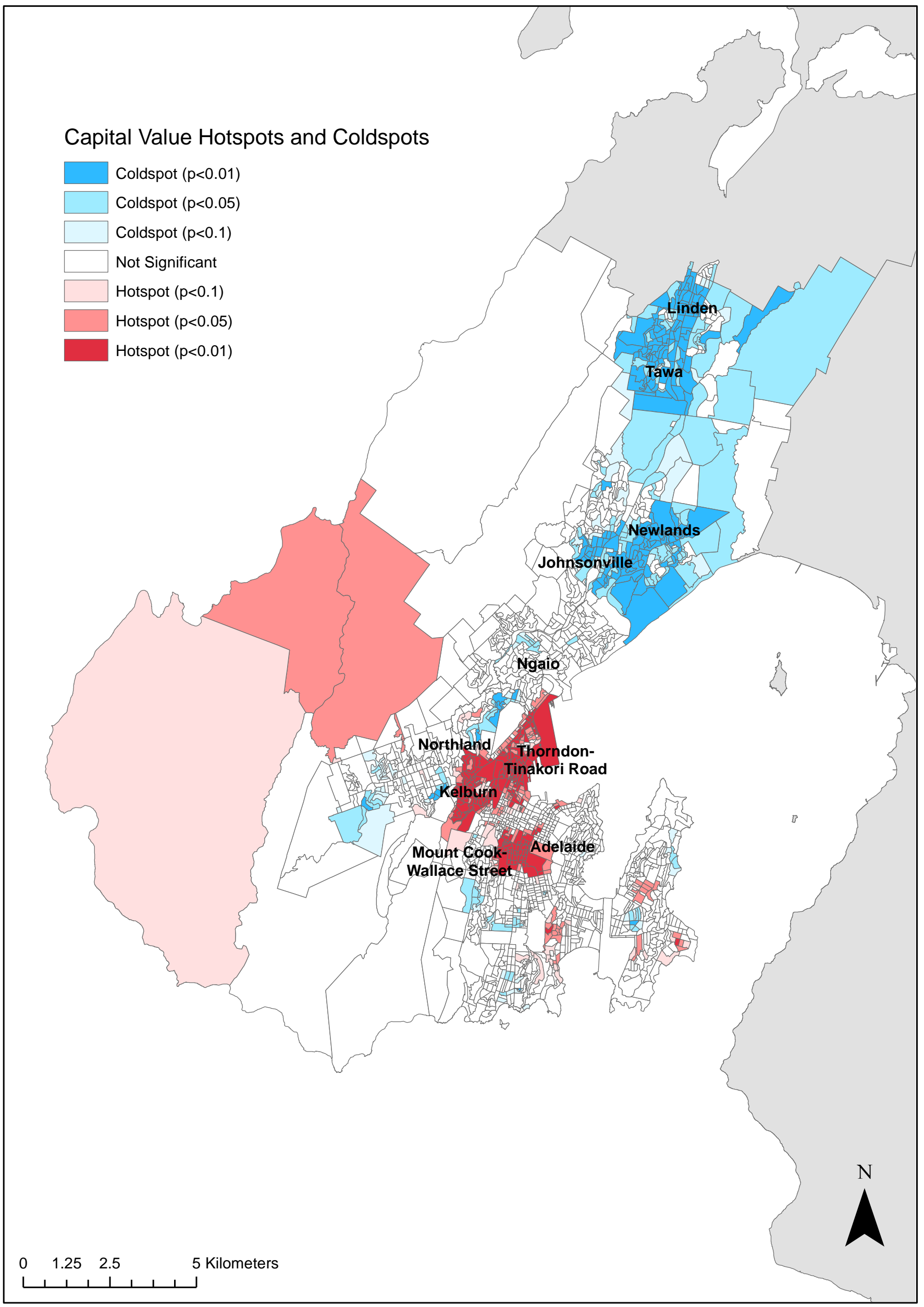




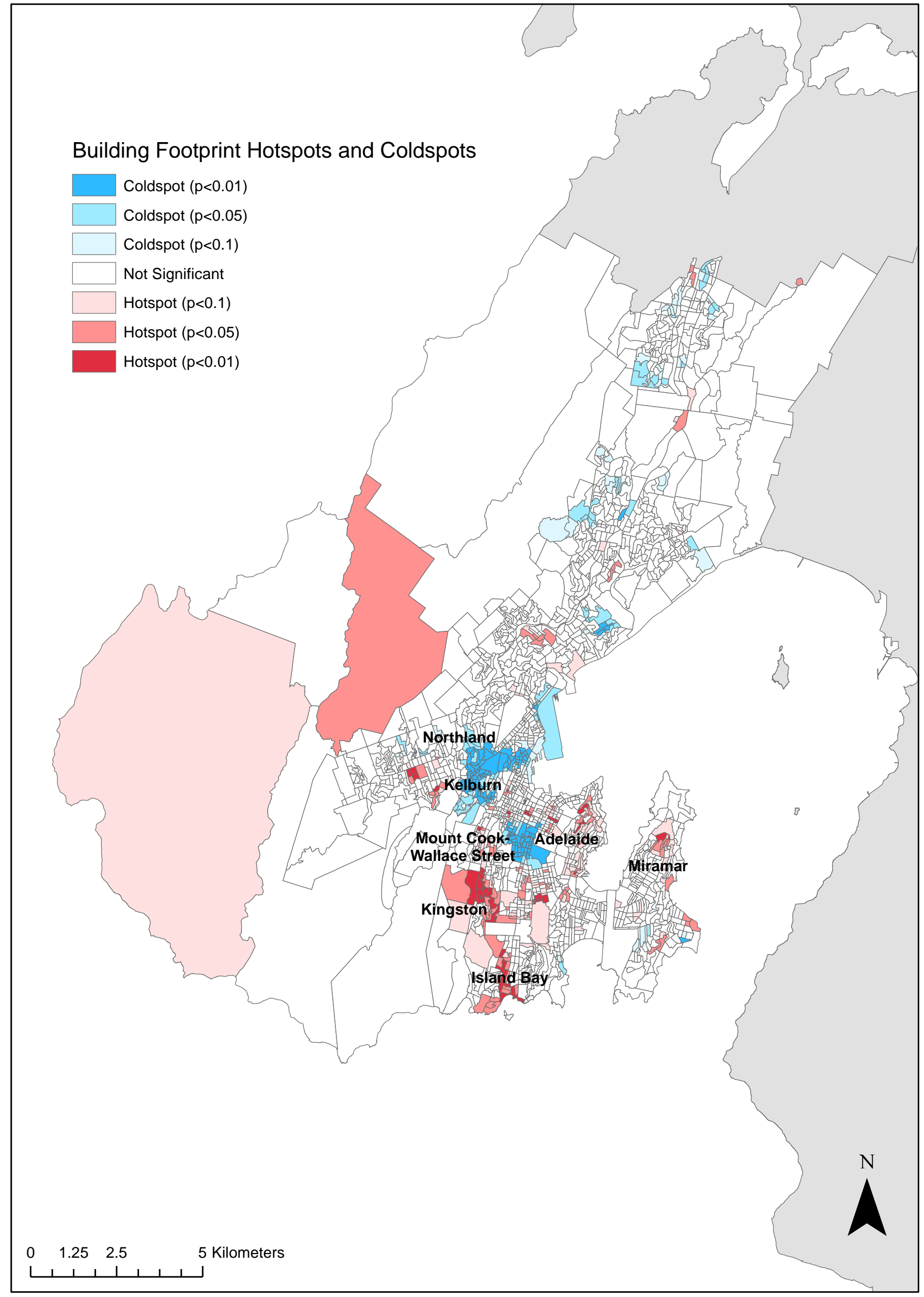




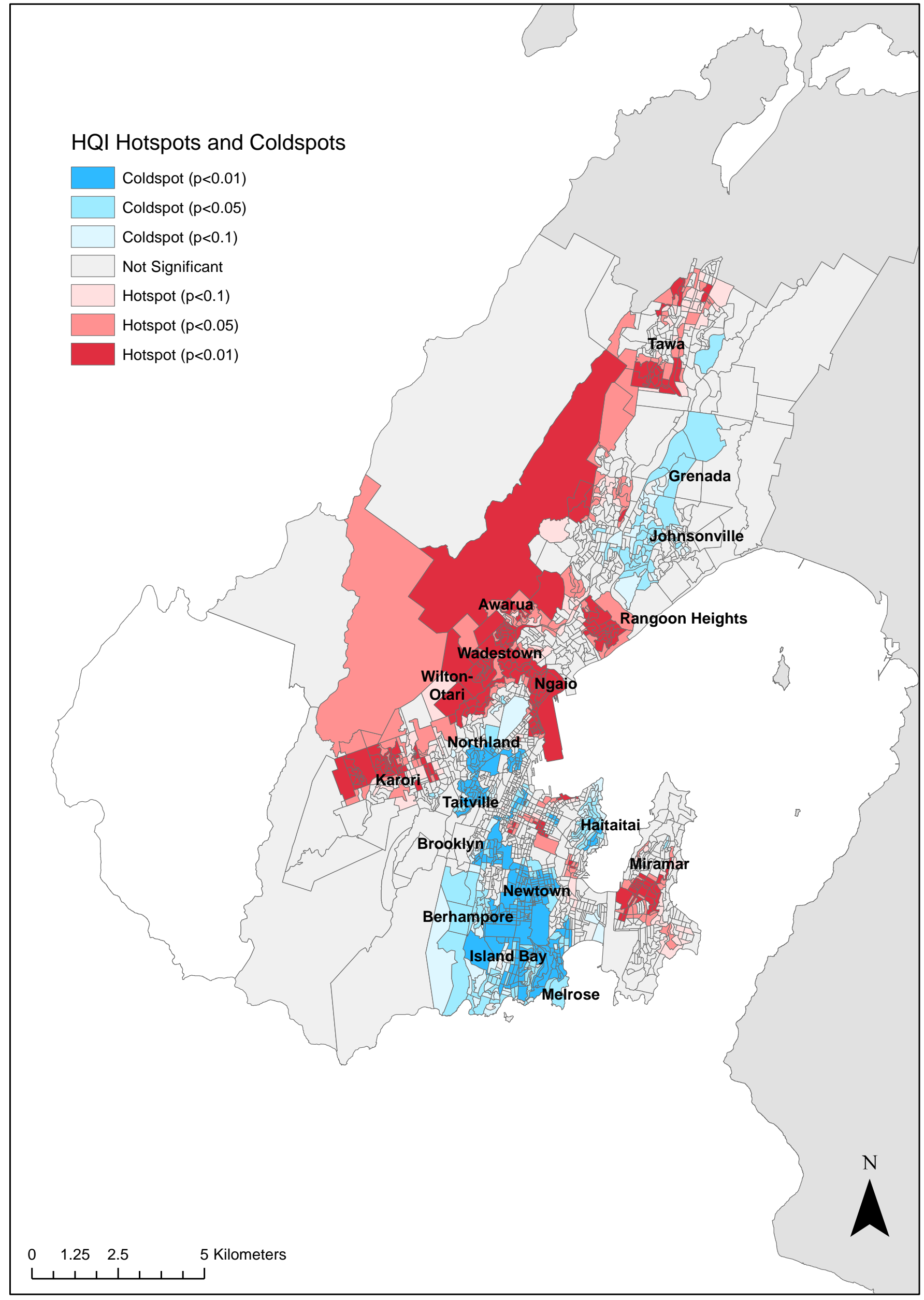




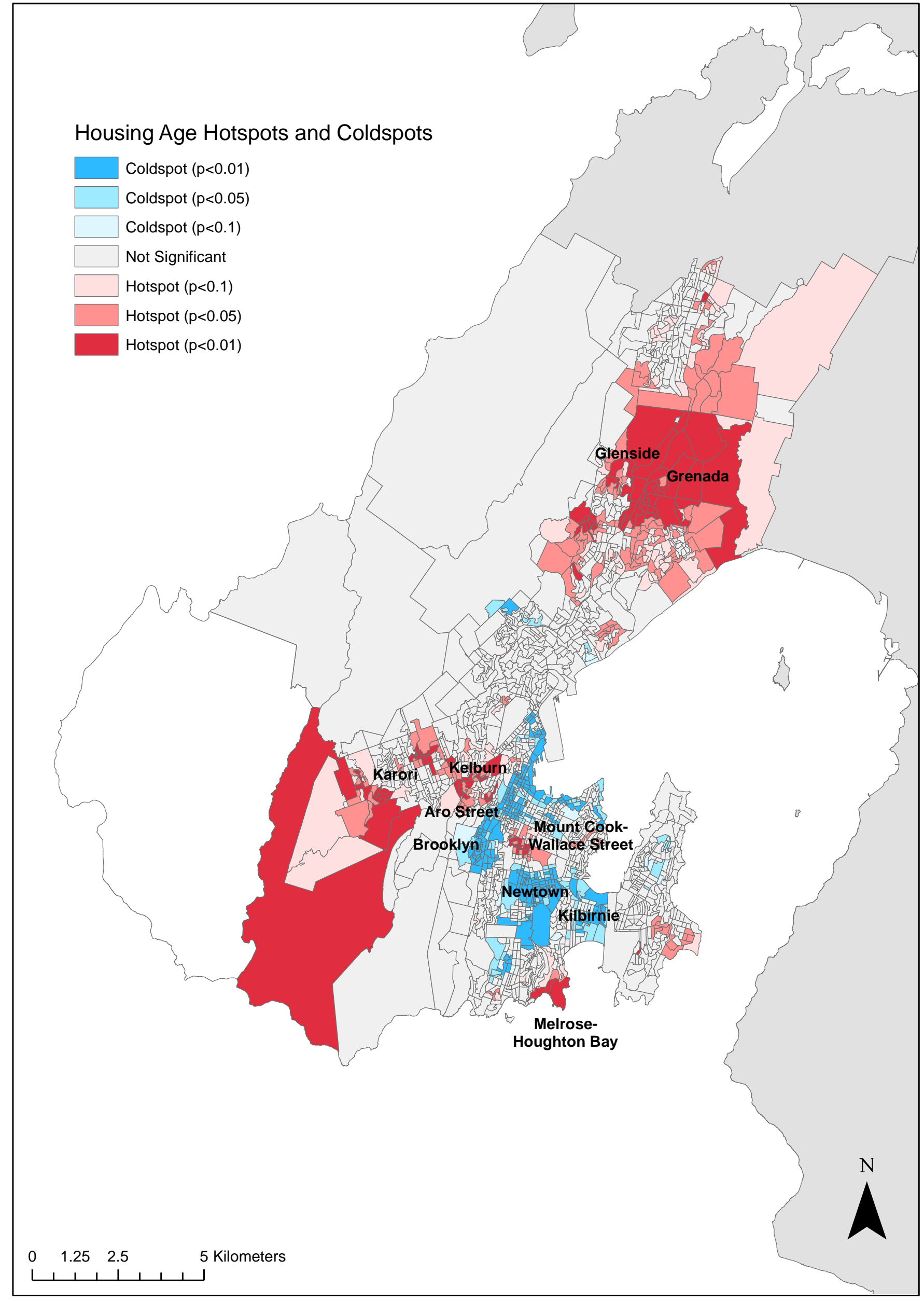




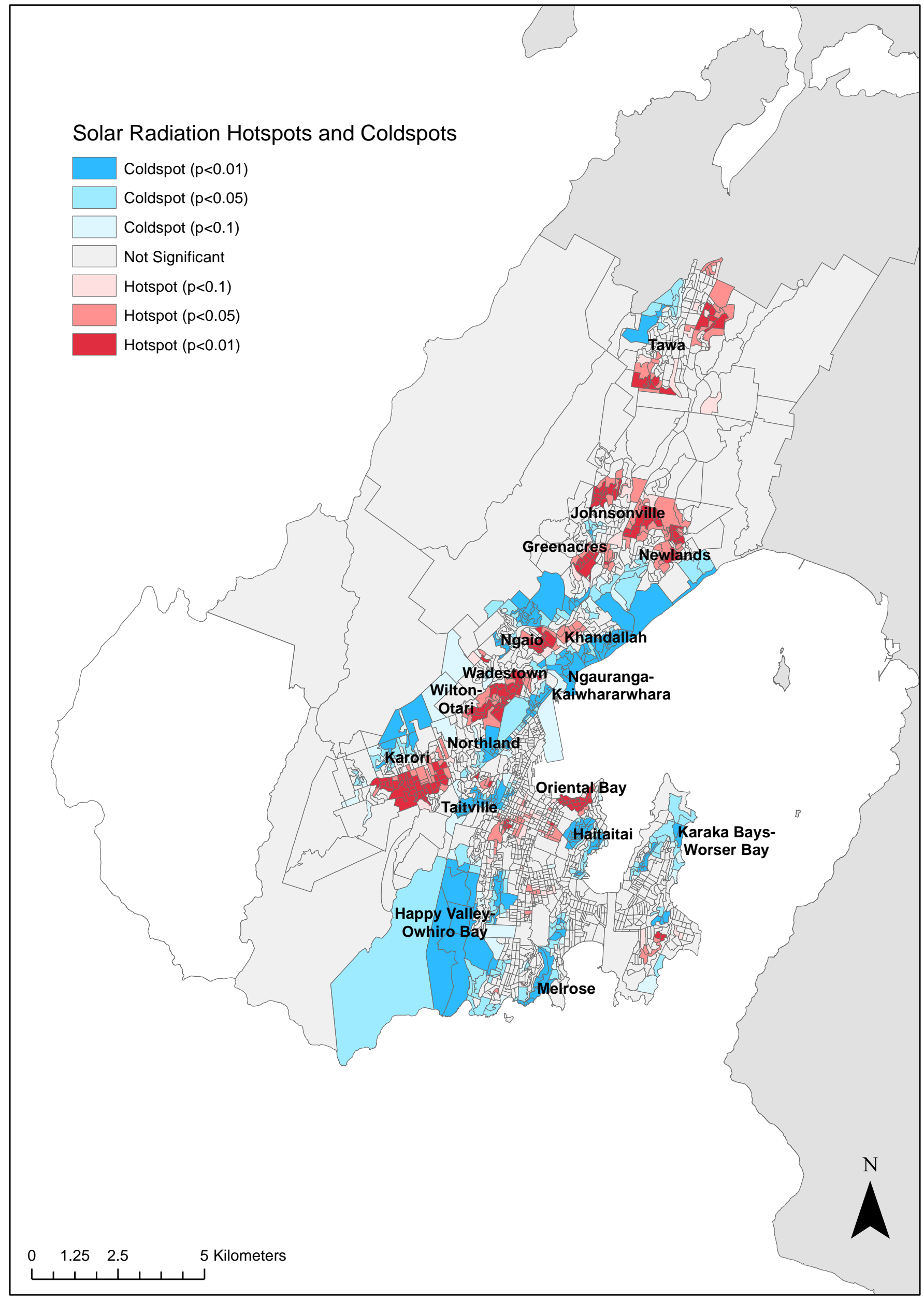



